\title{
Aplicação de um Processo de Avaliação de Usabilidade em uma Ferramenta de Suporte à Escrita Técnica em Inglês
}

\author{
Iris Fabiana de Barcelos
}

Orientadora: Profa. Dra. Sandra Maria Aluísio

Dissertação apresentada ao Instituto de Ciências Matemáticas e de Computação - ICMC-USP, como parte dos requisitos para obtenção do título de Mestre em Ciências de Computação e Matemática Computacional.

USP - São Carlos

Fevereiro de 2001 


\section{A Comissão Julgadora:}

Profa. Dra. Sandra Maria Aluísio

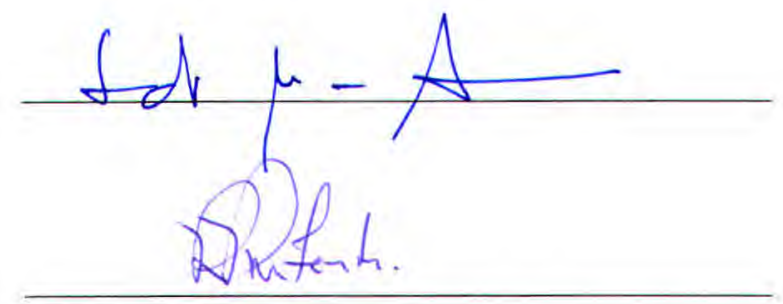

Profa. Dra. Renata Pontin de Mattos Fortes

Profa. Dra. Heloisa Vieira da Rocha

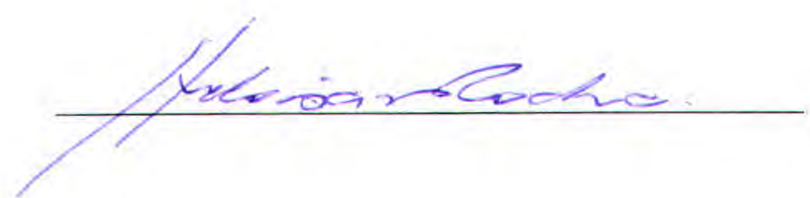




\section{Dedicatória}

Aos meus pais, José Gonzaga e Zamita e ao meu noivo Jairo 


\section{Agradecimentos}

A Deus, por iluminar os meus caminhos dando-me coragem e discernimento.

À Professora Sandra Maria Aluísio, por sua amizade e alegria, e pelo trabalho maravilhoso de orientação.

À Prof. Dra. Renata Pontin de Mattos Fortes, por ter me recebido nesta Universidade.

Ao Jander Sampaio, por ter contribuído muito com meu trabalho sempre de bom humor e com muita dedicação.

Aos usuários testadores da Ferramenta de Crítica, que muito contribuíram para a realização desse projeto.

Aos meus sogros, Jayme e Dalva, pelo carinho e por tantas palavras de incentivo.

À Débora, Lea e Elaine pela compreensão, amizade e companheirismo durante esta etapa tão importante.

Aos amigos Carlos, Werley, Walter, Cláudia e Sílvia pela amizade.

À minha família, pelo apoio, amor e compreensão por minha ausência. Em especial às minhas irmãs que sempre me incentivaram para realizar este trabalho.

Ao Jairo, pela compreensão, carinho e por participar de modo tão próximo desta etapa da minha vida.

Às funcionárias da pós-graduação, Marilia, Laura e Beth, por serem sempre tão prestativas e dóceis.

$\mathrm{A}_{0} \mathrm{CNPq}$ pelo apoio financeiro.

Àqueles que, de uma forma ou de outra, contribuíram para a realização deste trabalho. 


\section{Sumário}

Lista de Figuras.........................................................................................................ii

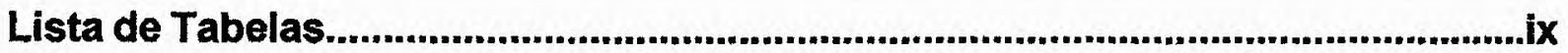

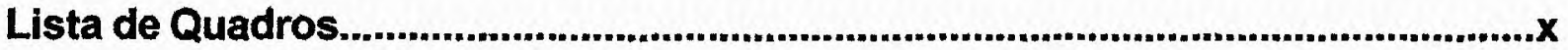

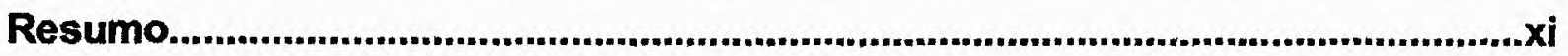

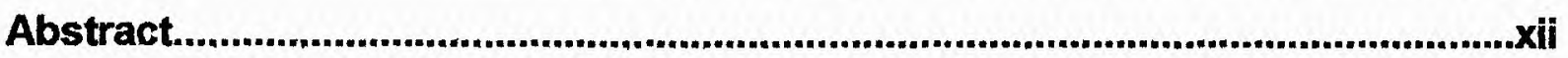

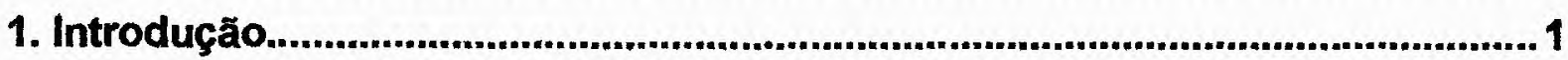

1.1 Contexto

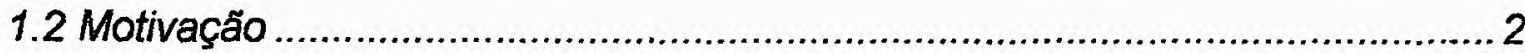

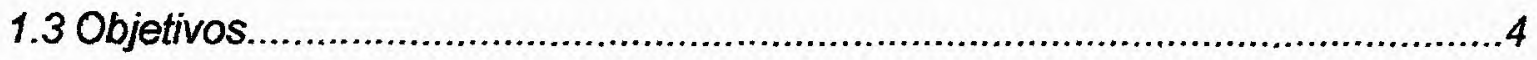

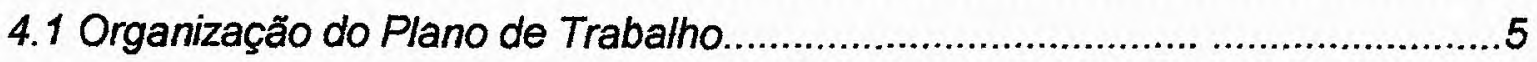

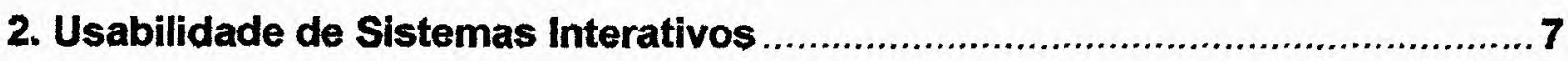

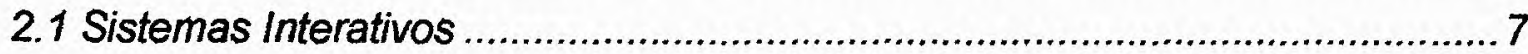

2.2 A Importância de Fatores Humanos em Sistemas Interativos.....................

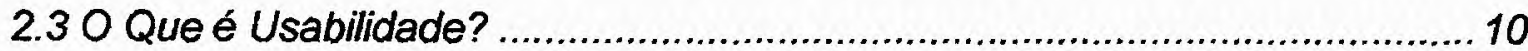

2.3.1 Facilidade de Aprendizado ......................................................................... 13

2.3.2 Eficiência de Uso...................................................................................... 13

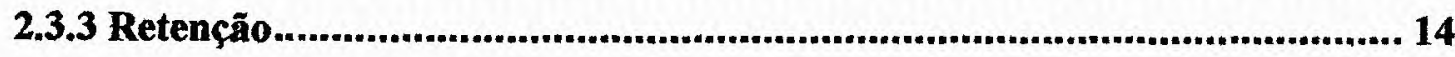

2.3.4 Mínimo de Erros......................................................................................... 14

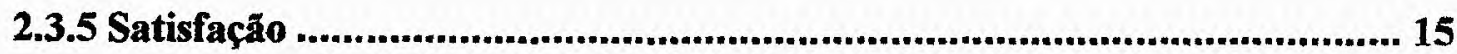

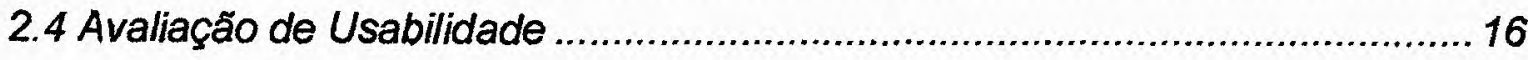

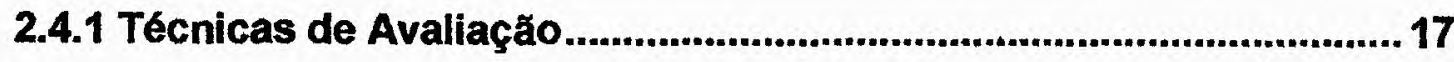

3. Métodos de Avaliação de Usabilidade ...........................................................19

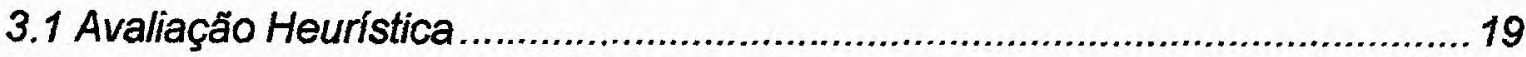

3.1.1 Como Conduzir uma Avaliaçăo Heurística ........................................20

3.1.2 Um Exemplo de Avaliaçăo Heurística .....................................................24

3.1.3 Análise de Custo e Benefício...........................................................26

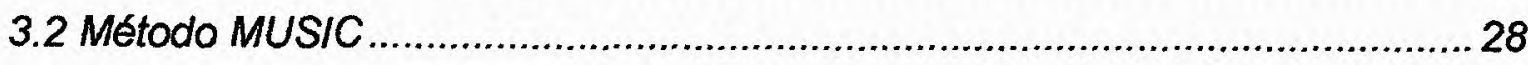

3.2.1 Como Conduzir o Método MUSIC ........................................................... 28

3.2.2 Um Exemplo de Aplicação do Método ................................................... 30

3.2.3 Análise de Custo e Benefício.....................................................................33 


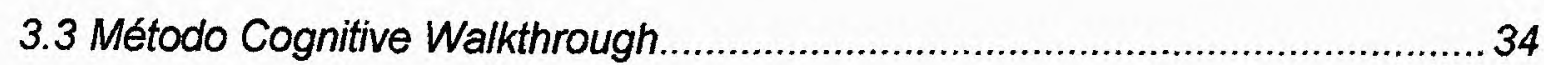

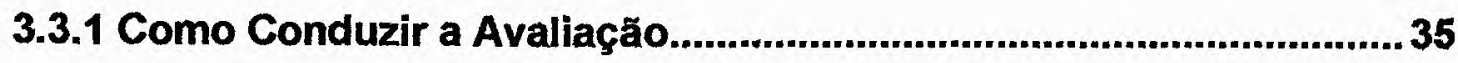

3.3.2 Um Exemplo de Aplicação do Cognitive Walkthrough ....................37

3.3.3 Análise de Custo e Benefícios.......................................................40

3.4 Método USINE/ RemUSINE ...................................................................41

3.4.1 Como Conduzir o Método ..................................................................41

3.4.2 Um Exemplo do Uso do Método de Avaliação Usine........................ 47

3.4.3 Análise de Custo e Benefício...........................................................50

4. Ferramenta de Crítica do Ambiente AMADEUS............................................53

4.1 Características da Ferramenta de Crítica ..................................................54

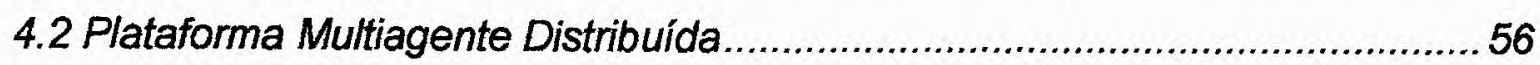

4.3 Uma Linguagem para Representação de Artigos como Estruturas de Árvore62 4.4 O Agente Gerador de Críticas: O Crítico ...................................................62 62

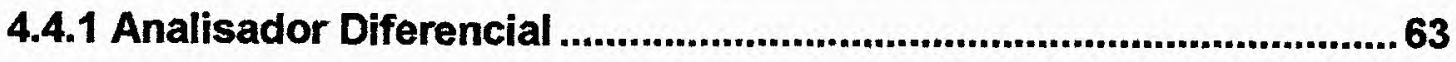

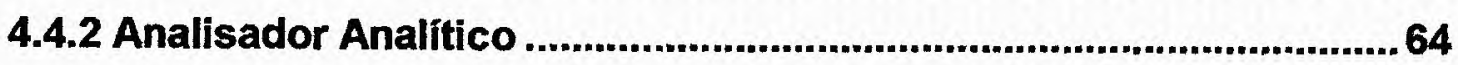

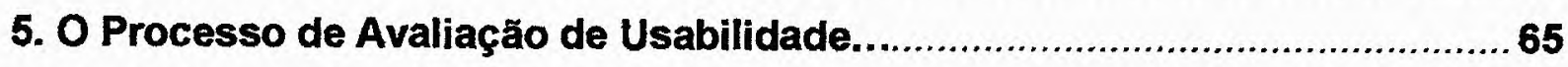

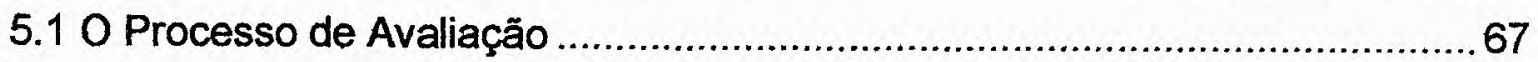

5.1.1 Definição da Aplicação..................................................................68

5.1.2 Definição do Contexto de Uso da Aplicação.....................................68 68

5.1.3 Definição dos Objetivos da Avaliação .............................................68

5.1.4 Especificação da Forma de Condução da Avaliação........................69

5.1.5 Realização da Avaliação.................................................................70

5.2 Instanciação do Planejamento da Avaliação ................................................. 70

5.2.1 Definiçăo da Aplicaçăo..................................................................70

5.2.2 Informações de Contexto...............................................................71

5.2.2.1 Usuários do Sistema e suas Necessidades.............................................71

5.2.2.2 Ambiente ........................................................................................... 71

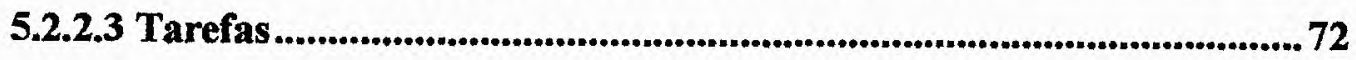

5.2.3 Definindo os Objetivos da Avaliação.................................................74

5.2.4 Especificação da Forma de Condução da Avaliação........................77

5.2.5 A Realização da Avaliação.............................................................83

6. Avaliação da Ferramenta de Crítica: Preparação, Análise e Apresentação dos

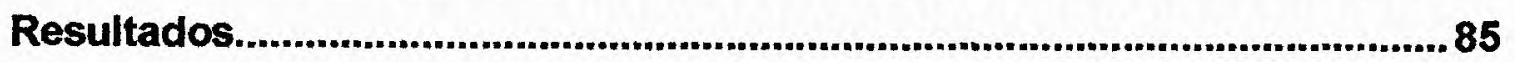

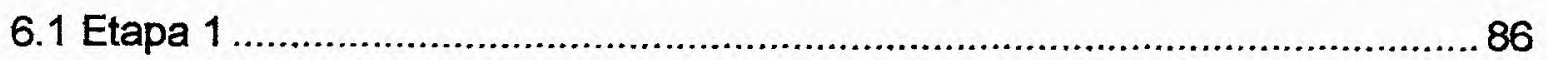


6.1.1 Fase de Preparação da Avaliação .......................................................86

6.1.2 Fase de Análise de Resultados .........................................................92

6.1.3 Fase de Apresentação dos Resultados .............................................98

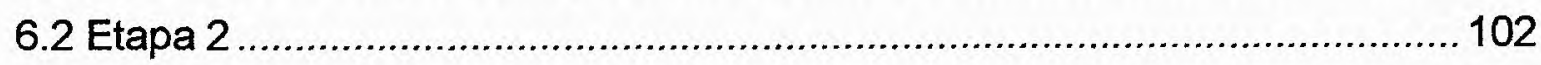

6.2.1 Fase de Preparação da Avaliaçăo .....................................................102

6.2.2 Fase de Análise de Resultados .........................................................103

6.2.3 Fase de apresentação dos resultados ............................................. 105

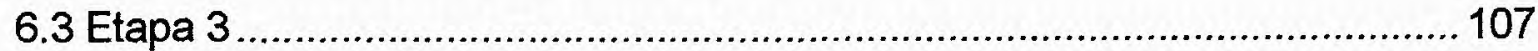

6.3.1 Fase de Preparação da Avaliação ..................................................... 108

6.3.2 Fase de Análise de Resultados .....................................................109

6.3.3 Fase de Apresentação dos Resultados .............................................111

6.4 Análise Comparativa dos Resultados ..............................................112

7. Conclusão …….............................................................................................115

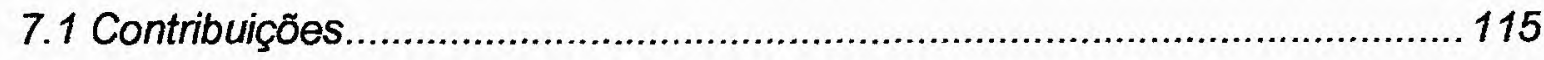

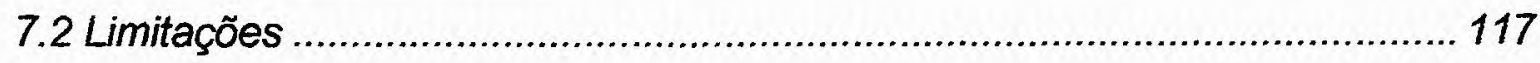

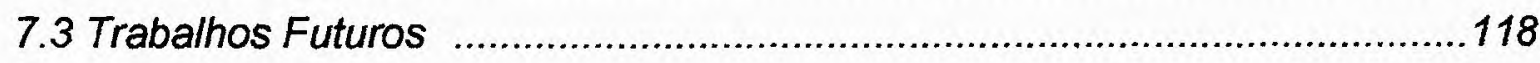

Referências Bibliográficas.......................................................................................119

APÊNDICE A

APÊNDICE B

APÊNDICE C 


\section{Lista de Figuras}

FIGURA 2.1 Um modelo de atributos de aceitabilidade do sistema (Nielsen, 1993)

FIGURA 3.1 A Interface Principal da Aplicação TRAVELweather (Nielsen, 1993)

FIGURA 3.2 Informação de Erro na Edição dos Horários de

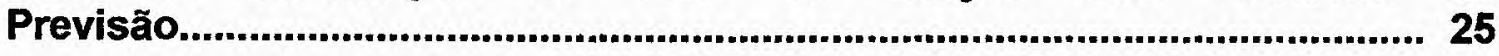

FIGURA 3.3 Informação de Erro na Edição do Mapa …............................... 25

FIGURA 3.4 Passos e Ferramentas Usadas no Método MUSIC (Macleod et al., 1997) 30

FIGURA 3.5 Estrutura do Método (Lacerof \& Paternò, 1998) ...................... 42

FIGURA 3.6 A Árvore de Tarefas do Exemplo Guia de Cinema (Lacerof \& Paternò, 1998) ................................................................................ 44

FIGURA 4.1 Interface Gráfica do Lego Workbench ...................................... 58

FIGURA 4.2 Palette Dinâmica (sensivel ao contexto) em Ação .................... 59

FIGURA 4.3 Seqüência de Substituição de um Vocábulo Abstrato Quando de

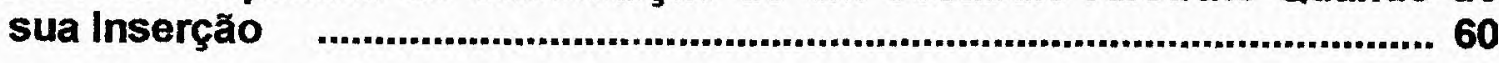

FIGURA 4.4 Lego Workbench: Ênfase em Anotações de Revisão ............ 61

FIGURA 4.5 Lego Workbench: Ênfase em Notificações ................................ 61

FIGURA 5.1 Passos do Processo de Avaliaçăo de Usabilidade ..................... 67

FIGURA 6.1 Modelo de Tarefas da Interface da Ferramenta de Crítica $\quad$.. 87

FIGURA 6.2 Sub-Árvore PrepararSelecaoCompEsquem ................................ 88

FIGURA 6.3 Sub-Árvore SelecionarComponentes ....................................... 88

FIGURA 6.4 Sub-Árvore Trocas $\quad$............................................................. 88

FIGURA 6.5 Sub-Árvore ExcluirComponentes $\quad$............................................. 89

FIGURA 6.6 Sub-Árvore VisualizarCriticas ................................................ 89

FIGURA B.1 Modelo de Tarefas da Interface da Ferramenta de Crítica da Segunda e Terceira Etapa/Turno de Avaliação

FIGURA B.2 Sub-árvore PrepararSelecaoCompEsquem da Segunda e Terceira Etapa/Turno de Avaliação

FIGURA B.3 Sub-árvore SelecionarComponentes da Segunda e Terceira Etapa/Turno de Avaliação

FIGURA B.4 Sub-árvore ExcluirComponentes da Segunda e Terceira Etapal Turno de Avaliaçăo 
FIGURA C.1 Mudança de Foco para "Intro" e Visualização de Componentes Esquemáticos na Palette

FIGURA C.2 Seleção do Componente Esquemático "structure"

FIGURA C.3 Escolna do Componente "Contents", Visualização de Lista de Componentes Esquemáticos e Seleção do Componente "Methodo/ogy Applied"

FIGURA C.4 Mudança de Foco e Visualizaçăo de Criticas

FIGURA C.5 Pedido ao Protótipo para que Recupere Casos Semelhantes ao Esquematizado

FIGURA C.6 Crítica que Indica os Casos da Base mais Semelhantes ao Caso Proposto

FIGURA C.7 Visualização do Caso Recuperado Anotado com os Componentes Esquemáticos

FIGURA C.8 Definição Precoce de um Tipo de Artigo

FIGURA C.9 - Crítica Intrusiva em Resposta a uma Decisão Precoce

FIGURA C.10 Tela Inicial da Ferramenta de Crítica

FIGURA C.11 Tela de Visualização de Críticas

FIGURA C.12 Tela de Inserção de Componentes Esquemáticos 


\section{Lista de Tabelas}

TABELA 3.1 Resultados da Avaliação Heurística para o Sistema TRAVELweather

TABELA 3.2 Características de Contexto de Uso de um Sistema de Informação

TABELA 3.3 Fase de Análise do Cognitive Walkthrough

TABELA 3.4 - Tabela de Pré-Condições Inicial (Lacerof \& Paternó, 1998) .. 48

TABELA 4.1 Componente da Estrutura Dual para Submissão de Artigos da CHI'96 ................................................................................................ 56

TABELA 5.1 Comparaçăo entre Métodos de Avaliaçăo de Usabilidade 66

TABELA 5. 2 Estudo de Contexto da Aplicação ............................................ 68

TABELA 5.3 Critérios de Usabilidade a Serem Avaliados

TABELA 6.1 Tabela de Tarefa-Log _............................................................. 90

TABELA 6.2 Tabela de Pré-Condiçōes do Modelo de Tarefas da Ferramenta de Critica

TABELA 6.3 Apresentação dos Resultados da Primeira Etapa de Avaliação...99

TABELA 6.4 Apresentação dos Resultados da Segunda Etapa de Avaliação.106

TABELA 6.5 Apresentação dos Resultados da Terceira Etapa de Avaliação..112

TABELA B.1 Tabela de Tarefa-Log da Segunda e Terceira Etapa/Turno de Avaliação

TABELA B.2 Tabela de Pré-Condições da Segunda e Terceira Etapa/Turno deAvaliação 


\section{Lista de Quadros}

QUADRO 5.1 Carta Convite ao Usuário

QUADRO 5.2 Questionário para Avaliação da Satisfação

QUADRO 6.1- Resumo da Análise dos Dados Obtidos dos Questionários da Primeira Etapa

QUADRO 6.2- Dados Resultantes da Primeira Etapa de Avaliação da Ferramenta de Crítica

QUADRO 6.3 Resumo da Análise dos Dados Obtidos dos Questionários da Segunda Etapa

QUADRO 6.4 Dados Resultantes da Segunda Etapa de Avaliação da Ferramenta de Crítica................................................................................. 104

QUADRO 6.5 Resumo da Análise dos Dados Obtidos dos Questionários da Terceira Etapa

QUADRO 6.6- Dados Resultantes da Terceira Etapa de Avaliação da Ferramenta de Crítica 


\section{Resumo}

À medida que os computadores se tornaram mais baratos, os fatores de usabilidade se tornaram cada vez mais determinantes nas decisões de aceitabilidade pelos usuários de software. Usabilidade é definida diferentemente por vários autores, porém nesse trabalho utiliza-se uma definição mais ampla que inclui os atributos: facilidade de aprendizado, eficiência de uso, retenção, mínimo de erros e satisfação. Como a usabilidade é um dos fatores que afetam a qualidade de software, muitos trabalhos têm desenvolvido métodos de avaliação de usabilidade para interfaces de sistemas computacionais interativos. Vários desses métodos têm se mostrado úteis, mas todos eles apresentam problemas relevantes. A partir de uma análise de custo e benefício, baseada em vários critérios (a importância de precisão, custo e tempo), escolheu-se o Método USINE, que utiliza modelos de tarefa e logs gerados de um teste com o usuário de uma aplicação, para ser adaptado e dar suporte a um processo de avaliação de usabilidade elaborado nesse trabalho de mestrado. $O$ processo elaborado utiliza o método USINE e a abordagem de melhoria contínua proposta por Nielsen, que aplica três etapas de avaliação, sendo que à cada etapa melhorias na interface são realizadas. $O$ processo de avaliação foi aplicado à Ferramenta de Crítica do ambiente de suporte e auxílio à escrita AMADEUS e modificaçöes foram realizadas para melhorar a interface da ferramenta. 


\section{Abstract}

As computers became cheaper, the quality factors became more and more decisive in the acceptability decisions for users and software buyers. There are several definitions of usability, and in this work we are using a broader definition that includes the following attributes: learnability of the system for initial use, efficiency, facility to remember, minimum number of errors, and users' satisfaction. As usability is one of the factors affecting software quality, several works have developed evaluation methods to interactive systems. Although several methods have proved to be useful in supporting usability engineering, all of them present relevant problems. After an extensive analysis considering several criteria, we have chosen the Usine Method, which uses task models and logs generated from a user test of an application, to be adapted and give support to an usability evaluation process, proposed in this work. The proposed process uses USINE and the iterative design approach suggested by Nielsen, which evaluates the interface in three turns, improving the interface design in each turn. The proposed process was applied to the AMADEUS' Critiquing Tool, improving the interface of this tool. 


\section{Capítulo 1}

\section{Introdução}

\subsection{Contexto}

Os primeiros modelos de sistemas computacionais de interação com o usuário foram severamente limitados pelo hardware disponivel. À medida que o hardware tornou-se mais sofisticado, aumentaram a complexidade dos softwares projetados para ele, as opções de estilo de interação (Dix, 1987) e o perfil dos usuários. Como conseqüência desse avanço na área de hardware e de software, ocorreram várias mudanças e evoluções na área de informática, que têm contribuído para a crescente necessidade de se ter softwares com mais qualidade.

Com mais e mais produtos de software aparecendo no mercado, obter uma margem competitiva torna-se cada vez mais dificil. Assim, a avaliação de usabilidade de interfaces de sistemas computacionais interativos constitui uma área em que a demanda cresceu significativamente, paralelamente ao desenvolvimento de métodos e técnicas para auxiliar no processo de avaliação. Os métodos de avaliação da usabilidade de software contribuem para a obtenção de softwares melhores. Usabilidade é um dos fatores que afetam a qualidade de software e que, segundo Pressman (1995), se enquadra no grupo dos fatores que podem ser medidos indiretamente, comparando-se o software com as metas de usabilidade preestabelecidas. Neste trabalho usa-se a definição de usabilidade dada em Nielsen (1993), 
que é definida através de cinco fatores: facilidade de aprendizado, eficiência de uso, retenção, mínimo de erros e satisfação do usuário. Mais detalhes se encontra no Capítulo 2.

Engenharia de Usabilidade é uma área de pesquisa da Interação Usuário-Computador (IHC), que objetiva construir sistemas usáveis, aplicando diferentes métodos de uma maneira sistemática e estruturada em estágios diferentes do processo de projeto e desenvolvimento (Lacerof \& Paternò, 1998). Nos estágios anteriores ao processo de projeto, a avaliação de usabilidade é usada para comparar projetos de interface alternativos e então identificar o preferido. Em estágios posteriores, a avaliação é executada para determinar. se o projeto atingiu seus requisitos. Neste trabalho, a meta é identificar problemas de usabilidade em uma ferramenta de suporte à escrita técnica e, com isto, dar informações ao projetista de como melhorar 'a interface do sistema. Detalhes dessa ferramenta são apresentados no Capítulo 4.

Ao longo da última década, muitos trabalhos sobre métricas de usabilidade têm sido realizados sendo que alguns deles têm provado ser de grande utilidade, porém apresentam limitações. De acordo com Jefries et al. (1991), o método Cognitive Walkthrough (Wharton et al.,1994) ainda permanece como uma boa alternativa para sistemas nos quais é especialmente importante que o usuário possa entender e usar a interface de forma rápida e fácil; possui um custo relativamente baixo, contudo não é provável que todos os problemas existentes na interface sejam encontrados. Teste empírico, teste usado no método MUSIC (Macleod, 1994), por consistir de teste executado com usuários finais, se torna mais caro, porém mais seguro por identificar o maior número de problemas, incluindo problemas graves que-não são vistos em Cognitive Walkthrough (Morris \& Dilon, 1996). No entanto, a escolha de um método de avaliação apropriado envolve uma análise de custo e beneficio baseada em vários critérios, por exemplo, a importância de precisão, custos e tempo. Existem outros métodos que têm se mostrado úteis em suportar a engenharia de usabilidade como a Avaliação Heurística (Nielsen, 1993) e .o Método USINE (Lacerof \& Paternò, 1998), mas também apresentam problemas relevantes de acordo com o que se pôde perceber a partir da literatura pertinente. Os métodos citados acima são detalhados no Capítulo 3.

\subsection{Motivação}

À medida que os computadores se tornam mais baratos, os fatores de usabilidade se tornam cada vez mais dominantes nas decisões de aceitabilidade tomadas pelos usuários e 
compradores de software. A usabilidade é largamente reconhecida como uma questão importante na qualidade de sistemas interativos, da mesma forma que outros aspectos, tais como funcionalidade, confiabilidade, eficiência, manutenibilidade e portabilidade.

Conseqüentemente, para que um produto de software não corra o risco de ser mal sucedido no mercado é preciso que ele não esteja limitado a possuir apenas a funcionalidade adequada, mas também que possibilite a utilização de todos os recursos que ele dispõe. Shneiderman (1987) alude que problemas como frustração e ansiedade, inerentes à utilização de uma interface fazem parte da vida diária de muitos usuários de sistemas de computação que tentam aprender a linguagem de comandos ou sistemas de seleção de menu. Para algumas pessoas isso é tão sério que evitam usar sistemas computadorizados. Tais problemas são os principais motivadores de muitas pesquisas na área de sistemas interativos, visando a qualidade da interface e do sistema como um todo.

Assim, o interesse por fatores humanos aliado ao desenvolvimento de aplicações interativas de software, tem crescido nos últimos anos com o objetivo de produzir softwares mais usáveis Muito embora o termo "qualidade" seja vago e subjetivo, pode-se adotar esta "qualidade" como sinônimo de adequação para uso. De acordo com Bevan (1995), as medidas de qualidade fornecem o critério para determinar se o projeto dos atributos do software (estilo e propriedades da interfạce do usuário) terá sucesso em alcançar usabilidade: Dentro deste contexto, um conceito chave no campo de interação é usabilidade, que é referida como a facilidade dos usuários em aprender e usar o sistema (Bevan, 1995). Um passo importante nesta direção é a avaliação da interface do usuário, que segundo Scholtz (1995), tem como meta avaliar a lacunạ entre o modelo do sistema e o modelo que o usuário tem dele, fornecendo como resultado informações ao projetista de como melhorar a interface do usuário e alcançar a boa usabilidade.

Atualmente, a Web está sendo oferecida como a panacéia universal para todos os usuários que executam qualquer tarefa de busca de informação (Smith et al., 1997). Este uso massificado da Internet faz com que o uso de softwares interativos com diferentes estilos de interação seja uma atividade quase que diária para diferentes tipos de usuários. A fim de que os softwares possam atingir os critérios de qualidade desejados e garantir seu sucesso, tornase evidente a necessidade de se avaliar a usabilidade de suas interfaces e consequentemente a necessidade de modelos, técnicas e processos sistemáticos para a avaliação de usabilidade. 


\subsection{Objetivos}

Como a usabilidade é um dos fatores que afetam a qualidade de software, muitos trabalhos têm desenvolvido métodos de avaliação de usabilidade em interfaces de sistemas computacionais interativos. Vários desses métodos têm se mostrado úteis, mas todos eles apresentam problemas relevantes. Assim, a fim de se obter resultados mais seguros a partir de uma avaliação com um custo menor e em um tempo mais curto, é preciso que seja seguido um processio de avaliação sistemático. Um dos objetivos deste trabalho de mestrado é fornecer uma visão geral de usabilidade, apresentando detalhada e comparativamente alguns métodos de avàliação de usabilidade.

O principal objetivo desta pesquisa de mestrado é elaborar um processo de avaliação sistemático criado à luz do estudo de vários métodos e aplicá-lo para avaliar a interface da Ferramenta de Crítica do ambiente AMADEUS (Barreviera e Silva, 1999; Barreviera e Silva et al., 1998). Especificamente, um processo que possa ser usado para avaliar a interface de sistemas, sejam eles mono ou multi-usuários, visando obter resultados mais seguros que possam reforçar e complementar aqueles obtidos por outros métodos da literatura. Tal processo está fundamentado na abordagem de melhoria contínua de Nielsen (2000) e no método USINE (USer INterface Evaluator) de avaliação de usabilidade (Lacerof \& Paternò, 1998), que é um método formal e automatizado que utiliza uma especificação de um modelo de tarefas e dados gerados de testes de usuários com a aplicação.

A escolha do Método USINE está relacionada ao objetivo de aumentar a confiabilidade dos resultados, por ser um método formal de avaliação de usabilidade, além de minimizar os custos e o tempo despendidos na avaliação. A escolha por múltiplos testes é devido ao fato de se querer melhorar o projeto e não somente reportar suas fraquezas. Finalmente, a escolha da ferramenta de crítica se deu por duas razões: a) ser um protótipo funcional desenvolvido em um mestrado do ICMC-USP (Barreviera e Silva, 1999), estando seu código facilmente disponível e à espera de melhorias para que seu uso seja difundido, e b) ser um sistema que dá suporte a uma tarefa com sobrecarga cognitiva (escrita) exigindo uma interface que não seja mais um peso para o usuário. 


\subsection{Organização do Plano de Trabalho}

No Capítulo 2 apresentam-se a definição de usabilidade utilizada neste trabalho e os principais conceitos relacionados à avaliação de usabilidade. No Capítulo 3 são apresentados alguns métodos de avaliação, relacionando os custos e beneficios de cada um. No Capítulo 4 faz-se uma descrição do sistema a ser avaliado: a Ferramenta de Crítica do ambiente AMADEUS. O Capítulo 5 apresenta o processo elaborado e uma instanciação dele para avaliar a ferramenta de crítica. No capítulo 6 são apresentados os resultados da avaliação da ferramenta de crítica, com a parte de preparação, análise e apresentação dos resultados. Finalmente, no Capítulo 7 tem-se as conclusões desse trabalho e considerações sobre os trabalhos futuros. 


\section{Capítulo 2}

\section{Usabilidade de Sistemas Interativos}

\subsection{Sistemas Interativos}

Sistemas interativos são ferramentas para a realização de tarefas, compostos pela aplicação e pela interface, definição apresentada no Segundo Workshop sobre Fatores Humanos em Sistemas Computacionais (IHC'99), realizado em Campinas - São Paulo. A interface é um subsistema com estrutura e processos. Ela suporta a interação entre o sistema e o usuário, fazendo a apresentação dos objetos do domínio e das funções de uso geral ativadas por botões, barra de rolagem e funções de Zoom. A interface é uma zona de contato entre duas entidades: pessoa e sistema. Como a diferença entre tais entidades é muito grande, objetiva-se diminuir essa diferença de forma a permitir que as pessoas usem a interface de maneira mais clara e fácil. Os problemas relacionados a interfaces de sistemas interativos têm como causas principais (IHC'99):

a) Desconhecimento do usuário: muitas vezes os aspectos cognitivos, fisicos e sociais do usuário não são considerados pelos projetistas de interface, assim como as questões relacionadas com habilidades e deficiências.

b) Desconhecimento da atividade: as pessoas não conhecem a fundo as tarefas que devem ser executadas. Isto se refere às estratégias, restrições e desvios devidos a erros e incidentes.

c) Priorização da lógica de funcionamento em detrimento da lógica de utilização: a lógica de funcionamento se refere aos aspectos internos para que uma meta seja alcançada, 
enquanto que a lógica de utilização se preocupa em adequar a interface para que se possa realizar as tarefas. $O$ projeto da interface deveria nascer junto com as funções do sistema, ao invés de separadamente.

De acordo com Prates (1998), a interface pode ser decomposta em expressão e conteúdo. A sua expressão é o seu modelo de interação, que é o conjunto de comandos que o projetista oferece ao usuário para interagir com a aplicação. $O$ seu conteúdo é a sua funcionalidade, ou seja, o que a aplicação é capaz de fazer. Assim, o modelo de usabilidade da aplicação é formado pela combinação dos modelos de interação e funcionalidade relacionados à expressão e conteúdo, respectivamente. Essa abordagem é definida segundo a engenharia semiótica Prates (1998), que prioriza a expressão do projetista sobre a interpretação do usuário, o que significa priorizar o conjunto de comandos que o projetista oferece ao usuário para que este possa interagir com a aplicação para resolver seu problema.

Sistemas interativos podem ser vistos também segundo uma abordagem ergonômica (Scapin \& Bastien, 1997), que é uma disciplina que busca produtividade no trabalho através da adaptação do trabalho ao homem, garantindo assim a satisfação, conforto, saúde e bem estar. De acordo com essa abordagem, o usuário precisa estar satisfeito para que seja produtivo. A ergonomia da informática tem como fundamentos conhecer o usuário e o trabalho dele. Para que um sistema interativo apresente as qualidades ergonômicas deve-se considerar os critérios de condução, carga de trabalho, controle do usuário, adaptabilidade, gestão de erros, significado dos códigos e denominações, homogeneidade/consistência e compatibilidade. Tais critérios podem ser vistos com detalhes em Bastien \& Scapin (1993). Essa será a abordagem utilizada para condução deste trabalho de mestrado.

\subsection{A Importância de Fatores Humanos em Sistemas Interativos}

No início da era digital, os projetistas e usuários eram especialistas. Com o reconhecimento do potencial dos computadores na indústria e no comércio, as primeiras máquinas foram desenvolvidas. Porém, elas foram projetadas por especialistas em computação, para uso de profissionais de processamento de dados, com a interação do usuário com o sistema sendo feita por intermédio do pessoal do Centro de Processamento de Dados (CPD).

A partir de meados de 1960 , os minicomputadores tornaram o uso de computadores mais próximo do leigo. Conseqüentemente, começaram as dificuldades para os usuários não 
especialistas e os problemas de interação usuário-computador foram reconhecidos (Shackel \& Richardson, 1991). Em 1978, com o advento do microcomputador, houve um grande aumento no uso de computadores para diferentes propósitos e por vários tipos de usuários. Esse crescimento difundiu problemas de usabilidade. Além disso, com o avanço tecnológico, os usuários passaram a ter diferentes necessidades a-serem satisfeitas. Esses novos usuários potenciais são pessoas que têm possibilidade de escolhas e somente utilizarão os sistemas com qualidade. Assim; para se ter êxito, a indústria da tecnologia da informação pode melhorar a usabilidade dos sistemas interativos. Para tanto, os aspectos relativos a fatores humanos se tornam essenciais, ou seja, o projetista deve considerar o usuário como o principal fator do sistema. Porém, o crescimento da atenção aos fatores humanos e aos aspectos de usabilidade foi se desenvolvendo lentamente. Em 1961, foi realizada a primeira conferência da sociedade de pesquisa ergonômica. Na década de 70, Nicholls (1979) enfatizou a importância de se desenvolver um novo ponto de vista de sistemas. de computação de forma a olhar o usuário sob uma perspectiva diferente, considerando o usuário como 'o centro de um sistema. Atualmente, uma atenção consideravelmente maior tem sido dada a fatores humanos e ergonômicos de sistemas interativos.

De acordo com Shackel \& Richardson (1991), o principal objetivo ou filosofia dos ergonomistas não é melhorar a produtividade, saída ou métodos humanos de trabalhar, mas sim entender o modo das pessoas trabalharem e se divertirem e, dessa.forma, melhorar a situação como um todo para as pessoas. Para Wisner (1987), ergonomia é o conjunto de conhecimentos científicos relativos ao homem e necessários à concepção de instrumentos, máquinas e dispositivos que possam ser utilizados com o máximo de conforto, segurança e eficiência.

Embora cada um dos referidos autores aborde a ergonomia de maneira diferente, o objetivo é que a ergonomia ajude a melhorar a produtividade. Em estudos de situação prática, ergonomia/fatores humanos dá maior ênfase à eficiência na operação de equipamentos, que é medida pelo desempenho humano dos usuários. Aliada à eficiência está a satisfação do operador do sistema.

Considerar os fatores humanos é essencial em sistemas modernos, pois a complexidade e sofisticação da tecnologia moderna continuamente demandam mais a interação humana. Assim, se os fatores humanos tiverem sido considerados, maior poderá ser o sucesso dos usuários em desempenhar suas tarefas. 
Para muitos usuários, o sistema de computação é o terminal ou a estação de trabalho que ele está usando, sendo que tais usuários freqüentemente são vistos pelos projetistas como "usuários finais". Segundo Shackel \& Richardson (1991), o termo "usuário final" leva a atitudes que causam projetos ruins e falhos em usabilidade, pois projetistas deveriam ver o usuário como o centro do sistema de computador.

A área de interação usuário-computador (IHC) se preocupa em melhorar a cooperação entre pessoas e sistemas em um ambiente organizacional interativo. IHC estuda os aspectos referentes ao ser humano, à organização, ao serviço, às tarefas, às máquinas e ao ambiente, bem como a-aceitabilidade do sistema pelo usuário. De forma a-se ter interfaces usáveis, devese estudar os requisitos particulares dos usuários, o ambiente em que está inserida a aplicação e as tarefas particulares que um usuário executa, ou seja, a interação usuário-computador.

\subsection{O Que é Usábilidade?}

Como descrito na Seção 2.1, com o uso massificado de microcomputadores por diferentes usuários com diferentes estilos de interação, intensificou-se a exigência por sistemas de qualidade.

A cada diâ, as interfaces dos sistemas interativos de software começam a ser utilizadas por todos e em todos os lugares. Assim, os projetistas de informática têm a obrigação, por questões relativas à concorrência entre produtos de software, de se comprometer a projetar os sistemas considerando os aspectos ergonômicos de interfaces usuário-cómputador.

De acordo com Shackel \& Richardson (1991), os sistemas devem ser “amigáveis". Porém, Nielsèn (1993) diz que este termo não é apropriado, poìs usuários não precisam de máquinas que sejam amigáveis para eles, precisam apenas de máquinas que não lhés sejam um impecilio quando eles precisam realizar seu trabalho. E ainda, usuários têm diferentes necessidades e um sistema que é amigável para um pode ser tedioso para outro.

Devido a esses problemas com o termo "amigável", nos últimos anos, profissionais de algumas áreas de estudo de interface de usuário usam outros termos. Dentre essas áreas se destacam a IHC, Projeto de Interfaces, Fatores Humanos, Ergonomia e Usabilidade. Usabilidade se enquadra dentro de ưm conceito mais amplo, que é a aceitabilidade do sistema pelo usuário. Aceitabilidade se refere ao sistema ser bom o suficiente para satisfazer todas as 
necessidades e requisitos dos usuários e de outras pessoas relacionadas à utilização do sistema.

A aceitabilidade global de um sistema é definida por Nielsen (1993) como uma combinaçãa de sua aceitabilidade social e prática, conforme mostrado na Figura 2.1. A aceitabilidade prática pode ser avaliada segundo os critérios de custo, suporte, confiabilidade de sistemas existentes e utilidade. Utilidade é o critério que diz se um sistema pode ser usado para alcançar alguma meta desejada, podendo este ser quebrado em duas categorias: funcionalidade e usabilidade. Assim, funcionalidade diz se o sistema pode fazer o que é pretendido e usabilidade se refere à quão bem o usuário pode usar aquela funcionalidade.

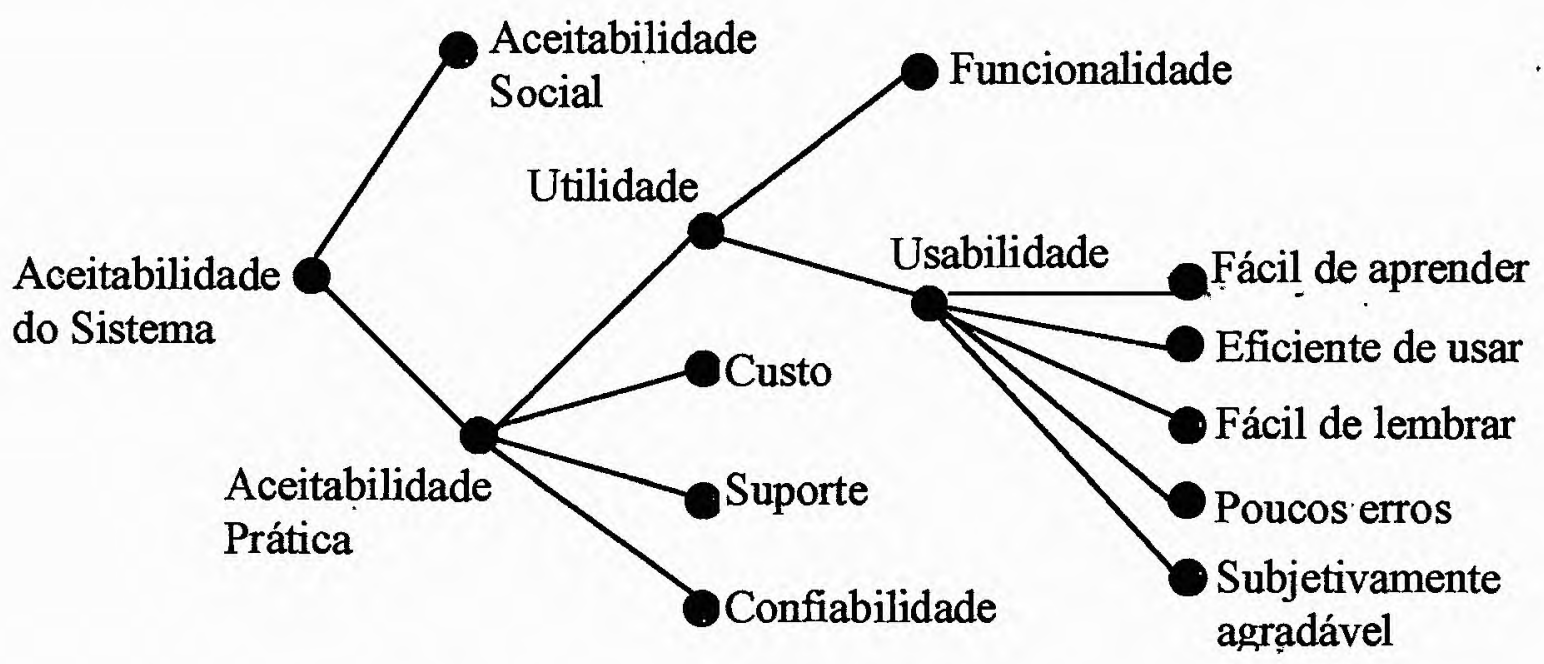

FIGURA 2.1 - Um modelo de atributos de aceitabilidade do sistemá (Nielsen, 1993)

Há diferentes pontos de vista de usabilidade de interfaces. Conforme discutido no IHC'99, usabilidade é a adequação entre características dos usuários e características da interação com o sistema, para a realização de tarefas, dentro de um determinado contexto. Usabilidade não é uma propriedade do sistema, é preciso levar em consideração o contexto em que o sistema está inserido (os usuários, o sistema, as tarefas suportadas e o ambiente). Desse ponto de vista, usabilidade é caracterizada pela facilidade de uso e de aprendizado, transparência da interface, previsibilidade (se refere a poder prever as ações do usuário), flexibilidade (possibilidade de configuração do sistema de acordo com as necessidades do usuário) e satisfação de uso.

De acordo com a norma ISO 9241 (1991), usabilidade está relacionada à eficácia, eficiência e satisfação no uso. Eficiência é o número de ações em uma unidade de tempo e eficácia é quando a eficiência se mantém por um grande período de tempo. Na visão dada 
pelo modelo GOMS (Card et al., 1983) e por Keystroke (Card et. al., 1980), usabilidade sẹ refere ao desempenho humano satisfatório, considerando assim a competência humana, a velocidade de uso e quantidade de erros.

A abordagem de usabilidade de acordo com Abowd (1992) pode ser expressa segundo três fatores:

a) Facilidade de Aprendizado, que agrupa os aspectos da interface que permitem ao usuário novato compreender inicialmente como usar o sistema e em seguida alcançar por experiência um nível elevado de desempenho.

b) Flexibilidade de Interação, que agrupa os aspectos que permitem uma multiplicidade de maneiras de trocar informações entre o usuário e o sistema.

c) Robustez de Interação, que agrupa os aspectos de interação que suportam a realização e a avaliação de objetivos.

Facilidade de aprendizado diz respeito aos critérios de previsibilidade (baseando-se no histórico de interações pode-se prever a interação futura), rastreabilidade (influência de operações passadas no estado atual da interação), familiaridade (correlação entre o que é çonhecido e o que é necessário) e generalidade (toma o conhecimento de uma interação específica e o aproveita para outras interações). $O$ fator flexibilidade de interação se refere dentre outros à configurabilidade e iniciativa do diálogo, que pode ser não preemptivo (não precisa seguir a ordem determinada de ações) e preemptivo local e global (neste caso, precisa seguir a ordem estipulada das tarefas). O último fator citado, robustez de interação, está relacionado à observabilidade do estado atual, recuperabilidade de erros e conformidade à tarefa do usuário.

Para Macleod et al. (1997), usabilidade pode ser definida operacionalmente em termos de efetividade, eficiência e satișfação com que usuários eșpecíficos podem executar certas tarefas em um dado.ambiente. Efetividade e eficiência são medidas de desempenho no dado contexto de uso. Por desempenho ser uma prẹocupação principal para usuários, organizações e produtores, ele deve ser medido.

O objetivo principal da engenharia de usabilidade é melhorar a interação homem máquina, tornando os sistemas fáceis de usar e de aprender. Porém, usabilidade não pode ser definida apenas em termos dessas condições. É desejável que se tenha uma definição mais ampla de usabilidade que, segundo Nielsen (1993), deve incluir ao menos esses atributos: facilidade de aprendizado; eficiência de uso; retenção; mínimo de erros; satisfação. Esta é a definição adotada neste trabalho e é detalhada abaixo. 


\subsubsection{Facilidade de Aprendizado}

Sistemas interativos precisam ser făceis de aprender, pois na maioria das vezes a primeira experiência que as pessoas têm com um novo sistema é a de aprender a usá-lo. Assim, facilidade de aprendizado é um atributo fundamental de usabilidade em grande partes dos sistemas. Porém, a dificuldade de se aprender a utilizar um sistema com interface diferente pode ser superada com treinamento.

Facilidade inicial de aprendizado é provavelmente o atributo de usabilidade mais fácil de se medir. Escolhe-se alguns usuários que não usaram o sistema antes e mede-se o tempo que eles levam para alcançar um nível especificado de proficiência em usá-lo. Os usuários do teste devem ser representativos dos pretendidos usuários do sistema e pode haver uma necessidade de se coletar medidas separadas de usuários sem qualquer experiência anterior e de usuários com alguma experiência de uso de computador.

O nível de proficiência pode ser medido pela capacidade do usuário executar umá certa tarefa com sucesso. Ou ainda, pode ser medido pela capacidade do usuário em-completar um conjunto de tarefas em um certo tempo mínimo diante do testador. Deve-se, no entanto, considerar que, geralmente, uma pessoa começa usando um sistema assim que ela aprende uma parte da interface; ao invés de aprendê-la completamente para só depois executar sua tarefa.

\subsubsection{Eficiência de Uso}

Este atributo é equivalente a dizer que, tendo o usuário aprendido o sistema; um alto nível de produtividade é possível. Para medir eficiência de uso por-usuários experientes, precisa-se-de ter acesso aos referidos usuários. Usuários são considerados experientes se eles se declaram ser ou se forem usuários por mais que um determinado tempo, por exemplo, um ano. Experiência pode também ser definida mais formalmente em termos de número de horas gastas usando $0^{\circ}$ sistema. Esta última definição é a mais freqüentemente usada em experimentos com novos sistemas sem uma base de usuário estabelecida: usuários teste são trazidos e pedidos para usar o sistema por um certo número de horas, depois é que sua eficiência é medida. Uma forma típica de medir eficiência de uso e com isto decidir sobre 
alguma definição de especialista é obter uma amostra representativa de usuários com aquela habilidade e medir o tempo que eles levam para executar algumas tarefas típicas.

\subsubsection{Retenção}

O sistema deve ser fácil de lembrar, tal que o usuário casual seja capaz de retornar ao sistema depois de algum período que o usou pela última vez, sem ter que aprender tudo de novo. Usuários casuais são pessoas que estão usando um sistema intermitentemente em vez de freqüentemente. São assim considerados por já terem usado o sistema antes, necessitando assim apenas de lembrar como usá-lo baseado em seu aprendizado anterior. Uso casual é tipicamente visto por programas utilitários, que são usados somente sobre circunstâncias excepcionais, como também por programas que são inerentemente usados somente após longos intervalos, tal como um programa para fazer um relatório trimestral.

Ter uma interface fácil de lembrar é também importante para usuários que retornam depois de ter estado de férias ou que por algum outro motivo deixaram temporariamente de usar um programa. Em grande parte, melhorias no aprendizado freqüentemente também fazem com que uma interface seja fácil de lembrar. Mas, em princípio, a usabilidade de retornar a um sistema é diferente daquela de usar o sistema pela primeira vez.

Retenção é um atributo de usabilidade que é raramente testado tão completamente quanto os outros, mas existe em princípio dois principais caminhos de medi-lo. Uma forma é executar um teste padrão, com usuários casuais, e medir o tempo que eles precisam para executar algumas tarefas típicas. Alternativamente, pode-se conduzir um teste de memória com usuários depois que eles terminaram uma sessão de teste com o sistema, pedindo a eles que expliquem o efeito de vários comandos ou para nomearem os comandos (ou desenharem os ícones) que fazem certas coisas. A pontuação da interface para memorização é então o número de respostas corretas dadas pelos usuários.

\subsubsection{Mínimo de Erros}

Esse atributo de usabilidade é relacionado à quantidade de erros que um usuário-pode cometer durante o uso do sistema. O que se busca é uma baixa taxa de erros e uma maior facilidade de 
recuperação caso eles ocorram. Tipicamente, um erro é alguma ação que não.culmina na meta desejada. A taxa de erros é medida contando-se o número de tais ações feitas pelos usuários enquanto executam alguma tarefa especificada, podendo essa taxa ser medida como parte de um experimento para avaliar outros atributos de usabilidade.

Simplesmente definir erros como sendo qualquer ação incorreta do usuário não nos dá a possibilidade de verificar diferentes erros em quantidade. Alguns erros são imediatamente corrigidos pelo usuário e não reduzem a velocidade da transação do usuário. Outros erros são mais catastróficos por natureza, porque eles não são descobertos pelo usuário, conduzindo assim a um trabalho final defeituoso. Tais erros catastróficos.deveriam ser contados separadamente dos erros menores, e esforços especiais deveriam ser feitos para minimizar sua freqüência.

\subsubsection{Satisfação}

O atributo final de. usabilidade, satisfação subjetiva, refere-se a quão agradáyel o sistema é de usar. A satisfação subjetiva pode ser um atributo de usabilidade especialmente importante para sistemas tais como contabilidade doméstica, jogos, fiç̧ão interativa, ou.pintura criativa. Para alguns desses sistemas seu valor de entretenimento é mais importante que a velocidade com que as tarefas são feitas, mesmo porque uma pessoa pode querer gastar um longo tempo se divertindo. Uma vez que a meta dos usuários é entretenimento eles deveriam estar se divertindo ou jogando e/ou ganhando experiência quando usando tais sistemas.

Em princípio, certas. medidas objetivas podem ser usadas em vez de perguntar as preferências subjetivas dos usuários para avaliar a natureza agradável de. uma interface. Em uns poucos casos, medidas psicofisiológicas tais como, dilatação da pupila, batimento do coração, pressão sanguínea e nível de adrenalina no sangue têm sido usadas para estimar o estresse de usuários e níveis de conforto: Infelizmente tais medidas requerem condiçõess experimentais intimidantes como tomar amostras de sangue. Uma vez que usuários de teste são normalmente nervosos e que o relaxamento é uma importante condição para muitos testes de usuários, a abordagem psicofisiologica freqüentemente será imprópria para estudos de engenharia de usabilidade.

Alternativamente, satisfação subjetiva pode ser medida simplesmente perguntando para os usuários sua opinião subjetiva. Da perspectiva de algum, usuário único a resposta para 
tal pergunta é subjetiva, mas quando é calculada a média das respostas de múltiplos usuários, - resultado é uma medida objetiva da agradabilidade do sistema. Como o propósito do atributo de satisfação subjetiva é avaliar se os usuários gostam do sistema, parece altamente apropriado medir isso por meio de perguntas aos usuários. Satisfação subjetiva é normalmente medida por um pequeno questionário subjetivo que é dado aos usuários como parte da sessão de teste de usuário.

\subsection{Avaliação de Usabilidade}

Avaliar usabilidade de um sistema interativo significa verificar se o sistema e sua interface suportam adequadamente as tarefas dos usuários. Sabendo-se que qualquer avaliação está contextualizada, deve-se compreender quais são os possíveis usuários, as tarefas e informações associadas, o contexto organizacional e social e as restrições tecnológicas existentes. Assim, quando se avalia uma interface do usuário é importante saber o que usabilidàde significà para a aplicação atual. Por exemplo, um software educativo infantíl deve tèr certas características que um processador de texto não precisa ter.

Problemas de usabilidade são vistos sob diferentes perspectivas. Para Karat (1992), problema de usabilidade é qualquer coisa que interfere com a habilidade do usuário em completar suas tarefás de forma efetiva e eficiente. Já, para Lavery et al. (1997), tais problemas são um aspecto do sistema que o torna desagradável, ineficiente, oneroso ou impossível de permitir a realização dos objetivos do usuário em uma situação típica de uso.

Qualquer que seja a definição utilizada, no processo de avaliação de usabilidade é importante usar um relatório como forma de descrever o problema encontrado, contendo o contexto, efeito sobre o usuário, efeito sobre a tarefa, a causa e uma sugestão para um possível re-design. Além disso, associar uma estimativa de seriedade a um problema é uma maneira de se avaliar seu peso na usabilidade de um produto final. Os tipos de problemas podem ser:

a) Sério/Recorrente: um aspecto da interface que representa obstáculo sério no qual o usuário esbarra sucessivas vezes.

b) Intermediário: um aspecto da interface que representa um obstáculo no qual o usuário esbarra uma vez e é capaz de suplantá-lo na próxima interação.

c) Menor: um aspecto da interface que representa um obstáculo que se coloca para ao menos um tipo de usuário. 
d) Falso: um aspecto da interface que, apesar de quebrar padrões para o projeto não representa um obstáculo à interação.

e) Novo: um aspecto da interface que representa um obstáculo, que é introduzido no projeto como fruto de uma revisão de usabilidade.

A avaliação pode ser executada em diferentes fases no processo de desenvolvimento de um sistema para atender a diversos fins (Słneiderman, 1998). Algumas. possíveis finalidades são: propor correções em projetos em desenvolvimento; propor revisões em produtos acabados; definir a aceitação ou não de projetos encomendados; e comparar o desempenho efetivo de softwares interativos. Nas primeiras fases, a avaliação da interface é feita para prever a usabilidade do produto ou verificar o entendimento da equipe de projeto sobre os requisitos dos usuários. Em estágios posteriores ao processo de projeto está voltada para a identificação de problemas de usabilidade e melhorias da interface do usuário. Esse último, é o enfoque que será utilizado neste trabalho.

Os principais objetivos da avaliação de usabilidade são, dentre outros, prever dificuldades de aprendizado; diagnosticar as características do projeto da interface com o usuário, que provavelmente representam obstáculos à interação; inspecionar o software contra padrões de qualidade de uso; observar e registrar de maneira objetiva os problemas efetivamente enfrentados pelo usuário na interação com o sistema; observar, quantificar e medir as taxas de eficácia, eficiência e produtividade do usuário na interação com o sistema; conhecer a satisfação do usuário em relação ao sistema, nem sempre relacionada diretamente com produtividade. Visando atingir esses objetivos várias técnicas são aplicadas.

\subsubsection{Técnicas de Avaliação}

As várias técnicas existentes para avaliar a usabilidade de um sistema podem ser classificadas em prospectivas, preditivas e objetivas. As prospectivas são baseadas na opinião do usuário sobre a interação com o sistema. Nesse caso, basicamente é feita a aplicação de questionários para avaliar a satisfação do usuário. As técnicas preditivas podem ser baseadas em modelos ou ainda baseada em conhecimento. As técnicas baseadas em conhecimento são técnicas primitivas como, Avaliação Heurística, Inspeção de Conformidade, Inspeção Cognitiva, as quais podem ser combinadas para se ter técnicas mais elaboradas. Já as técnicas objetivas são baseadas em ensaios de interação do usuário ou em sistemas de monitoramento (observação 
do usuário, por exemplo, com câmaras). Ensaios de interação é uma abordagem baseada em tarefas, pode revelar problemas sérios e intermediários. Neste trabalho de mestrado, são utilizadas as três técnicas. Para avaliar a satisfação do usuário é elaborado um questionário a ser respondido pelos usuários, que se enquadra nas técnicas prospectivas. Para avaliar os critérios facilidade de aprendizado, eficiência de uso e mínimo de erros é usado um modelo de tarefas e dados obtidos de testes de usuários, que correspondem respectivamente às técnicas preditivas baseadas em modelos e técnicas objetivas.

É importante considerar aspectos relacionados à tarefa na avaliação da interface do usuário. Uma tarefa é uma atividade executada para se alcançar uma meta. De acordo com Lacerof \& Paternò (1998), pode-se pensar em tarefas em diferentes níveis de abstração, variando de tarefas de alto nível, como imprimir um arquivo até tarefas de baixo nível como selecionar um botãe na tela. Tanto nas tarefas de baixo quanto nas de alto nível, pode-se pensar nas tarefas que podem ou não ser executadas e a relação temporal entre elas (ou seja, qual tarefa :deve ser executada primeiro para alcançar a meta desejada). Nas tarefas de alto nível, as relações temporais são determinadas pelas dependências lógicas entre elas, por exemplo, a tarefa imprimir um arquivo pode ser executada apenas após indicar o nome do arquivo.

A qualidade das técnicas de avaliação de usabilidade deve ser avaliada em relação a:

1. Adequabilidade, que significa se a técnica é adequada aos objetivos da avaliação.

2. Validade/Poder de Previsão, se a técnica é capaz de prever obstáculos efetivos.

3. Completitude/Abrangência, se a técnica pode prever o maior número de obstáculos efetivos.

4. Sistematização, se a técnica pode repetir ou reproduzir resultados.

5. Facilidade de Uso significa a técnica poder ser aplicada facilmente.

6. Poder de Persuasão, se os resultados obtidos pela técnica são capazes de convencer os projetistas a realizar mudanças.

Neste capitulo foi ressaltada a importância dos fatores humanos em sistemas interativos e o significado do termo usabilidade. O próximo capítulo apresenta quatro métodos de avaliação, com exemplo de aplicação e análise de custo e beneficio de cada um. 


\section{Capítulo 3}

\section{Métodos de Avaliação de Usabilidade}

Nesse capítulo serão apresentados alguns dos métodos que têm se provado úteis em suportar a engenharia da usabilidade. Inspeção de usabilidade é o nome genérico para um conjunto de

métodos baseado em avaliadores para inspeção ou exame de aspectos relacionados a usabilidade de uma interface de usuário. Dentre esses destacam-se Avaliação Heurística e Cognitive Walkthrough. Outro enfoque é testar a usabilidade (Dumas \& Redish, 1994). Nesse caso, o projetista estuda o usuário executando algumas tarefas e recolhe dados dos problemas que surgem. Um exemplo é o método MUSIC. Além disso, pode-se ter suporte automático na avaliação de usabilidade, como no método USINE. Os quatro métodos citados acima serão detalhados nas próximas seções.

\subsection{Avaliação Heurística}

Nesse método é feita uma inspeção sistemática da interface em questão, visando encontrar os problemas de usabilidade presentes na interface com ajuda de princípios que são nọmalmente referidos como heurísticas, por isso dá-se ao método o nome de Avaliação Heurística. 
Muitos desenvolvedores acham que alguns métodos de usabilidade são intimidantes, caros, dificeis de usar e-consomem muito tempo. Avaliação Heurística é um dos principais métodos de engenharia de usabilidade que supera alguns destes problemas, por ser fácil (pode ser ensinado em um seminário de meio dia), rápido (leva um dia para a maioria das avaliações), barato (tão barato quanto se queira) e menos intimidante. É o método de inspeção de usabilidade mais geral e mais informal, em que os resultados da avaliação melhoram à medida que aumenta o conhecimento e a cautela em sua aplicação.

\subsubsection{Como Conduzir uma Avaliação Heurística}

A condução da avaliação heurística por uma única pessoa é dificil, porque uma pessoa nunca será capaz de encontrar os problemas de usabilidade existentes em uma interface. Assim, a efetividade do método pode ser melhorada envolvendo-se múltiplos especialistas de usabilidade.julgando se cada elemento de diálogo está conforme os princípios de usabilidade estabelecidos. Esses princípios podem ser usados para explicar uma grande proporção dos problemas que uma pessoa -observa em um projeto de interface de usuário. Infelizmente requer-se alguma experiência dos avaliadores de forma a aplicá-los suficientemente a fundo, por isso pode ser necessário gastar algum dinheiro para adquirir consultores de usabilidade para ajudar com a avaliação heurística. De acordo com Nielsen (1994a), as heurísticas (ou princípios) de usabilidade são definidas abaixo.

\section{Diálogo Simples e Natural}

É desejável que a interface com o usuário seja tão simples quanto possível. Cada elemento de diálogo ou item de informação extra colocado numa tela representa uma coisa a mais para aprender, uma fonte a mais de possível confusão para o usuário e um obstáculo a mais quando se está procurando por outro item de informação desejado. Dessa forma, para que uma interface esteja de acordo com os critérios de usabilidade é necessária uma avaliação do uso desses elementos de diálogo. Além disso, a realização de tarefas com o sistema também deve minimizar a navegação do usuário pelo sistema.

A informação que o usuário irá precisar deve ser oferecida exatamente no tempo e local em que ela será necessária. Assim, as informações que serão usadas em conjunto devem 
aparecer sempre que possível na mesma tela. Os objetos e operações do sistema também devem ser acessados numa seqüência que permita maximizar a eficiência e a produtividade do usuário. Além disso, o projeto gráfico da interface deve por si só mostrar as.relações entre os elementos de diálogo, seguindo regras básicas de percepção humana.

Em aplicações em que é necessário dar prioridade à atenção do usuário, deve-se destacar os elementos mais importantes do resto. É também importante que o uso da cor nos diálogos seja moderado e, que apenas a informação relevante para uma determinada tarefa do usuário deva aparecer na tela correspondente.

\section{Falar a Língua do Usuário}

Os diálogos não devem ser orientados aos sistemas, mas expressos claramente em palavras, expressões e conceitos familiares à comunidade de usuários. Por exemplo, um sistema bancário não deve exigir que os usuários especifiquem o tipo de moeda com códigos, mas sim com termos como "Dólares" ou "Reais". Devem ser seguidas convenções do mundo real, fazendo com que as informações apareçam de uma forma lógica e natural. Assim, 'as interações devem ser vistas da perspectiva do usuário.

\section{Minimizar a Carga de Memória do Usuário}

É importante tornar visíveis objetos, ações e opções. O usuário não deve ser forçado a memorizar informações de uma parte do diálogo a outra. Informações para uso do sistema devem ser visíveis e fáceis de recuperar sempre que apropriado, pois em geral as pessoas são melhores em reconhecer algo que lhes é mostrado do que em recuperar a mesma informação da memória sem nenhuma ajuda.

\section{Consistência}

Os usuários não devem ficar em dúvida se diferentes palavras, situações ou ações significam ou não a mesma coisa. A consistência é um dos princípios mais básicos de usabilidade. Se os usuários souberem que o mesmo comando ou a mesma ação terá sempre o mesmo efeito, eles se sentirão mais confiantes e o aprendizado do sistema ficará mais fácil porque a cada nova etapa uma parte do conhecimento necessário já estará disponível. 
É 'importante que se siga convenções de plataforma. A mesma informação deve ser apresentada no mesmo local em todas as telas e caixas de diálogo e deve ser formatada da mesma maneira para facilitar seu reconhecimento. Além disso, o sistema deve ser consistente com o padrão de interface gráfica do usuário (GUI) utilizado. Esta medida por si só garante certo grau de consistência da interface do sistema, mas não é suficiente, pois o padrão obviamente deixa muitos graus de liberdade para o projetista.

\section{Retroalimentação}

O sistema deve informar o usuário continuamente sobre o que está sendo feito e como a entrada do usuário está sendo interpretada. A retroalimentação (Feedback) não deve esperar até que um erro ocorra, mas deve prosseguir paralelamente à entrada de informação. Não deve ser expresso em termos gerais abstratos, mas deve reescrever a entrada do usuário e indicar o que está sendo feito com ela. Por exemplo, enviar uma mensagem de aviso quando um usuário está a caminho de realizar uma ação irreversível. A retroalimentação se torna especialmente importante quando o sistema tem tempos de resposta longos para algumas operações. Além disso, outro ponto em que a retroalimentação é necessária é na ocorrência de falhas do sistema. $O$ usuário deve saber que a falha foi do sistema e $o$ que se pode fazer a respeito dela.

\section{Saídas Claramente Indicadas}

Usuários freqüentemente escolhem erradamente algumas funções do sistema e necessitariam de uma saída claramente indicada para deixar o estado indesejável alcançado sem ter que fazer muitas tentativas. Para aumentar o sentimento de controle do usuário sobre o sistema, deve-se fornecer uma saída fácil e explícita dessas situações tanto quanto possível. Por exemplo, dar um suporte de undo e redo.

\section{Atalhos}

Atalhos (invisiveis para usuários novatos) podem acelerar a interação para o usuário experiente. Aceleradores típicos incluem abreviações de comandos, combinações de teclas, 
que são mapeadas em comandos do sistema, clique duplo do mouse sobre um elemento para realizar sua ação mais comum e menus de botões.

\section{Boas Mensagens de Erro}

Situações de erro são críticas do ponto de vista da usabilidade, dentre outras razões por elas representarem um ponto em que o usuário teve problemas e potencialmente será impedido de atingir seu objetivo original. Mas, se os erros ocorrem é preciso ser criterioso na forma de expressá-los. Algumas considerações são feitas em relação às mensagens de erro: a) devem ser escritas em linguagem clara e evitar o uso de códigos obscuros; b) devem ser precisas e não vagas ou genéricas; c) devem ser construtivas e ajudar o usuário a resolver o problema; d) devem ser educadas e nunca intimidar o usuário ou culpá-lo explicitamente.

\section{Prevenção de Erros}

Melhor do que ter boas mensagens de erro é ter um projeto cuidadoso que impede um problema de acontecer. Geralmente, é possível identificar os pontos que os erros são mais prováveis e os sistemas podem ser adaptados de forma a contornar essas situações.

Erros com conseqüências muito graves podem diminuir em freqüência se a confirmação do usuário for explicitamente pedida pelo sistema antes de continuar o processamento de uma operação arriscada.

\section{Ajuda e Documentação}

Embora seja melhor que o sistema possa ser usado sem documentação suplementar à interface com o usuário, este objetivo nem sempre é atingido. Porém, a ajuda e documentação não reduzem os requisitos de usabilidade da interface. Como os usuários que recorrem aos manuais estão provavelmente em algum tipo de emergência e precisarão de ajuda imediata, qualquer informação deveria ser fácil de procurar, enfocada na tarefa do usuário, listada em passos concretos a serem realizados, e não ser muito extensa. 


\subsubsection{Um Exemplo de Avaliação Heurística}

Visando tornar mais clara a aplicação do método avaliação heurística, é apresentado a seguir um exemplo retirado de Nielsen (1993).

A Figura 3.1 mostra uma das telas da interface de um sistema cujo objetivo é fornecer informações meteorológicas para viajantes. O TRAVELweather (um sistema hipotético) pode fornecer informações sobre o tempo às 3AM, 9AM, 3PM e 9PM para o dia atual e para os próximos dois dias, usando uma base de dados. A interface é projetada para uso em um computador pessoal gráfico com mouse e aparecerá como uma janela na tela.

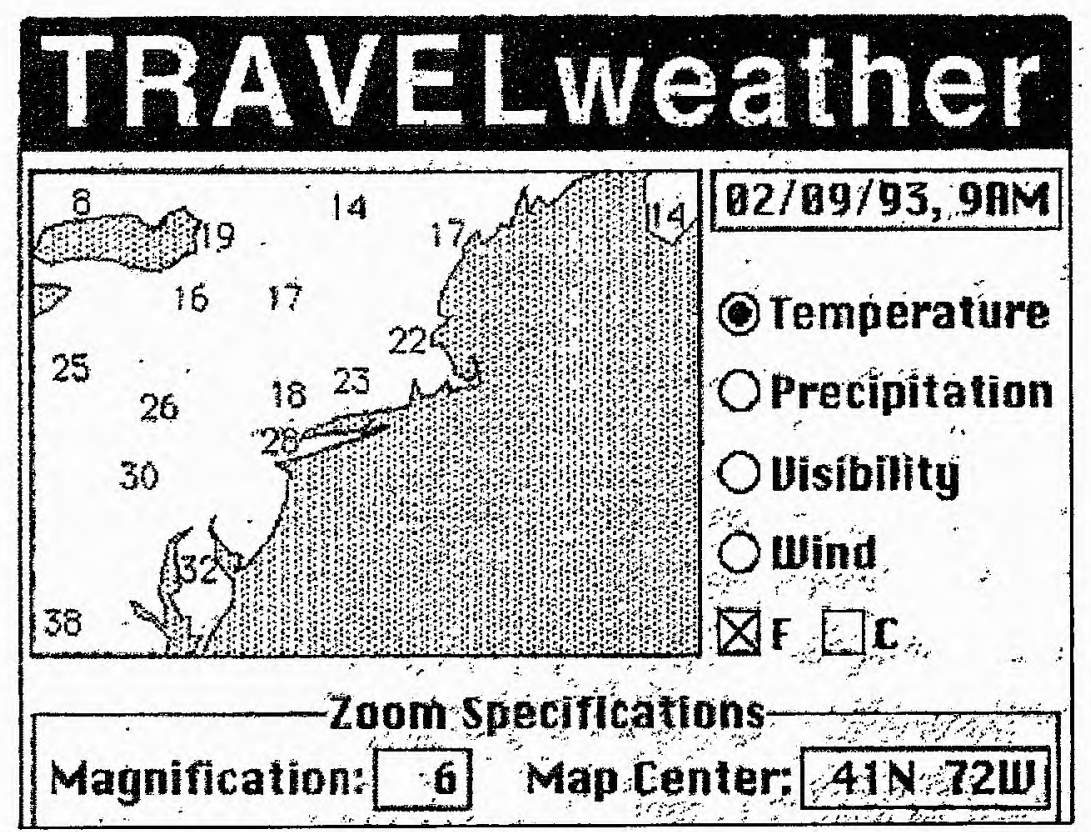

FIGURA 3.1 - A Interface Principal da Aplicação TRAVELweather (Nielsen, 1993)

O usuário opera a interface digitando o dia e hora desejada na caixa no canto superior direito da janela. Se o usuário digitar uma data que não seja hoje ou os próximos dois dias, ou se o usuário digitar uma hora que não seja uma das quatro horas disponíveis, o sistema mostrará o diálogo de alerta mostrado na Figura 3.2. Quando o botão "OK" é pressionado, a caixa de alerta desaparece e o sistema volta o dia e a hora para o último valor válido. 


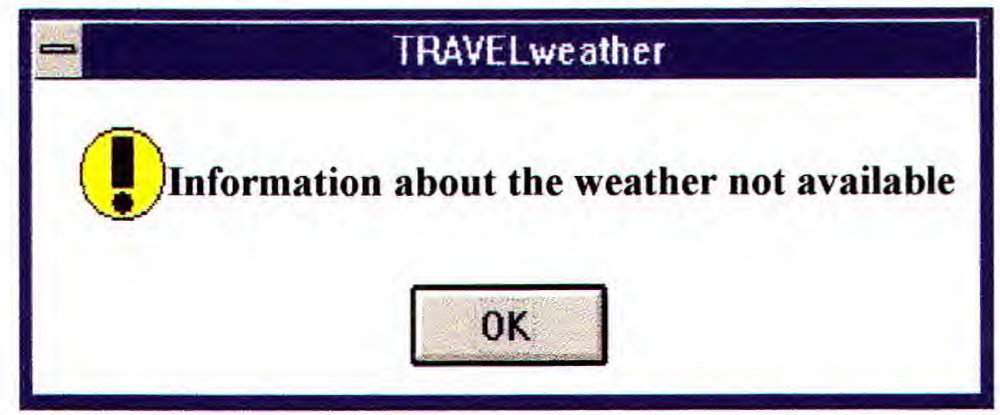

FIGURA 3.2 - Informação de Erro na Edição dos Horários de Previsão

O usuário muda o conteúdo do mapa editando as caixas de amplificação e centro do mapa. O sistema só permite que inteiros sejam digitados na caixa "Magnification" (Amplificações), emitindo um aviso sonoro se o usuário pressionar uma tecla não numérica. Se o usuário digitar algo que não seja uma coordenada válida na caixa "Map Center" (Centro do Mapa) o sistema mostrará o diálogo de alerta mostrado na Figura 3.3. Uma coordenada válida é definida por um inteiro de 0 a 90 seguido pela letra $\mathrm{N}$ ou $\mathrm{S}$, e por um inteiro de 0 a 179 seguido da letra W ou E. Quando o botão "OK" é pressionado a caixa de diálogo desaparece e o sistema volta as coordenadas para o último valor válido.

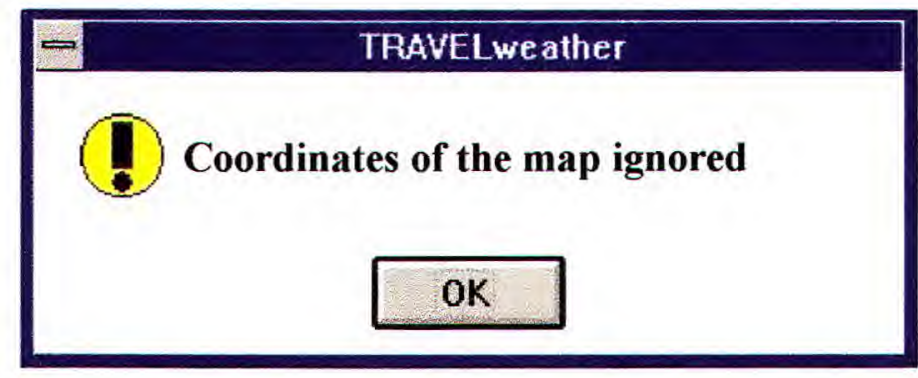

FIGURA 3.3 - Informação de Erro na Edição do Mapa

Após executar a avaliação heurística da interface, tem-se como resultado uma lista de problemas de usabilidade referentes aos princípios de usabilidade desobedecidos por algum aspecto da interface. A Tabela 3.1 mostra uma possível lista de problemas de usabilidade detectados pelos avaliadores, em que a primeira coluna se refere ao princípio de usabilidade e a segunda coluna se refere ao problema encontrado. 
TABELA 3.1 - Resultados da Avaliação Heurística para o Sistema TRAVELweather

\begin{tabular}{|c|c|}
\hline Principio de l sabilidade & Problenia Encontrado \\
\hline Diálogo Simples e Natural & $\begin{array}{l}\text { O nome do sistema ocupa muito espaço. Com um nome menor, haveria } \\
\text { mais espaço para elementos de diálogo alternativos, ou a tela ficaria } \\
\text { menos carregada. }\end{array}$ \\
\hline Falar a Língua do Usuário & $\begin{array}{l}\text { Fica dificil de ler o mapa sem indicações geográficas, por exemplo } \\
\text { fronteiras entre paises. }\end{array}$ \\
\hline $\begin{array}{l}\text { Boas Mensagens de errol } \\
\text { Minimizar a Carga de Memória } \\
\text { do Usuário }\end{array}$ & $\begin{array}{l}\text { O usuário não deveria ser punido por seu erro, com o sistema apagando } \\
\text { todos -os dados que ele entrou... Para.manter.os campos na tela principal } \\
\text { corretos, o sistema poderia repetir a entrada na caixa de alerta e permitir } \\
\text { ao usuários editá-la ali. }\end{array}$ \\
\hline Consistência & $\begin{array}{l}\text { Os modos de exibição de temperatura (F e C) são mutuamente exclusivos, } \\
\text { logo não deveria ter sido usada a check-box. }\end{array}$ \\
\hline Retroalimentação & $\begin{array}{l}\text { p padrão usado para representar oceanos e lagos não torna } \\
\text { suficientemente claro quais partes do mapa são terra e quais são água. } \\
\text { Poderia ter usado um padrão mais explícito, por exemplo, ondulado. }\end{array}$ \\
\hline Saidas_Claramente Indicadas & $\begin{array}{l}\text { Não é explicito na tela principal como se faz para sair do sistema. } \\
\text { Adicionar um botão de "Exit" (sair) poderia ser uma boa soluçẫo. }\end{array}$ \\
\hline Atalhos & $\begin{array}{l}\text { Como uma ação comum dos usuários é centrar o mapa ao redor de } \\
\text { determinada localidade e dar um Zoom naquela localização, um atalho } \\
\text { poderia ser oferecido combinando ambas as ações quando o usuário clica } \\
\text { no mapa. }\end{array}$ \\
\hline Prevenção de Erros & $\begin{array}{l}\text { O formato dia/mês/ano pode ser interpretado erroneamente por turistas } \\
\text { estrangeiros. Uma forma de evitar problemas seria representar os meses } \\
\text { por strings no lugar de número. }\end{array}$ \\
\hline Ajuda e Documentação & $\begin{array}{l}\text { O usuário não tem condições de saber que a caixa com a data e a hora } \\
\text { pode ser editada por não existir nenhum rótulo, prompt ou texto de ajuda }\end{array}$ \\
\hline
\end{tabular}

\subsubsection{Análise de Custo e Benefício}

A análise de custo e beneficio da avaliação heurística inclui dois elementos básicos: primeiro a estimativa de custos em termos de tempo gasto executando a avaliação e, segundo a estimativa dos beneficios em termos de aumento de usabilidade (Nielsen, 1994b).

As estimativas de custo são mais fáceis de se calcular. $\mathrm{O}$ tempo gasto em um projeto de avaliação heurística é baseado no número de pessoas envolvidas e horas despendidas em cada uma das atividades requeridas para a avaliação. A lista das atividades pode ser vista detalhadamente em (Nielsen, 1994b).

O tempo despendido para a preparação do cenário é dado apenas pelo esforço de colocar o cenário em uma forma que possa ser utilizada pelos avaliadores durante a avaliação. O projeto baseado em cenários é um método bem conhecido para o projeto de interface de usuário (Carroll \& Rosson, 1990; Clarke, 1991). Assim, uma pessoa freqüentemente será capaz de utilizar cenários de interação que foram desenvolvidos em fases anteriores à avaliação de usabilidade. Além disso, um cenário desenvolvido para um sistema pode ser 
utilizado por outro sistema, sendo necessário apenas um pouco mais de esforço. A transformação da estimativa em tempo para uma estimativa em dinheiro pode ser feita multiplicando o número de horas pelo custo por hora do profissional. Devem também ser considerados custos adicionais com computadores e espaço de laboratório usado para o teste.

Para Nielsen (1994b), a única forma de se medir os benefícios da avaliação heurística seria implementando duas versões da interface do usuário: uma sem qualquer. mudança e uma com as mudanças fornecidas pelos resultados da avaliação. As duas versões seriam usadas por um grande número de usuários reais, fornecendo assim as medidas exatas das diferenças em tempo de aprender e desempenho pelas duas interfaces. Porém, esse modo de se medir não é adequado se a versão avaliada for apenas um protótipo não funcional, pois uma pessoa não pode fazer qualquer trabalho real com ela. Uma maneira alternativa para se obter estimativas nesse caso seria pedir aos avaliadores para estimar as melhorias em usabilidade a partir dos problemas de usabilidade identificados pela avaliação. Por exemplo, as melhorias em relação a alguns parâmetros de usabilidade: redução de tempo de aprendizado, velocidade no desempenho de usuários experientes; freqüência de erros e satisfação subjetiva dos usuários. Entretanto, as estimativas de beneficio seriam puramente baseadas em julgamentos subjetivos de especialistas em vez de em evidência empírica.

De acordo com Hartson (1998), métodos de inspeção são efetivos para encontrar alguns tipos de problemas de usabilidade, mas não definem seguramente todos os tipos de problemas que podem ser observados em testes baseados no usuário. Em especial, avaliação heurística é um método de inspeção menos caro, mas é limitado pelo escopo das guidelines usadas.

A avaliação heurística representa um julgamento de valor sobre as qualidades ergonômicas das interfaces usuário-computador. Essa avaliação é realizada pọ especialistas em ergonomia, baseados em sua experiência e competência no assunto. A técnica produz ótimos resultados, em termos da rapidez de avaliação e da quantidade e importância de problemas diagnosticados, mas exige um grupo razoável de ergonomistas, de modo a identificar a maior parte dos problemas ergonômicos das interfaces (Jeffries et al, 1991). 


\subsection{Método MUSIC}

O método MUSIC (Metrics for Usability Standards In Computing) é um método de medida de desempenho desenvolvido na Europa por Bevan e Macleod (1994) para prover um meio seguro de medir usabilidade. MUSIC é usado para medir até que ponto usuários específicos de um produto alcançam metas específicas em um ambiente específico. Isso pode ser realizado derivando-se medidas de desempenho de usuário e diagnosticando-se informações a partir da análise de um vídeo de interação.

As saídas básicas derivadas em todas as versões deste Método de Medida de Desempenho são: efetividade e eficiência. Além disso, o método completo, suportado por vídèo, inclui medidas de eficiência relativa do usuário (um indicador de experiência, em que relaciona a eficiência de usuários específicos àquela de experientes), produtividade (proporção de tempo não tendo problemas) e tempo gasto superando problemas, buscando improdutivamente pelo sistema e procurando ajuda. As próximas seções apresentam como o método pode ser conduzido, um exemplo de sua aplicação e quais os custos e beneficios em aplicâ-lo.

\subsubsection{Como Conduzir o Método MUSIC}

De acordo com Macleod et al. (1997), apenas revisar um sistema protótipo poderia levar a conclusões enganosas, sendo necessário um teste de usabilidade. Neste caso, são dadas ao usuário tarefas simples para executar e registra-se seu desempenho, seus pensamentos e atitudes. $\mathrm{O}$ método MUSIC tem evoluído e sido refinado para atender as exigências das aplicações comerciais, sendo apoiado por uma variedade de ferramentas, que podem ser escolhidas e usadas de acordo com as necessidades específicas de desenvolvimento, orçamento e escala de tempo.

Para obter medidas de desempenho que possam ser seguramente exploradas, é fundamental que se selecione usuários verdadeiramente representativos, estabeleça tarefas reais de trabalho e forneça um ambiente de trabalho realístico. Isso é possível de alcançar aplicando-se a Análise de Contexto de Usabilidade (Macleod, 1996; Thomas \& Bevan, 1996), que recolhe informação sobre o contexto atual ou intencional de uso e produz uma especificação das características a serem implementadas no contexto de avaliação. Tal 
especificação serve para duplo propósito: primeiro para assegurar validade externa (em que se verifica se o contexto de avaliação se relaciona com o contexto de uso) e validade interna (em que se verifica se o contexto de avaliação está consistente com outras partes das sessões de avaliação). A Análise de Contexto de Usabilidade, requer que todas as características contextuais sejam consideradas explicitamente e documentadas.

Também são usadas outras ferramentas de apoio: o Manual de Medida de Desempenho (Thomas \& Curson, 1996), e o software DRUM (Diagnostic Recorder for Usability Measurements) (Macleod \& Rangge, 1993) que facilita o gerenciamento de dados de avaliação, análise de tarefa, análise de protocolo de avaliação e derivação de medidas.

A Figura 3.4, mostra a seqüência de passos requerida para avaliar usabilidade e derivar medidas pelo Método de Medida de Desempenho. A coluna do lado direito da figura mostra as ferramentas MUSIC que direcionam e apoiam cada fase, esboçando os procedimentos necessários. Os passos 4 ao 7 podem ser repetidos como progresso de desenvolvimento. Detalhes sobre cada passo e ferramentas podem ser obtidos em. (Macleod et al., 1997).

Qualquer avaliação deve declarar claramente os objetivos. Como as saídas do Método de Medida de Desempenho incluem uma variedade de medidas opcionais e dados diagnósticos, é essencial que ao aplicar o método se comece com um conjunto de objetivos específicos de avaliação, e, se possível, objetivos de deșempenho. Os passos iniciais dessa abordagem, particularmente, a análise de contexto que o método utiliza, são melhores executados antes que um protótipo seja produzido.

Para avaliações serem executadas calmamente e eficazmente, é conveniente que os estudos sejam realizados em um laboratório de usabilidade, que permite que sistemas protótipos sejam estudados sem rompimento impróprio do trabalho comercial de cliente para avaliações. Alternativamente, os dados podem ser capturados no local de trabalho se, por exemplo, fatores chaves em um sistema de informação ou -sua colocação ambiental não puderem ser reproduzidos adequadamente em um laboratório. O Método de Medida de Desempenho inclui um processo documentado para a realização da avaliação, projetado para maximizar a confiabilidade e validade dos resultados que são obtidos. 


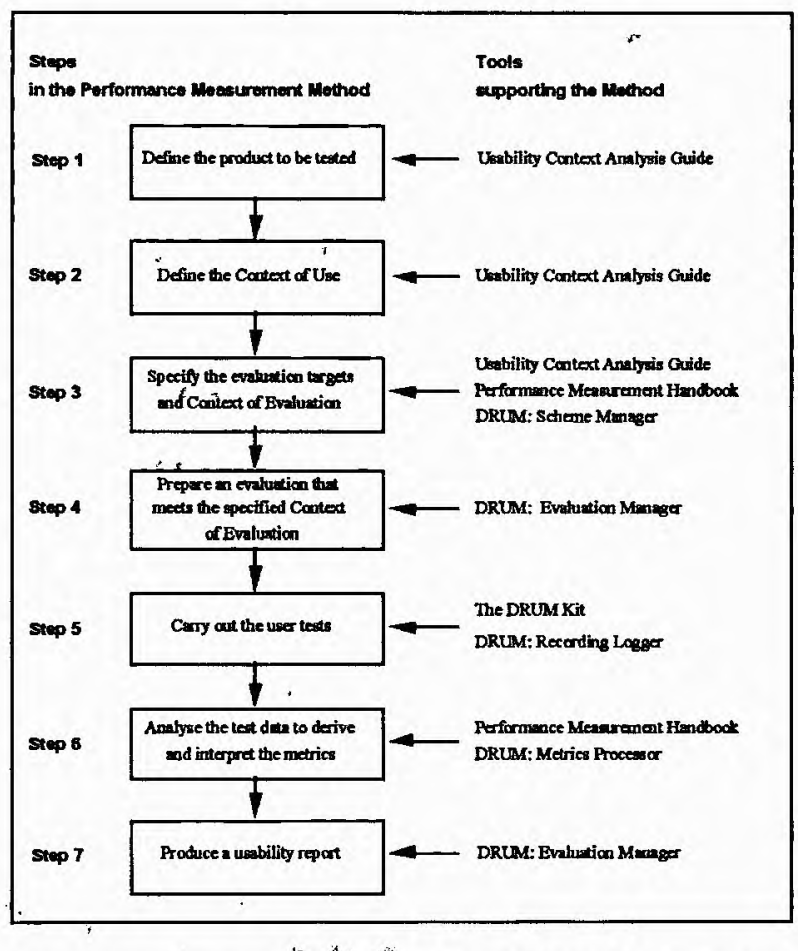

FIGURA 3.4 - Passos e Ferramentas usadas nótodo MUSIC (Macleod et al., 1997)

\subsubsection{Um Exemplo de Aplicação do Método}

O Método de Medida de Desempenho é aplicável em uma grande variedade de desenvolvimento de sistemas interativos e cenários de teste. Um exemplo de seu uso é no setor financeiro. Nesse caso, ele é baseado em um dado número de avaliações, conduzidas como parte do desenvolvimento de sistemas de informação de clientes por instituições bancárias e financeiras. De acordo com Macleod et al. (1997), os dados apresentados abaixo são realísticos e representativos, sendo separada uma síntese de várias decisões.

\section{Objetivos de Desenvolvimento}

Muitos provedores de serviços financeiros estão modernizando os sistemas de computador de suas filiais. Desenvolvimentos atuais dão ênfase ao uso de sistemas cliente-servidor com interfaces gráficas. Os principais objetivos no desenvolvimento desses novos sistemas são melhorar o nível de produtividade e satisfação no contexto de trabalho. Objetivos específicos podem ser: a produtividade do pessoal deveria aumentar; o novo sistema deveria ser mais fácil de usar que o antigo; e o novo sistema deveria ser fácil de aprender. 


\section{Definir o Contexto de Uso e de Avaliação}

A avaliação é baseada no uso de sistemas de informação que apoiam o processamento de transações de cliente, que representa um elemento principal da atividade diária da filial da empresa. A fase inicial da avaliação é uma análise das características do contexto de uso (Thomas e Bevan, 1996) em termos de usuários, serviços e tarefas, ambiente organizacional, ambiente técnico e ambiente fisico. Essas informações são mostradas na Tabela 3.2.

TABELA 3.2 - Características de Contexto de Uso de um Sistema de Informação

\begin{tabular}{|l|l|}
\hline Usuários & $\begin{array}{l}\text { São selecionadas as pessoas de filiais, que refletem as características do grupo e que estão } \\
\text { disponíveis e dispostas a participar das sessões de avaliação. }\end{array}$ \\
\hline Tarefas & $\begin{array}{l}\text { Um conjunto de tarefas críticas e freqüentes é definido e combinado com o cliente, utilizando os } \\
\text { resultados da Análise de Contexto e os requisitos de avaliação de clientes. Em serviços financeiros, } \\
\text { as tarefas podem envolver executar de } 15 \text { a } 30 \text { transações com } 8 \text { a } 15 \text { clientes em um periodo de } 30 \\
\text { minutos. Para cada transação, regras são combinadas para avaliar a quantidade e qualidade de } \\
\text { produções de tarefa. }\end{array}$ \\
\hline Ambiente & $\begin{array}{l}\text { O ambiente deveria simular as caracteristicas essenciais do local de trabalho, neste caso um } \\
\text { ambiente de filial. Fatores chave são o espaço de trabalho fisico (o balcão) e os dispositivos } \\
\text { periféricos (cartões de leitura, impressoras, cofres, e suporte para qualquer elemento de papel do } \\
\text { trabalho) que são exigidos para apoiar transações. Uma solução ideal é um escritório modelo com } \\
\text { uma área de observação embutida e máquinas fotográficas discretamente posicionadas. } \\
\text { Alternativamente, o balcão e o equipamento pertinente podem ser montados em umm laboratório de } \\
\text { usabilidade. Qualquer solução habilita o contexto de trabalho a ser recriado com algum realismo; as } \\
\text { transações são observadas discretamente através dos caixas, e todas as avaliações são registradas } \\
\text { por video (com tempo real e análise retrospectiva de desempenho). }\end{array}$ \\
\hline
\end{tabular}

\section{Projeto da Avaliação}

Medidas básicas são obtidas avaliando-se primeiro o uso do sistema velho. Tipicamente, cerca de 12 pessoas de balcão de filial participam de uma avaliação. Nesse exemplo, cada sistema é apresentado com transações frequientes ou críticas (algumas transações repetidas, com diferentes parâmetros dão um total de 20 tarefas): primeiro com o sistema velho e posteriormente com o protótipo do sistema novo. As tarefas são apresentadas da mesma maneira que elas ocorrem no local de trabalho.

O protótipo de sistemas novos é apoiado por bancos de dados locais confeccionados para a avaliação. Aos usuários é dado treinamento para usar o sistema protótipo, realizando tarefas de trabalho familiares às deles, anterior à sessão de avaliação. Esse treinamento pode durar tipicamente de uma a quatro horas e é a base para o treinamento que será dado a todos os usuários do sistema novo. 
Em condições formais, esse é um projeto de medidas repetidas: Restrições práticas e de escala de tempo, normalmente tornam impossível ao projeto da avaliação alcançar efeitos de método. Normalmente, o pessoal está bastante qualificado para usar os sistemas existentes devido à experiência diária deles com tais sistemas. As principais questões. se referem a quão bem os usuários podem usar o sistema.novo e a percepção deles de sua usabilidade. Além das medidas desempenho, os participantes são entrevistados a fim de se extrair as opiniões deles como um todo sobre o sistema e qualquer aspecto de interesse específico.

\section{Medidas}

As medidas de avaliação são de desempenho e satisfação. As seguintes medidas de desempenho são analisadas:

- Efetividade da tarefa: quão completamente e precisamente um usuário alcança as metas de cada tarefa.

- Tèmpo'da tarefa para cada tarefa: isto é, cada transação diferente.

- Eficiência do usuário para cada tarefa: Efetividade da Tarefa / Tempo da Tarefa.

- Tempo gasto superando obstáculos, fazendo busca e procurando ajuda: usado para identificar períodos improdutivos, e como um diagnóstico de ajuda.

- Eficiência relativa do usuário [Eficiência de Usuário/ Eficiência de Usuário Especialista]: indica o nivel de desempenho do pessoal depois de um pequeno trènamento (relativo ao desempenho de experientes).

Para medidas de satisfação é aplicado o questionário SUMI (Kirakowski, 1995; Kirakoswski \& Corbett, 1993), depois de usar o velho e o novo sistema. SUMI dá medidas de usabilidade de todas as tarefas executadas.

\section{Resultado de Desempenho}

As transações consideradas são depósito e retirada de dinheiro vivo, depósito e retirada de cheques. Nesse exemplo, foi extraído um conjunto de medidas, apresentado por Macleod et al. (1997). De acordo com testes estatísticos, o novo sistema mostra melhorias para transações em dinheiro vivo em relação ao Tempo de Tarefa e Eficiência. A diferença entre o novo e o velho sistema, em relação ao Tempo de Tarefa e Eficiência para transações em cheque, foi 
consideravelmente menor: após uma certa quantidade de treino, os meios para-realizar as tarefas usando o novo sistema foram mais lentos e menos eficientes que com o velho.

O resultado de efetividade indica erros mais secundários em produção de tarefa com.o sistema novo, o que pode ser comum em casos :em que um sistema novo tem uma interface radicalmente diferente. Qualquer erro crítico é uma causa para preocupação. A avaliação de registro de vídeo e dados de entrevista ajudam identificar causas específicas: Estudo dos dados referentes aos obstáculos, busca e ajuda possibilitam definir áreas específicas de dificuldade, que junto com dados de entrevistas de teste habilita o avaliador alimentar sugestões para melhorias potenciais específicas no projeto do sistema e no treinamento.

\subsubsection{Análise de Custo e Beneficio}

O método MUSIC, além de fornecer informações úteis para melhorar a usabilidade, inclui ferramentas e técnicas para medir desempenho e satisfação do usuário. $\mathrm{O}$ referido método avalia quais metas são alcançadas, qual o tempo gasto improdutivamente (por exemplo, procurando ajuda) e fornece informações sobre a localização de tais dificuldades e sobre melhorias que precisam ser realizadas.

A ferramenta DRUM é utilizada para dar suporte à análise com vídeo e auxilia no gerenciamento da avaliação. Segundo Bevan (1995), a gravação em vídeo oferece consideráveis vantagens para a avaliação de usabilidade, pois o vídeo de usuários finais trabalhando proporciona garantias convincentes da usabilidade e de problemas específicos. As pessoas observadas e as tarefas que elas executam são selecionadas como um resultado do contexto do estudo assistido pelo MUSIC, com o suporte da ferramenta DRUM, que acelera a análise através de vídeo e provê (para projetistas) evidências da usabilidade do sistema. Entretanto, é requerida uma análise para conduzir essa informação efetivamente, devido aos detalhes de baixo nível. A ferramenta DRUM auxilia o analista construir uma seqüência de tempos de logs e ações pré-definidas do usuário e através dessas seções é possível avaliar automaticamente a usabilidade para usuários de forma individual ou em grupo.

O Método de Medida de Desempenho pode ser adaptado a diferentes necessidades de avaliação e restrições de orçamento. As saídas básicas podem ser realizadas sem o uso de vídeo, seguindo a versão mínima do método, o Basic MUSIC Performance Method. Neste caso, o esforço é menor do que seria gasto no método completo, mas fornece menos dados 
para a avaliação. $O$ método básico pode ser empregado de forma mais tápida, em avaliação de pequena escala ou quando o orçamento é mais limitado. $O$ uso de vídeo adiciona a vantagem de se ter registros mais seguros e revisáveis dos incidentes nos quais os usuários encontraram problemas. E ainda, capacitar uma análise retrospectiva das sessões de avaliação.

Os dados quantitativos fornecem informações aos projetistas sobre o treinamento requerido para uma classe particular de usuário e provêem uma comparação do desempenho de usuários com a primeira versão do sistema, com projetos alternativos, com produtos competitivos ou com outras formas de se alcançar a mesma meta de trabalho. $O$ teste usado no método MUSIC (teste empírico) é executado pelos usuários finais e são coletados dados relacionados. O envolvimento de usuários finais torna o projeto caro e por outro lado, mais seguro. A grande desvantagem é o custo, devido ao fato de que na maioria das vezes o usuário deixa o trabalho para realizar os testes.

\subsection{Método Cognitive Walkthrough}

Cognitive Walkthrough envolve um grupo de avaliadores que inspeciona a interface no contexto de uma ou mais tarefas específicas, avaliando a facilidade de aprendizado do usuário através da exploração (Lewis et al., 1990; Polson et al., 1992). Essẻ enfoque é motivado pela observação de que muitos usuários não querem ler manuais, nem assistir aulas, preferem aprénder intuitivamente as principais tarefas e aprender o restante com o tempo, ou seja, preferem aprender o software por exploração (Carroll \& Rosson, 1987; Fischer, 1991). De acordo com Wharton et al. (1994), a origem do Cognitive Walkthrough vem da idéia do Walkthrough de Código (Yourdon, 1989) usado na Engenharia de Software como técnica de revisão formal de projetos, em que o projeto é avaliado com o objetivo de se encontrar defeitos.

O método pode ser aplicado depois da especificação de um projeto detalhado da interface do usuário, que ocorre depois da análise de requisitos e definição das funcionalidades de uma aplicação. Podendo também ser aplicado durante a codificação, teste e outros estágios de desenvolvimento. A próxima seção descreve o prócesso de avaliação. 


\subsubsection{Como Conduzir a Avaliação}

Nesse método, os revisores avaliam uma interface proposta no contexto de uma ou mais tarefas específicas do usuário. Ele é dividido em fase preparatória e fase de análise.

$\mathrm{Na}$ fase preparatória são definidas as entradas. As entradas incluem o perfil do usuário (principalmente o conhecimento do usuário sobre as tarefas), as tarefas, seqüências de ações para cada tarefa e a interface que será submetida à análise. Entre os avaliadores podem existir engenheiros, desenvolvedores de software, pessoas de marketing entre outros profissionais. Para definir as entradas do Cognitive Walkthrough deve-se responder a algumas questões, tais como:

a) Quem serão os usuários do sistema?

Neste caso bastaria uma simples descrição, mas o Cognitive Walkthrough pode ser mais revelador se a descrição incluir uma experiência específica ou conhecimento técnico que pode influenciar os usuários na forma de como eles tentam lidar com uma nova interface. Um exemplo de descrição poderia ser: "usuário Macintosh que trabalhou com MacPaint". O conhecimento da tarefa e da interface dos usuários deveria ser considerado.

\section{b) Quais tarefas serão analisadas?}

o Cognitive Walkthrough envolve uma análise detalhada de uma série de tarefas. É possível fazer uma análise de todas as tarefas importantes para um sistema com funcionalidade simples. Além disso, para sistemas reais (isto é, não protótipos), uma única tarefa pode ser avaliada, tal como uma tarefa que provou ser problemática em uma versão anterior. Em geral, para sistemas de qualquer complexidade a análise deveria ser limitada por uma coleção razoável, mas representativa de tarefas benckmark, em que a seleção de tais tarefas fosse baseada nos resultados de estudos de marketing, análise de necessidades, teste de conceitos e análise de requisitos. Algumas tarefas de benckmark deveriam ser selecionadas a partir de funcionalidades centrais da aplicação, que são as operações básicas do sistema. Em Wharton et al. (1992), encontra-se uma discussão mais detalhada sobre este tópico.

\section{c) Qual é a correta seqüência de ações para cada tarefa?}

Para cada tarefa, deve haver uma descrição de como é esperado que o usuário veja a tarefa antes de aprender a interface. Deve existir também uma descrição da seqüência de ações que realiza a tarefa, de acordo com a atual definição da interface. Essas ações podem ser 
movimentos simples, como "pressionar a tecla Return" ou pode ser executar um bloco, como "login para o sistema" por usuários experientes do UNIX.

\section{d) Como a interface é definida?}

Se a interface foi implementada, todas as informações estão disponíveis a partir da implementação. Caso contrário, a avaliação pode ser executada com uma descrição da interface em papel. Neste último caso, algumas características importantes do sistema serão dificeis de estimar, tal como tempo de resposta, distinção de cores e interação física. Para uma descrição em papel, o nível de detalhes necessários na definição da interface dependerá da experiência que os possiveis usuários tem com outros sistemas.

A fase de análise consiste em examinar cada ação ou caminho da solução e tentar contar uma estória-sobre.por que os usuários escolheriam aquela ação. As estórias devem ser baseadas no conhecimento e metas do usuário e no processo de entendimento do problema que capacita o usuário a supor a ação correta. Em suma, o processo de resolução do problema julga que os usuários comecem com uma descrição precisa das tarefas que eles querem executar; explorem a interface e selecionem as ações que eles pensam que realizarão a tarefa; observem as reações da interface para ver se suas ações tiveram o efeito esperado e determinem qual a próxima ação a fazer. Os avaliadores tentam construir uma história de sucesso para cada tarefa. Para condições gerais em que uma estória de sucesso pode ser contada, tem-se um exemplo de sucesso. Quando uma história real não pode ser contada temse um: exemplo de fracasso. Alguns critérios de análise podem ser vistos no exemplo dado na próxima seção.

Durante a realização da avaliação, é importante capturar informações em um meio que permitirá o grupo executar a avaliação mais eficientemente e efetivamente. Existe uma variedade de meios de registrar informações, que foram projetados para ser usados durante este processo. Por exemplo, a sessão de avaliação pode ser registrada por vídeo, (Rowley \&Rhoads, 1992). O vídeo pode servir para voltar e verificar comentários ou decisões.

O Cognitive Walkthrough pode ser um processo em grupo ou individual. Para um grupo de avaliadores, o projetista apresenta o projeto para um grupo de pares tipicamente depois de um marco tal como a criação de um protótipo, e então usa a retroalimentação para modificar ou forçar a próxima revisão. Os pares podem incluir outros projetistas, engenheiros de software e representantes de outras unidades organizacionais. Adicionalmente, tem-se uma presença cognitiva, que pode ser um especialista em avaliação de interface. Cada membro da 
equipe de avaliação tem um papel específico: uma pessoa deveria assumir o papel de registrador ou escritor, outro faz o papel de facilitador, e o resto contribui com vários tipos de experiências, tal como conhecimento do potencial mercado, análise de necessidades de usuários e outras coisas mais. Todos são geralmente responsáveis por levar a cabo a avaliação.

\subsubsection{Um Exemplo de Aplicação do Cognitive Walkthrough}

Esta seção apresenta um exemplo detalhado de um Walkthrough. A tarefa é redirecionar chamadas em um sistema de telefone de campus universitário. Nota-se que o Cognitive Walkthrough trata este sistema como uma aplicação seqüencial (walk-up-and-use), que pode não ter sido a intenção do projetista. Todavia, sabe-se por experiência que pelo menos alguns usuários se acham na posição de precisar usar o sistema sem treinar. A aplicação do método consta de duas fases: preparação e análise.

\section{A Fase de Preparação do Walkthrough}

Esta fase é composta pelas seguintes atividades:

a) Identificação dos Usuários: a classe maior de usuários inclui professores, funcionários e alunos do campus da universidade, mais os convidados deles e outras visitas. É esperado que alguém que precise fazer um telefonema tenha usado previamente um telefone digital ou de disco giratório. Para a avaliação que se segue, assume-se que o usuário é um professor da universidade. $\mathrm{O}$ professor usou o sistema de fone várias vezes para fazer e receber chamadas. O professor, além disso, sabe que pode-se programar o telefone para fazer tarefas sortidas, tal como redirecionar suas chamadas.

b) Tarefa: Redirecionar meus telefonemas ao escritório de meu sócio. O número de meu sócio é 492-1234.

c) Seqüencia de Ações: As sete ações exigidas para realizar essa tarefa e as respostas do sistema associadas ao sistema telefônico são:

1. Apanhe o receptor 
Fone: tom de discar

2. Pressione \#2 (comando para cancelar envio)

Fone: bip bip bip

3. Desligue o receptor

4. Apanhe o receptor

Fone: tom de discar

5. Pressione *2 (Comando para redirecionar chamadas)

Fone: tom de discar

6. Pressione 21234

Fone: bip bip bip

7. Desligue o receptor

d) Descrição da Interface: O fone é de tamanho padrão, digital e localizado na escrivaninha do professor. Há um modelo que reveste o bloco de chave do telefone, que inclui o seguinte material: FWD*2; CNCL \#2; SEND ALL *3.

\section{Fase de Análise}

Usa-se o processo de Cognitive Walkthrough para trabalhar sobre a interação e avaliar cada passo. Este processo é representado pela Tabela 3.3, em que a primeira coluna se refere à ação, a segunda coluna diz se a história é de sucesso ou de fracasso e a terceira se refere à história que é contada a respeito da ação. Se a história for de fracasso ela se baseia nos seguintes critérios:

Critério1: O usuário estará tentando alcançar o efeito certo?

Critério 2: O Usuário saberá qual a ação correta que alcançará o efeito desejado?

Critério 3: Se a ação correta é executada, o usuário verá que as coisas estão indo OK?

O enfoque do Cognitive Walkthrough está em ver problemas em uma interface, mas também em prover uma explicação desses problemas. Neste exemplo, um dos problemas com a interface é a confusão de FWD e SEND ALL, pois elas são relacionadas entre si. Porém, o maior problema é o requisito inesperado de cancelar o envio da chamada. Isto poderia ser fixado de duas formas: 1) eliminando tal requisito ou; 2) fazendo com que se tornasse esperada, fornecendo um prompt. A primeira solução apesar de melhor, pode ser que não seja 
aceita por algumas razões técnicas subjacentes. A segunda solução tem alguns problemas: adicionar um prompt de áudio é quase impossível, pois parece ter somente tons como saída.

\section{TABELA 3.3 - Fase de Análise do Cognitive Walkthrough}

\begin{tabular}{|c|c|c|}
\hline Tarefa & Tipo & iistória \\
\hline $\begin{array}{l}\text { 1. Apanhe o } \\
\text { receptor } \\
\text { Fone: bip, bip, bip }\end{array}$ & Sucesso & $\begin{array}{l}\text { Isto parece OK baseado em experiência anterior com telefones. Mas note que } \\
\text { agora há telefones que você " programa " sem ós apanhar! }\end{array}$ \\
\hline $\begin{array}{l}\text { 2. Pressione \#2 } \\
\text { (Comando para } \\
\text { cancelar envio) } \\
\text { Fone: bip, bip, bip }\end{array}$ & Fracasso & $\begin{array}{l}\text { Critériol: Há aqui um problema. Porque o usuário estaria tentando cancelar } \\
\text { uma remissão de chamada neste contexto? } \\
\text { Critério2: Se os usuários sabem cancelar uma remissão, eles podem não } \\
\text { reconhecer a sigla CNCL no modelo e eles podem pensar que a ação requerida } \\
\text { é pressionar apenas o numero "2", não "\#2". Também eles podem tentar } \\
\text { pressionar estes botões (simultaneamente) ao invés de em ordem. } \\
\text { Critério3: Além disso, como os usuários sabem que eles tiveram sucesso? } \\
\text { Depois da experiência eles reconhecerão os bips como uma confirmação, mas } \\
\text { eles concordarão no princípio? }\end{array}$ \\
\hline $\begin{array}{l}\text { 3. Desligue } \\
\text { receptor }\end{array}$ & acasso & $\begin{array}{l}\text { Critériol: Resulta em uma maior dificuldade. Se você sabe que tem que } \\
\text { cancelar uma remissão, porque você deveria ter de desligar antes de } \\
\text { reestabelecê-la? Esta ação tem um efeito orientado a sistema que o usuário não } \\
\text { terá razão para tentar alcançá-la. }\end{array}$ \\
\hline $\begin{array}{l}\text { 4. Apanhe } 0 \\
\text { receptor } \\
\text { Fone: tom de } \\
\text { discar }\end{array}$ & Sucesso & em experiência (mas lembre-se que hoje, nem todos \\
\hline $\begin{array}{lr}\text { 5. Pressione } & * 2 \\
\text { (Comando para } \\
\text { redirecionar } \\
\text { chamadas) } \\
\text { Fone: tom de } \\
\text { discar }\end{array}$ & Fracasso & $\begin{array}{l}\text { itério2: Aqui a questão é decidir entre *2 e *3. A descrição no modelo é de } \\
\text { uca ajuda: algumas pessoas não reconhecerão FWD, e SEND ALL parecerá } \\
\text { m se eles o executa. Também, há a pequena preocupação mencionada acima, } \\
\text { "*" deveria ser apertado simultaneamente ou como parte de uma seqüência. } \\
\text { itério 3: Também, retroalimentação pode ser problemático: ele sugere que } \\
\text { cê pode discar alguma coisa, mas ele é também inalterado a partir do que } \\
\text { cê ouviu antes de fazer esta ação. }\end{array}$ \\
\hline $\begin{array}{l}\text { 6. Pressione } 21234 \\
\text { Fone: bip bip bip }\end{array}$ & Fracasso & $\begin{array}{l}\text { Critériol: Como o usuário sabe entrar o número agora? Talvez não seja uma } \\
\text { sugestão irracional, mas o tom de discar não direciona muito, porque ele } \\
\text { somente sugere que o telefone está ativo. } \\
\text { Critério 2: Também, há uma probabilidade de erro em não trabalhar o formato } \\
\text { do número que é necessário. Isto é, o usuário tem que entender que é suficiente } \\
\text { e correto entrar "21234" e que a sequêencia inteira de número "4921234" não é } \\
\text { necessária } \\
\text { Critério3: Como mencionado anteriormente, o bip pode não significar muito } \\
\text { para alguém começando. }\end{array}$ \\
\hline $\begin{array}{l}\text { 7. Desligue } \\
\text { receptor }\end{array}$ & & 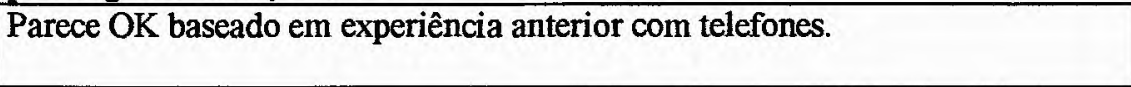 \\
\hline
\end{tabular}

Cada uma das sugestões fixada ocorreu devido ao processo Cognitive Walkthrough a a categorização dos problemas de acordo com o tipo de fracasso. Diretrizes gerais sobre as dificuldades resultantes por tipo de falha são dadas por Wharton et al. (1992). 


\subsubsection{Análise de.Custo e Benefícios}

$\mathrm{O}$ foco em um único aspecto de usabilidade e o fato que o método fornece uma avaliação bastante detalhada de facilidade de aprendizado são fontes: das fraquezas e forças do método, respectivamente.

Há muitas críticas em relação ao Walkthrough. Várias pessoas se mostraram preocupadas com os tipos de problemas de usabilidade que o Cognitive Walkthrough identifica, dentre elas Cuomo e Bowen (1992). Os principais aspectos levantados por esses autores são severidade, conteúdo, escopo e número total de problemas de usabilidade identificados pelo método.

Severidade significa o quanto o problema impede o progresso do usuário e quanto o problema precisa de reparo. De acordo com Jefries et al. (1991), dentre os quatro métodos que ele comparou, Cognitive Walkthrough é o método que apresenta a menor média em taxa absoluta de severidade.

Cuomo e Bowen (1992), examinaram o conteúdo dos problemas de interface considerando os sete estágios de atividade do usuário definidos por Norman (1986). Em relação a estes estágios, o Walkthrough, quando comparado com Avaliação Heurística é melhor para predizer problemas que atualmente afetam o desempenho do usuário.

Segundo Jefries et al. (1991), Cognitive Walkthrough identifica mais problemas específicos do que problemas gerais, pois este método é baseado em tarefa e segue um caminho limitado de análise.

Para Cuomo e Bowen (1992), Cognitive Walkthrough rende o segundo maior número de problemas de usabilidade. Porém, é importante considerar que, quando aplicados estudos comparativos entre métodos, muitos fatores influenciam os resultados. Dentre estes fatores, $o$ número de tarefas usadas para análise, a habilidade dos avaliadores, a familiaridade dos avaliadores com as tarefas e o estilo de interface.

A quantidade de tempo que se leva para executar um Walkthrough, em geral, será maior que a de outros métodos porque se tem uma análise mais detalhada. Um outra dificuldade apresentada pelo método é a necessidade de se ter pelo menos um avaliador com conhecimento da ciência cognitiva, o que não é fácil de se conșeguir. Contudo, isso acontece com outros métodos, que são aplicados com sucesso por desenvolvedores de software típicos, porém apresentando resultados melhores quando se tem alguém com conhecimentos da ciência cognitiva (Desurvire et al., 1992; Nielsen, 1992). 
Cognitive Walkthrough não envolve usuários na avaliação, então não permite obter informações dos usuários para melhorar a interface. Diferente de Lacerof e Paternò (1998), que considera que os erros trazem informações importantes, guiando o projetista em como melhorar a interface. Em vista dos beneficios e problemas apresentados por um e por outro método, aconselha-se que se use múltiplos métodos para uma minuciosa avaliação.

\subsection{Método USINE/ RemUSINE}

O método USINE faz a avaliação de usabilidade da interface do usuário usando um Modelo de Tarefas e logs gerados de testes de usuários com a aplicação. De acordo com Lacerof e Paternò (1998), a vantagem do Modelo de Tarefas é devido ao relacionamento temporal entre as tarefas, que pode indicar as tarefas que podem ser executadas a cada momento. Em todo'o processo de avaliação é dado suporte automático, combinando teste empírico com informação do Modelo de Tarefas da aplicação. A abordagem de Modelo de Tarefas será descrita na próxima seção.

O método RemUSINE (Paternò, 1999) é uma extensão do método USINE (Lacerof e Paternò, 1998), que utiliza a mesma abordagem :e conceitos utilizados pelo método USINE mas acrescenta outra característica: permite que se possa fazer uma avaliação de usabilidade remota, em que os avaliadores podem estar separados em tempo e espaço dos usuários. Esta abordagem foi introduzida por várias razões:

- Aumento da disponibilidade e melhorias das conexões de rede.

- Ao custo e rigidez de avaliações de usabilidade baseadas em laboratórios tradicionais.

- À necessidade de se diminuir os custos de avaliação de usabilidade para torná-la mais acessivel.

A próxima seção apresenta a forma de condução do método USINE. Detalhes sobre RemUSINE são dados em Paternò (1999).

\subsubsection{Como Conduzir o Método}

Em Paternò et al. (1995), a interface do usuário é avaliada usando a especificação arquitetural e Modelo de Tarefas da interface do usuário. O enfoque usado no método USINE é similar, 
mas omite a especificação arquitetural e usa um Modelo de Tarefas mais avançado, permitindo aos projetistas expressarem um conjunto mais rico de relações entre as tarefas. Isso dá informação útil para entender porque os erros ocorreram durante o teste com o usuário, permitindo que o projetista descubra como a interface pode ser melhorada.

A estrutura do método é a seguinte: o projetista cria o Modelo de Tarefas (descrito a seguir) com o editor ConcurTaskTrees e cria a Tabela de Tarefa-Log com a ferramenta USINE, que foi desenvolvida para fornecer suporte automático para a avaliação de usabilidade. Esta tabela permite aos projetistas mapearem as ações fisicas executadas pelo usuário sobre as tarefas básicas do Modelo de Tarefas. Os logs do usuário são fornecidos por uma ferramenta de gravação de logs, que captura logs de testes de usuários da atual aplicação. A Tabela de Pré-Condições é então criada automaticamente a partir do Modelo de Tarefas. $O$ método de avaliação encontra as tarefas disponíveis no estado atual da sessão do usuário que é indicada pela ação armazenada no arquivo de logs e ao final da análise da sessão fornece os resultados da avaliação.

Ao analisar. a Figura 3.5, que ilustra a estrutura do método, conclui-se que este método requer como entrada: a) o Modelo de Tarefas da aplicação considerada; b) o Arquivo de Logs gerado pelas sessões do usuário com a aplicação; c) a Tabela de Tarefa-Log criada com informações fornecidas pelo Modelo de Tarefas e pelo arquivo de logs; d) a Tabela de PréCondições criada automaticamente a partir do Modelo de Tarefas. Essas entradas são melhores detalhadas a seguir.

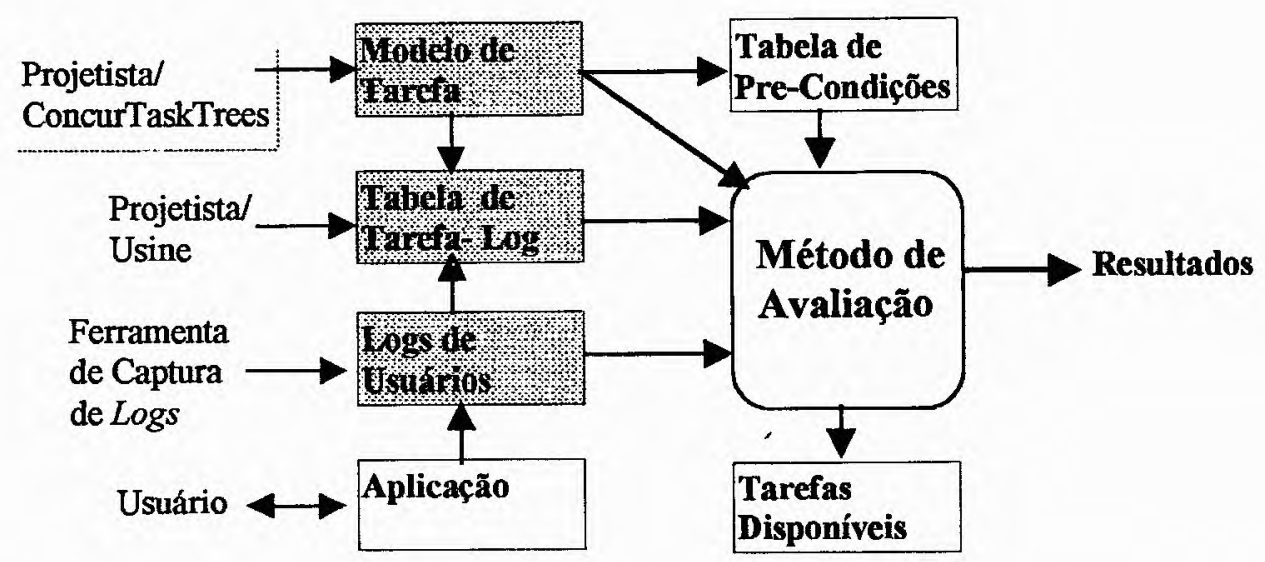

FIGURA 3.5 - Estrutura do Método (Lacerof \& Paternò, 1998) 


\section{a) Modelo de Tarefas}

Modelo de Tarefas tem sido usado para desenvolver aplicações interativas. Métodos como TLIM (Task LOTOS Interactor Modeling) (Paternò et. al., 1997b) e Adept (Wilson et. al., 1993) usam Modelo de Tarefas para apoiar o projeto de interface. Porém, no método USINE os autores o usam para dar suporte ao processo de avaliação de usabilidade de interface de usuário. Modelo de Tarefas pode dar informações úteis para a avaliação de interfaces de usuários, uma vez que descreve o conjunto de atividades requeridas para alcançar as metas dos usuários e como essas atividades são relacionadas umas com as outras. Devido à descrição dos relacionamentos temporais entre as tarefas, o modelo indica quais tarefas podem ser executadas a cada momento.

Segundo Diaper (1989), para construir tais modelos é necessário que se faça uma análise de tarefas, que geralmente começa com investigações sobre os atuais problemas do usuário e com a divisão das tarefas que potenciais usuários do sistema realizam ou podem realizar. A notação para especificar o Modelo de Tarefas abordado em Paternò et al. (1997a) é "ConcurTaskTrees", que é suportada por um editor gráfico (veja detalhes em http://giove.cnuce.cnr.it/ctte.html) para criar a árvore de tarefas e especificar os relacionamentos entre as tarefas de acordo com sua sintaxe e semântica. Essa notação permite aos projetistas especificarem as relações temporais entre tarefas e outras informações úteis para o projeto da interface do usuário.

O Modelo de Tarefas em "ConcurTaskTrees" é representado por uma hierarquia de tarefas, na qual os niveis superiores são mais abstratos e lógicos e níveis inferiores são mais refinados e concretos de forma a descrever as ações fisicas requeridas para interagir com a interface do usuário. As folhas na árvore de tarefa (as tarefas que não são mais decompostas) são chamadas tarefas básicas. De acordo com Paternò e Menicone (1998), é possível ter quatro tipos de tarefas:

1. Tarefas do usuário: são tarefas executadas pelo usuário sem qualquer interação com o sistema. Por exemplo, ler uma mensagem na tela.

2. Tarefas de aplicação: são tarefas executadas completamente pela aplicação. Por exemplo, apresentar resultados fornecidos por uma base de dados.

3. Tarefas de interação: são tarefas executadas pelo usuário interagindo com o sistema. Por exemplo, pressionar um botão. 
4. Tarefas abstratas: são tarefas que requerem ações complexas, cuja previsão de desempenho não tenha ainda sido definida. Por exemplo, uma sessão do usuário com um sistema.

Como o interesse é avaliar as interações de usuários, o interesse maior são as tarefas de interação. .

Para construir o Modelo de. Tarefas faz-se uma decomposição hierárquica e lógica das tarefas representado-as em estrutura de árvore. As tarefas de nível mais alto são decompostas em subtarefas que descrevem mais precisamente possíveis atividades do usuário. Em seguida, identifica-se o relacionamento temporal entre as tarefas. Um exemplo de árvore de tarefa pode ser visto na Figura 3.6.

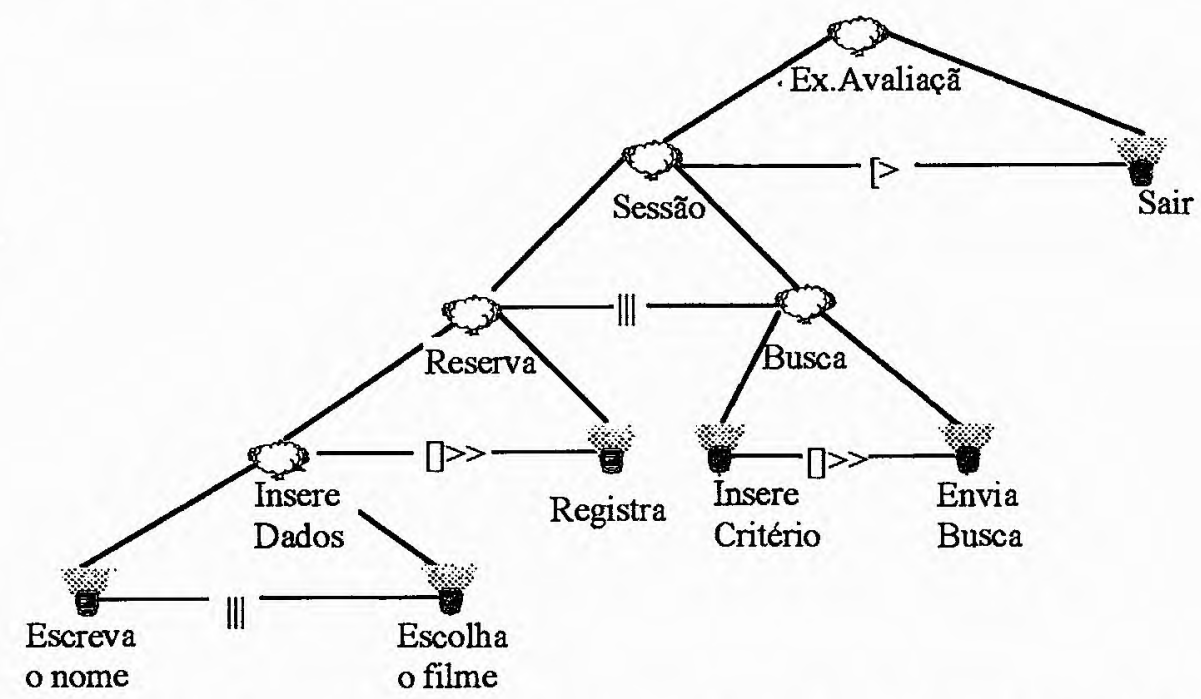

FIGURA 3.6 - A Árvore de Tarefas do Exemplo Guia de Cinema (Lacerof \& Paternó, 1998)

Os relacionamentos temporais entre as tarefas são expressos por operadores estendidos da notação LOTOS (ISO, 1988). ConcurTaskTrees permite que projetistas descrevam tarefas concorrentes, diferentemente de GOMS (Card et al., 1983), que permite descrever somente tarefas seqüenciais. Os principais operadores usados são:

1. $\mathrm{T} 1 \mid \| \mathrm{T} 2$, interpolar, a tarefa $\mathrm{T} 1$ e a tarefa $\mathrm{T} 2$ podem ser executadas em qualquer ordem.

2. $\mathrm{T} 1|\mathrm{C}| \mathrm{T} 2$, sincronizar, as tarefas $\mathrm{T} 1$ e $\mathrm{T} 2$ têm que sincronizar, ou seja, elas têm de executar alguma ação ao mesmo tempo para trocar informação.

3. $\mathrm{T} 1>>\mathrm{T} 2$, habilitar, a execução da tarefa $\mathrm{T} 1$ torna possível executar $\mathrm{T} 2$. A tarefa $\mathrm{T} 2$ não pode ser executada antes que $\mathrm{T} 1$ termine sua execução. 
4. T1 [] > T2, habilitar com passagem de informação, quando a tarefa T1 termina ela fornece informação à $\mathrm{T} 2$, além de ativá-la.

5. T1[] T2, escolher, ao começar ambas as tarefas são avaliadas, mas quando uma delas é iniciada a outra não é mais avaliada.

6. T1[> T2, desabilitar, quando a tarefa T2 é executada não é mais possível executar T1.

7. $\mathrm{T} 1^{*}$, interação, a tarefa é interativa e pode ser executada mais de uma vez.

Pode-se também especificar tarefas ótimas, tarefas que o usuário decide se quer ou não executar, que são marcadas com []. Um exemplo dessas tarefas é o uso de valores default.

\section{b) Os Logs do Usuário}

Os logs de testes dos usuários são obtidos, registrando-se as ações executadas pelos usuários com a ferramenta Replay (http://www.centerline.com/productline/qcreplay/qcreplay.html). QC/Replay é um software comercial, versão 2.5 da CenterLine Software, que trabalha no ambiente $\mathrm{X}$ Windows. Outras ferramentas podem ser usadas, porém requerem modificações para o ambiente provido pelo método.

\section{c) A Tabela de Tarefa-Log}

Na Tabela de Tarefa-Log, logs e tarefas são associados usando a ferramenta USINE (Avaliador da Interface do Usuário - User Interface Evaluator). A ferramenta USINE (Lacerof \& Paternò, 1998) automatiza e facilita o processo de avaliação. Ela foi implementada em Java, o que a torna independente da plataforma utilizada.

A ferramenta é dividida em duas partes: a parte da preparação e a parte dos resultados. Preparação é a parte em que o projetista cria a Tabela de Tarefa-Log e fornece os nomes de diferentes arquivos necessários para a avaliação. Esses arquivos são: arquivo de Logs; arquivo com o Modelo de Tarefas; e arquivo com a Tabela de Tarefa-Log, A parte de resultado contém os resultados da avaliação e as possibilidades para o projetista apresentá-los de diferentes modos. 


\section{d) A Tabela de Pré-Condições}

No Modelo de Tarefas da aplicação é possível ver tarefas habilitando e desabilitando outras tarefas. Portanto, do Modelo de Tarefas cria-se automaticamente uma Tabela de PréCondições que é usada internamente no método. Nesta Tabela tem-se o nome da tarefa e a pré-condição ou pré-condições que devem ser executadas antes que a tarefa seja realizada. Cada pré-condição está associada com um valor booleano (verdade ou falso) indicando se a pré-condição foi satisfeita ou não. Inicialmente, as variáveis booleanas têm o valor falso. A notação é a seguinte:

\section{$<$ tarefa $>$ pré-condição1 <falso $>$ pré-condição2<falso $>$}

Assim que o usuário executa uma pré-condição, muda-se o valor da variável boleana para verdade, indicando que a pré-condição foi executada. Por exemplo, a tarefa "enviar mensagem" tem uma pré-condição que é "escrever seu nome". Se o usuário executou a tarefa 'escrever seu nome", então a Tabela de Pré-Condições estaria assim:

\section{enviar mensagem | escrever seu nome<verdade>}

Se a tarefa tem mais que uma pré-condição, então as pré-condições são escritas separadas por "l", significando que elas devem ser executadas uma após a outra antes que a tarefa seja realizada. Diferentemente, se a pré-condição para uma tarefa pode ser escolhida entre múltiplas tarefas, insere-se uma linha para cada tarefa que pode ser escolhida e quando uma dessas tarefas é executada a linha referente a ela é marcada com o valor "verdade". Neste casó, de forma a verificar se a pré-condição para a tarefa considerada foi satisfeita, basta realizar a operação de "ou" lógico entre as pré-condições.

\section{Tarefas Disponíveis}

As tarefas disponíveis são aquelas que o usuário pode executar corretamente após ter executado a tarefa atual. O avaliador pode usar a tarefa disponível para entender as preferências do usuário dentre as alternativas fornecidas pelo sistema, quando desempenha uma tarefa.

Quando o usuário tem sucesso em desempenhar uma tarefa, a Tabela de PréCondições é modificada e é possível obter a lista modificada de tarefas disponíveis, identificando-se as tarefas que tem a pré-condição satisfeita em adição àquelas que não tem pré-condição e assim elas são disponíveis a qualquer momento. 
Ao analisar uma árvore de tarefa para identificar -as tarefas disponíveis, " apenas as tarefas de interação são interessantes. O método para obter as tarefas disponiveis é usado após o método para decidir se as pré-condições da tarefa foram satisfeitas ou não. Este método pode ser visto em Lacerof \& Paternò (1998). Se as pré-condições de uma tarefa não foram realizadas não se pode contar esta tarefa como uma tarefa disponível.

\section{O Método de Avaliação}

O processo de avaliação começa considerando a primeira ação do arquivo de log. Primeiro obtém-se uma ação do arquivo de dados, verifica se a ação existe na tabela de tarefa-dado. Se existe, então procura-se a tarefa associada, do contrário um erro é gerado. Se a tarefa tem précondições e se elas são satisfeitas, a tarefa pode ser realizada. Se as pré-condições não foram satisfeitas então tem-se um erro de pré-condição. Se a tarefa realizada é uma pré-condição de outra tarefa, então faz-se a mudança de seu valor na Tabela de Pré-Condições para verdade. Então, obtém-se as tarefas disponíveis do estado corrente e se retoma ao método considerando a próxima ação no arquivo de dados.

\subsubsection{Um Exemplo do Uso do Método de Avaliação Usine}

Para aplicar o método de avaliação USINE, Lacerof \& Paternò (1998) escolheram avaliạr a aplicação Guia de Cinema (MOVIE GUIDE), desenvolvida em JAVA. Esta aplicação consiste de uma parte com uma base de dados de filmes, da qual é possível conseguir informação sobre filmes, e de outra parte na qual é possível reservar.ingressos no çinema.É também possível cancelar uma reserva e buscar por filmes na base de dados.

A parte da base de dados permite buscar por filme, por diretor, por estréias, por categoria ou tudo ao mesmo tempo. Quando um filme é escolhido, pode-se ver um clip do filme, ler sobre o filme (a estória, os atores, etc.), dar uma opinião sobre o filme e ver a opinião de outras pessoas.

A parte de reserva permite usuários escolher um filme da lista e então fazer uma reserva num certo cinema, para um determinado horário, e para um número de pessoas. É também possível decidir aonde se deseja sentar: na frente, no meio ou atrás. 
Esse exemplo usa o Modelo de Tarefas mostrado na Figura 3.6 acima. O Modelo de Tarefas é relacionado com a interface do usuário acima descrita, em que é possível fazer uma reserva por um filme inserindo um nome e escolhendo um filme. A reserva é então executada com a tarefa registrar. Também existe uma possibilidade de busca, para se procurar por filmes.

A Tabela de Pré-Condições foi criada automaticamente a partir da árvore de tarefa, como mostrado na Tabela 3.4. A primeira coluna representa a tarefa e a segunda coluna representa as pré-condições (se mais que uma) para que a tarefa seja realizada.

TABELA 3.4 - Tabela de Pré-Condições Inicial (Lacerof \& Paternó, 1998)

\begin{tabular}{|l|l|}
\hline Tarefa & Pré-Condições \\
\hline Ex.Avaliação & $\mid$ Sair $<$ falso $>$ \\
Ex.Avaliação & $\mid$ Sessão $<$ falso $>$ \\
\hline Sessão & $\mid$ Reserva $<$ falso $>\mid$ Busca $<$ falso $>$ \\
\hline Reserva & $\mid$ Registra $<$ falso $>$ \\
\hline Busca & Envia Busca $<$ falso $>$ \\
\hline Registra & $\mid$ Insere Dados $<$ falso $>$ \\
\hline Envia Busca & $\mid$ Insere Critério $<$ falso $>$ \\
\hline Insere Dados & $\mid$ Escreve Nome $<$ falso $>$ Escolhe Filme $<$ falso $>$ \\
\hline
\end{tabular}

Antes de iniciar a sessão do usuário é colocado o valor falso em todas as précondições. No começo da sessão de avaliação, as tarefas imediatamente disponíveis são: Escreve Nome, Escolhe Filme, Insere Critério e Sair.

A primeira coisa que se faz no processo de avaliação é ler uma ação do arquivo de $\log$. A seguir é mostrado como os elementos da Tabela de Pré-Condições são modificados de acordo com o log detectado:

\section{Click \{ tela 1$\}$}

A tarefa referente a esta ação não é encontrada na Tabela de Tarefa-Log, ou seja, ela não está associada com nenhuma tarefa e isso é registrado como um erro. Neste caso, o usuário clicou em uma imagem pensando que alguma coisa aconteceria. Este tipo de erro ocorre quando o usuário clica em itens que não têm função, assim como imagens, labels ou textos.

\section{Click \{ envia busca\}}


Esta ação é associada na Tabela de Tarefa-Log com a tarefa Enviar.Busca. Primeiro verifica-se na Tabela de Pré-Condições se a tarefa tem pré-condições. Uma vez que o valor de sua pré-condição "Insere Critério" é falso, então considera-se esta ação do usuário como um erro de pre-condição. Ou seja, o usuário tentou executar uma tarefa de busca antes de inserir os critérios para a busca.

\section{Texto \{ Insere critério\}}

Esta ação está associada com a tarefa Insere Critério (para inserir um critério de busca) na Tabela de Tarefa-Log. Esta tarefa não tem nenhuma pré-condição, sendo então completada e seu valor na Tabela de Pré-Condições é mudado de falso para verdadeiro: Envia Busca | Insere Critério <verdade>.

\section{Click \{ envia busca\}}

Quando se procura na Tabela de Pré-Condições pela tarefa (Envia Busca) relacionada a esta ação, verifica-se que a pré-condição para esta tarefa é satisfeita (pela ação anterior) e então o usuário desta vez executou a tarefa Envia Busca com sucesso.

\section{Texto \{CampoNome\}}

Esta ação está associada com a tarefa Escreve Nome na Tabela de Tarefa-Log, A tarefa não tem uma pré-condição e é desta forma completada. Como ela é uma pré-condição para a tarefa Insere Dados, muda-se o valor de Escreve Nome para verdade: Insere Dados | Escreve Nome <verdade $>\mid$ Escolhe Filme <falso $>$.

\section{Click \{ Dia da Independência\}}

Esta ação está associada com a tarefa Escolhe Filme na Tabela de Tarefa-Log. Como no passo anterior a tarefa não tem uma pré-condição e é completada. Porém, ela é uma précondição e seu valor deve ser mudado para verdade na Tabela de Pré-Condições: Insere Dados | Escreve Nome < verdade $>$ | Escolhe Filme < verdade $>$.

\section{Click \{ Registra\}}

Esta ação é associada com a tarefa Registra na Tabela de Tarefa-Log. A tarefa registra tem como pré-condição Insere Dados, que por sua vez é satisfeita.(com todos seus campos verdadeiros). Com.isto a tarefa Registra é executada com sucesso.

Os resultados do método de avaliação dizem respeito aos erros que o usuário cometeu e a quanto êxito os usuários tiveram em executar suas tarefas. Os resultados derivados do método de avaliação e dos logs fornecido pela ferramenta QC/Replay incluem: as tarefas realizadas e frustradas e aquelas nunca tentadas; quantas vezes as tarefas e os erros foram executados e a ordem temporal das tarefas e dos erros; quanto tempo cada tarefa levou para 
ser completada; os tempos para realizar as tarefas abstratas' são calculados somando-se os tempos dos filhos da tarefa abstrata; em que momento na interação os erros ocorreram; as tarefas disponiveis do estado corrente da sessão do usuário e outras informações úteis, tais como, quantas vezes o scrollbar foi usado e quantas vezes a janela foi reformatada. Estes resultados são elaborados e apresentados pela ferramenta USINE.

\subsubsection{Análise de Custo e Benefício}

Uma dúvida que se tem em relação ao método é se seus beneficios justificam o tempo extra e esforços envolvidos. $O$ esforço adicional requerido se refere ao projeto do Modelo de Tarefas para a aplicação considerada e para fazer a Tabela de Tarefa-Log, pois todas as outras tabelas são automaticamente criadas na parte de preparação do método. Apesar de ser um esforço extra, o Modelo de Tarefas é um exercício útil para projetistas de interface de usuário entenderem a aplicação e por isso deveria ser feito mesmo se este método de avaliação não fosse aplicado.

O mapeamento entre ações do usuário no arquivo de logs e as tarefas deve ser feito apenas uma vez para uma aplicação e então ele é usado para analisar todos os testes de usuário daquela aplicação. Assim, este é um esforço adicional limitado. Por outro lado é possível ter avaliações mais seguras, pois pode-se detectar automaticamente quando as ações ocorrem e desta forma nenhuma ação a ser analisada pode ser omitida. Resultados adicionais como tarefas nunca tentadas são fornecidos. De acordo com Lacerof e Paternò (1998), este método apresenta algumas vantagens em relação aos resultados obtidos por métodos baseados no enfoque de observar o usuário. Dentre elas a capacidade de executar vários testes de usuário em paralelo nos locais de trabalho dos usuários sem ter de movê-los para um laboratório de usabilidade ou mover os observadores aos locais de trabalho dos usuários. Além disso, pode-se deixar a ferramenta automática avaliar os resultados enquanto que no outro enfoque é necessário que um observador siga seqüencialmente cada usuário e analise manualmente seu comportamento. Nas avaliações em que as interações do usuário são rápidas e envolvem múltiplos observadores, podem ocorrer problemas de consistência entre os resultados das observações. 
Uma preocupação com este método é que os avaliadores possam estar carecendo de alguma informação importante que poderia ser apenas adquirida observando-se usuários e ouvindo seus comentários.

Nesse capítulo apresentou-se alguns métodos de avaliação de usabilidade estudados na literatura, com exemplo de aplicação e análise de custo e beneficio de cada um. $O$ próximo capítulo aborda as questões relacionadas ao protótipo da ferramenta de ensino da escrita técnica em inglês, direcionada à seção introdutória de artigos científicos. 


\section{Capítulo 4}

\section{Ferramenta de Crítica do Ambiente AMADEUS}

Problemas com a escrita podem afetar o desempenho de profissionais de maneira marcante, principalmente no caso de pesquisadores e acadêmicos que precisam escrever com proficiência e desembaraço não apenas na língua materna, mas também em uma ou mais línguas estrangeiras. Uma vez que, atualmente, o Inglês é a língua dominante para a escrita e divulgação de pesquisas técnicas e científicas, foi desenvolvido o ambiente modular de auxílio e ensino da escrita técnica, chamado AMADEUS (AMiable Article DEvelopment for. User Support) (Fontana et al., 1993; Aluísio, 1995; Aluísio \& Oliveira Jr., 1995a,1995b). O principal objetivo do desenvolvimento deste ambiente foi o de amenizar os problemas de usuários da língua inglesa que sofrem interferência da língua materna quando escrevem em inglês. A estrutura do AMADEUS consiste de várias ferramentas inter-relacionadas: Ferramenta de Referência, Ferramenta de Suporte, Ferramenta de Crítica e Ferramenta Tutorial.

Neste trabalho, a ferramenta escolhida para ser avaliada foi a Ferramenta de Crítica, que visa indicar os componentes e as seqüências mais apropriadas dos componentes para cada uma das várias seções de um artigo. Além disso, permite o desenvolvimento da criatividade no processo de escrita de um texto e a escrita de textos apropriados a um propósito e audiência específicos (por exemplo, para uma comunidade de pesquisa específica dentro da computação). É importante ressaltar que apenas a seção "Introdução" se encontra 
implementada até o momento. As próximas seções apresentam um resumo das principais características e funcionalidades da Ferramenta de Crítica, descritas em (Barreviera e Silva et al., 1998; Barreviera e Silva, 1999).

\subsection{Características da Ferramenta de Crítica}

Recentemente, surgiu uma abordagem baseada no aprendizado colaborativo para o desenvolvimento de ambientes computacionais que evitam o modelo tutor/aprendiz (Blandford, 1994; Fisher, 1995; Renié \& Chanier, 1995). Colaboração é um processo em que dois ou mais agentes trabalham juntos para resolver metas comuns e se caracteriza como uma atividade síncrona e coordenada, resultando da tentativa constante de se construir e manter uma concepção compartilhada do problema (Blandford, 1994; Burton et al., 1997).

A colaboração (i) permite que o aprendiz seja um agente (ou autor) no ambiente; (ii)permite que o aprendiz tenha acesso ao conhecimento do sistema quando realmente desejar; e (iii) encoraja a interação, o que, consequentemente, incrementa o aprendizado. Os domínios tratados por sistemas de aprendizado colaborativos são aqueles onde existem várias respostas aceitáveis. O domínio da escrita é propício para a implementação das abordagens colaborativas, pois o conhecimento envolvido nem sempre pode ser prescrito. Neste sentido, a Feŗramenta de Crítica segue uma abordagem colaborativa da segunda geração dos sistemas baseados em crítica.

De acordo com Silverman (1992), Rankin (1993) e Fisher (1995) um sistema de crítica apresenta uma opinião/crítica, não necessariamente negativa, de um produto ou ação gerada por um agente humano/colaborador. A abordagem de críticas constitui no uso efetivo de bases de conhecimento que auxiliam tanto na resolução de problemas como em atividades de aprendizado (Fisher et al., 1991, 1993; Fisher, 1995). Em sistemas de crítica, o usuário e o sistema trabalham colaborativamente, compartilhando do processo de solução de problemas, tomando decisões baseadas nos abjetivos e conhecimentos do usuário e no domínio da tarefa em questão. Alem disso, o sistema examina a solução proposta pelo usuário e fornece um retorno especifico tanto para uma ação que ele executou de modo errônẹo ou não adequado quanto para uma que foi executada corretamente (Silverman, 1992).

A Ferramenta de Crítica é baseada na abordagem de críticas e utiliza um corpus de artigos da comunidade de Interação Usuário-Computador (CHI). A análise do corpus se 
restringiu a seção introdutória de publicações da CHI'96 da seção de papers. Escolheu-se analisar Introduções :porque elas são uma das partes mais dificeis de serem escritas: é na introdução que o autor deve convencer a comunidade de pesquisa sobre a relevância de seu trabalho, principalmente nesta era de crescimento exponencial e fácil acesso da literatura. Ela possui a função de resumir as informações que o leitor vai encontrar no artigo, as vezes descrevendo sucintamente ou fornecendo indicações do que se encontrará em outras seções. Alem disso, possui uma posição estratégica no artigo e as primeiras impressões realmente importam. O corpus de artigos utilizados é constituído de 51 artigos chamados casos.

Os artigos publicados na CHI'96 foram escolhidos não somente por ela ser uma conferencia bastante prestigiada, mas também porque os artigos devem obedecer diversos requisitos rigorosos para serem aceitos. Alem disso, esta conferência apresenta uma grande variedade de tipos de artigos cujo conhecimento relativo aos tipos de informações que diferencia cada tipo pode sr reutilizado se a ferramenta for portada para uma nova comunidade.

Outra característica da ferramenta de critica é a utilização de uma estrutura dual, composta de uma estrutura esquemática e de uma estrutura de critérios específicos para os cinco tipos de artigos representados na conferência. Os componentes e subcomponentes da estrutura esquemática são apresentados na primeira coluna da Tabela 4.1. Na segundà coluna da Tabela 4.1 são apresentados os componentes da estrutura de critérios específicos dos 5 tipos de artigos contemplados na CHI'96: Experimental Papers; Experience Pápers; Sistem Papers; Theory Papers; Methodology Papers; Opinion Papers. A estrutura esquemática para os vários tipos de artigos parece ser um consenso para a Computação e outras áreas, e a estrutura de critérios específicos vai variar de comunidade para comunidade. Porém, para o protótipo atual, utiliza-se apenas informações sobre a estrutura esquemática. Nenhuma crítica é dirigida à estrutura de critérios específicos, podendo esta parte ser realizada em trabalhos futuros.

Em resumo, um sistema de crítica pode sr visto como um sistema de colaboração entre agentes, um dos quais é artificial, o critico (Fisher et al., 1991). Para o projeto e implementação desta abordagem, trabalhou-se basicamente com:

- A elaboração de uma plataforma multiagente distribuída para a construção de estruturas em arvore, denominada lego, composta por três modulos: Lego Middleware, Lego Workbench e Lego Prolog Agent. 
- A geração de uma linguagem para representar artigos da CHI como estruturas em arvore, representado, em um alto nível; os objetivos genéricos e específicos de um artigo; e

- A programação de úm agente artificial (crítico) que auxiliasse o usuário a dominar a linguàgem em questão. Nesse caso, espera-se que um usuário proficiente tenha aprendido a organizar e até escrever artigos segundo os critérios da $\mathrm{CHI}$.

As próximas seções descrevem estas três atividades.

TABELA 4:1 - Componente da Estrutura Dual para Submissão de Artigos da CHI’96

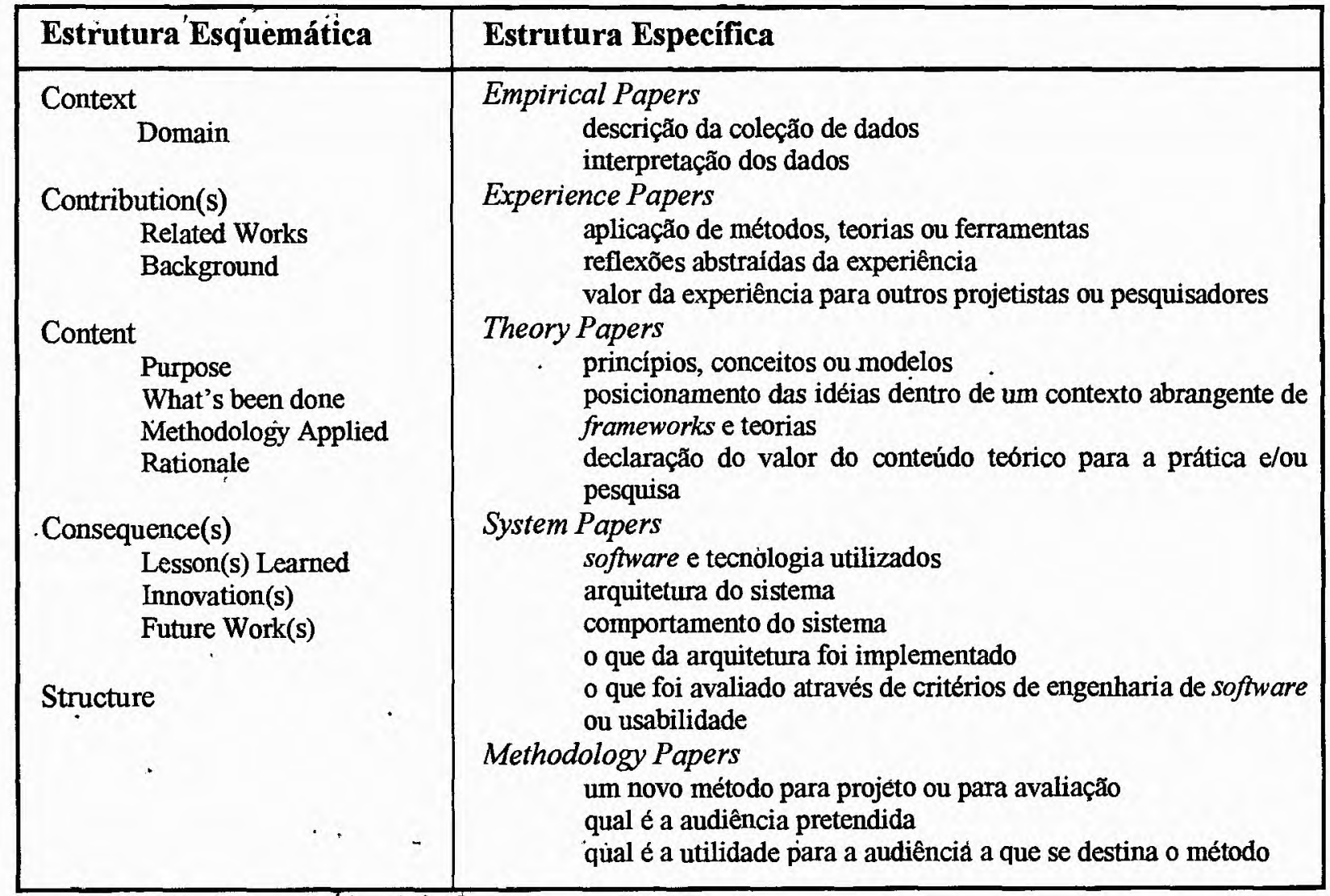

\subsection{Plataforma Multiagente Distribuída}

Foi construído um sistema que suporta adequadamente a colaboração entre diversos agentes (possivelmente heterogêneos e distribuídos) na construção de estruturas em árvore outilines, para servir de plataforma à ferramenta de ensino da escrita técnica em Inglês seguindo a abordagem de críticas.

Este sistema resulta da articulação dos seguintes módulos: (a) Lego Middleware, um subsistema de comunicação inter-agentes, compreendendo um servidor simples de broadcast 
e uma pilha de protocolos para difundir primitivas de transformação estrutural e emissão de opiniões; (b) Lego Workbench, um ambiente gráfico de trabalho por meio do qual um usuário pode funcionar confortável e efetivamente como colaborador e que não só representa o fluxo de informação inter-agentes numa forma estruturada e amigável como também favorece o domínio do vocabulário em uso; e (c) Lego Prolog Agent, um arcabouço para agentes artificiais a serem programados em Prolog, munido de plenos poderes expressivos, sensibilidade às ações de seus colaboradores e predicados para reconhecer padrões na estrutura em construção ou quantificar a similaridade desta com outras preexistentes. $\mathrm{Na}$ seqüência, abordamos cada um desses módulos, dando ênfase ao Lego Workbench, que é a parte que contém a interface do usuário, a qual sèrá avaliada sua usabilidade.

\section{(a) Lego Middleware}

Para que agentes humanos e artificiais possam colaborar no desenvolvimento de um projeto, é necessário que eles sejam capazes de construir e manter uma concepção compartilhada do mesmo projeto. No jargão de computação, isso eqüivale a dizer que, sempre que um número de colaboradores procurar saber simultaneamente o estado atual de um projeto compartilhado, eles devem obter representações semanticamente equivalentes. Essa característica é referida como compartilhamento de projeto.

No caso do protótipo Lego, buscando a independência de plataforma, maior simplicidade e flexibilidade no que diz respeito à implementação dos possíveis agentes, o compartilhamento do projeto não é implementado como uma estrutura de dados única; em vez disso, o sistema permite que cada um dos agentes mantenha uma representação individual (estrutura privada) do projeto em andamento, semanticamente equivalente às representações dos seus colaboradores. Esse modelo foi inspirado nos bate-papos (IRC-Internet Relay Chat). Para mais detalhes sobre este módulo ver (Barreviera e Silva, 1999).

\section{(b) Lego Workbench}

Lego Workbench é um ambiente que permite a criação de estruturas no formato de árvore, apoiando-se em um arquivo de especificação de vocabulário (extensão “.voc”). Esse arquivo contém, além da especificação do vocabulário com que o usuário quer trabalhar, um conjunto 
de regras, fornecido pelo criador do vocabulário em questão, para racionalizar a tarefa de codificação.

A aparência deste módulo pode ser visualizada na Figura 4.1. Nela pode-se ver as funcionalidades que o módulo pode proporcionar aos colaboradores, como a interface gráfica de fácil utilização. Para inserir componentes da estrutura de uma introdução, por exemplo, o usuário precisa arrastá-los da palette à esquerda para a área de trabalho à direita. Outras operações naturalmente necessárias, como a exclusão ou a troca da posição de componentes, são realizadas de forma intuitiva para usuários acostumados ao uso de aplicações como o Windows Explorer.

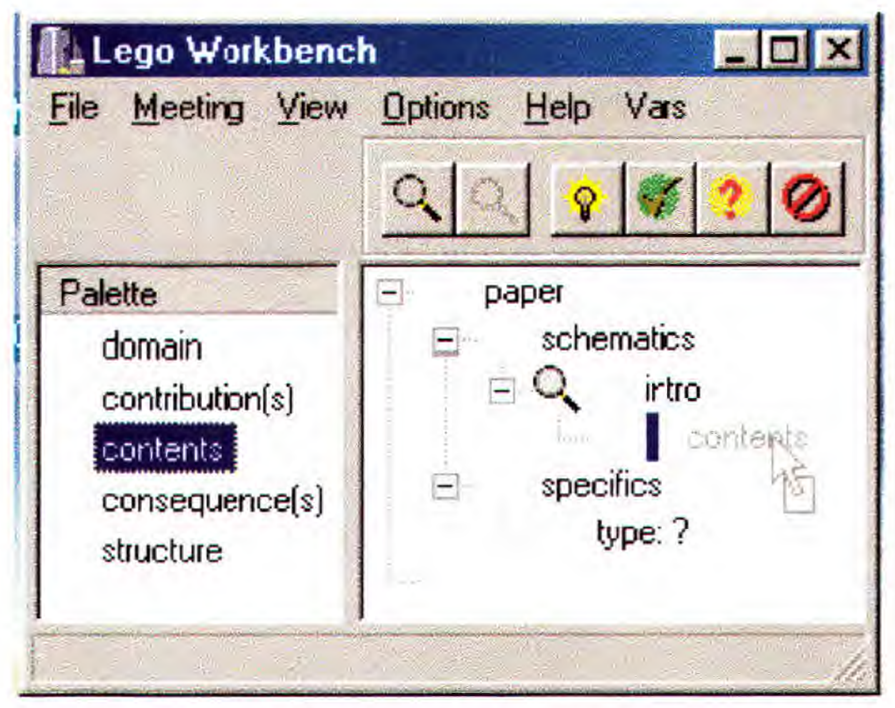

FIGURA 4.1 - Interface Gráfica do Lego Workbench

Um dos objetivos do ambiente Lego Workbench não é testar a memória ou persistência do usuário final, mas levá-lo a expressar sua vontade com naturalidade num código que o computador possa interpretar com facilidade. Tentou-se apresentar as diversas características da interface resultante de uma forma evolutiva, numa seqüência de figuras não necessariamente igual à que foi desenvolvida no ciclo de vida do projeto, mas que permita maior clareza na apresentação de justificativas.

A fim de evitar a sobrecarga cognitiva do usuário (em ter que memorizar os vários componentes que podem compor uma introdução), os elementos ou vocábulos são apresentados na forma de uma palette. Além disso, especificou-se uma ordem para a apresentação dos elementos na palette, de forma a favorecer o uso e memorização de seu significado. Porém, somente o estabelecimento de ordem na palette não parece ajudar muito, 
pois os vocábulos podem ser muitos, talvez não sendo possível a apresentação de todos simultaneamente, o que acarreta o uso um tanto incômodo da barra de rolagem e a necessidade de memorização dos itens não visíveis em um dado momento. Dois mecanismos foram concebidos a fim de tratar este problema:

- Palette dinâmica: Na especificação de árvore é freqüente que alguns vocábulos só façam sentido quando inseridos como filhos de um vocábulo pai em específico. Quando isso valer, é interessante que aqueles só se tornem disponíveis na palette quando no refinamento deste estiver se concentrando o usuário. Para isso, através da operação de focalização, o usuário deve explicitar para onde está voltada a sua atenção a cada momento. A Figura 4.2 ilustra o funcionamento deste mecanismo: no screemdump de tela a seguir o elemento Intro foi focalizado (clica-se sobre o botão que representa uma lupa e em seguida sobre o vocábulo a ser focalizado), momento em que os componentes da estrutura esquemática podem ser inseridos

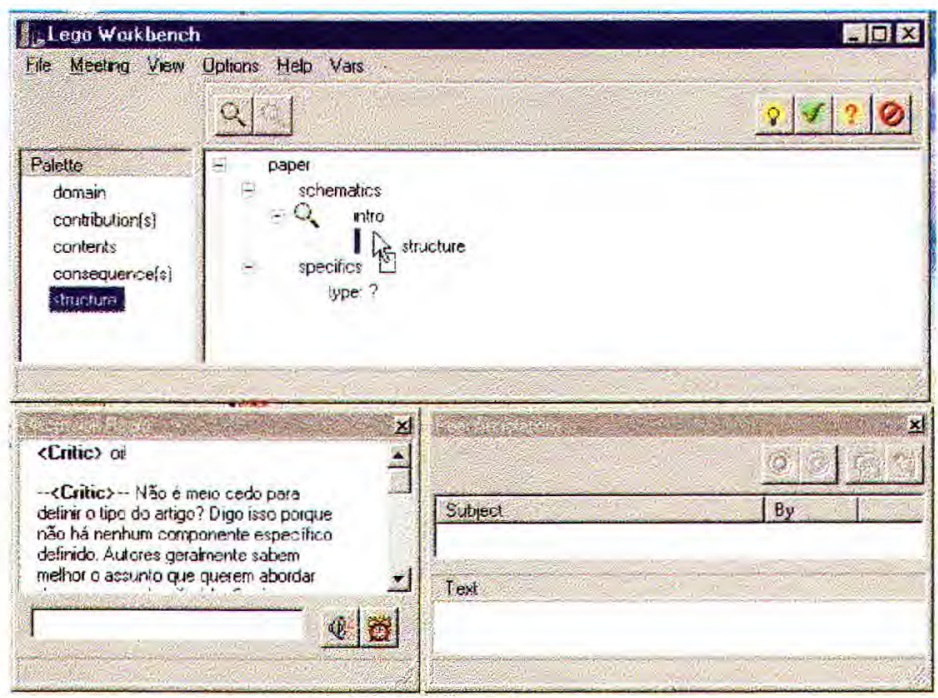

FIGURA 4.2 - Palette Dinâmica (sensivel ao contexto) em Ação

- Vocábulos abstratos: Este mecanismo considera que, se pelo menos alguns itens puderem ser agrupados em conjuntos devido a algum tipo de semelhança natural, é explicável a idéia de vocábulos abstratos. Um vocábulo abstrato, quando focalizado ou inserido, requisita sua substituição por um dos elementos de uma palette auxiliar específica (chamada de palette de substitutos do vocábulo em questão). A Figura 4.3 ilustra o funcionamento desse mecanismo. 

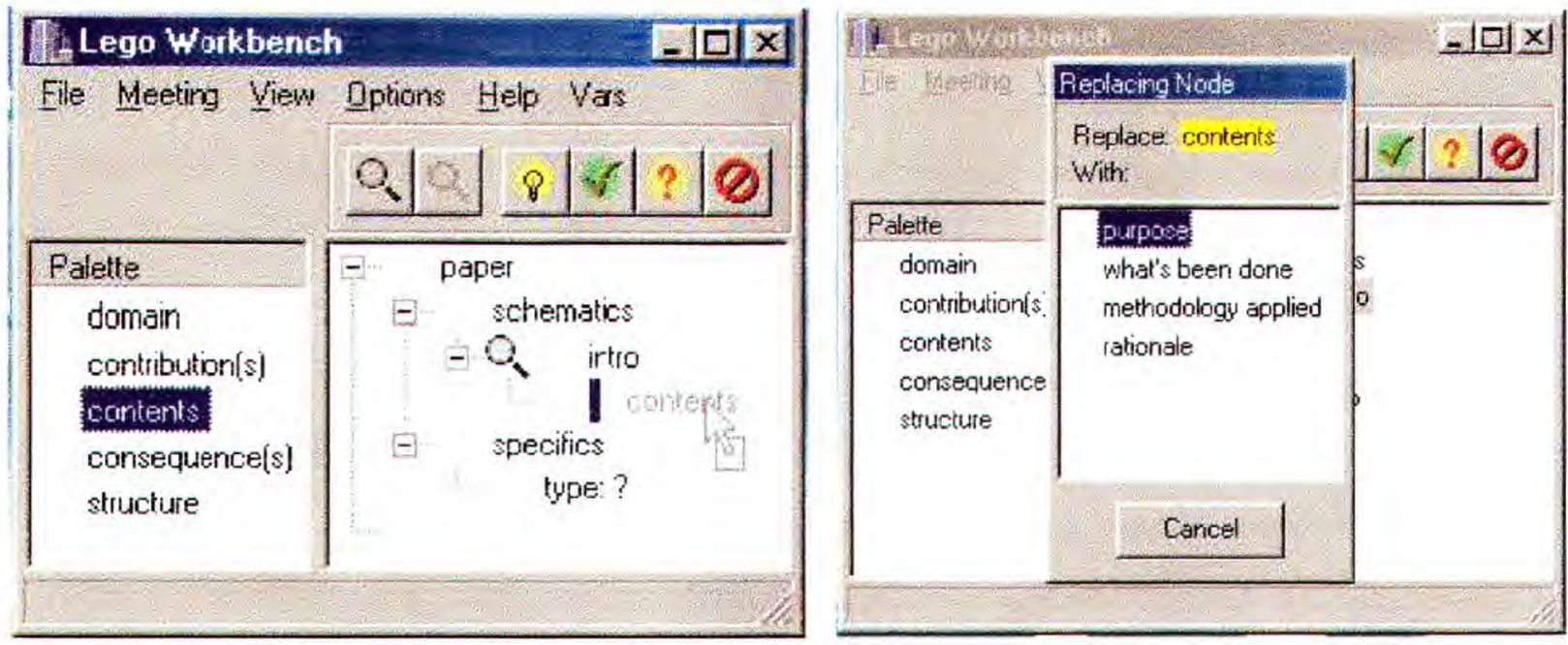

FIGURA 4.3 - Seqüência de Substituição de um Vocábulo Abstrato Quando de sua Inserção

Lego Workbench se insere num contexto de desenvolvimento colaborativo, que implica em intensa comunicação inter-agentes. Ou seja, deve ser fornecida uma mídia capaz de possibilitar a comunicação interpessoal, de forma que os colaboradores possam coordenar o desenvolvimento do projeto, bem como expressar opiniões sobre ele através de anotações de revisão, notificações e discussões. O usuário de Lego Workbench tem acesso às anotações referentes ao componente correntemente selecionado por meio da janela auxiliar Peer Annotations, como pode observar na Figura 4.4. Essas anotações podem ser feitas tanto pelo crítico artificial, quanto por colaboradores humanos.

Para que um colaborador possa emitir uma crítica na forma de anotação de revisão, basta que selecione um dos quatro botões posicionados no canto superior direito da janela de lego Workbench e clique sobre o componente/ vocábulo que deseja criticar. Os botões \& 4 ? ? 1 estão relacionados às forma de crítica do tipo New, Good, Hum e Bad, respectivamente. 


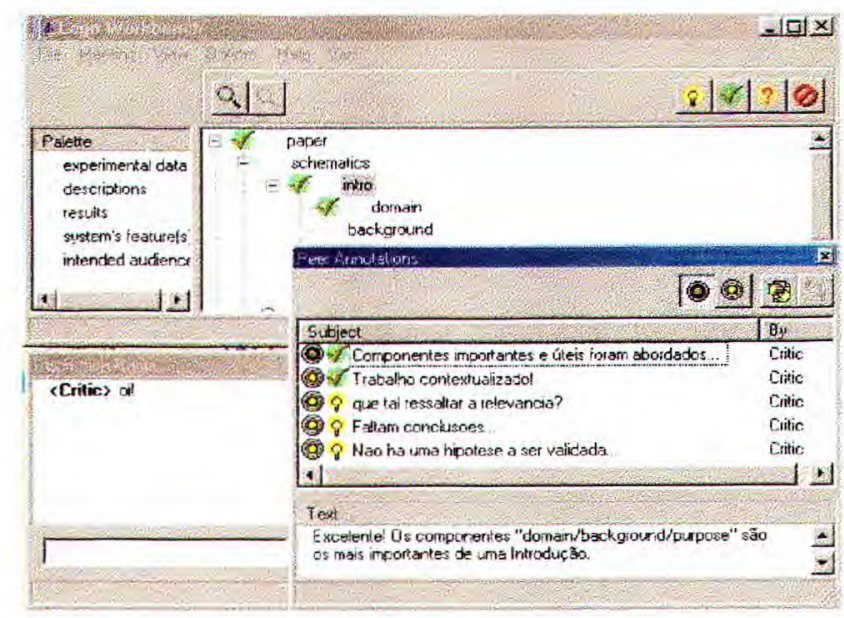

FIGURA 4.4 - Lego Workbench: Ênfase em Anotações de Revisão

Outra forma de comunicação interpessoal é a notificação. Para o colaborador a chegada de uma notificação representa inevitavelmente a interrupção de suas atividades (caracterizando uma crítica intrusiva), como exemplificado na Figura 4.5.

O colaborador pode ainda tomar parte de discussões por meio da janela auxiliar Discussion Room, que funciona à maneira de um "Chat" convencional. Como exemplo, na Figura 4.5 pode-se visualizar a tentativa de comunicação de um colaborador com os demais.

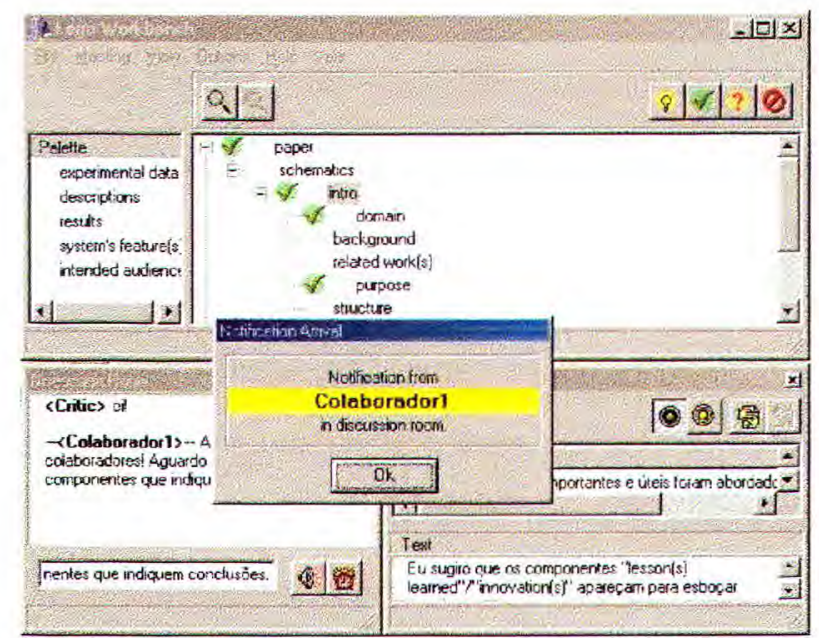

FIGURA 4.5 - Lego Workbench: Ênfase em Notificações

\section{(c) Lego Prolog Agent}

É o módulo que ao ser executado carrega o crítico num servidor de lógica embutido e, em seguida conecta-se a uma seção com a Ferramenta de Crítica. A partir desse momento passa a 
executar, no servidor de lógica, predicados especiais, chamados operadores passivos ou eventos, correspondentes às mensagens que recebe de Lego Meeting Server. Um evento atualiza a representação interna da árvore em desenvolvimento e chama a totalidade dos predicados de reação que se aplicam ao evento em questão. A condição de prova de um predicado de reação, por sua vez, pode conter chamadas a predicados especiais, denominados operadores ativos, que desencadeiam a emissão de mensagens de Lego Prolog Agent aos seus colaboradores.

\subsection{Uma Linguagem para Representaçăo de Artigos como Estruturas de Árvore}

Para a construção do protótipo da Ferramenta de Crítica definiu-se uma linguagem para a especificação em alto nível de textos técnicos e escritos em inglês. Esta linguagem possui algumas características que são imprescindíveis a qualquer linguagem, por exemplo, ser expressiva e simples.

Tendo-se uma linguagem com essas características, pode-se então usar o computador para criticar o usuário quanto ao próprio uso dessa linguagem e quanto à escolha e ordenação dos componentes da estrutura dual, verificar se os requisitos expressos pelo usuário atingem algum objetivo e recuperar e disponibilizar casos para que estes auxiliem o usuário na escrita de um texto real uma vez atingida uma especificação satisfatória.

Essa linguagem é sintaticamente, uma linguagem de construção de árvores que mantêm uma relação de ordem total entre nós-irmãos. Quando uma nova sessão com a Ferramenta de Crítica é iniciada, a estrutura principal de um artigo é automaticamente gerada pela linguagem e apresentada aos colaboradores. A linguagem implementada se baseia fortemente nas estruturas esquemáticas e de componentes específicos.

\subsection{O Agente Gerador de Críticas: $O$ Crítico}

O crítico constitui-se de um programa prolog que alimenta o módulo Lego Prolog Agent, que, desta forma pode colaborar na construção de estruturas de introduções de artigos. O crítico 
compreende: a) o reconhecedor de objetivos; b) o analisador analítico; c) o analisador diferencial; d) o conhecimento utilizado por estes analisadores e as estratégias utilizadas na apresentação das críticas.

Esta subseção enfoca os módulos agentes do crítico, ou seja, os analisadores diferencial e analítico e o reconhecedor de objetivos. $\mathrm{O}$ conhecimento utilizado no protótipo da Ferramenta de Crítica foi representado de três formas: casos, regras heurísticas/guidelines e estruturas (esquemática e de critérios específicos). $\mathrm{O}$ reconhecedor de objetivos trabalha com o conhecimento das estruturas enquanto que $o$ analisador diferencial trabalha com os casos e $o$ analítico com as regras heurísticas/guidelines. Esses dois últimos são apresentados com mais detalhes nas Subseções 4.5.1 e 4.5.2, respectivamente.

\subsubsection{Analisador Diferencial}

A função básica do analisador diferencial é comparar o produto apresentado com os casos armazenados na base. Para a obtenção da base de casos, que se constitui no conhecimento utilizado por este analisador, inicialmente classificou-se os artigos de acordo com os tipos possíveis e, na seqüência, realizou-se uma análise para identificar os componentes da estrutura dual de cada um deles. Em seguida, os casos foram codificados em Prolog levandose em consideração a estrutura dual.

As introduções de artigos que constituem a base de casos do protótipo foram anotadas de acordo com gramáticas livre de contexto (um para a estrutura de componentes esquemáticos e outra para a estrutura de critérios específicos), que foram criadas para possibilitar a visualização das introduções no browser Panorama PRO (http://www.softquad.com), durante o processo de utilização da Ferramenta de Crítica, quando da emissão de críticas que indicam a recuperação de casos.

As críticas apresentadas por esse analisador dizem respeito ao grau de similaridade entre os caso comparados (o produzido e os da base). $\mathrm{O}$ analisador diferencial funciona de modo passivo e é acionado pelo colaborador através da emissão de crítica do tipo "Hum", com subject "example", momento em que compara a estrutura apresentada com os casos da base e disponibiliza links para a visualização dos casos similares.

Com base nas diferenças encontradas em decorrência do processo de comparações, uma crítica torna-se disponível ao colaborador, indicando os nomes dos casos mais 
semelhantes ao apresentado, em relação aos diversos critérios. Estes nomes são apresentados na forma de links, e podem ser visualizados ao serem selecionados.

\subsubsection{Analisador Analítico}

O conhecimento que permite ao analisador analítico emitir críticas são regras heurísticas/guidelines. Pelo fato da escrita técnica se constituir em um domínio não prescritivo, existe a necessidade da extração de tais regras, para que elas possam auxiliar os usuários no desenvolvimento do processo da escrita.

Para a extração das regras heurísticas/guidelines, além de ter se baseado nos erros típicos relatados por revisores de submissões em conferências $\mathrm{CHI}$, também baseou-se no CHI'96 Guide to Successful Papers Submission. Na sequencia, estas regras heurísticas /guidelines foram codificadas para constituírem as regras heurísticas/guidelines utilizadas pelo crítico analitico. Para cada uma das regras heurísticas/guidelines que identificam falta de componentes, também foi codificada a regra heurística positiva, na forma de elogios.

No processo de estrủturação de uma introdução de artigo, sempre que o colaborador mudar o foco de trabalho, de schematics para specifics, ou vice-versa, este analisador, baseado nas regras heurísticas/guidelinès, irá emitir críticas, com relação à falta de componentes essenciais, quantidade pequena de componentes, componentes iguais na sequência, etc. Essas críticas poderão ser lidas pelo usuário na janela auxiliar Peer Annotation.

Neste capítulo abordou-se as questões relacionadas ao protótipo da ferramenta de ensino da escrita técnica em inglês, direcionada à seção introdutória de artigos científicos. Foram abordadas as características e funcionalidades do protótipo. A descrição do protótipo, bem como a do analisador analítico e do diferencial constituem de etapas extremamente importantes para que o leitor/pesquisador compreenda um pouco mais sobre o funcionamento do protótipo. Em (Barreviera e Silva, 1999), encontra-se uma descrição detalhada dos passos de desenvolvimento, desde a coleta e análise do corpus até a construção do protótipo. 


\section{Capítulo 5}

\section{O Processo de Avaliação de Usabilidade}

Dentre os fatores de usabilidade, a importância de cada fator depende do sistema a ser avaliado (Lacerof \& Paternò, 1998). Por exemplo, para crianças é muito importante que o sistema seja fácil de usar, já para sistemas bancários a eficiência é um dọs fatores mais importantes. Dessa forma, para se realizar uma boa avaliação se faz necessário a aplicação de um processo que defina os usuários da aplicação, entre outros fatores.

Esse capítulo apresenta um processo de avaliação que se baseia no método USINE (Lacerof \& Paternò) adaptado e na abordagem de melhoria contínua da interface proposta por Nielsen (2000), que utiliza três etapas/turnos de avaliação (problemas são identificados e melhorias são realizadas a cada etapa).

A partir de uma análise de custo e beneficio, baseada em vários critérios (a importância de precisão dos resultados, custo e tempo gasto para realizar uma avaliação), escolheu-se dentre os vários métodos estudados na literatura, o método USINE (descrito no Capítulo 3) para ser adaptado e utilizado no processo de avaliação de usabilidade descrito nesse capítulo. A Tabela 5.1 ilustra o resultado da análise dos métodos considerados, em que a primeira coluna se refere aos métodos estudados, as colunas 2,3 e 4 representam, respectivamente, a importância de precisão, o custo e o tempo gasto. 
TABELA 5.1 - Comparação entre Métodos de Avaliação de Usabilidade

\begin{tabular}{|c|c|c|c|}
\hline Metodo & Importancia de Precisato & Custo & $\mathbf{T}$ \\
\hline $\begin{array}{l}\text { Avaliação } \\
\text { Heurística }\end{array}$ & $\begin{array}{l}\text { Por não usar usuários reais } \\
\text { na avaliação é provável } \\
\text { que alguns problemas } \\
\text { relevantes não sejam } \\
\text { encontrados. Além disso, } \\
\text { as heurísticas em que se } \\
\text { baseia o método pode } \\
\text { torná-lo limitado quanto a } \\
\text { esse critério. }\end{array}$ & $\begin{array}{l}\text { Como o método requer } \\
\text { vários especialistas em } \\
\text { usabilidade (a fim de se } \\
\text { alcançar resultados } \\
\text { melhores) o custo pode } \\
\text { se tornar alto } \\
\text { dependendo da precisão } \\
\text { desejada dos resultados. }\end{array}$ & $\begin{array}{l}\text { Por ser fácil de se aplicar } \\
\text { (contando-se com alguns } \\
\text { especialistas em usabilidade) o } \\
\text { tempo de avaliação é } \\
\text { relativamente baixo. }\end{array}$ \\
\hline $\begin{array}{l}\text { Método } \\
\text { MUSIC }\end{array}$ & $\begin{array}{l}\text { Por utilizar usuários } \\
\text { representativos do sistema } \\
\text { a ser avaliado e, por } \\
\text { registrar em vídeo o } \\
\text { desempenho, pensamentos } \\
\text { e atitudes dos usuários, é } \\
\text { possivel obter resultados } \\
\text { bastante seguros. }\end{array}$ & $\begin{array}{l}\text { O método completo é } \\
\text { relativamente caro. } \\
\text { Apesar do método } \\
\text { poder ser adaptado a } \\
\text { diferentes restrições de } \\
\text { orçamento, a adaptação } \\
\text { poder interferir } \\
\text { negativamenter na } \\
\text { precisão dos resultados. }\end{array}$ & $\begin{array}{l}\text { O tempo gastó é grande. Apesar } \\
\text { de possuir ferramentas } \\
\text { automáticas para auxiliar na } \\
\text { análise dos resultados, requer } \\
\text { um tempo extra para analisar os } \\
\text { detalhes de baixo nível. Esse } \\
\text { tempo pode ser diminuído } \\
\text { aplicando-se o método básico, } \\
\text { porém sacrificando os } \\
\text { resultados. }\end{array}$ \\
\hline $\begin{array}{l}\text { Cognitive } \\
\text { Walkthroug } \\
\mathrm{h}\end{array}$ & $\begin{array}{l}\text { Apesar de fornecer uma } \\
\text { avaliação bem detalhada } \\
\text { em relação à facilidade de } \\
\text { aprendizagem, os } \\
\text { resultados são limitados } \\
\text { Quanto à severidade, o } \\
\text { conteúdo, escopo e número } \\
\text { de problemas, pois o } \\
\text { método não emprega } \\
\text { usuários reais e se } \\
\text { preocupa apenas com esse } \\
\text { critério de usabilidade. }\end{array}$ & $\begin{array}{l}\text { O alto nível de detalhes } \\
\text { envolvido na avaliação } \\
\text { faz com que se leve } \\
\text { muito tempo para } \\
\text { realizar a avaliação. } \\
\text { Com isto, o custo de se } \\
\text { aplicar o método se } \\
\text { torna alto, calculando- } \\
\text { se o valor da hora de } \\
\text { cada profissional } \\
\text { envolvido (engenheiros, } \\
\text { desenvolvedores de } \\
\text { software, entre outros). }\end{array}$ & $\begin{array}{l}\text { Por fazer uma análise mais } \\
\text { detalhada, considerando todas } \\
\text { as pequenas ações para se } \\
\text { realizar uma tarefa, uma } \\
\text { avaliação utilizando esse } \\
\text { método leva uma grande } \\
\text { quantidade de tempo. }\end{array}$ \\
\hline $\begin{array}{l}\text { Método } \\
\text { USINE }\end{array}$ & \begin{tabular}{|lr} 
Esse método fornece \\
informações úteis para \\
entender porque os erros \\
ocorreram, facilitando \\
assim no processo de \\
identificação r dos \\
problemas, onde e como \\
melhorias podem ser feitas \\
na interface. Por empregar \\
usuários reais os resultados \\
são mais seguros. Porém, \\
por não observar o usuário \\
realizando as atividades, \\
pode-se perder algumas \\
informações importantes, \\
como expressão corporal e \\
comentários.
\end{tabular} & $\begin{array}{l}\text { O suporte automático } \\
\text { fornecido nesse método } \\
\text { diminui os custos, uma } \\
\text { vez que se pode deixar } \\
\text { a ferramenta automática } \\
\text { avaliar os resultados } \\
\text { sem que um observador } \\
\text { siga seqüencialmente } \\
\text { cada usuário e analise } \\
\text { manualmente seu } \\
\text { comportamento. }\end{array}$ & $\begin{array}{l}\text { Por ser dado suporte automático } \\
\text { durante toda a avaliação, } \\
\text { diminui-se o tempo gasto na } \\
\text { aplicação desse método, } \\
\text { gastando um tempo adicional } \\
\text { para especificar o Modelo de } \\
\text { Tarefas. Porém este tempo extra } \\
\text { é justificado pela utilidade do } \\
\text { Modelo de Tarefas como meio } \\
\text { de entender melhor a aplicação. }\end{array}$ \\
\hline
\end{tabular}


A abordagem iterativa de Nielsen (2000) foi escolhida devido à necessidade de não somente identificar os problemas, mas também de melhorar o sistema. O processo elaborado é descrito na Seção 5.1 e na Seção 5.2 define-se um procedimento documentado da avaliação da Ferramenta de Crítica realizada neste mestrado.

\subsection{O Processo de Avaliação}

Esse processo é constituído do seguinte conjunto de passos: 1) definição da aplicação a ser avaliada; 2) definição do contexto de uso do sistema; 3) definição dos objetivos da avaliação; 4) especificação da forma de coñdução da avaliação; 5) realização das três etapas de avaliação, de acordo com a éspecificação feita no passo 4.

A Figura 5.1, mostra a seqüência de passos requeridos para avaliar a usabilidade e derivar resultados aplicando-se esse processo genérico de avaliação elaborado. A coluna do lado direito da figura mostra as ferramentas usadas pelo método USINE, que apoiam o passo 5 do processo. Os passos são realizados de forma seqüencial e são detalhados na Seção 5.1 como parte do processo. O quinto passo desse processo, que é a aplicação da avaliação propriamente dita, é apresentado no Capítulo 6.

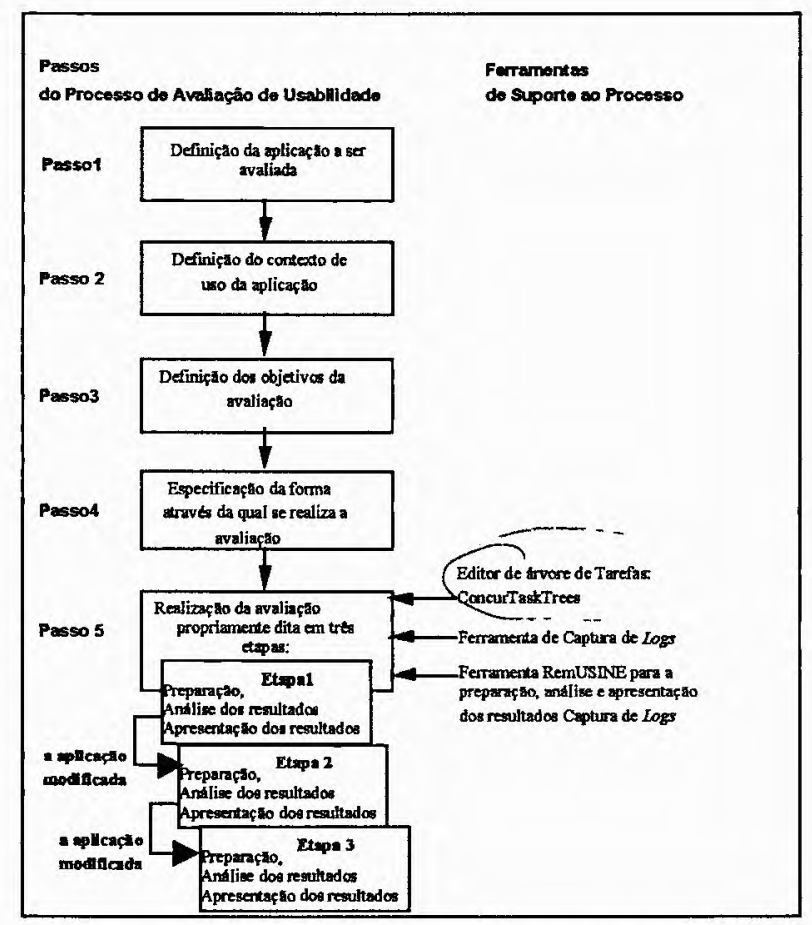

FIGURA 5.1 - Passos do Processo de Avaliação de Usabilidade 


\subsubsection{Definição da Aplicação}

O escopo da aplicação a ser avaliada é especificado, incluindo o software, a documentação que forma parte da aplicação e o hardware. Esta definição fornece a base para o subsequente estudo de contexto.

\subsubsection{Definição do Contexto de Uso da Aplicação}

É essencial identificar o perfil de usuários para os objetivos específicos da avaliação, o ambiente em que está inserida a aplicação e as tarefas de avaliação apropriadas: Geralmente, isto é obtido como um estudo de contexto feito pela equipe de usabilidade por meio de questionários. Um estudo de contexto documenta as características reais ou assumidas dos usuários atuais ou pretendidos do produto, do ambiente e das tarefas. A Tabela 5.2 especifica estas características de contexto de uso do sistema.

TABELA 5.2 - Estudo de Contexto da Aplicação

\begin{tabular}{|l|l|}
\hline Contevto & Descrição \\
\hline Usuários & $\begin{array}{l}\text { São pessoas que refletem as características do grupo e que estão disponíveis e dispostas a } \\
\text { participar das sessões de avaliação. }\end{array}$ \\
\hline Ambiente & $\begin{array}{l}\text { O ambiente deve ser o própprio local de trabalho ou simular às características essenciais do local de } \\
\text { trabalho. Isto inclui, entre outros, equipamentos, aspectos relacionados a ruídos e material de } \\
\text { suporte. }\end{array}$ \\
\hline Tarefas & $\begin{array}{l}\text { A partir de um estudo detalhado do sistema a ser avaliado escolhe-se as tarefas que parecem mais } \\
\text { críticas e que explorem o máximo a interface. Tais tarefas são dadas aos usuários para realizarem, } \\
\text { sendo que as mesmas tarefas são dadas a todos os usuários, fornecendo-se uma descrição } \\
\text { detalhada das mesmas em papel. }\end{array}$ \\
\hline
\end{tabular}

\subsubsection{Definição dos Objetivos da Avaliação}

Antes de começar uma avaliação é importante definir uma meta global. De acordo com Paternò (1999a), a principal meta da avaliação é geralmente uma das seguintes:

- Engenharia em direção a um alvo - O projeto é bom o suficiente?

- Comparar projetos alternativos - Qual é o melhor?

- Entender o mundo real - Quão bem o projeto trabalha no mundo real? 
- Verificar a conformidade a um padrão - Este produto está conforme o padrão?

Após ter definido a grande meta do teste, é importante que se defina exatamente o que irá se testar, ou seja, quais são os objetivos específicos da avaliação. Tomando o.conceito de usabilidade adotado nesse trabalho, tem-se que os objetivos específicos se referem aos fatores facilidade de aprendizado, eficiência de uso, retenção, mínimo de erros e satisfação. Porém, é necessário que se tente operacionalizar a definição de usabilidade para o sistema a ser avaliado em termos de fatores mensuráveis.

O beneficio de se ter termos mensứáveis é fornecer meios para se saber quanto mais de trabalho é requerido em usabilidade. Como já mencionado, a relevância de se avaliar cada um desses fatores depende do sistema a ser avaliado, devendo se basear no estudo de contexto para a aplicação em questão.

\subsubsection{Especificação da Forma de Condução da Avaliação}

A condução da avaliação é realizada segundo a abordagem iterativa de Nielsen (2000), que defende a realização de três etapas de avaliação. A cada etapa são testados 5 usuários (5 é o número tido como ideal), que interagindo com o sistema tentam realizar as tarefas críticas. Isto significa que é utilizado um total de 15 usuários. Em todas as etapas são capturados arquivos de logs das sessões de testes dos usuários. A seguir é detalhada cada etapa.

a) Etapa I: Segundo Nielsen (2000), nesta etapa são encontrados $85 \%$ dos problemas de usabilidade. Os dados dos testes dos 5 primeiros usuários são analisados e baseando-se na análise dos resultados do teste e do Modelo de Tarefas da aplicação serão apresentadas sugestões de melhoria para os problemas diagnosticados. Em seguida, é feito um redesign do sistema, incorporando as sugestões levantadas e corrigindo os problemas encontrados.

b) Etapa II: Depois de criar o novo design são realizadas 5 novas sessões de teste, a fim de se saber se as dificuldades encontradas na interação com a aplicação foram superadas ou não, ou mesmo porque sempre existe o risco de se introduzir novos problemas de usabilidade no novo design. Assim, novas sessões de testes são realizadas, porém utilizando 5 usuários diferentes. Novamentè os dados dos testes são analisados e baseando-se na análise dos resultados do teste e do Modelo de Tarefas da aplicação é proposto e implementado um re-design da interface do sistema, de forma a melhorar seu 
uso. De acordo com Nielsen (2000), nesta etapa-descobre-se a maioria dos $15 \%$ dos problemas de usabilidade originais restantes, que não foram encontrados no primeiro teste, faltando ainda $2 \%$ destes problemas para serem encontrados.

c) Etapa III: Finalmente, outras 5 sessões de testes são realizadas, considerando também que os 5 usuários são diferentes daqueles da primeira e segunda etapas. Os dados dos testes são analisados em relação ao Modelo de Tarefas da Ferramenta de Crítica, e baseando-se nesta análise sugestões de melhoria são dadas ao projetista (caso ainda se descubra algum problema de usabilidade).

Além disso, para executar uma avaliação controlada, após uma análise das seções anteriores, deve-se definir: a) o critério de seleção de usuários; b) o material de suporte ao usuário e ao avaliador; c) os critérios de realização das tarefas (com ou sem treinamento); d) as medidas a serem tomadas; e) a forma de preparação e análise; e f) apresentação dos resultados.

\subsubsection{Realização da Avaliação}

São realizadas três etapas de avaliação, sendo que ao final de cada etapa são sugeridas soluções para os problemas encontrados como resultado da avaliação realizada. Cada etapa de avaliação é realizada usando-se o Método USINE de avaliação de usabilidade, que utiliza um modelo de tarefas da aplicação a ser avaliada, dados de testes de usuários e dados obtidos de um questionário aplicado aos usuários após a sessão de teste. Este método é descrito no Capítulo 3, Seção 3.4 .

\subsection{Instanciação do Planejamento da Avaliação}

\subsubsection{Definição da Aplicação}

A Ferramenta de Crítica do Ambiente AMADEUS é uma ferramenta de ensino à escrita técnica em inglês, 'seguindo uma abordagem colaborativa e destinada à estruturação e escrita através de exemplos (chamados de casos devido o uso de Raciocínio Baseado em Casos 
(Mantaras \& Plaza, 1995)). Esta ferramenta contém uma Base de 51 casos, consistindo da seção introdutória de artigos científicos. Para a escrita é necessário também; o uso de um editor de texto à escolha do autor (por exemplo, NotePad ${ }^{@ \text { Microsoft }}$, WordPad ${ }^{@ M i c r o s o f}$ ). 0 protótipo pode ser utilizado por um único ou por vários colaboradores engajados na tarefa de estruturação de uma introdução. Neste trabalho, a ferramenta será usada com um único usuário.

A Ferramenta de Crítica é um sistema de colaboração entre agentes, um dos quais é artificial. Para tanto, foi construído um sistema que suporta adequadamente a colaboração entre diversos agentes para servir de plataforma à ferramenta de ensino da escrita técnica em inglês seguindo uma abordagem de críticas. Por ser ainda um protótipo a documentação pertinente se restringe à uma dissertação de mestrado (Barreviera e Silva, 1999), artigos (Barreviera e Silva, 1998) e Help on-line na forma de manual do usuário reproduzido aqui na Seção 5.2.6.

\subsubsection{Informações de Contexto}

\subsubsection{Usuários do Sistema e suas Necessidades}

Esta ferramenta é direcionada a usuários com alguma experiência no domínio da escrita técnica, porém que ainda possuem problemas de coesão e interferência da língua materna quando escrevem em inglês. Em nosso processo de avaliação, os usuários são alunos de pósgraduação (mestrado e doutorado) do curso de Ciência da Computação do Instituto de Ciências Matemáticas e de Computação da USP, São Carlos (ICMC/USP).

\subsubsection{Ambiente}

O ambiente em que o sistema está inserido é o acadêmico, em que alunos estão diante de situações que exigem a escrita de artigos na língua inglesa para divulgar os seus resultados de pesquisa. $\mathrm{O}$ ambiente que será utilizado para a avaliação é um ambiente real de utilização da ferramenta a ser avaliada, no caso um dos laboratórios do ICMC/.USP. Este laboratório inclui 
um microcomputador, uma câmara de vídeo e uma TV, uma mesa com uma cadeira. Além disso, representa um ambiente bastante silencioso, típico ao ambiente necessário ao processo de escrita, que se exige bastante concentração.

\subsubsection{Tarefas}

No processo de avaliação serão consideradas tarefas todas as subtarefas necessárias para a realização de uma tarefa global. Considerando-se a Ferramenta de Crítica, o propósito desta aplicação é ensinar e fornecer auxílio na escrita da introdução de um artigo na língua inglesa. Desta forma, considera-se que ao realizar as seguintes tarefas globais, toda a interface do usuário fornecida pela Ferramenta de Crítica seja explorada, com exceção da parte do sistema que envolve outros colaboradores humanos, que está fora do escopo desta avaliação.

Tarefa Global 1: "Estruturar uma introdução de um artigo na língua inglesa"

Tarefa Global 2: "Obter um primeiro rascunho da introdução, utilizando a estrutura desenvolvida na tarefa global " 1 ", e salvar este rascunho em um editor de texto"

Para a realização da tarefa " 1 " descrita acima são consideradas tarefas as seguintes subtarefas:

a.1. O usuário deverá preparar o processo de seleção dos componentes esquematicos:

- O usuário deverá focalizar o componente schematics.

- O usuário deverá introduzir Intro, que esta na Pallete, na área de trabalho como componente de schematics.

- O usuário deverá focalizar Intro.

a.2. O usuário deverá definir os componentes esquemáticos da introdução:

- O usuário deverá escolher os componentes desejados, que estão na Pallete, para compor a introdução e inseri-los como componentes de Intro.

a.3. O usuário deve pedir e visualizar as críticas: aqui o usuário receberá as críticas do crítico quanto aos componentes esquemáticos. Esta tarefa é, geralmente, realizada depois que o usuário escolhe os componentes que ele julga necessários para compor sua introdução:

- O usuário deverá focalizar em specifics. 
- O usuário deverá clicar no ícone de crítica que aparece ao lado de um dos componentes.

- O usuário deverá clicar no Item de crítica exibido na Peer annotation.

\section{a.4. O usuário deve, baseado nas críticas, escolher uma das seguintes opções:}

(1) Focalizar em "Intro" e acrescentar, excluir componentes ou alterar a ordem deles; ou

(2) Pedir ao protótipo que encontre e recupere os casos armazenados que mais se assemelham à estrutura da introdução definida. Para isso o usuário deverá:

(2.1) clicar sobre o botão "Hum..." ? I e em seguida;

(2.2) clicar sobre o componente "paper" de Lego Workbench;

(2.3) deve digitar "example" e clicar sobre o botão OK, na janela Peer Annotation que surgirá no espaço para o "subject".

a.5. Se a opção escolhida foi a (1) ou se a opção escolhida foi a (2) e as estruturas dos casos recuperados não se assemelham ao proposto, o usuário poderá fazer alterações na estrutura da introdução proposta. Neste caso deverá realizar as tarefas a.2, a.3 e a.4.

a.6. Se a opção escolhida foi o (2) e os casos satisfazem o usuário, então a partir dos links disponibilizados para a visualização de casos anotados, o usuário poderá visualizar exemplos de introduções de artigos.

Depois de realizar a tarefa global "1", atingindo-se a subtarefa "a.6", o usuário deverá realizar a tarefa global " 2 ", que se constitui das seguintes subtarefas:

b.1 Escolher o exemplo de introdução com a estrutura que mais se assemelha à estrutura definida;

b.2 Ativar um editor de texto;

b.3 Marcar e copia as partes do exemplo que lhe interessam;

b.4 Colar a parte da introdução que foi anteriormente marcada;

b.5 Repetir as tarefas "b.3" e "b.4" até que se consiga um rascunho da introdução;

b.6 Salvar o rascunho editado. 


\subsubsection{Definindo os Objetivos da Avaliação}

Neste trabalho, apesar de se usar dados mensuráveis não são especificadas quaisquer metas particulares de usabilidade antes de começar a avaliação, uma vez que não está se testando em direção a um alvo quantitativo, por exemplo, ver se a aplicação é boa o suficiente, nem mesmo a fim de comparar projetos alternativos. Neste trabalho, o enfoque é identificar problemas de usabilidade e com isto dar informação ao projetista de como melhorar a interface, de modo que os usuários não tenham problemas em usar o sistema. Desta forma, a finalidade da avaliação é melhorar a interface do usuário, através da análise de quais tarefas o usuário executou e os erros que ele cometeu.

Baseado na análise do ambiente em que está inserido o sistema, das tarefas que o usuário deve ser capaz de realizar com a referida aplicação e sobre os possíveis usuários do sistema descritos na seção anterior, definimos os critérios mais importantes a serem avaliados. Através desta análise foi possível estabelecer uma seleção destes critérios, com justificativas (Tabela 5.3).

\section{TABELA 5.3 - Critérios de Usabilidade a Serem Avaliados}

\begin{tabular}{|l|l|}
\hline Cácil de Usar & $\begin{array}{l}\text { Justificativa a } \\
\text { usar de forma a evitar a sobrecarga cognitiva do usuário em ter que aprender a interface, } \\
\text { consultar o help ou buscar ajuda na documentação. }\end{array}$ \\
\hline Poucos Erros & $\begin{array}{l}\text { É importante que, ao usar o sistema, a interface ofereça condições ao usuário para que o } \\
\text { número de erros seja o menor possível, pois a ocorrência de um erro leva à uma "ruptura" de } \\
\text { idéias no processo da escrita, quando o usuário tenta entender o que aconteceu e como reverter } \\
\text { aquele estado de erro. }\end{array}$ \\
\hline Agradável & $\begin{array}{l}\text { Uma vez que o processo de escrita, na maioria das vezes, é feito em papel (o usuário tem o } \\
\text { hábito de escrever em papel) ou no processador de textos preferido, o usuário não usará o } \\
\text { sistema se ele não for agradável de usar. }\end{array}$ \\
\hline Eficiente & $\begin{array}{l}\text { O perfil de usuário deste sistema procura por meios que lhe permitam realizar a escrita de } \\
\text { artigos de forma mais rápida e segura, uma vez que sempre existem datas de submissão } \\
\text { marcadas. Assim, é improvável que o usuário usará o sistema se ele não for eficiente. }\end{array}$ \\
\hline
\end{tabular}

A retenção não foi considerada como um critério importante a ser avaliado para esta aplicação, por ser esta uma aplicação com funcionalidade simples, ou melhor, por se tratar de uma interface em que a navegação é simples, o critério de retenção é intrínseco à aplicação. Portanto, não faz sentido avaliar este critério. Uma descrição detalhada de cada um dos critérios a serem avaliados é dada a seguir. Em tal descrição, serão consideradas tarefas todas as subtarefas necessárias para realizar as tarefas globais "1" e "2" (todas as subtarefas descritas na Seção 5.2.2.3). Assim como no método USINE, tais critérios são avaliados a 
partir da análise de logs de testes de usuários com a Ferramenta de Crítica e da análise do Modelo de Tarefas desta aplicação. Também, serão utilizados para esta avaliação dados fornecidos por um questionário. A forma de avaliação é descrita na próxima seção.

\section{Objetivo 1: Avaliar Quanto ao Critério Facilidade de Aprendizado}

Isto significa que a Ferramenta de Crítica deve fornecer uma interface que permita ao usuário inicial aprender com facilidade como usar o sistema de forma a realizar as tarefas globais "1" e "2". Serão consideradas tarefas todas as subtarefas necessárias para realizar as tarefas globais (descritas na Seção 5.2.2.3). A facilidade de aprendizado pode ser medida em termos de fatores mensuráveis, medindo-se:

- Número de tarefas completadas e quais tarefas foram completadas.

- As tarefas que o usuário não foi capaz de executar: estas tarefas são importantes porque indicam problemas que o usuário teve com a interface do usuário. É provável que o usuário necessite de alguma ajuda para executar essas tarefas.

- Quanto tempo cada tarefa levou para completar. Isto é calculado baseado no tempo que existe em toda ação, mostrando quanto tempo passou desde a última ação executada. $O$ tempo para as tarefas abstratas é calculado somando-se o tempo das tarefas filhas.

- Quantas vezes se usou de documentação e de help.

- Quantidade de tarefas nunca tentadas e quais são elas.

- Quantas vezes o usuário teve que recomeçar desde o início. Isto se refere à quão fácil é navegar dentro da aplicação.

\section{Objetivo 2: Avaliar Quanto ao Critério Mínimo de Erros}

O que se busca é que a Ferramenta de Crítica apresente o mínimo de erros e uma maior facilidade de recuperação dos erros caso eles ocorram. Um erro é alguma ação que não culmina na meta desejada. Desta forma, o critério "Mínimo de Erros" de um sistema é medido verificando-se quais e quantas de tais ações os usuários cometeram enquanto executavam as tarefas especificadas. Os tipos de erros são divididos em duas categorias, que devem ser consideradas quando avaliando este critério: 
- Erros de pré-condição (que são erros cometidos por o usuário tentar executar uma ação referente a uma tarefa sem antes executar a pré-condição para aquela tarefa).

- Outros erros (por exemplo, clicar em uma imagem pensando que fosse um botão)

\section{Objetivo 3: Avaliar Quanto ao Critério Satisfação}

A Ferramenta de Crítica deve atender às preferências subjetivas ou satisfação do usuário. $O$ grau de satisfação pode ser medido utilizando-se um questionário e estabelecendo valores ao resultado obtido do questionário. Por exemplo, em uma escala de 0-5 (de acordo com uma tabela de pontos obtidos no questionário), o sistema pode ser considerado respectivamente como desagradável, médio-baixo, médio, médio-alto, agradável. Porém este é um critério dificil de se medir, visto que é preciso fazer suposições.

Um outro critério que poderia ser usado para avaliar este fator seria registrar os comentários do usuário ao interagir com a ferramenta, porém sem pedir ao usuário que fale em voz alta. Neste caso só seriam gravadas falas "casuais". Porém, ao utilizar este recurso corre-se o risco de ser intrusivo. Assim, neste trabalho, para a avaliação do critério de Satisfação do Usuário utiliza-se apenas do questionário aplicado ao usuário ao final da sessão de teste e uma conversa informal com o usuário sobre o uso do sistema.

\section{Objetivo 4: Avaliar Quanto ao Critério Eficiência de Uso}

A Ferramenta de Crítica deve atender as necessidades do usuário que deseja escrever uma introdução em inglês, de forma que ele possa realizar completamente e precisamente suas tarefas em um determinado período de tempo. O grau de eficiência pode ser medido verificando:

- Tempo total de teste.

- Quantidade de tarefas realizadas.

- Quantidade de tarefas realizadas com sucesso.

- Quantidade de tarefas realizadas com falhas.

- O tempo gasto para completar cada tarefa.

- Quantas vezes cada tarefa foi executada: Se uma tarefa é executada frequentemente seu desempenho deve ser suportado eficientemente (por exemplo, projetistas podem decidir fornecer atalhos ou macros). 
- Em qual ordem as tarefas foram executadas: O projetista geralmente tem uma opinião em qual ordem o usuário irá executar as tarefas. Se o usuário deseja quebrar esta ordem isto pode significar que o projetista deve possibilitar a execução em ordem diferente. Outro assunto é se o usuário escolhe executar uma tarefa antes de outra, neste caso a segunda tarefa pode ser ativada automaticamente.

\subsubsection{Especificação da Forma de Condução da Avaliação}

A avaliação da Ferramenta de Crítica foi realizada utilizando-se três etapas de avaliação, em que é aplicado a cada etapa o método USINE de avaliação. A fim se obter resultados mais seguros dessa avaliação, a seguir são especificados: (1) o critério de seleção de usuários e o número de usuários; (2) o material de suporte ao usuário e ao avaliador; (3) os critérios de realização das tarefas; (4) as medidas a serem tomadas; (5) a forma de preparação e análise dos resultados (6) a apresentação dos resultados.

\section{Critério de Seleção de Usuários}

Foram escolhidos como usuários teste da aplicação, 15 estudantes do programa de mestrado e doutorado do ICMC/ USP da subárea de Ciência da Computação e Matemática Computacional com idade entre 24 e 29 anos que nunca tinham visto a aplicação, sendo que apenas 5 usuários era recrutado para cada etapa de avaliação, de acordo com a sugestão de Nielsen (2000).

O convite para realizar o teste se deu a partir de uma conversa informal, seguida de uma carta convite explicando como seria realizado o teste. $\mathrm{O}$ formato da carta é apresentado no item 4.

\section{Material de Suporte ao Usuário e ao Avaliador}

Os itens 4.1 e 4.2 descrevem os materiais de suporte ao usuário e ao avaliador, respectivamente. Além dos materiais distribuídos a cada usuário envolvido nas sessões de testes, foi usada a aplicação - que contém uma camada de software para a captura dos eventos gerados pela interação do usuário com a aplicação em um computador Pentium II. Este 
material é fornecido a fim de que a realização das tarefas se dê de forma segura e proporcione aos envolvidos o.máximo de conforto.

\subsection{Material de Suporte ao Usuário}

\section{I - Carta Convite: além de ser um meio formal de convidar o usuário a participar da sessão de} teste, é também um instrumento em que são passadas ao usuário as tarefas a serem realizadas e as regras do teste.

\section{QUADRO 1 - Carta Convite ao Usuário}

\section{Carta Convite: Teste para Avaliação da Interface da Ferramenta de Crítica do Ambiente AMADEUS}

Propósito. O propósito deste teste é avaliar a usabilidade da interface da Ferramenta de Crítica do Ambiente AMADEUS, que é uma ferramenta para o auxílio e ensino da escrita técnica em inglês. Este teste faz parte de um projeto de mestrado cuja fase inicial consiste em realizar testes de usuários com um protótipo da ferramenta em questão. Os resultados desta etapa de teste serão usados para encontrar os possiveis problemas de usabilidade da interface da Ferramenta de Crítica e assim determinar as modificações necessárias ao protótipo para otimizar a qualidade da aplicação. Desta forma, ao participar deste teste, os problemas que o usuário encontrar, serão de grande importância para a melhoria desta aplicação. Ressalto ainda que os erros não são considerados falhas do usuário e sim da aplicação. Em face disto o usuário deve se sentir a vontade durante a interação e procurar explorar o máximo a interface.

Tarefas. Será pedido a você que estruture e escreva um rascunho de uma introdução de um artigo sobre sua área de pesquisa/ seu projeto de pesquisa. A estruturação da introdução será monitorada pela Ferramenta de Critica e a escrita do rasçunho será auxiliada pelos textos fomecidos pela ferramenta e utilizando o editor de texto de sua preferência. Como o teste é um experimento controlado, nós precisamos estabelecer critérios para garantir uniformidade na tarefa de escrita entre todos os participantes. Tais critérios são:

Após o início do teste nenhuma pergunta lhe será respondida. Desta forma, nenhuma ajuda será dada durante o teste.

Você deverá ler a lista de tarefas em anexo, a fim de que você possa fazer perguntas e esclarecer qualquer dúvida em relação a realização das tarefas antes do início da sessão de teste.

Será disponibilizado a você; antes do teste começar, uma documentação que poderá lhe auxiliar na realização das tarefas. Além disso, a aplicação consta de um help on-line que também the poderá ser útil em caso de dúvidas.

: Você deverá trazer para a realização do teste um assunto sobre o qual você deseja escrever uma introdução de seu artigo, bem como material relacionado ao assunto para lhe servir de suporte

A sessão constará de no máximo duảs horas de duração. Sèrá réalizada no dia ........de de 200-, terá início às. horas e término às horas

Procedimento. Será oferecida a vọcê uma ferramenta de escrita gráfica, que utiliza a abordagem baseada em casos e em críticas para estruturar uma introdução de artigo, ou seja, escolher os componentes que devem compor sua introdução. Além disso, a ferramenta permite a você visualizar casos semelhantes e escolher partes destes casos para compor sua introdução. O propósito da ferramenta é melhorar a coesão e coerência da introdução. A fim de realizar o teste você deverá seguir o procedimento descrito em anexo a esta carta.

Confiabilidade. Os logs dos testes serão capturados para uma análise posterior, porém cada teste será identificado por uma etiqueta "randômica". Assim, nenhuma informação de identificação sobre você será registrada.

Questōes. Para informações Adicionais sobre ó projeto, por favor, contactë:

$$
\begin{aligned}
& \text { Iris Fabiana de Barcelos } \\
& \text { iris(a)icmc.sc.usp.br }
\end{aligned}
$$

Instituto de Ciências Matemáticas e de Computação - ICMC/ USP

Sua participação é voluntária e sua recusa para participar não envolverá nenhuma penalidade ou perda de beneficios. Você pode cancelar a participação a qualquer momento sem penalidade ou perda de beneficios. Obrigada pela colaboração. 
II - Descrição das Tarefas: A descrição seguinte é dada ao usuário junto com a carta convite, que deverá ser lida atentamente pelo usuário antes da sessão de teste, a fim de que o usuário se familiarize com as tarefas a serem realizadas. $\mathrm{O}$ usuário deverá realizar as seguintes tarefas:

Tarefa Global 1: "Estruturar uma introdução de um artigo na lingua inglesa"

Tarefa Global 2: "Obter um primeiro rascunho da introdução, utilizando a estrutura desenvolvida na tarefa global " $I$ ", e salvar este rascunho em um editor de texto"

Para a realização da tarefa "1" descrita acima são consideradas tarefas as seguintes subtarefas:

\section{a.1. O usuário deverá preparar o processo de seleção dos componentes esquematicos:}

- O usuário deverá focalizar o componente schematics.

- O usuário deverá introduzir Intro, que esta na Pallete, na área de trabalho como componente de schematics.

- O usuário deverá focalizar Intro

\section{a.2. O usuário deverá definir os componentes esquemáticos da introdução:}

- O usuário deverá escolher os componentes desejados, que estão na Pallete, para compor a introdução e inseri-los como componentes de Intro.

a.3. O usuário deve pedir e visualizar as críticas: aqui o usuário receberá as críticas do crítico quanto aos componentes esquemáticos. Esta tarefa é, geralmente, realizada depois que o usuário escolhe os componentes que ele julga necessários para compor sua introdução:

- O usuário deverá focalizar em specifics.

- O usuário deverá clicar no ícone de crítica que aparece ao lado de um dos componentes.

- O usuário deverá clicar no Item de crítica exibido na Peer annotation.

\section{a.4. O usuário deve, baseado nas críticas, escolher uma das seguintes opções:}

(1) Focalizar em "Intro" e acrescentar, excluir componentes ou alterar a ordem deles; ou

(2) Pedir ao protótipo que encontre e recupere os casos armazenados que mais se assemelham à estrutura da introdução definida. Para isso o usuário deverá:

(2.1) clicar sobre o botão "Hum..." ? I e em seguida;

(2.2) clicar sobre o componente "paper" de Lego Workbench. 
(2.3) deve digitar "example" e clicar sobre o botão OK, na janela Peer Annotation que surgirá no espaço para o "subject".

a.5. Se a opção escolhida foi a (1) ou se a opção escolhida foi a (2) e as estruturas dos casos recuperados não se assemelham ao proposto, o usuário poderá fazer alterações na estrutura da introdução proposta. Neste caso deverá realizar as tarefas a.2, a.3 e a.4.

a.6. Se a opção escolhida foi o (2) e os casos satisfazem o usuário, então a partir dos links disponibilizados para a visualização de casos anotados, o usuário poderá visualizar exemplos de introduções de artigos.

Depois de realizar a tarefa global "1", atingindo-se a subtarefa "a.6", o usuário deverá realizar a tarefa global " 2 ", que se constitui das seguintes subtarefas:

b.1 Escolher o exemplo de introdução com a estrutura que mais se assemelha à estrutura definida.

b.2 Ativar um editor de texto.

b.3 Marcar e copia as partes do exemplo que the interessam.

b.4 Colar a parte da introdução que foi anteriormente marcad.

b.5 Repetir as tarefas "b.3" e "b.4" até que se consiga um rascunho da introduçã.

b.6 Salvar o rascunho editado.

III - Documentação de Auxílio ao Usuário: É fornecido ao usuário, antes de iniciar a sessão de testes, um conjunto de instruções que o direciona na forma de realização das tarefas, podendo também ser utilizada para consulta durante o teste. Esta documentação é mostrada no Apêndice C.

\subsection{Material de Suporte ao Avaliador}

Questionário: Este questionário foi usado pelo avaliador a fim de saber a impressão que o usuário teve da aplicação. Uma vez que o usuário ao terminar uma sessão de teste pode estar cansado de manipular informações usando a tela do computador, optou-se por aplicar o questionário em papel. Pelo mesmo motivo, o questionário consta de algumas poucas 
questões objetivas e subjetivas. Às questões subjetivas deve ser atribuído apenas um valor variando em uma escala de 1 a 5 . O Quadro 5.2 apresenta o questionário utilizado, o qual consta de sete questões em que as três primeiras são retiradas de (Lacerof \& Paternò, 1998). Tais questões devem ser respondidas pelos usuários ao final da sessão de teste.

QUADRO 5.2 - Questionário para Avaliação da Satisfação

1. Você teve problemas durante o teste? Se algum, quais?

2. Qual parte da interface da Ferramenta de Crítica foi a mais dificil (se alguma) ou a mais irritante? Porque?

3. Você usaria a Ferramenta de Crítica (uma versão melhorada) no futuro? Porque? Ou Porque não?

4. A leitura de caracteres na tela estava:

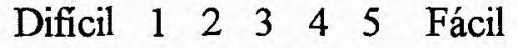

Porquê?

5. A velocidade do sistema é:

Lenta $1 \begin{array}{llllllll}1 & 2 & 3 & 4 & 5 & \text { Rápida }\end{array}$

6. Você se sentiu à vontade em usar o sistema?

Pouco $1 \quad 2 \quad 3 \quad 4 \quad 5$ Bastante

$\square \square \square \square \square$

7. No geral, você ficou satisfeito com o sistema?

Pouco $1 \quad 2 \quad 3 \quad 4 \quad 5$ Bastante

$\square \square \square \square \square$

\section{Critérios de Realização das Tarefas}

A camada de software desenvolvida para captura de logs de usuários é capaz de armazenar os eventos gerados pelo usuário, tal que é possível conhecê-los sem a presença fisica de um avaliador durante a sessão de usuário. Assim, como descrito na carta convite que foi enviada aos usuários, após o início do teste nenhuma pergunta foi respondida diretamente.

Esta opção apesar de não dar retroalimentação durante a sessão de teste foi escolhida visando ser o menos intrusivo possível, desta forma não interferindo na maneira com que o usuário interage com a aplicação. A sessão consta de no máximo duas horas de duração e as tarefas devem ser realizadas individualmente. 


\section{Medidas a Serem Tomadas}

As medidas a serem tomadas se referem às medidas que foram especificadas na instanciação dos objetivos na Seção 5.2.3. Dentre elas, se destacam:

- As tarefas realizadas e quantas vezes elas foram executadas.

- As tarefas que o usuário tentou realizar, mas falharam porque suas pré-condições não foram satisfeitas e quantas vezes cada tarefa falhou.

- As tarefas que o usuário nunca tentou executar.

- Os erros divididos em erros de pré-condição e outros.

- As tarefas padrões encontradas entre as tarefas realizadas.

\section{Forma de Preparação e Análise dos Resultados}

Como descrito no Capítulo 3, o método USINE é dividido em três fases: a fase de preparação, a fase de execução da ferramenta e finalmente a fase de elaboração dos resultados. Neste trabalho, com exceção do Modelo de Tarefas que foi feito usando o editor ConcurTaskTrees, todas essas etapas foram realizadas manualmente seguindo a abordagem do método em questão conforme descrito em (Lacerof \& Paternò, 1998).

A preparação corresponde ao desenvolvimento do Modelo de Tarefas da Ferramenta de Crítica, usando o editor de árvore de tarefa ConcurTaskTrees, e à associação entre eventos físicos, extraídos do arquivo de logs e as tarefas de interação básicas deste Modelo de Tarefas.

Durante a etapa de execução da ferramenta de avaliação a ferramenta primeiro elabora para cada tarefa a pré-condição relacionada (se alguma) a partir dos relacionamentos temporais definidos no Modelo de Tarefas e em seguida usa esta informação para elaborar os resultados.

A terceira fase, que corresponde à apresentação dos resultados, é descrita no item 8 a seguir.

\section{Apresentação dos Resultados}

Identificar erros na análise de resultados de testes de usuários indica uma lacuna entre o comportamento do usuário e o Modelo de Tarefas associado com a Ferramenta de Crítica. Uma das razões para essa lacuna pode ser: em alguns casos a interface do usuário impõe 
restrições ilógicas, por isso deve ser mudada de forma a suportar um Modelo de Tarefas mais flexível, mais próximo àquele do usuário. Neste caso mudanças devem ser introduzidas na interface. Por exemplo, usar rótulos mais explicativos.

Uma vez que o objetivo desta avaliação é fornecer informações de como melhorar a interface da Ferramenta de Crítica, é preciso que, para cada problema identificado na análise dos resultados, se prepare um curto relatório sobre este problema. Tal relatório é útil como sugestão de melhoria da interface e deve ser estruturado em quatro campos: o problema, a identificação, a motivação cognitiva do erro, a solução proposta. A motivação cognitiva do erro pode ser identificada analisando-se as possíveis etapas de uma interação de usuário de acordo com o modelo de Norman (1988), em particular:

- Intenção: o usuário pretendeu executar uma tarefa errada.

- Ação: a tarefa que o usuário pretendeu realizar era correta, mas as ações que a supọrtava eram erradas.

- Percepção: o usuário percebeu de forma errada as ações.

- Interpretação: o usuário interpretou mal a informação fornecida pela aplicação.

\subsubsection{A Realização da Avaliação}

Para a realização da avaliação da Ferramenta de Crítica, em todas etapas, 1,2 e 3 foram utilizados os conceitos envolvidos no método USINE para preparação, análise e apresentação dos resultados. Porém algumas adaptações foram feitas, tendo em vista as limitações encontradas em relação às ferramentas utilizadas pelo referido método, que são: o editor de árvore de tarefa - ConcurTaskTrees; uma ferramenta para captura dos logs de. testes dos usuários; e a ferramenta RemUSINE (Paternò, 1999), usada para preparação e análise de resultados.

A primeira está disponível no endereço (http://giove.cnuce.cnr.it/ctte.html) e é utilizada para a especificação do Modelo de Tarefas relacionado com a interface da Ferramenta de Crítica. As tarefas de alto nível são especificadas em níveis mais altos da árvore e as tarefas básicas (ou de interação) compõem o nível mais baixo da árvore (as folhas).

Quanto à captura da interação dos dados dos testes do usuário; foi especificada, como parte deste trabalho de mestrado, uma camada de software interna à Ferramenta de Crítica, 
que monitora a interação do usuário com a aplicação e gera um arquivo de logs. Esta camada captura as ações dos usuários, incluindo pressionar e movimentar o mouse, duplos-clicks e pressionar teclas. Uma linha típica do arquivo de logs inclui:

- O tipo de ação do usuário, tal como um click do mouse;

- O nome do Widget afetado, ou seja, o alvo da ação;

- O conteúdo do Widget afetado, tal como um texto;

- O tempo decorrido desde a ação anterior.

O desenvolvimento da camada de software foi realizado em um trabalho de iniciação científica do aluno Jander Sampaio, do ICMC/ USP.

A terceira ferramenta - a RemUSINE - foi concedida e enviada pelo autor Paterno. Porém, por ela ser ainda um protótipo e apresentar alguns problemas em sua execução, não foi possível sua utilização. Dessa forma, neste trabalho, a avaliação foi feita de forma manual, seguindo o enfoque da Ferramenta RemUSINE, que utiliza como entradas: um arquivo gerado por ConcurTaskTrees - contendo o Modelo de Tarefas da interface da Ferramenta de Crítica; outro arquivo contendo os logs dos usuários interagindo com a Ferramenta de Crítica gerado pela camada de software desenvolvida; um arquivo contendo uma Tabela de TarefaLogs (tabela em que as tarefas básicas do Modelo de Tarefas da Ferramenta de Crítica estão associadas com ações dos usuários) - que é gerado pela ferramenta RemUSINE, na fase referente à preparação da avaliação; um arquivo com a Tabela de Pré-Condições - que contém as tarefas relacionadas com suas respectivas pré-condições. A partir destas entradas, fez-se manualmente a análise dos resultados. O método de avaliação USINE é descrito no Capítulo 3, Seção 3.4. Os resultados da avaliação da Ferramenta de Crítica usando essa abordagem são mostrados no Capítulo 6. 


\section{Capítulo 6}

\section{Avaliação da Ferramenta de Crítica: Preparação, Análise e Apresentação dos Resultadós}

O objetivo da avaliação da Ferramenta de Crítica é identificar problemas de usabilidade e baseado neles propor e realizar melhorias na interface da aplicação.

A fim de conseguir uma boa avaliação da usabilidade fez-se um estudo detalhado da Ferramenta de Crítica de forma a entender seus objetivos, seu contexto de uso e regras de implementação. Em seguida, realizou-se a avaliação da Ferramenta de Crítica, aplicando-se o processo de avaliação descrito no Capítulo 5 . Este processo é constituído de um plano de avaliação, que se baseia no método USINE de avaliação de usabilidade desenvolvido por Lacerof \& Paternò (1998), e na abordagem de melhoria contínua da interface, proposta por Nielsen (2000), que utiliza três etapas/turnos de avaliação.

De acordo com o método USINE, a avaliação é realizada em três fases: a parte de preparação da avaliação; a parte de análise, que é a execução da ferramenta de avaliação RemUSINE (Paternò. 1999); e a parte de apresentação dos resultados. Porém, neste trabalho todas estas fases foram feitas de forma manual seguindo os algoritmos e passos realizados pela ferramenta, como explicado no Capítulo 5 .

As Seções 6.1, 6.2 e 6.3 descrevem, respectivamente, a primeira, segunda e terceira etapas da avaliação da Ferramenta de Crítica, cada uma delas constituída das fases de 
preparação, análise e apresentação dos resultados. A Seção 6.4 faz uma análise comparativa dos resultados obtidos das três etapas/turnos de aplicação do processo de avaliação de usabilidade na Ferramenta de Crítica do Ambiente AMADEUS.

\subsection{Etapa 1}

Esta fase foi o ponto de partida para a aplicação do processo de avaliação, em que o objetivo foi o de identificar o maior número possível de problemas de usabilidade. Ela consta das Seções 6.1.1, 6.1.2, 6.1.3 que mostram, respectivamente, a preparação da avaliação, a análise e apresentação dos resultạdos.

\subsubsection{Fase de Preparaçăo da Avaliação}

Esta fase é constituída da geração dos arquivos de $\operatorname{logs}$ a partir de testes de 5 usuários diferentes, do desenvolvimento do Modelo de Tarefas e da associação entre eventos físicos (extraídos dos arquivos de $l o g s$ ) e as tarefas básicas de interação do Modelo de Tarefas. Ésses dados são apresentados abaixo.

\section{a) Captura dos Arquivos de Logs}

Existem várias ferramentas disponíveis para coletar automaticamente os logs dos testes dos usuários (QC/Replay (http://www.centerline.com/productline/qcreplay/qcreplay.html), JovaStar (http://www.sun.com/forte/testingtools/javastar.html), dentre outras), porém por questões técnicas optou-se por desenvolver uma camada de software interna à aplicação para realizar esta tarefa. Os eventos considerados são: click de mouse (um click e duplo click), movimentos do mouse (dragover, e dragdrop), entrada de texto e toque de teclas. Os arquivos resultantes são do tipo texto (um dos arquivos de logis é mostrado no Apêndice A).

\section{b) Especificação do Modelo de Tarefas}

A especificação do Modelo de Tarefas foi feita a partir de um estudo da notação ConcưrTaskTrees (Paternò, 1999) e utilização do editor gráfico (http://giove.cnuce.cnr.it/ctte.html) para criar Árvore de Tarefas e especificar 
relacionamentos entre tarefas de acordo com suas sintaxe e semântica. As outras características do modelo podem ser melhor compreendidas consultando a notação apresentada no Capítulo 3, Seção 3.4. Por exemplo, os conceitos envolvendo relacionamento temporal entre as tarefas, conceitos de tarefas abstratas, tarefas de interação, tarefas do usuário e tarefas da aplicação.

A Árvore de Tarefas da Ferramenta de Critica foi feita de forma que cada tarefa básica de interação tenha uma ação correspondente na interface do usuário. O Modelo de Tarefas completo é apresentado na Figura 6.1. As Figuras 6.2, 6.3, 6.4, 6.5 e 6.6 representam a especificação das sub-árvores: PrepararSelecaoCompEsquem, SelecionarComponentes, Trocas, ExcluirComponentes e VisualizarCriticas, respectivamente

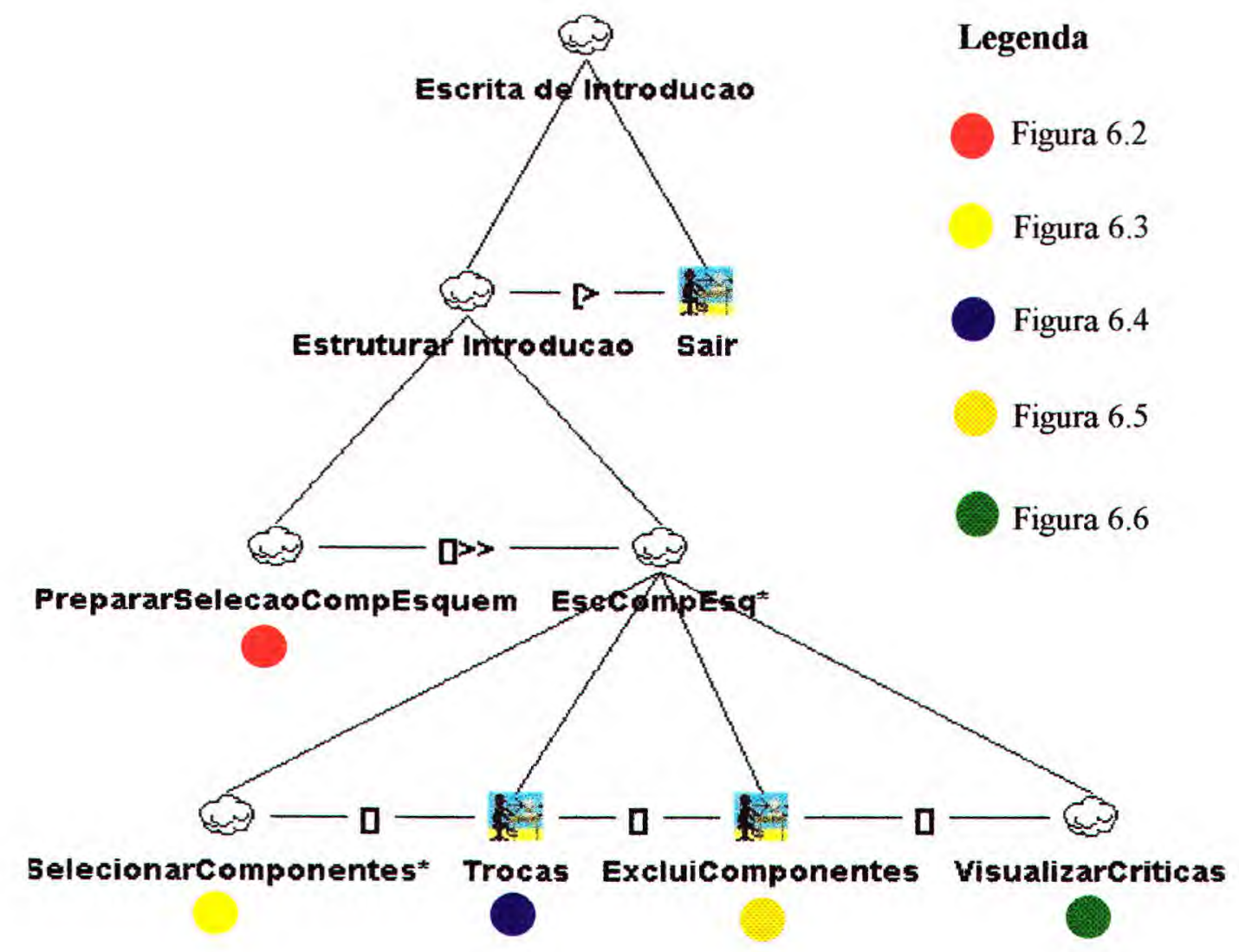

FIGURA 6.1 - Modelo de Tarefas da Interface da Ferramenta de Crítica 


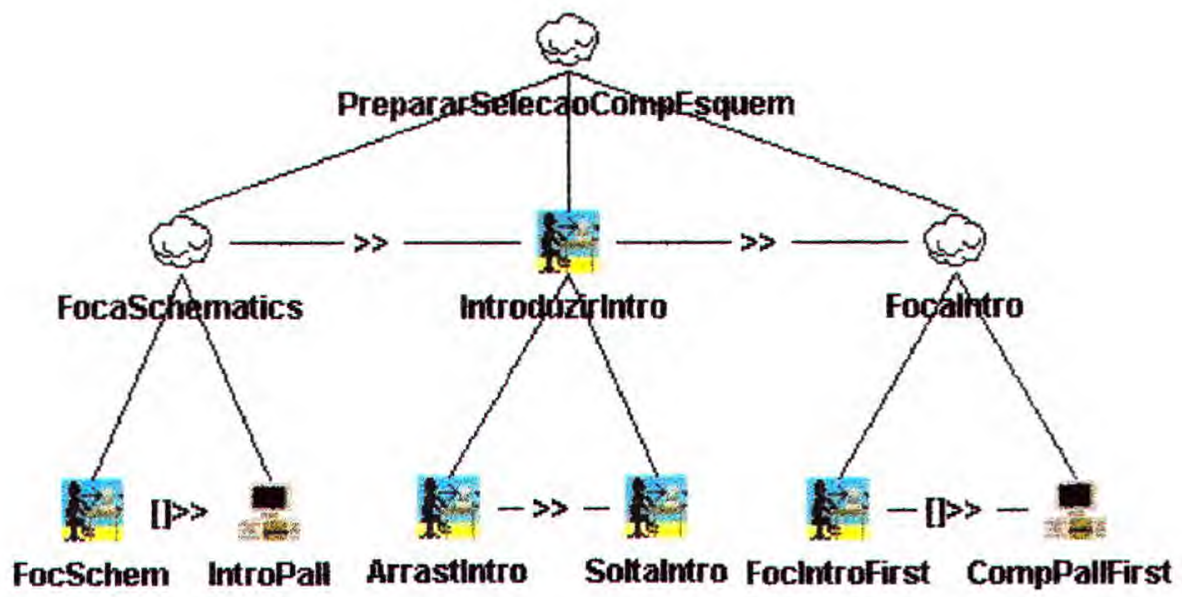

FIGURA 6.2 - Sub-Árvore PrepararSelecaoCompEsquem

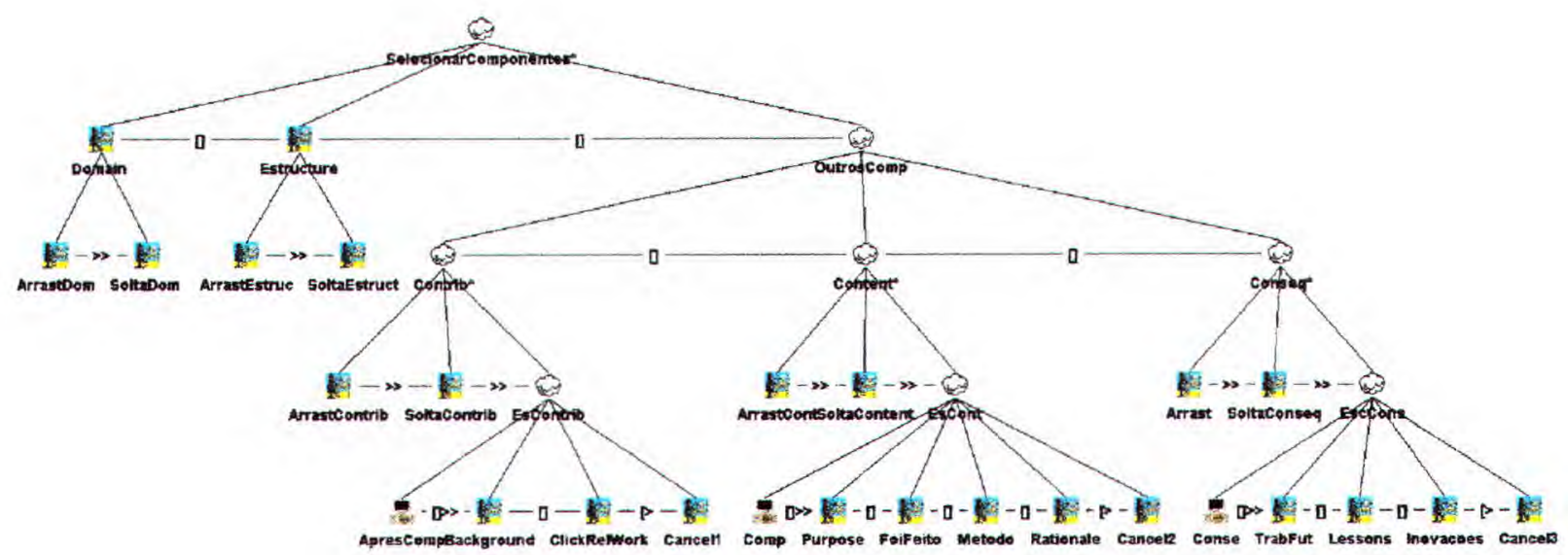

FIGURA 6.3 - Sub-Árvore SelecionarComponentes

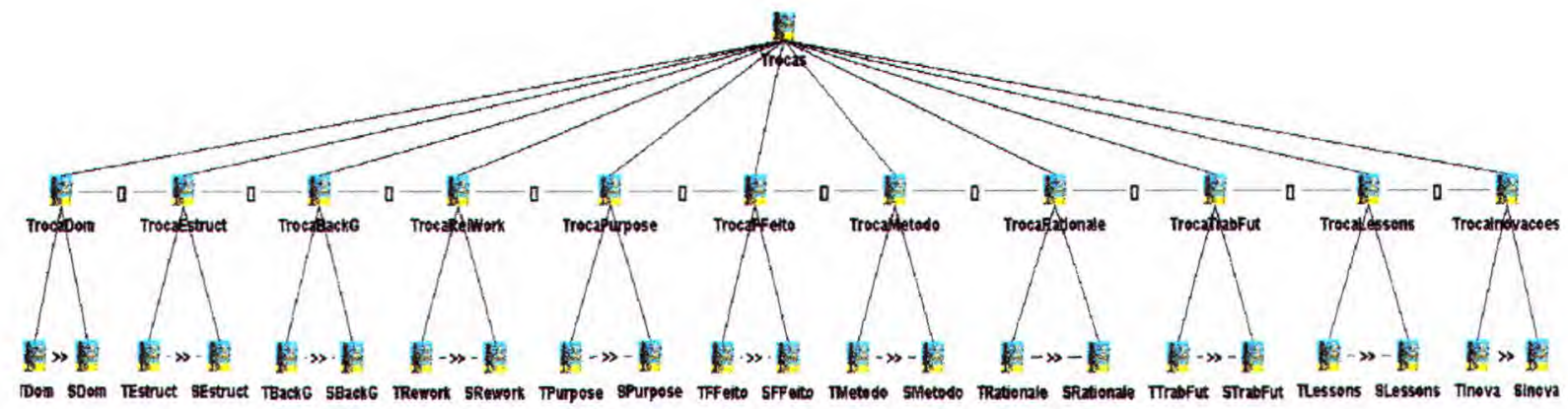

FIGURA 6.4 - Sub-Árvore Trocas 


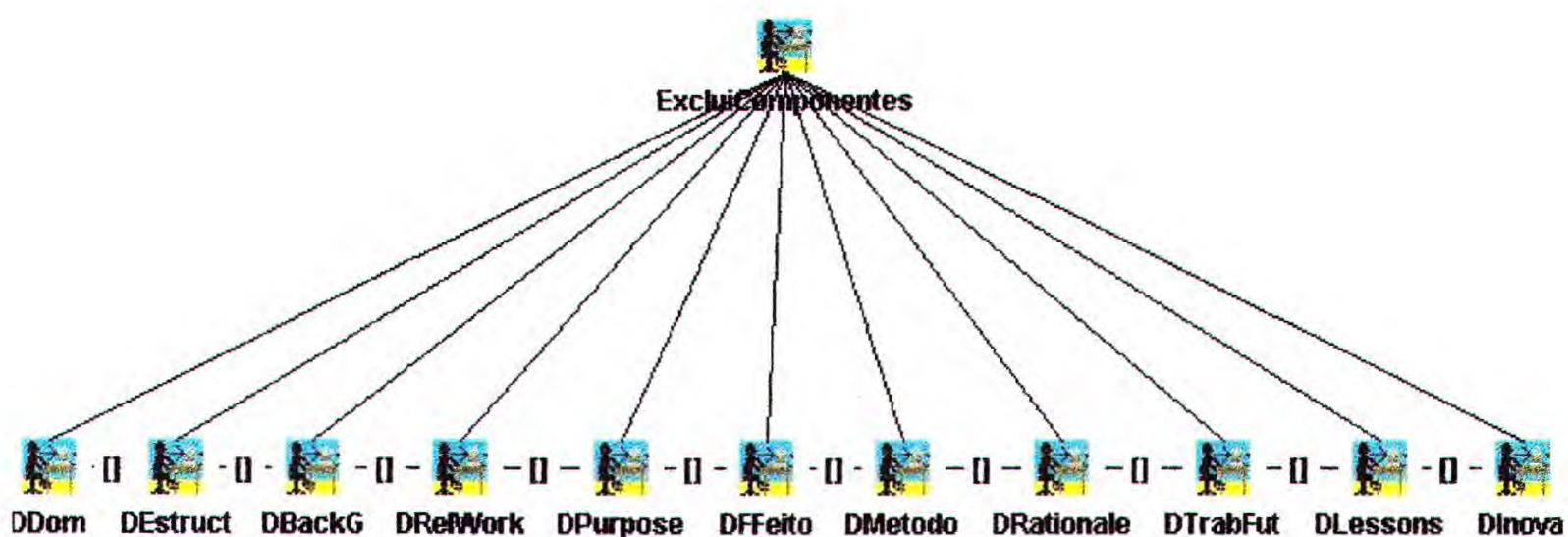

FIGURA 6.5 - Sub-Árvore ExcluirComponentes

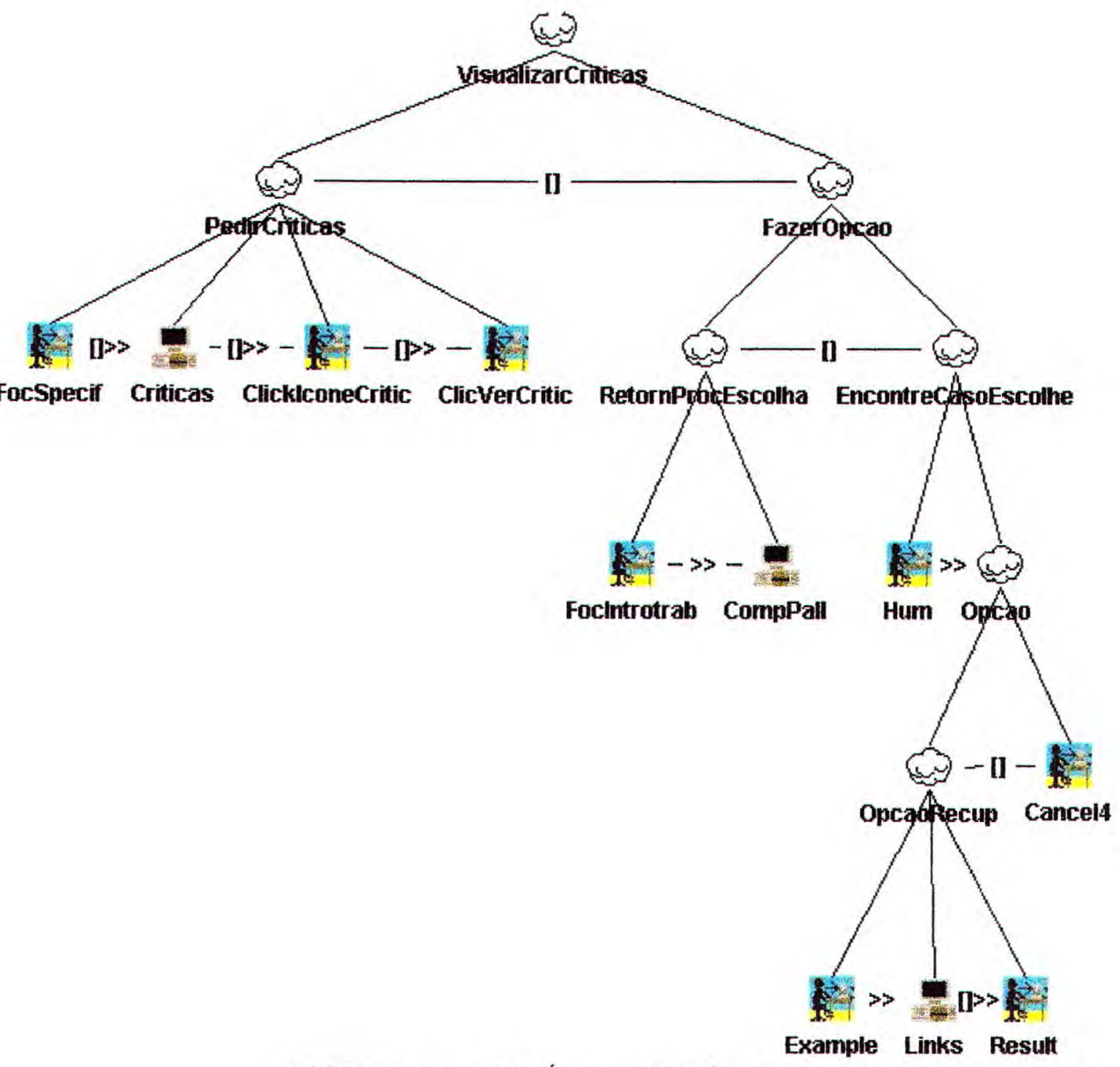

FIGURA 6.6 - Sub-Árvore VisualizarCriticas 


\section{c) Tabela de Tarefa-Log}

Assim como o Modelo de Tarefas, esta tabela é construída uma única vez para analisar os logs de todos os usuários testados nesta fase, pớr isso a complexidade de se aplicar o método é minimizada, mesmo quando aplicando-o manualmente.

A Tabela 6.1 mostra as tarefas básicas do Modelo de Tarefas da Ferramenta de Crítica, cada uma associada à respectiva ação que a executa. A primeira coluna da tabela contém as ações físicas do usuário/eventos, que sã́o extraídas do arquivo de logs. A segunda coluna contém as tarefas básicas correspondentes às ações que as executam.

As tarefảs básicas são auto-expliçativas: FocSchem significa focalizar em "Schematics"; ArrastDom. significa arrastar "Domain"; TDom significa arrastar "Domain" (início da ação de arraste) para trocá-lo de lugar na área de trabalho; SDom significa soltar "Domain" (fim da ação de arraste) para trocá-lo de lugar na área de trabalho.

Os eventos aparecem concatenados com o Widget. Por exemplo: ClickTrab_Schematics para focalizar o componente " "Schematics"; DragOvePalette_domain para arrastar o componente "Domain" da Palette; DragDropT_Trab_F_Palette_domain para soltar o componente "Domain" arrastado da Palette para a área de trabalho; ClickReplacePalette purpose para selecionar o componente " Purpose" da janela dinâmica; DragOveTrab_domain para iniciar a ação trocar o componente "Domain" de posição na área de trabalho; DragDropT_Trab_F_Trab_domain para concluị a ação trocar o componente "Domain" de posição na área de trabalho; DeleteltemTrab_purpose para excluir o componente "Purpose" da área de trabalho; ActivatePeerAnnotation para ativar a Janela Peer Annotation quando'se clica no item de crítica apresentado pelo crítico; ClickCrítica para ler as críticas, ClickTrab_paper para ativar a janela relacionada à pedir casos semelhantes; TextWrite_example para a entrada de texto (example) na janela relacionada à pedir casos semelhantes; ClickLink para ver um caso semelhante; ClickCancelAnnotationEditor para cancelar uma tentativa de pedido de casos semelhantes e CloseWorkbenck para sair da aplicação.

TABELA 6.1- Tabela de Tarefa-Log

\begin{tabular}{|c|c|}
\hline 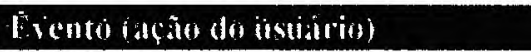 & Tarefa Basica de Interaçăn \\
\hline ClickTrab_schematics 0 & FocSchem \\
\hline DragOverPalette intro 0 & ArrastIntro \\
\hline DragDropT Trab F Palette intro 0 & Soltalntro \\
\hline ClickTrab intro First 0 & FocIntroFirst \\
\hline DragOverPalette_domain 0 & ArrastDom \\
\hline
\end{tabular}


TABELA 6.1- Tabela de Torefa-Log

\begin{tabular}{|c|c|}
\hline DragDropT_Trab_F Palette domain 0 & SoltaDom \\
\hline DragOverPalette structure 0 & ArrastEstruc \\
\hline DragDropT Trab F Palette_structure 0 & SoltaEstruct \\
\hline DragOverPalette contribution(s) 0 & ArrastContrib \\
\hline DragDropT Trab F Palette contribution(s) 0 & SoltaContrib \\
\hline ClickReplacePalette background 0 & Background \\
\hline ClickReplacePalette related work(s) 0 & ClickRelWork \\
\hline ClickCancelReplacePalette contribution(s) 0 & Cancell \\
\hline DragOverPalette contents 0 & ArrastCont \\
\hline DragDropT Trab F Palette contents () & SoltaContent \\
\hline ClickReplacePalette purpose 0 & Purpose \\
\hline ClickReplacePalette what's been done 0 & FoiFeito \\
\hline ClickReplacePalette_methodology applied 0 & Metodo \\
\hline ClickReplacePalette rationale 0 & Rationale \\
\hline ClickCancelReplacePalette_contents 0 & Cancel2 \\
\hline DragOverPalette_consequence(s)0 & Arrast \\
\hline DragDropT Trab F Palette consequence(s) 0 & SoltaConseq \\
\hline ClickReplacePalette future work(s) 0 & TrabFut \\
\hline ClickReplacePalette lesson(s) learned 0 & Lessons \\
\hline ClickReplacePalette innovation(s) 0 & Inovacoes \\
\hline ClickCancelReplacePalette consequence(s) 0 & Cancel3 \\
\hline DragOverTrab_domain 0 & TDom \\
\hline DragDropT Trab_F Trab domain 0 & SDom \\
\hline DragOverTrab structure 0 & TEstruct \\
\hline DragDropT_Trab_F_Trab_structure 0 & SEstruct \\
\hline DragOverTrab background 0 & TBackG \\
\hline DragDropT_Trab_F_Trab_background 0 & SBackG \\
\hline DragOverTrab related work(s) 0 & TRework \\
\hline DragDropT Trab F Trab related work(s) 0 & SRework \\
\hline DragOverTrab purpose () & \begin{tabular}{|l|} 
TPurpose \\
\end{tabular} \\
\hline DragDroṕT_Trab_F_Trab_purpose 0 & SPurpose \\
\hline DragOverTrab what's been done 0 & TFFeito \\
\hline DragDropT Trab F Trab what's been done 0 & SFFeito \\
\hline DragOverTrab methodology applied 0 & TMetodo \\
\hline DragDropT_Trab F_Trab_methodology applied 0 & SMetodo \\
\hline DragOverTrab rationale(0) & TRationale \\
\hline DragDropT Trab F Trab rationale0 & SRationale \\
\hline DragOverTrab future work(s) 0 & TtrabFut \\
\hline DragDiopT Trab F Trab future work(s) 0 & StrabFut \\
\hline DragOverTrab lesson(s) learned (0) & Tlessons \\
\hline DragDropT_Trab F Trab lesson(s) learned () & Slessons \\
\hline DragOverTrab Innovation(s) 0 & Tinova \\
\hline DragDropT Trab F Trab Innovation(s) 0 & Sinova \\
\hline DeleteltemTrab domain 0 & Ddom \\
\hline DeleteltemTrab structure) & Destruct \\
\hline DeleteItemTrab_background 0 & DbackG \\
\hline DeleteItemTrab related work(s) 0 & DRelwork \\
\hline DeleteItemTrab purpose() & Dpurpose \\
\hline DeleteItemTrab_what's been done $(0$ & DFFeito \\
\hline DeleteItemTrab methodology applied0 & Dmetodo \\
\hline DeleteItemTrab_rationale 0 & DRationale \\
\hline
\end{tabular}


TABELA 6.1 - Tabela de Tarefa-Log

\begin{tabular}{|l|l|}
\hline DeleteltemTrab future work(s) 0 & DtrabFut \\
\hline DeleteltemTrab lesson(s) learned 0 & DLessons \\
\hline DeleteltemTrab innovation(s)0 & Dinova \\
\hline ClickTrab_specifics 0 & FocSpecif \\
\hline ActivatePeerAnnotation 0 & ClickIconeCritic \\
\hline ClickCritica 0 & ClicVerCritic \\
\hline ClicTrab intro 0 & FocIntrotrab \\
\hline ClicTrab paper O & Hum \\
\hline TextWrite example 0 & Example \\
\hline ClickLink O & Result \\
\hline ClickCancelAnnotationEditor O & Cancel4 \\
\hline CloseWorkbench 0 & Sair \\
\hline
\end{tabular}

\subsubsection{Fase de Análise de Resultados}

Durante esta fase foram tomados a Tabela de Pré-Condições, os dados dos questionários dos usuários e todas as entradas da fase de preparação (os logs dos usuários, o Modelơ de Tarefas e a Tabela de Tarefa-Log) para se realizar a análise.

A partir dos relacionamentos temporais definidos no Modelo de Tarefas, foi elaborada para cada tarefa sua pré-condição e criada a Tabela de Pré-Condições. O método para encontrar as pré-condições e criar a tabela delas faz uma busca transversal "pré-ordem" na Árvore de Tarefas (Paternò, 1999). A Tabela 6.2 mostra a Tabela de Pré-Condições da Ferramenta de Crítica, em que a primeira coluna contém o nome da tarefa e a segunda coluna representa suas pré-condições (se mais que uma), considerando que cada pré-condição é associada com um valor booleano "true" ou "false", indicando respectivamente se a précondição foi ou não satisfeita. Quando a tabela é criada os valores são fixados em "false".

TABELA 6.2 - Tabela de Pré-Condições do Modelo de Tarefas da Ferramenta de Critica

\begin{tabular}{|c|c|c|}
\hline I" & Tarcia & Pre-Conilicies \\
\hline 1 & $\begin{array}{l}\text { Escrita de Introducao } \\
\text { Escrita de Introducao }\end{array}$ & $\begin{array}{c}\text { | Estruturar Introducao <false }> \\
\text { | Sair <false }>\end{array}$ \\
\hline 2 & Estruturar Introducao & EscCompEsq <false $>$ \\
\hline 3 & PrepararSelecaoCompEsq & Focalntro <false $>$ \\
\hline 4 & FocaSchematics & IntroPall $<$ false $>$ \\
\hline 5 & FocSchem & 10 \\
\hline 6 & IntroPall & FocSchem <false $>$ \\
\hline 7 & IntroduzirIntro & $\mid$ Soltalntro | FocaSchematics < false $>$ \\
\hline 8 & Arrastintro & | FocaSchematics <false > \\
\hline 9 & SoltaIntro & ArrastIntro <false $>$ \\
\hline 10 & FocaIntro & IntroduzirIntro | CompPall \\
\hline
\end{tabular}


TABELA 6.2 - Tabela de Pré-Condições do Modelo de Tarefas da Ferramenta de Critica

\begin{tabular}{|c|c|c|}
\hline 11 & FocIntroFirst & IntroduzirIntro $<$ false $>$ \\
\hline 12 & CompPallFirst & FocIntroFirst $<$ false $>$ \\
\hline 13 & $\begin{array}{l}\text { EscCompEsq } \\
\text { EscCompEsq } \\
\text { EscCompEsq } \\
\text { EscCompEsq }\end{array}$ & $\begin{array}{c}\text { | PrepararSelecaoCompEsq }<\text { false }>\& \\
\text { | SelecionarComponentes }<\text { false }> \\
\text { | Trocas }<\text { false }> \\
\text { | VisualizarCriticas }<\text { false }>\end{array}$ \\
\hline 14 & $\begin{array}{l}\text { SlecionarComponentes } \\
\text { SlecionarComponentes } \\
\text { SlecionarComponentes } \\
\text { SlecionarComponentes }\end{array}$ & $\begin{array}{c}\text { | PrepararSelecaoCompEsq }<\text { false }>\text { \& } \\
\text { | Domain }<\text { false }> \\
\text { | Structure }<\text { false }> \\
\mid \text { OutrosComp }<\text { false }>\end{array}$ \\
\hline 15 & Domain & | SoltaDom < false $>$ \\
\hline 16 & ArrastDom & 10 \\
\hline 17 & SoltaDom & ArrastDom <false $>$ \\
\hline 18 & Structure & SoltaEstruct $<$ false $>$ \\
\hline 19 & ArrastEstruc & 10 \\
\hline 20 & SoltaEstruct & ArrastEstruc $<$ false $>$ \\
\hline 21 & $\begin{array}{l}\text { OutrosComp } \\
\text { OutrosComp } \\
\text { OutrosComp }\end{array}$ & $\begin{array}{l}\mid \text { Contrib <false }> \\
\mid \text { Content }<\text { false }> \\
\mid \text { Conseq }<\text { false }>\end{array}$ \\
\hline 22 & Contrib & EsContrib <false > \\
\hline 23 & ArrastContrib & 10 \\
\hline 24 & SoltaContrib & ArrastContrib $<$ false $>$ \\
\hline 25 & $\begin{array}{l}\text { EsContrib } \\
\text { EsContrib } \\
\text { EsContrib } \\
\text { EsContrib }\end{array}$ & $\begin{array}{c}\text { | SoltaContrib }<\text { false }>\text { \& } \\
\text { | Background }<\text { false }> \\
\text { | ClickRelWork }<\text { false }> \\
\mid \text { Cancell }<\text { false }>\end{array}$ \\
\hline 26 & ApresComp & | SoltaContrib <false $>$ \\
\hline 27 & Background & $\mid$ ApresComp $<$ false $>$ \\
\hline 28 & ClickRelWork & ApresComp <false $>$ \\
\hline 29 & Cancel1 & ApresComp <false $>$ \\
\hline 30 & Content & EsCont $<$ false $>$ \\
\hline 31 & ArrastCont & 10 \\
\hline 32 & SoltaContent & ArrastCont <false $>$ \\
\hline 33 & $\begin{array}{l}\text { EsCont } \\
\text { EsCont } \\
\text { EsCont } \\
\text { EsCont } \\
\text { EsCont } \\
\text { EsCont } \\
\end{array}$ & $\begin{array}{c}\text { |SoltaContent }<\text { false }>\& \\
\text { | Purpose }<\text { false }> \\
\text { | FoiFeito <false } \\
\text { | Metodo < false }> \\
\text { | Rationale <false }> \\
\text { | Canel2 < false }\end{array}$ \\
\hline 34 & Comp & $\mid$ SoltaContent $<$ false $>$ \\
\hline 35 & Purpose & Comp <false $>$ \\
\hline 36 & FoiFeito & Comp <false $>$ \\
\hline 37 & Metodo & Comp <false $>$ \\
\hline 38 & Rationale & Comp <false $>$ \\
\hline 39 & Cancel2 & Comp $<$ false $>$ \\
\hline 40 & Conseg & EscCons <false $>$ \\
\hline 41 & Arrast & 10 \\
\hline 42 & SoltaConseq & | Arrast $<$ false $>$ \\
\hline$\overline{43}$ & $\begin{array}{l}\text { EscCons } \\
\text { EscCons } \\
\text { EscCons } \\
\text { EscCons } \\
\text { EscCons }\end{array}$ & $\begin{array}{c}\text { | SoltaConseq }<\text { false }>\& \\
\mid \text { TrabFut }<\text { false }> \\
\mid \text { Lessons }<\text { false }> \\
\text { | Inovacoes }<\text { false }> \\
\mid \text { Cancel3 }<\text { false }> \\
\end{array}$ \\
\hline 44 & Conse & SoltaConseg <false $>$ \\
\hline 45 & TrabFut & $\mid$ Conse $<$ false $>$ \\
\hline
\end{tabular}


TABELA 6.2 - Tabela de Pré-Condições do Modelo de Tarefas da Ferramenta de Critica

\begin{tabular}{|c|c|c|}
\hline 46 & $\overline{\text { Lessons }}$ & Conse $<$ false $>$ \\
\hline 47 & Inovações & Conse $<$ false $>$ \\
\hline 48 & Cancel3 & Conse $<$ false $>$ \\
\hline 49 & $\begin{array}{l}\text { Trocas } \\
\text { Trocas } \\
\text { Trocas } \\
\text { Trocas } \\
\text { Trocas } \\
\text { Trocas } \\
\text { Trocas } \\
\text { Trocas } \\
\text { Trocas } \\
\text { Trocas } \\
\text { Trocas } \\
\text { Trocas }\end{array}$ & $\begin{array}{c}\text { | PrepararSelecaoCompEsq }<\text { false }>\text { \& } \\
\text { | TrocaDom }<\text { false }> \\
\text { | TrocaEstruct }<\text { false } \\
\text { | TrocaBackG }<\text { false } \\
\text { | TrocaRelWork }<\text { false }> \\
\text { | TrocaPurpose }<\text { false } \\
\text { | TrocaFFeito }<\text { false> } \\
\text { | TrocaMetodo }<\text { false }> \\
\text { | TrocaRationale }<\text { false } \\
\text { | TrocaTrabFut }<\text { false }> \\
\text { | TrocaLessons }<\text { false }> \\
\text { | TrocaInovacoes }<\text { false }\end{array}$ \\
\hline 50 & TrocaDom & |SDom $<$ false $>$ \\
\hline 51 & TDom & 10 \\
\hline 52 & SDom & |TDom <false $>$ \\
\hline 53 & TrocaEstruct & Sestruct <false $>$ \\
\hline $54^{\circ}$ & TEstruct & 10 \\
\hline 55 & SEstruct & TEstruct <false > \\
\hline 56 & TrocaBackG & SBackG < false $>$ \\
\hline 57 & TBackG & 10 \\
\hline 58 & SBackG & TBackG $<$ false $>$ \\
\hline 59 & TrocaRelWork & SReWork $<$ false $>$ \\
\hline 60 & TReWork & 10 \\
\hline 61 & SReWork & TReWork $<$ false $>$ \\
\hline 62 & TrocaPurpose & SPurpose <false $>$ \\
\hline 63 & TPurpose & 10 \\
\hline 64 & SPurpose & TPurpose $<$ false $>$ \\
\hline 65 & TrocaFFeito & SFFeito <false $>$ \\
\hline 66 & TFFeito & 10 \\
\hline 67 & SFFeito & TFFeito <false $>$ \\
\hline 68 & TrocaMetodo & SMetodo <false $>$ \\
\hline 69 & TMetodo & 10 \\
\hline 70 & SMetodo & TMetodo <false $>$ \\
\hline 71 & TrocaRationale & SRationale $<$ false $>$ \\
\hline 72 & TRationale & 10 \\
\hline 73 & SRationale & TRationale <false > \\
\hline 74 & TrocaTrabFut & STrabFut $<$ false $>$ \\
\hline 75 & TTrabFut & 10 \\
\hline 76 & STrabFut & TTrabFut $<$ false $>$ \\
\hline 77 & TrocaLessons & SLessons $<$ false $>$ \\
\hline 78 & TLessons & 10 \\
\hline 79 & SLessons & TLessons $<$ false $>$ \\
\hline 80 & Trocalnovações & ISInova <false $>$ \\
\hline 81 & TInova & 0 \\
\hline 82 & SInova & | TInova <false $>$ \\
\hline
\end{tabular}


TABELA 6.2 - Tabela de Pré-Condições do Modelo de Tarefas da Ferramenta de Critica

\begin{tabular}{|c|c|c|}
\hline 83 & ExcluirComponentes & $\begin{array}{c}\text { | PrepararSelecaoCompEsq }<\text { false }>\& \\
\text { | Ddom }<\text { false } \\
\text { | Destruct }<\text { false }> \\
\text { | DBackG }<\text { false }> \\
\text { | DRelWork }<\text { false }> \\
\text { | DPurpose }<\text { false }> \\
\text { | DFFeito }<\text { false }> \\
\text { | DMetodo }<\text { false }> \\
\text { | DRationale }<\text { false }> \\
\text { | DTrabFut }<\text { false }> \\
\text { | DLessons }<\text { false }> \\
\text { | DInova }<\text { false }>\end{array}$ \\
\hline 84 & Ddom & 0 \\
\hline 85 & Destruct & 0 \\
\hline 86 & DBackG & 0 \\
\hline 87 & DRelWork & 0 \\
\hline 88 & DPurpose & 0 \\
\hline 89 & DFFeito & 0 \\
\hline 90 & DMetodo & 0 \\
\hline 91 & DRationale & 0 \\
\hline 92 & DTrabFut & 0 \\
\hline 93 & DLessons & $\mathbf{0}$ \\
\hline 94 & DInova & 0 \\
\hline 95 & $\begin{array}{l}\text { VisualizarCriticas } \\
\text { VisualizarCriticas } \\
\text { VisualizarCriticas }\end{array}$ & $\begin{array}{c}\mid \text { PrepararSelecaoCompEsquem }<\text { false }>(\&) \\
\mid \text { PedirCriticas < false }> \\
\mid \text { FazerOpcao }<\text { false }>\end{array}$ \\
\hline 96 & PedirCriticas & ClicVerCritic < false $>$ \\
\hline 97 & FocSpecif & 10 \\
\hline 98 & Criticas & FocSpecif $<$ false $>$ \\
\hline 99 & ClickIconeCritic & |Criticas < false $>$ \\
\hline 100 & ClicVerCritic & | ClickIconeCritic <false $>$ \\
\hline 101 & $\begin{array}{l}\text { FazerOpcao } \\
\text { FazerOpcao }\end{array}$ & $\begin{array}{l}\text { | RetornProcEscolha <false> } \\
\text { | EncontreCasoEscolhe <false }>\end{array}$ \\
\hline 102 & RetornProcEscolha & CompPall < false $>$ \\
\hline 103 & FocIntroTrab & 10 \\
\hline 104 & CompPall & | FocIntrotrab <false $>$ \\
\hline 105 & EncontreCasoEscolhe & | Opcao <false > \\
\hline 106 & Hum & 0 \\
\hline 107 & $\begin{array}{l}\text { Opcao } \\
\text { Opcao } \\
\text { Opcao }\end{array}$ & $\begin{array}{c}\mid \text { Hum < false }>\& \\
\mid \text { OpcaoRecup }<\text { false }> \\
\mid \text { Cancel4 < false }>\end{array}$ \\
\hline 108 & $\begin{array}{l}\text { OpcaoRecup } \\
\text { OpcaoRecup }\end{array}$ & $\begin{array}{l}\mid \text { Hum }<\text { false }>\& \\
\mid \text { Result }<\text { false }>\end{array}$ \\
\hline 109 & Example & Hum <false $>$ \\
\hline 110 & Links & Example $<$ false $>$ \\
\hline 111 & Result & | Links < false > \\
\hline 112 & Cancel4 & Hum $<$ false $>$ \\
\hline 113 & Sair & 10 \\
\hline
\end{tabular}

$\mathrm{Na}$ fase de avaliação (ou análise dos resultados), para cada ação do arquivo de logs verifica-se se existe uma tarefa básica correspondente na Tabela de Tarefa-Log. Se a tarefa não existe na tabela, então o usuário executou um erro, por exemplo, um click em uma 
imagem pensando que era um botão. Se a tarefa existe, então verifica-se na Tabela de PréCondições se a tarefa considerada tem pré-condições (tarefas que precisam ser executadas antes que esta tarefa). Caso existam pré-condições verifica se elas foram satisfeitas: se as précondições para a tarefa considerada estão com o valor booleano fixado em "true", então a tarefa é executada com sucesso, senão ocorreu um erro de pré-condição. Se a tarefa é realizada corretamente e ela é pré-condição para outra tarefa, muda-se seu valor na Tabela de Pré-Condições para "true". Parte de uma análise derivada dos logs de um usuário é relatada no Apêndice $\mathrm{A}$.

Nessa fase também foram analisados os dados obtidos dos questionários respondidos pelos usuários após as sessões de teste com a aplicação. Esses dados foram úteis para avaliar a aplicação quanto ao critério "Satisfação", além de servir como um veículo de sugestões de melhoria para a Ferramenta de Crítica. O Quadro 6.1 apresenta o resumo da análise dos dados dos questionários aplicados aos usuários após as sessões de teste.

\section{QUADRO 6.1 - Resumo da Análise dos Dados Obtidos dos Questionários da Primeira Fase}

\begin{tabular}{|c|c|}
\hline Questrics & Dadas ahtidus \\
\hline $\begin{array}{l}\text { Você teve problemas durante o } \\
\text { teste? Se algum, quais? }\end{array}$ & $\begin{array}{l}\text { - A maioria dos usuários teve problemas na fase inicial da ferramenta, } \\
\text { principalmente na fase de preparação do ambiente para escolher os } \\
\text { componentes esquemáticos, mais especificamente em inserir "Intro" na } \\
\text { área de trabalho dentro de "Schematics". } \\
\text { - A maioria dos usuários teve problemas em enxergar que as críticas } \\
\text { antigas não eram apagadas da Janela "Peer Annotation" e com isto } \\
\text { achavam que as criticas apresentadas eram inconsistentes. } \\
\text { - Houve problemas relacionados à tarefa de excluir componentes. } \\
\text { A maioria dos usuários teve problemas em identificar como ler as } \\
\text { críticas. }\end{array}$ \\
\hline $\begin{array}{l}\text { Você usaria a Ferramenta de } \\
\text { Crítica (uma versão melhorada) } \\
\text { no futuro? Porque? Ou Porque } \\
\text { não? }\end{array}$ & $\begin{array}{l}\text { Todos os usuários disseram que usaria a ferramenta em uma versão } \\
\text { melhorada no futuro porque: } \\
\text { A ferramenta dá uma visão geral antes que se tenha o produto final } \\
\text { (introdução do artigo), orientando a organização e disposição das idéias. } \\
\text { É bom ver como os outros fizeram suas introduções e se basear nos } \\
\text { casos apresentados. } \\
\text { Auxilia muito na parte de estruturação da introdução, visto que esta é } \\
\text { uma das maiores dificuldades no processo de escrita de introduções. }\end{array}$ \\
\hline $\begin{array}{l}\text { Qual parte da interface da } \\
\text { Ferramenta de Crítica foi a mais } \\
\text { dificil (se alguma) ou a mais } \\
\text { irritante? Porque? }\end{array}$ & $\begin{array}{l}\text { As partes mais irritantes foram: } \\
\text { - Preparação do ambiente de seleção dos componentes } \\
\text { - Mudança voluntária e aleatória dos componentes não alterou a lista de } \\
\text { críticas fornecidas na "Peer Annotation". } \\
\text { O fato de não ter um botão ou um meio mais claro que informasse sobre } \\
\text { como ler as críticas. }\end{array}$ \\
\hline $\begin{array}{l}\text { A leitura de caracteres na tela } \\
\text { estava: } \\
\text { Dificil } 12345 \text { Fácil } \\
\text { Porquê? }\end{array}$ & $\begin{array}{l}\text { Todos os usuários assinalaram a opção correspondente ao valor " } 5 \text { ", o que } \\
\text { significa que a leitura dos caractetes na tela estava fácil. }\end{array}$ \\
\hline $\begin{array}{l}\text { A velocidade do sistema é: } \\
\text { Lenta } 12345 \text { Rápida }\end{array}$ & inalaram a opça correspondente ao valor " 5 ", o que \\
\hline
\end{tabular}


QUADRO 6.1 - Resumo da Análise dos Dados Obtidos dos Questionários da Primeira Fase

\begin{tabular}{|l|l|}
\hline $\begin{array}{l}\text { Você se sentiu à vontade em } \\
\text { usar o sistema? } \\
\text { Pouco } 12345 \text { Bastante }\end{array}$ & $\begin{array}{l}\text { A maioria dos usuários (quatro usuários) assinalou a opção " } 5 \text { ", significando } \\
\text { que se sentiram bastante à vontade em usar o sistema. Um dos usuários } \\
\text { assinalou a opcão 4, que corresponde a dizer que se sentiu um tanto quanto à } \\
\text { vontade em usar o sistema. }\end{array}$ \\
\hline $\begin{array}{l}\text { No geral, você ficou satisfeito } \\
\text { com o sistema? }\end{array}$ & $\begin{array}{l}\text { A maioria dos usuários (três usuários) assinalou a opção " } 5 \text { ", significando } \\
\text { que ficaram bastante satisfeitos com o sistema. Dois dos usuários } \\
\text { assinalaram a opção 4, que corresponde a dizer que ficou um tanto quanto } \\
\text { satisfeito com o sistema. }\end{array}$ \\
\hline
\end{tabular}

O Quadro 6.2 apresenta os dados obtidos como resposta à análise completa realizada nesta fase. Para a representação destes dados foi feita uma média dos dados obtidos da análise das cinco sessões de teste de usuário com a ferramenta.

\section{QUADRO 6.2 - Dados Resultantes da Primeira Etapa de Avaliação da Ferramenta de Crítica}

\begin{tabular}{|c|c|}
\hline Item counsillcrardn & Dados abtidos \\
\hline $\begin{array}{l}\text { Em média, qual o tempo total de } \\
\text { teste? }\end{array}$ & $\begin{array}{l}\text { Os usuários levaram em média 1:45 (uma hora e quarenta e cinco minutos) } \\
\text { para realizar o teste. }\end{array}$ \\
\hline $\begin{array}{l}\text { Em média, qual o número de } \\
\text { tarefas completadas e quais } \\
\text { tarefas foram completadas? }\end{array}$ & $\begin{array}{l}\text { Todas as tarefas descritas no Capítulo } 5 \text {, Seção } 5.2 .2 .3 \text { föram realizadas. } \\
\text { Isto soma um total de } 12 \text { tarefas. }\end{array}$ \\
\hline $\begin{array}{l}\text { Em média, quantas e quais } \\
\text { tarefas foram realizadas, porém } \\
\text { com falhas? }\end{array}$ & $\begin{array}{l}\text { As duas tarefas seguintes foram realizadas com falhas: } \\
\text { - A tarefa "Preparar o processo de seleção dos componentes } \\
\text { esquemáticos", mais especificamente a subtarefa "Introduzir Intro em } \\
\text { Schematics". } \\
\text { A tarefa "Visualizar Criticas"; mais especificamente as subtarefas } \\
\text { "Focalizar Specifics" e "Ler Críticas". } \\
\text { - A tarefa "Visualizar exemplos de Introducooes de Artigos". }\end{array}$ \\
\hline $\begin{array}{l}\text { Em média, quais as tarefas que } \\
\text { os usuários não foram capazes de } \\
\text { executar? }\end{array}$ & 0 (zero tarefas). \\
\hline $\begin{array}{l}\text { Em média, quanto tempo cada } \\
\text { tarefa levou para completar (o } \\
\text { tempo de realização das tarefas } \\
\text { abstratas é calculado somando-se } \\
\text { o tempo das tarefas filhas)? }\end{array}$ & $\begin{array}{l}\text { Preparar o Processo de Seleção dos Componentes Esquemáticos: } 3: 95 \mathrm{~min} \\
\text { Definir os Componentes Esquemáticos: } 6: 97 \mathrm{~min} \\
\text { Pedi e Visualiza Críticas: } 2: 29 \mathrm{~min} \\
\text { Pedir Casos Semelhantes: } 0: 62 \mathrm{~min} \\
\text { Reestruturar a Introdução: } 3: 44 \mathrm{~min} \\
\text { Visualizar Casos Semelhantés: } 18.73 \mathrm{~min} \\
\end{array}$ \\
\hline $\begin{array}{l}\text { Em média, qual o número de } \\
\text { erros cometidos (classificados } \\
\text { por tipo de erro).e quais são os } \\
\text { erros (classificados por tipo de } \\
\text { erro)? }\end{array}$ & $\begin{array}{l}\text { Foi cometida uma média de } 2 \text { erros de pré-condição; que estão relacionados } \\
\text { às tarefas básicas de interação do Modelo de Tarefas "ClickIconeCritic" e } \\
\text { "ClicVerCritic". } \\
\text { Foram cometidos, em média } 12 \text { outros erros, que são: } \\
\text { - DblClickPalette_intro0 ( } 5 \text { vezes); } \\
\text { - DblClickTrab_Intro 0; } \\
\text { - DblClickPalette_consequence(s) 0; } \\
\text { - DblClickTrab_Schematics } 0 \text { (2 vezes consecutivas); } \\
\text { - DblClickPalette_consequence(s) 0; } \\
\text { - DblClickTrab_structure 0; } \\
\text { - DblClickTrab_specifics 0. }\end{array}$ \\
\hline
\end{tabular}


QUADRO 6.2 - Dados Resultantes da Primeira Etapa de Avaliação da Ferramenta de Crítica

\begin{tabular}{|c|c|}
\hline $\begin{array}{l}\text { Em média, quantas vezes e } \\
\text { quando os usuários consultaram } \\
\text { a documentação e/ou o help? }\end{array}$ & $\begin{array}{l}\text { Em média, o usuário consultou a documentação 4,2 vezes. A maioria quase } \\
\text { absoluta dos usuários consultou a documentaça na fase inicial do teste, } \\
\text { que se refere a tarefa de preparação do ambiente para seleçáa dos } \\
\text { componentes esquemáticos. }\end{array}$ \\
\hline $\begin{array}{l}\text { Em módia, quantas tarefas nninca } \\
\text { foram tentadas e quais são elas? }\end{array}$ & Todas as tarefas foram tentadas por todos os usuários. \\
\hline $\begin{array}{l}\text { Em média, quantas vezes os } \\
\text { usuários tiveram que } \\
\text { recomeçarem desde o início? }\end{array}$ & $\begin{array}{l}\text { A maioria quase absoluta dos usuários teve que recomeçar a estruturação da } \\
\text { introdução uma vez, isso porque eles achavam que havia uma } \\
\text { inconsistência na apresentação das críticas (as mesmas críticas apareciam } \\
\text { mesmo mudando os componentes), o que deixou o usuário confuso. }\end{array}$ \\
\hline $\begin{array}{l}\text { Em média, quantas vezes cada } \\
\text { tarefa foi realizada? }\end{array}$ & $\begin{array}{l}\text { Por se tratar de um sistema recursivo, o número de vezes que cada tarefa foi } \\
\text { realizada não é. necessário ser.avaliado. Por exemplo, o número de vezes } \\
\text { que se realiza a tarefa "Escolher Componentes Esquemáticos" é } \\
\text { proporcional ao número de componentes que se deseja colocar na } \\
\text { introdução, uma vez que para escolher cada elemento é preciso executá-la. }\end{array}$ \\
\hline $\begin{array}{l}\text { Em média, em que ordem as } \\
\text { tarefas foram executadas? }\end{array}$ & $\begin{array}{l}\text { Por ser a aplicação bastante flexível em relaçăo a ordem de execução das } \\
\text { tarefas percebe-se que a execução das tarefas ocorreu aleatoriamente. }\end{array}$ \\
\hline $\begin{array}{l}\text { Em média, qual o grau de } \\
\text { satisfação dos usuários? }\end{array}$ & \\
\hline
\end{tabular}

\subsubsection{Fase de Apresentaçăo dos Resultados}

$\mathrm{Na}$ fase anterior foi feita uma análise baseando-se principalmente nos logs dos usuários e no Modelo de Tarefas da aplicação. Dessa análise, dentre outras informações, alguns dos dados obtidos são os erros que os usuários cometeram, classificados em dois tipos: erros de précondição e outros erros. A partir da interpretação desses resultados obtidos das fases anteriores, foi possivel propor mudanças a serem introduzidas na interface da aplicação.

A apresentação dos resultados obtidos desta etapa de avaliação é feita em um relatório estruturado em quatro colunas, conforme a Tabela 6.3: A primeira coluna se refere aos problemas identificados através dos erros cometidos pelos usuários. A segunda coluna diz respeito à identificação do problema, que é uma descrição de como o erro foi identificado. Na terceira coluna é feita uma descrição dos possíveis problemas cognitivos que podem ter gerado o problema. E por último, na quarta coluna é apresentada a solução proposta, que é uma indicação para melhorar o projeto da interface do usuário. 


\section{TABELA 6.3 - Apresentação dos Resultados da Primeira Etapa de Avaliação}

\begin{tabular}{|c|c|c|c|}
\hline Problema & Iflentificaleinin & Notis açĩu Cogniitis & Soluçâo Propost: \\
\hline $\begin{array}{l}\text { Dificuldade } \\
\text { para preparar } \\
\text { o ambiente de } \\
\text { seleção dos } \\
\text { componentes } \\
\text { esquemáticos. }\end{array}$ & $\begin{array}{l}\text { Este problema foi identificado a partir dos } \\
\text { seguintes erros que os usuários } \\
\text { cometeram: } \\
\text { - DblClickTrab_Schematics(0.Os } \\
\text { usuários deram duplo click, em média, } 2,4 \\
\text { vezes no componente Schematics, } \\
\text { tentando visualizar Intro. } \\
\text { DblClickPalette_intro0. Em média, } \\
\text { os usuários deram duplo click, cinco } \\
\text { vezes em Intro na Palette, tentando } \\
\text { coloca-lo dentro de Schematics. }\end{array}$ & $\begin{array}{l}\text { Os usuários perceberam } \\
\text { de forma errada as ações. } \\
\text { Isso porque eles } \\
\text { executaram estas ações } \\
\text { um número significativo } \\
\text { de vezes, o que representa } \\
\text { que eles estavam com } \\
\text { dificuldade na fase inicial } \\
\text { de execução da } \\
\text { ferramenta, mas } \\
\text { especificamente em saber } \\
\text { como, a partir de que se } \\
\text { poderia visualizar os } \\
\text { componentes a serem } \\
\text { escolhidos para compor a } \\
\text { introdução. E uma outra } \\
\text { dificuldade dos usuários } \\
\text { foi a de perceber como } \\
\text { deveriam proceder para } \\
\text { inserir Intro na área de } \\
\text { trabalho. }\end{array}$ & 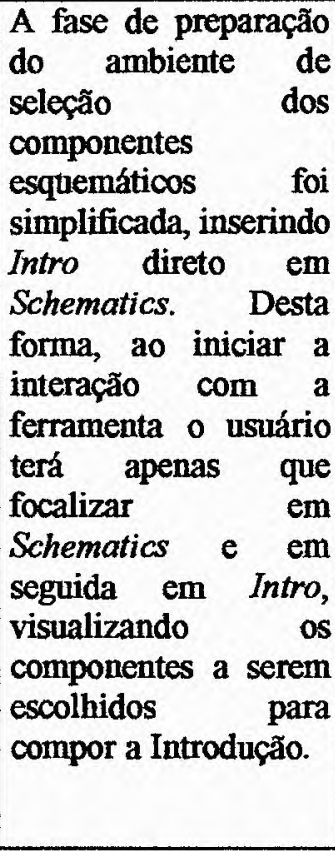 \\
\hline $\begin{array}{l}\text { Dificuldade } \\
\text { em Inserir os } \\
\text { componentes } \\
\text { esquemáticos } \\
\text { em Intro. }\end{array}$ & $\begin{array}{l}\text { Este problema foi identificado a partir das } \\
\text { seguintes aç̃es dos usuários: } \\
\text { DblClickPalette_consequence(s) } 0 \text {. } \\
\text { Em média, os usuários deram um duplo } \\
\text { click no componente Consequence. } \\
\text { DblClickTrab_structure 0. Em } \\
\text { média, os nsuários deram duplo click, } 2,6 \\
\text { vezes no componente Structure.. } \\
\text { DblClickPalette_contents } \quad 0 \text {. Em } \\
\text { média, os usuários deram duplo click, } 0,4 \\
\text { vezes no componente Contents. }\end{array}$ & $\begin{array}{l}\text { A tarefa que o usuário } \\
\text { pretendeu realizar era } \\
\text { correta mas as ações que a } \\
\text { suportavam eram erradas. } \\
\text { Os usuários imaginaram } \\
\text { que para inserir os } \\
\text { componentes } \\
\text { esquemáticos que estavam } \\
\text { na Palette, em Intro, eles } \\
\text { devessem dar duplo click, } \\
\text { enquanto que a ferramenta } \\
\text { não aceitava esta opção. }\end{array}$ & $\begin{array}{l}\text { A aplicação foi } \\
\text { alterada de forma a } \\
\text { permitir que os } \\
\text { componentes } \\
\text { esquemáticos fossem } \\
\text { escolhidos na Palette e } \\
\text { inseridos em Intro } \\
\text { através de um duplo } \\
\text { click no componente } \\
\text { ou arrastando-o da } \\
\text { Palette para dentro de } \\
\text { Intro. Além disso, será } \\
\text { exibida na barra de } \\
\text { status uma mensagem } \\
\text { ao usuário, } \\
\text { informando-lhe sobre } \\
\text { as possíveis formas de } \\
\text { escolha do } \\
\text { componentes. dos. }\end{array}$ \\
\hline $\begin{array}{l}\text { Dificuldade } \\
\text { para excluir } \\
\text { componentes } \\
\text { esquemáticos } \\
\text { da área de } \\
\text { trabalho, ou } \\
\text { seja, da } \\
\text { estrutura de } \\
\text { introdução } \\
\text { proposta. }\end{array}$ & $\begin{array}{l}\text { Este problema foi identificado a partir das } \\
\text { respostas de dois usuários à primeira } \\
\text { questão do questionário e a partir de uma } \\
\text { seqüência de ações do usuário, que apesar } \\
\text { de näo ter cometido nenhum erro mostra } \\
\text { que hourve problemas relacionados à } \\
\text { exclusão de componentes. Nesta } \\
\text { seqüência de açōes executada pelo } \\
\text { usuário, ele clicou com o botão direito do } \\
\text { mouse e tentou arrastar o componente (o } \\
\text { que acabava caindo em um ato de apenas } \\
\text { trocar o componente de lugar). As ações } \\
\text { referentes a trocar um componente de } \\
\text { lugar, por exemplo, Structure, são: } \\
\text { DragOverTrab_structure } 0 \\
\text { DragDropT_Trab_F_Trab_structure } 0 .\end{array}$ & $\begin{array}{l}\text { A tarefa que o usuário } \\
\text { pretendeu realizar era } \\
\text { correta, mas as açóes que } \\
\text { a suportavam eram } \\
\text { erradas. Isso porque o } \\
\text { usuário tentou excluir um } \\
\text { elemento, que é uma ação } \\
\text { perfeita e corretamente } \\
\text { desejável em se tratando } \\
\text { desta aplicação, enquanto } \\
\text { que a única forma de } \\
\text { realizá-la era através da } \\
\text { tecla delete do teclado. }\end{array}$ & $\begin{array}{l}\text { A aplicação foi } \\
\text { alterada de forma a } \\
\text { permitir a exclusão de } \\
\text { componentes } \\
\text { esquemáticos através } \\
\text { da exibição de um } \\
\text { item "Excluir" no } \\
\text { menu popup de cada } \\
\text { componente. }\end{array}$ \\
\hline
\end{tabular}




\section{TABELA 6.3 - Apresentação dos Resultados da Primeira Etapa de Avaliação}

\begin{tabular}{|c|c|c|c|}
\hline $\begin{array}{l}\text { O usuário tem } \\
\text { dificuldade } \\
\text { em pedir as } \\
\text { críticas. }\end{array}$ & 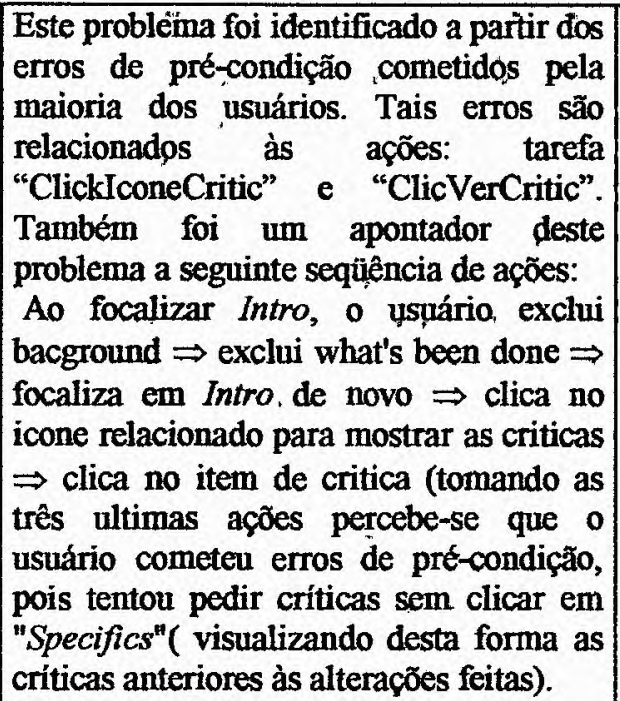 & $\begin{array}{l}\text { A partir da análise das } \\
\text { ações dos usuários } \\
\text { constatou-se que o usuário } \\
\text { percebeu de forma errada } \\
\text { as ações e precisaria de } \\
\text { informações adicionais } \\
\text { alertando-o sobre a } \\
\text { necessidade de mudança } \\
\text { de foco a fim de obter as } \\
\text { críticas. }\end{array}$ & $\begin{array}{l}\text { A aplicação foi } \\
\text { alterada de forma a } \\
\text { exibir uma mensagem } \\
\text { informando ao usuário } \\
\text { que para pedir críticas } \\
\text { ele deverá focalizar } \\
\text { em Specifics. }\end{array}$ \\
\hline $\begin{array}{l}\text { Dificuldade } \\
\text { em identificar } \\
\text { como ler as } \\
\text { críticas. }\end{array}$ & $\begin{array}{l}\text { A seguinte sequência de ações da maioria } \\
\text { dos usuários (4 usuários) leva a identificar } \\
\text { problemas da ferramenta, apesar dos } \\
\text { usuários não terem cometido nenhum } \\
\text { erro: os usuários escolheram os } \\
\text { componentes da Palette e os inseriram em } \\
\text { Intro } \Rightarrow \text { clicou em "Specifics" para pedir } \\
\text { criticas } \Rightarrow \text { voltaram a focalizar "Intro". } \\
\text { Desta sequiência observa-se que os } \\
\text { usíários apesar de terem pedido as } \\
\text { criticas clicando em Specifics eles não } \\
\text { entenderam que para vê-las teriam que } \\
\text { clicar no icone exibido ao lado do } \\
\text { componente (por exemplo, ao lado de } \\
\text { Intro, Structure, Domain, etc), por isso } \\
\text { eles não viram as críticas e voltaram a } \\
\text { focalizar Intro como pode ser visto nesta } \\
\text { última ação. }\end{array}$ & $\begin{array}{l}\text { Os ícones exibidos ao } \\
\text { lado dos componentes } \\
\text { objetivam expressar aos } \\
\text { usuários a idéia de críticas } \\
\text { positivas; ou críticas } \\
\text { negativas; ou críticas } \\
\text { sugestivas; ou uma crítica } \\
\text { que insinua dúvida. O } \\
\text { objetivo inicial da } \\
\text { aplicação era que esses } \\
\text { ícones comunicassem ao } \\
\text { usuário que clicando ali, } \\
\text { pudessem ler as críticas } \\
\text { correspondentes ao } \\
\text { componente relacionado. } \\
\text { Porém os usuários } \\
\text { interpretaram mal a } \\
\text { informação fornecida pela } \\
\text { aplicaça. }\end{array}$ & $\begin{array}{l}\text { A aplicação foi } \\
\text { alterada de forma a } \\
\text { deixar mais claro aos } \\
\text { usuários como eles } \\
\text { devem proceder para } \\
\text { ler as críticas. Para } \\
\text { isso incluin-se na } \\
\text { barra de status uma } \\
\text { mensagem informando } \\
\text { ao usuário de que para } \\
\text { ler as críticas deve-se } \\
\text { dar um click no } \\
\text { componente } \\
\text { relacionado ao ícone } \\
\text { de interesse do crítico. }\end{array}$ \\
\hline $\begin{array}{lr}\text { Falta } & \text { de } \\
\text { clareza } & \text { na } \\
\text { forma } & \text { de } \\
\text { exibição } & \text { das } \\
\text { críticas, } & \\
\text { levando } & \text { o } \\
\text { usuário a } & \text { se } \\
\text { perder } & \\
\text { durante } & \text { a } \\
\text { interação com } \\
\text { a ferramenta. }\end{array}$ & $\begin{array}{l}\text { A identificação desse problema baseou-se } \\
\text { principalmente nas respostas dadas pela } \\
\text { maioria dos usuários à primeira questão } \\
\text { do questionário. Eles responderam que: } \\
\text { - Mudanças voluntária e aleatória dos } \\
\text { componentes não mudaram a. lista de } \\
\text { críticas fornecidas na janela "Peer } \\
\text { Annotation". } \\
\text { - As críticas apresentadas não são } \\
\text { consistentes, por exemplo, dizia que } \\
\text { faltava Purpose sendo que este } \\
\text { componente já existia na estrutura } \\
\text { proposta. } \\
\text { Vários itens com o nome "Resultados } \\
\text { da Comparação" eram 'apresentados na } \\
\text { janela "Peer Annotation", porém todos } \\
\text { eles com o mesmo conteudo, ou seja, os. } \\
\text { mesmos links. }\end{array}$ & $\begin{array}{l}\text { A partir das respostas do } \\
\text { usuário ao questionário e } \\
\text { da seqüência de ações } \\
\text { obtidas dos logs do teste } \\
\text { do usuário, verifica-se que } \\
\text { o usuário interpretou mal } \\
\text { a informação fornecida } \\
\text { pela aplicação. Desta } \\
\text { forma, o usuário perdeu } \\
\text { muito tempo nesta fase, } \\
\text { em que esteve perdido } \\
\text { durante a interação, na } \\
\text { tentativa de encontrar uma } \\
\text { explicação para as críticas } \\
\text { que apareciam. O usuário } \\
\text { não percebeu que as } \\
\text { criticas antigas } \\
\text { continuavam na Peer } \\
\text { Annotation. }\end{array}$ & $\begin{array}{l}\text { A aplicação foi } \\
\text { alterada de forma a dar } \\
\text { uma visão mais clara } \\
\text { ao usuário de que as } \\
\text { criticas antigas são } \\
\text { mantidas na Peer } \\
\text { Annotation, caso elas } \\
\text { não sejam apagadas } \\
\text { pelo próprio usuário. } \\
\text { Para isso incluiu-se } \\
\text { um campo "hora" no } \\
\text { item de critica, dando } \\
\text { a aparência de' uma } \\
\text { caixa de e-mail. } \\
\text { Assim, o usuário vai } \\
\text { perceber quais são as } \\
\text { criticas mais recentes } \\
\text { e que lhe interessam a } \\
\text { cada momento. }\end{array}$ \\
\hline
\end{tabular}


TABELA 6.3 - Apresentação dos Resultados da Primeira Etapa de Avaliação .

\begin{tabular}{|c|c|c|c|}
\hline & $\begin{array}{l}\text { Um outro fator que levou a identificar o } \\
\text { problema foi as seqüências de ações do } \\
\text { usuário descritas a seguir, apesar do } \\
\text { usuário não ter cometido nenhum erro: } \\
1-\text { o usuário focalizou em Intro } \Rightarrow \\
\text { escolheu os componentes desejados } \Rightarrow \\
\text { focalizou em "Specifics" para pedir } \\
\text { criticas } \Rightarrow \text { clicou nos ícones relacionados } \\
\text { ao que desejava obter crítica } \Rightarrow \text { clicou no } \\
\text { item de critica a fim de ver o que a crítica } \\
\text { dizia (neste ponto o usuário começou a } \\
\text { ficar confuso, pois a crítica dizia que } \\
\text { faltava "Purpose", enquanto este } \\
\text { componente já estava na estrutura) } \Rightarrow \text { o } \\
\text { usuário troca o componente de lugar } \\
\text { várias vezes. } \\
2 \text { - O usuário pede casos semelhantes ao } \\
\text { crítico } \Rightarrow \text { clica no ícone "Resultados da } \\
\text { Comparação" } \Rightarrow \text { clica nos links } \\
\text { exibidos } \Rightarrow \text { o usuário parece brincar de } \\
\text { clicar no ícone de crítica "Resultados da } \\
\text { Comparação". Isto é pelo fato de aparecer } \\
\text { o mesmo ícone várias vezes dando ao } \\
\text { usuário a impressão de que são resultados } \\
\text { diferentes, ou seja, que vai aparecer } \\
\text { estatísticas diferentes. }\end{array}$ & $\cdot$ & . \\
\hline $\begin{array}{|lr|}\text { Falta } & \text { de } \\
\text { retroalimenta } \\
\text { ção } & \text { ao } \\
\text { usuário } & \text { sobre } \\
\text { quando } & \text { ele } \\
\text { está } & \\
\text { focalizado em } \\
\text { Intro r r e } \\
\text { quando esta } \\
\text { focalizado em } \\
\text { Specifics }\end{array}$ & $\begin{array}{l}\text { Este problema foi identificado a partir das } \\
\text { seguintes açöes dos usuários; que } \\
\text { confirmaram que os usuários escolheram } \\
\text { componentes referentes a componentes } \\
\text { especificos pensando que estavam } \\
\text { focalizados em Intro e escolhendo } \\
\text { componentes esquemáticos: } \\
\text { - DragOverPalette_experimental data0 } \\
\text { - DragDropT_Trab_F_Palette_experim } \\
\text { ental data0 } \\
\text { - ClickCancelReplacePalette_experime } \\
\text { ntal data0 } \\
\text { - DragOverPalette_descriptions0 } \\
\text { - DragDropT_Trab_F_Palette_descript } \\
\text { ions0 } \\
\text { - ClickCancelReplacePalette_descripti } \\
\text { ons0 O DragOverPalette_results0 } \\
\text { - DragDropT_Trab_F_Palette_results0 } \\
\text { - DlickCancelReplacePalette_results0 } \\
\text { - DragOverPalette_system's } \\
\text { feature(s)O } \\
\text { - DragDropT_Trab_F_Palette_system's } \\
\text { feature(s)O } \\
\text { - ClickCancelReplacePalette_system's } \\
\text { feature(s)O } \\
\text { - DragOverPalette_intended andience0 } \\
\text { - DragDropT_Trab_F_Palette_intende. } \\
\text { d audience0 }\end{array}$ & $\begin{array}{l}\text { A partir das informaçães } \\
\text { obtidas da análise dos } \\
\text { logs dos testes dos } \\
\text { usuários, percebeu-se que } \\
\text { o usuário tentou executar } \\
\text { uma ação errada ou o o } \\
\text { usuário percebeu de } \\
\text { forma errada as ações. }\end{array}$ & $\begin{array}{lr}\text { A aplicação } & \text { foi } \\
\text { modificada para } \\
\text { fornecer uma } \\
\text { retroalimentaçao aos } \\
\text { usuários, de forma.que } \\
\text { quandó o usuário } \\
\text { estiver focalizado em } \\
\text { Specifics aparece na } \\
\text { barra de status uma } \\
\text { mensagem } \\
\text { informando-o de que o } \\
\text { foco esta em Specifics } \\
\text { e que se deverá } \\
\text { focalizar em Intro } \\
\text { cáso queira realizar } \\
\text { qualquer } \\
\text { relacionada a Intro, } \\
\text { por exemplo, inserir, } \\
\text { alterar o excluir } \\
\text { componentes. }\end{array}$ \\
\hline
\end{tabular}




\subsection{Etapa 2}

Novos problemas podem ser inseridos a partir das implementações realizadas para solucionar os problemas encontrados na primeira fase. Assim, essa etapa/turno tem como objetivo identificar tais problemas e encontrar problemas de usabilidade da interface que não foram identificados no primeiro turno. Essa etapa consta das Seções 6.2.1, 6.2.2, 6.2.3 que mostram, respectivamente, a preparação da avaliação, a análise e apresentação dos resultados.

\subsubsection{Fase de Preparação da Avaliação}

Esta fase constitui-se da geração dos arquivos de logs a partir da interação de cinco usuários diferentes com a Ferramenta de Crítica modificada de acordo com as soluções propostas na Seção 6.1.3 (Tabela 6.3), da realização de mudanças na especificação do Modelo de Tarefas (as mudanças são baseadas nas modificaçðes realizadas na interface no primeiro turno da avaliação) e da associação entre eventos físicos extraídos dos arquivos de logs e as tạrefas básicas de interação do Modelo de Tarefas. Esses dados,são apresentados abaixo.

\section{a) Captura do Arquivo de Logs}

A captura dos arquivos de logs se deu da mesma forma que para o primeiro turno, considerando-se os mesmos eventos e o mesmo tipo de arquivo (arquivo texto apresentado no Apêndice A).

\section{b) Especificação do Modelo de Tarefas}

O Modelo de Tarefas desenvolvido previamente foi modificado utilizando-se a mesma notação, ferramenta e conceitos utilizados no primeiro turno de avaliação. Sendo que o esforço para realizar tais modificações foi somente o de incorporar no modelo já desenvolvido as propostas de melhoria obtidas da avaliação realizada no primeiro turno. A Árvore de Tarefas modificada da Ferramenta de Critica é apresentada no Apêndice B.

\section{c) Tabela de Tarefa-Log}

A primeira coluna da Tabela de Tarefa-Log contém as ações físicas do usuário, que são extraídas do arquivo de logs. A segunda coluna contém as tarefas básicas do Modelo de 
Tarefas que correspondem às ações do usuário que as executam. Como algumas das tarefas básicas do Modelo de Tarefas foram alteradas em decorrência das modificações propostas no primeiro turno, a Tabela de Tarefa-Log também é modificada de forma a incorporar tais alterações. A Tabela de Tarefa-Log modificada é mostrada no Apêndice B.

\subsubsection{Fase de Análise de Resultados}

Seguindo a mesma abordagem aplicada na primeira etapa, tomou-se como entradas: os logs dos usuários, o Modelo de Tarefas, a Tabela de Tarefa-Log, a Tabela de Pré-Condiçóes e os dados dos questionários dos usuários para se realizar a análise.

As três primeiras entradas são resultantes da fase de preparação. A Tabela de PréCondições foi criada a partir do Modelo de Tarefas modificado da Ferramenta de Crítica, utilizando-se o mesmo método da etapa anterior para obter as pré-condições. A Tabela de Pré-Condições criada é apresentada no Apêndice B. Nessa fase também foram analisados os dados obtidos dos questionários respondidos pelos usuários após as sessões de teste com a aplicação. Os dados dos questionários contêm o resumo da análise dos questionários aplicados aos usuários após as sessões de teste. O Quadro 6.3 apresenta esses dados.

QUADRO 6.3 - Resumo da Análise dos Dados Obtidos dos Questionários da Segunda Etapa

\begin{tabular}{|c|c|}
\hline & \\
\hline $\begin{array}{l}\text { Você teve } \\
\text { problemas } \\
\text { durante o teste? } \\
\text { Se algum, quais? }\end{array}$ & $\begin{array}{l}\text { - A maioria dos usuários teve problemas em enxergar que as críticas antigas não eram } \\
\text { apagadas da janela "Peer Annotation" e com isto ficaram confusos. Isso significa que } \\
\text { o campo hora inserido na janela "Peer Annotation" para a realização desta etapa de } \\
\text { avaliação não foi intuitivo para os usuários. } \\
\text { - Alguns usuários tiveram problemas pelo fato da janela "Peer Annotation" ser muito } \\
\text { pequena e ter que redimensioná-la toda vez que a abre. } \\
\text { A maioria dos usuários teve problemas em encontrar os resultados da comparação. } \\
\text { Isso porque a janela "Peer Annotation" não estava ativada ou se encontrava em baixo } \\
\text { da janela principal. }\end{array}$ \\
\hline $\begin{array}{l}\text { Você usaria a } \\
\text { Ferramenta de } \\
\text { Crítica (uma } \\
\text { versão } \\
\text { melhorada) no } \\
\text { futuro? Porque? } \\
\text { Ou Porque não? }\end{array}$ & $\begin{array}{l}\text { Todos os usuários disseram que usariam a ferramenta em uma versão melhorada no futuro } \\
\text { porque: } \\
\text { - Ajuda muito o usuário iniciante na escrita de artigos em inglês, orientando na } \\
\text { organização e disposição das idéias. } \\
\text { Ajuda a fazer uma boa estruturação e isso é importante não só para a introdução, mas } \\
\text { para o artigo todo. } \\
\text { Facilita muito o processo de escrita de introdução, que geralmente é a parte mais } \\
\text { complicada de escrever. } \\
\text { Permite ver a estrutura de casos semelhantes, dando uma idéia de por onde começar a } \\
\text { escrever. } \\
\text { Ajuda na escrita em inglês, uma vez que o ajudou a construir a introdução de sua } \\
\text { monografia de doutorado. }\end{array}$ \\
\hline
\end{tabular}




\section{QUADRO 6.3 - Resumo da Análise dos Dados Obtidos dos Questionários da Segunda Etapa}

\begin{tabular}{|c|c|}
\hline $\begin{array}{l}\text { Qual parte da } \\
\text { interface da } \\
\text { Ferramenta de } \\
\text { Crítica foi a mais } \\
\text { difícil (se } \\
\text { alguma) ou a } \\
\text { mais irritante? } \\
\text { Porque? }\end{array}$ & $\begin{array}{l}\text { As partes mais irritantes foram: } \\
\text { - O fạto da janela "Peer Annoțation" ser muito pequena e ter que redimensioná-la toda } \\
\text { vez que a abre. } \\
\text { - A dificuldade para perceber que o sistema exibia também as críticas antigas (isso } \\
\text { aconteceu mesmo tendo o campo hora, que lhe informa sobre o tempo em que aquela } \\
\text { crítica foi exibida). } \\
\text { A dificuldade para encontrar os casos semelhantes, ou seja, visualizar os itens } \\
\text { "Resultados da Comparação". }\end{array}$ \\
\hline $\begin{array}{l}\text { A leitura de } \\
\text { caracteres na tela } \\
\text { estava: } \\
\text { Dificil } 12345 \\
\text { Fácil } \\
\text { Porquê? }\end{array}$ & $\begin{array}{l}\text { Todos os usuários assinalaram a opção correspondente ao valor “5”, o que significa que a } \\
\text { leitura dos caracteres na tela estava fácil. Porém, um dos usuários sứgeriu que fosse } \\
\text { adicionado algum símbolo aos componentes compostos que indicasse que existe sub- } \\
\text { componentes relacionados a eles. }\end{array}$ \\
\hline $\begin{array}{l}\text { A vèlocidade do } \\
\text { sistema é: } \\
\text { Lenta } 12345 \\
\text { Rápida }\end{array}$ & $\begin{array}{l}\text { Todos os usuários assinalaram a opção correspondente ao valor " } 5 \text {, o que significa que a } \\
\text { velocidade do sistema é rápida. }\end{array}$ \\
\hline $\begin{array}{l}\text { Você se sentiu à } \\
\text { vontade em usar } \\
\text { o sistema? } \\
\text { Pouco } 12345 \\
\text { Bastante } \\
\end{array}$ & $\begin{array}{l}\text { Alguns usuários (dois usuários) assinalaram a opção "5", significando que se sentiram } \\
\text { bastante à vontade em usar o sistema. Os outros } 3 \text { usuários assinalaram a opção "3", que } \\
\text { corresponde a dizer que se sentiu mais ou menos à vontade em usar o sistema. }\end{array}$ \\
\hline $\begin{array}{l}\text { No geral, você } \\
\text { ficou satisfeito } \\
\text { com o sistema? } \\
\text { Pouco } 12345 \\
\text { Bastante. }\end{array}$ & $\begin{array}{l}\text { A maioria dos usuários (três usuários) assinalou a opção "4", significando que ficaram } \\
\text { satisfeitos com o sistema. Um dos usuários assinalaram a opção "3", que correspọnde a } \\
\text { dizer que ficou mais ou menos satisfeito com o sistema. Outro usuário assinalou a opção } \\
\text { "2", que significa que o usuário ficou um tanto quanto insatisfeito com o sistema. }\end{array}$ \\
\hline
\end{tabular}

A avaliação ou análise dos resultados é realizada da mesma forma que na primeira etapa/ turno de avaliação (Seção 6.1.2). O Quadro 6.4 apresenta os dados obtidos como resposta à análise completa realizada nesta fase. Para a representação destes dados foi feita uma média dos dados obtidos da análise das cinco sessões de teste de usuário com a ferramenta.

\section{QUADRO 6.4 - Dados Resultantes da Segunda Etapa de Avaliação da Ferramenta de Crítica}

\begin{tabular}{|c|c|}
\hline Itein comsideradln & Dadom ohtidos \\
\hline $\begin{array}{l}\text { Em média, qual o tempo total } \\
\text { de teste? }\end{array}$ & $\begin{array}{l}\text { Os usuários levaram em média 1:15 (uma hora e quinze minutos) para } \\
\text { realizar o teste. }\end{array}$ \\
\hline $\begin{array}{l}\text { Em média, qual o número de } \\
\text { tarefas completadas e quais } \\
\text { foram completadas? }\end{array}$ & $\begin{array}{l}\text { Todas as tarefas descritas no Capitulo 5, Seção 5.2.2.3 foram realizadas. Isto } \\
\text { soma um total de } 12 \text { tarefas. }\end{array}$ \\
\hline $\begin{array}{l}\text { Em média, quantas e quais } \\
\text { tarefas foram realizadas, porém } \\
\text { com falhas? }\end{array}$ & $\begin{array}{l}\text { As duas tarefas seguintes foram realizadas com falhas: } \\
\text { - A tarefa "Pedir e Visualizar "Críticas". } \\
\text { - A tarefa "Visualizar exemplos de Introduçöes de Artigos". }\end{array}$ \\
\hline $\begin{array}{l}\text { Em média, quais as tarefas que } \\
\text { os usuários não foram capazes } \\
\text { de executar? }\end{array}$ & $0(\mathrm{z}$ \\
\hline
\end{tabular}




\section{QUADRO 6.4 - Dados Resultantes da Segunda Etapa de Avaliação da Ferramenta de Crítica}

\begin{tabular}{|c|c|}
\hline $\begin{array}{l}\text { Em média, quanto tempo cada } \\
\text { tarefa levou para completar (o } \\
\text { tempo de realização das tarefas } \\
\text { abstratas é calculado somando- } \\
\text { se o tempo das tarefas filhas)? }\end{array}$ & $\begin{array}{l}\text { Preparar o Processo de Seleção dos Componentes Esquemáticos: 0:84 min } \\
\text { Definir os Componentes Esquemáticos: } 5: 33 \mathrm{~min} \\
\text { Pedi e Visualiza Críticas: } 3: 92 \mathrm{~min} \\
\text { Pedir Casos Semelhantes: } 3: 95 \mathrm{~min} \\
\text { Reestruturar a Introdução: } 0: 98 \mathrm{~min} \\
\text { Visualizar Casos Semelhantes: } 8: 22 \mathrm{~min}\end{array}$ \\
\hline $\begin{array}{l}\text { Em média, qual o número de } \\
\text { erros cometidos (classificados } \\
\text { por tipo de erro) e quais são os } \\
\text { erros (classificados por tipo de } \\
\text { erro)? }\end{array}$ & $\begin{array}{l}\text { Não foram cometidos erros de pré-condição e nenhum outro tipo de erro } \\
\text { durante a interação do usuário com a ferramenta, apesar de se ter encontrado } \\
\text { alguns problemas com a interface (por exemplo, foi adicionado um novo } \\
\text { problema a partir das implementações de melhoria realizadas na primeira } \\
\text { fase: a Janela Peer Annotation passou a aparecer em baixo da Janela } \\
\text { Principal Lego Workbench). }\end{array}$ \\
\hline $\begin{array}{l}\text { Em média, quantas vezes e } \\
\text { quando os usuários consultaram } \\
\text { a documentação e/ou o help? }\end{array}$ & $\begin{array}{l}\text { Em média, os usuários consultaram a documentação } 2,8 \text { vezes. A maioria } \\
\text { quase absoluta dos usuários consultou a documentação na fase relacionada à } \\
\text { visualização das críticas e a pedir para recuperar casos semelhantes. }\end{array}$ \\
\hline $\begin{array}{l}\text { Em média, quantas tarefas } \\
\text { nunca foram tentadas e quais } \\
\text { são elas? }\end{array}$ & Todas as tarefas foram tentadas por todos os usuários. \\
\hline $\begin{array}{l}\text { Em média, quantas vezes os } \\
\text { usuários tiveram que recomeçar } \\
\text { desde o início? }\end{array}$ & $\begin{array}{l}\text { A maioria quase absoluta dos usuários teve que recomeçar a estruturação da } \\
\text { introdução, em média o número de vezes que os usuários tiveram que } \\
\text { recomeçar a introdução foi } 2,2 \text { vezes. Isso porque as mesmas críticas } \\
\text { apareciam mesmo mudando os componentes da introdução, o que deixou os } \\
\text { usuários confusos. }\end{array}$ \\
\hline $\begin{array}{l}\text { Em média, quantas vezes cada } \\
\text { tarefa foi realizada? }\end{array}$ & $\begin{array}{l}\text { Por se tratar de um sistema recursivo, o número de vezes que cada tarefa foi } \\
\text { realizada não é necessário ser avaliado. Por exemplo, o número de vezes que } \\
\text { se realiza a tarefa "Escolher Componentes Esquemáticos" é proporcional ao } \\
\text { número de componentes que se deseja colocar na introdução, uma vez que } \\
\text { para escolher cada elemento é preciso executá-la. }\end{array}$ \\
\hline $\begin{array}{l}\text { Em média, em que ordem as } \\
\text { tarefas foram executadas? }\end{array}$ & $\begin{array}{l}\text { Por ser a aplicação bastante flexível em relação a ordem de execução das } \\
\text { tarefas percebe-se que a execução das tarefas ocorreu aleatoriamente. }\end{array}$ \\
\hline $\begin{array}{l}\text { Em média, qual o grau de } \\
\text { satisfação dos usuários? }\end{array}$ & usuários ficaram satisfeitos com o sistema. \\
\hline
\end{tabular}

\subsubsection{Fase de apresentação dos resultados}

$\mathrm{Na}$ fase anterior foi feita uma análise baseando-se principalmente nos logs dos usuários, no Modelo de Tarefas da aplicação e nos questionários respondidos pelos usuários. A partir da interpretação dos resultados obtidos dessa análise, tornou-se possível propor soluções aos problemas encontrados na interface da aplicação. A apresentação dos resultados obtidos desta etapa de avaliação é feita no mesmo modelo de relatório estruturado em quatro colunas usado no turnol, conforme a Tabela 6.4 . 


\section{TABELA 6.4 - Apresentação dos Resultados da Segunda Etapa de Avaliação}

\begin{tabular}{|c|c|c|c|}
\hline Problemit & Identificatyä! & Vlötivacion Cogntitia & $\begin{array}{l}\text { Soluçati } \\
\text { Propenstal }\end{array}$ \\
\hline $\begin{array}{lr}\text { O fato das } \\
\text { críticas } \\
\text { exibidas serem } \\
\text { escritas em } \\
\text { Português } \\
\text { representa um } \\
\text { problema, visto } \\
\text { que este er um } \\
\text { sistema para } \\
\text { suporte à } \\
\text { escrita } \\
\text { Inglês. em }\end{array}$ & $\begin{array}{l}\text { Este problema foi identificado através das } \\
\text { respostas dos usuários ao questionário. Porém, } \\
\text { este problema não levou a nenhum erro ou } \\
\text { sequiência de ações indesejável durante a } \\
\text { interação com a ferramenta. }\end{array}$ & $\begin{array}{l}\text { Umà vez que nenhum } \\
\text { erro foi cometido e } \\
\text { nenhuma sequiência de } \\
\text { ações indesejável } \\
\text { ocorreu, não há } \\
\text { nenhuma motivação } \\
\text { cognitiva explicita para } \\
\text { este problemá. O que } \\
\text { ocorre é uma mistura de } \\
\text { idiomas na interface. }\end{array}$ & $\begin{array}{l}\text { A aplicação } \\
\text { pode } \\
\text { alterada der } \\
\text { forma a exibir } \\
\text { as criticas na } \\
\text { lingua inglesa. }\end{array}$ \\
\hline $\begin{array}{l}\text { A dificuldade } \\
\text { para o usuário } \\
\text { perceber que o } \\
\text { sistema exibia } \\
\text { também as } \\
\text { críticas antigas } \\
\text { (inclusive os } \\
\text { itens } \\
\text { "Resultado da } \\
\text { Comparação", } \\
\text { quando se pede } \\
\text { para recuperar } \\
\text { casos } \\
\text { semelhantes). }\end{array}$ & 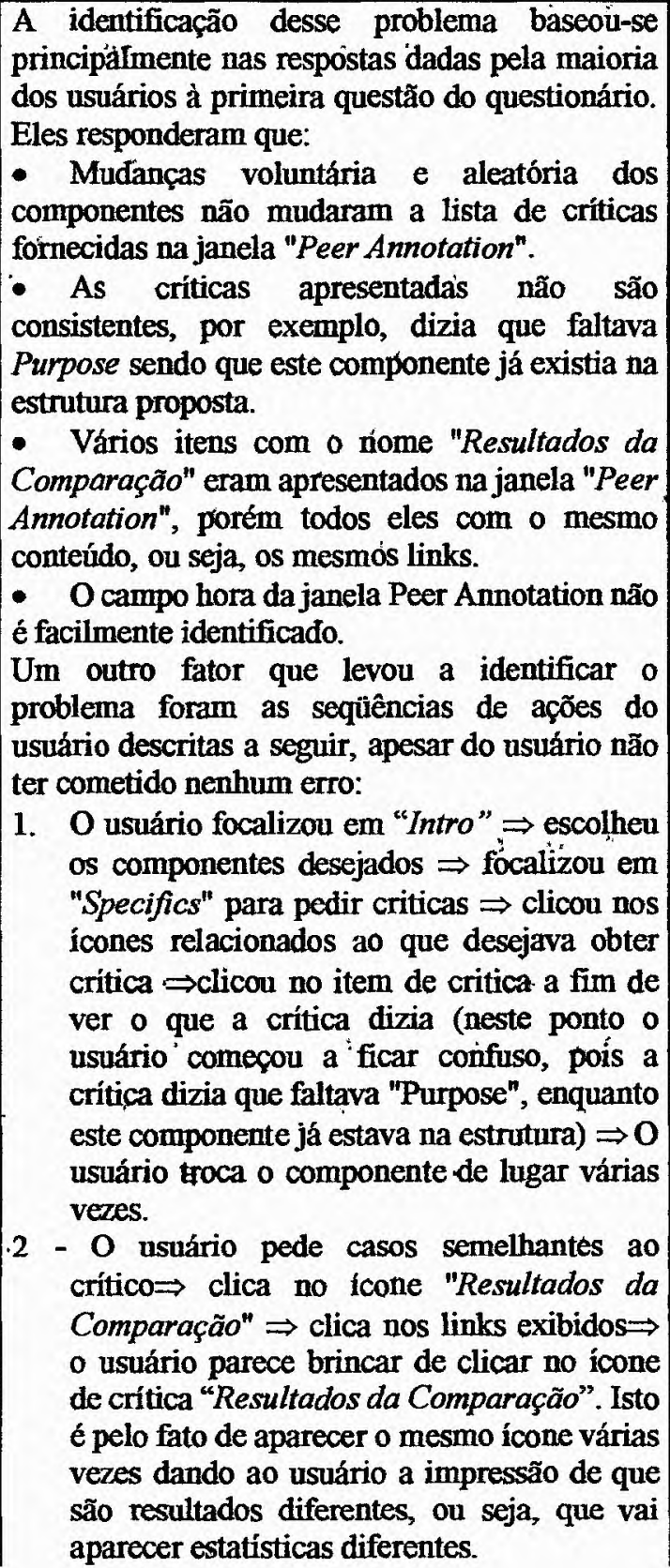 & $\begin{array}{l}\text { A partir das respostas do } \\
\text { usuário ao questionário } \\
\text { e da seqüência de ações } \\
\text { obtidas dos logs do teste } \\
\text { do usuário, verifica-se } \\
\text { que o rusuário } \\
\text { interpretou mal a } \\
\text { informação fornecida } \\
\text { pela aplicação. O } \\
\text { usuário não percebeu } \\
\text { que as criticas antigas } \\
\text { continuavam na Peer } \\
\text { Annotation. } \\
\text { significa que o campo } \\
\text { hora inserido na janela } \\
\text { "Peer Annotation" para } \\
\text { a realização desta etapa } \\
\text { de avaliação não foi } \\
\text { intuitivo para os } \\
\text { usuários ou nem mesmo } \\
\text { visualizado. }\end{array}$ & $\begin{array}{l}\text { A aplicação foi } \\
\text { alterada de } \\
\text { forma a dar } \\
\text { uma visão mais } \\
\text { clara ao usuário } \\
\text { de que as } \\
\text { críticas antigas } \\
\text { são mantidas } \\
\text { na Peer } \\
\text { Annotation, } \\
\text { caso elas não } \\
\text { sejam apagadas } \\
\text { pelo próprio } \\
\text { usuário. Para } \\
\text { isso a Janela } \\
\text { Peer a } \\
\text { Annotation foi } \\
\text { redimensionada } \\
\text { de forma a } \\
\text { permitir uma } \\
\text { melhor } \\
\text { visualização } \\
\text { dos itens de } \\
\text { crítica } \\
\text { incluiu-se um } \\
\text { campo } \\
\text { contendo uma } \\
\text { imagem escrito } \\
\text { “New" no item } \\
\text { de crítica. } \\
\text { Assim, espera- } \\
\text { se que o } \\
\text { usuário perceba } \\
\text { quais são as } \\
\text { críticas mais } \\
\text { recentes e que } \\
\text { lhe interessam } \\
\text { a cada } \\
\text { momento. }\end{array}$ \\
\hline
\end{tabular}




\section{TABELA 6.4 - Apresentação dos.Resultados da Segunda Etapa de Avaliação}

\begin{tabular}{|c|c|c|c|}
\hline $\begin{array}{l}\text { No início da } \\
\text { interação, os } \\
\text { usuários dizem } \\
\text { não terem uma } \\
\text { retroalimentaçã } \\
\text { o ("Feedback") } \\
\text { do sistema } \\
\text { sobre quais são } \\
\text { os } \\
\text { componentes } \\
\text { compostos por } \\
\text { subcomponente } \\
\text { s. }\end{array}$ & $\begin{array}{l}\text { Este problema foi identificado através das } \\
\text { respostas dos usuários ao questionário. Porém, } \\
\text { este problema não levou a nenhum erro ou } \\
\text { sequêencia de açóes indesejável durante a } \\
\text { interação com a ferramenta. }\end{array}$ & $\begin{array}{l}\text { Uma vez que nenhum } \\
\text { erro foi cometido e } \\
\text { nenhuma sequiência de } \\
\text { açöes } \\
\text { ocorreu, nandesejável } \\
\text { nenhuma motivação } \\
\text { cognitiva explicita para } \\
\text { este problema. O que } \\
\text { ocorre é uma falta de } \\
\text { retroalimentação do } \\
\text { sistema. }\end{array}$ & $\begin{array}{l}\text { A aplicação foi } \\
\text { alterada, } \\
\text { colocando-se } \\
\text { um sinal "+" ao } \\
\text { lado dos } \\
\text { componentes } \\
\text { que são } \\
\text { constituidos } \\
\text { por } \\
\text { subcomponente } \\
\text { s. }\end{array}$ \\
\hline $\begin{array}{l}\text { A dificuldade } \\
\text { em visualizar } \\
\text { os itens } \\
\text { "Resultados da } \\
\text { Comparação" } \\
\text { se a Janela Peer } \\
\text { Annotation } \\
\text { ainda não tiver } \\
\text { sido ativada } \\
\text { pelo sistema. }\end{array}$ & $\begin{array}{l}\text { A identificação desse problema se deu através } \\
\text { das respostas da maioria dos usuários ao } \\
\text { questionário: Eles disseram que a maior irritação } \\
\text { foi a dificuldade para encontrar os resultados da } \\
\text { comparação. Isso porque a janela Peer } \\
\text { Annotation não estava ainda ativada, não } \\
\text { permitindo a visualização imediata dos itens } \\
\text { "Resultados da Comparação". Isso foi } \\
\text { confirmado pela análise dos logs, em que a } \\
\text { seqüência de eventos para pedir ao sistema para } \\
\text { recuperar casos semelhantes foi realizada várias } \\
\text { vezes consecutivas. }\end{array}$ & $\begin{array}{l}\text { Pode-se deduzir que o } \\
\text { usuário tentou realizar a } \\
\text { tarefa correta ("Pedir } \\
\text { casos semelhantes"), } \\
\text { mas as ações que a } \\
\text { suportavam eram } \\
\text { erradas. Isso porque a } \\
\text { janela "Peer } \\
\text { Annotation" não estava } \\
\text { ativada. }\end{array}$ & $\begin{array}{l}\text { A aplicação foi } \\
\text { alterada de } \\
\text { forma a exibir a } \\
\text { Janela Peer } \\
\text { Annotation } \\
\text { assim que se } \\
\text { inicia } \\
\text { sistema. }\end{array}$ \\
\hline $\begin{array}{l}\text { A Janela Peer } \\
\text { Annotation } \\
\text { passou a } \\
\text { aparecer em } \\
\text { baixo da Janela } \\
\text { Principal Lego } \\
\text { Workbench, } \\
\text { causando uma } \\
\text { dificuldade } \\
\text { para se } \\
\text { visualizar os } \\
\text { itens } \\
\text { "Resultados da } \\
\text { comparação", } \\
\text { quando se pede } \\
\text { para o sistema } \\
\text { recuperär casos }\end{array}$ & $\begin{array}{l}\text { Esse problema foi identificado através das } \\
\text { respostas da maioria dos usuários à primeira } \\
\text { questão do questionário. Eles disseram que: } \\
\text { - Pediram ao sistema por duas ou mais vezes } \\
\text { consecutivas para recuperar casos semelhantes e } \\
\text { não viram imediatamente os itens "Resultados da } \\
\text { Comparação", ou seja não tiveram uma } \\
\text { retroalimentação do sistema. Isto foi confirmado } \\
\text { pela análise dos logs, em que a seqüência de } \\
\text { eventos para pedir ao sistema para recuperar } \\
\text { casos semelhantes foi realizada várias vezes } \\
\text { consecutivas. }\end{array}$ & $\begin{array}{l}\text { Com isto, pode-se } \\
\text { deduzir que o usuário } \\
\text { tentou realizar a tarefa } \\
\text { correta ("Pedir casos } \\
\text { semelhantes"), mas as } \\
\text { ações que a suportavam } \\
\text { eram erradas. Isso } \\
\text { porque a janela "Peer } \\
\text { Annotation" se } \\
\text { encontrava em baixo da } \\
\text { janela principal e } \\
\text { deveria ser ativada } \\
\text { anteriormente. }\end{array}$ & $\begin{array}{l}\text {.A aplicação foi } \\
\text { alterada de } \\
\text { forma a exibir a } \\
\text { Janela Peer } \\
\text { Annotation } \\
\text { abaixo da } \\
\text { Janela } \\
\text { Principal assim } \\
\text { que se inicia o } \\
\text { sistema. } \\
\end{array}$ \\
\hline
\end{tabular}

\subsection{Etapa 3}

Novos problemas podem ser inseridos a partir das implementações realizadas para solucionar os problemas encontrados na segunda fase. Assim, essa etapa/turno tem como objetivo identificar tais problemas e encontrar problemas de usabilidade da interface que não foram 
identificados no primeiro e segundo turnos. Essa etapa consta das Seções 6.3.1, 6.3.2, 6.3.3 que mostram, respectivamente, a preparação da avaliação, a análise e apresentação dos resultados.

\subsubsection{Fase de Preparação da Avaliação}

Esta fase constitui-se da geração dos arquivos de logs a partir da interação de cinco usuários diferentes com a Ferramenta de Crítica modificada de acordo com as soluções propostas na Seção 6.2.3 (Tabela 6.4), do Modelo de Tarefas especificado na segunda etapa de avaliação (as propostas de mudanças da interface realizadas no segundo turno da avaliação não acarretaram alterações no Modelo de Tarefas dessa etapa de avaliação) e da associação entre eventos fisicos extraídos dos arquivos de logs e as tarefas básicas de interação do Modelo de Tarefas. Esses dados são apresentados abaixo.

\section{a) Captura do Arquivo de Logs}

A captura dos arquivos de logs se deu da mesma forma que para o primeiro turno e segundo turnos, considerando-se os mesmos eventos e o mesmo tipo de arquivo (arquivo texto apresentado no Apêndice A).

\section{b) Especificação do Modelo de Tarefas}

O Modelo de Tarefas utilizado na segunda etapa de avaliação não sofreu nenhuma alteração após as mudanças da interface da Ferramenta de Críticas. Isso porque foi alterada somente a forma de apresentação dos objetos e não a forma de realização das tarefas. A Árvore de Tarefas da Ferramenta de Critica é a mesma daquela utilizada na segunda etapa e é apresentada no Apêndice B.

\section{c) Tabela de Tarefa-Log}

A primeira coluna da Tabela de Tarefa-Log contém as ações fisicas do usuário, que são extraídas do arquivo de logs. A segunda coluna contém as tarefas básicas do Modelo de Tarefas, que correspondem às ações do usuário que as executam. Como as tarefas básicas do Modelo de Tarefas não foram alteradas (em decorrência das modificações propostas como 
resultado da avaliação realizada no segundo turno) a Tabela de Tarefa-Log também.não. foi modificada.

\subsubsection{Fase de Análise de Resultados}

Seguindo a mesma abordagem aplicada na primeira e segunda etapas, tomou-se como entradas: os logs dos usuários, o Modelo de Tarefas, a Tabela de Tarefa-Log, a Tabela de Pré-Condições é os dados dos questionários dos usuários para se realizar a análise.

As três primeiras entradas são resultantes da fase de preparação. A Tabela de PréCondições é criada a partir do Modelo de Tarefas. Nessa fase também foram analisados os dados obtidos dos questionários respondidos pelos usuários após as sessões de teste com a aplicação. Os dados dos questionários contêm o resumo da análise doș questionários aplicados ạos usuários após as sessões de teste. O Quadṛo 6.5 apresenta esses dados.

QUADRO 6.5 - Resumo da Análise dos Dados Obtidos dos Questionários da Terceira Etapa

\begin{tabular}{|c|c|}
\hline Questries & Dados obuticlos \\
\hline $\begin{array}{l}\text { Você teve problemas durante o } \\
\text { teste? Se algum, quais? }\end{array}$ & $\begin{array}{l}\text { A maioria dos usuários disse não ter tido problemas durante a interação com } \\
\text { a Ferramenta. Outros tiveram problemas relacionados à: } \\
\text { - parte conceitual da estrutura de uma introdução. Para os usuários a } \\
\text { interface não explicita o significado de cada componente. } \\
\text { - Dificuldade de identificar qual a crítica que está sendo lida. Isso porque } \\
\text { o item de crítica não fica selecionado enquanto o usuário lê a crítica. }\end{array}$ \\
\hline $\begin{array}{l}\text { Você usaria a Ferramenta de } \\
\text { Critica (uma versão melhorada) } \\
\text { no futuro? Porque? Ou Porque } \\
\text { não? }\end{array}$ & $\begin{array}{l}\text { Todos os usuários disseram que usariam a ferramenta em uma versão } \\
\text { melhorada no futuro, porque: } \\
\text { E É importante escrever um bom artigo e uma ferramenta como esta } \\
\text { realmente ajuda. } \\
\text { Pode direcionar na criação de uma estrutura adequada a um trabalho } \\
\text { cientifico. } \\
\text { As críticas relacionadas à estrutura do artigo e a apresentação de } \\
\text { exemplos semelhantes são relevantes e muito úteis. }\end{array}$ \\
\hline $\begin{array}{l}\text { Qual parte da interface da } \\
\text { Ferramenta de Critica foi a mais } \\
\text { dificil (se alguma) ou a mais } \\
\text { irritante? Porque? }\end{array}$ & $\begin{array}{l}\text { As partes mais irritantes foram: } \\
\text { - O fato de existir um botão para focalizar e um para tirar o foco pode } \\
\text { deixar o usuário confuso. Na opinião do usuário seria suficiente apenas o } \\
\text { botão "Change Focus". } \\
\text { A dificuldade para definir os componentes esquemáticos, pois sentiu a } \\
\text { necessidade de um pouco mais de explicação sobre o significado dos } \\
\text { componentes. }\end{array}$ \\
\hline
\end{tabular}




\section{QUADRO 6.5 - Resumo da Análise dos Dados Obtidos dos Questionários da Terceira Etapa}

\begin{tabular}{|c|c|}
\hline $\begin{array}{l}\text { A leitura de caracteres na tela } \\
\text { estava: } \\
\text { Dificil } 12345 \text { Fácil } \\
\text { Porquê? }\end{array}$ & $\begin{array}{l}\text { Todos os usuários assinalaram a opcão correspondente ao valor " } 5 \text { ", o que } \\
\text { significa que a leitura dos caracteres na tela estava fácil. }\end{array}$ \\
\hline $\begin{array}{l}\text { A velocidade do sistema é: } \\
\text { Lenta } 12345 \text { Rápida }\end{array}$ & $\begin{array}{l}\text { A maioria dos usuários assinalou a opçá correspondente ao valor " } 5 \text { ", o que } \\
\text { significa que a velocidade do sistema é rápida. }\end{array}$ \\
\hline $\begin{array}{l}\text { Você se sentiu à vontade em } \\
\text { usar o sistema? } \\
\text { Pouco I } 2345 \text { Bastante }\end{array}$ & $\begin{array}{l}\text { Alguns usuários (dois usuários) assinalaram a opção " } 5 \text { ", significando que se } \\
\text { sentiram bastante à vontade em usar o sistema. Um usuário assinalou a opção } \\
\text { "4", o que significa que se sentiu um tanto quanto d̀ vontade em usar o } \\
\text { sistema. Os oútros dois usuários assinalarám a opł̧ão " } 3 " \text {, que corresponde a } \\
\text { dizer que se sentiram mais ou menos à vontade em usar o sistema. }\end{array}$ \\
\hline $\begin{array}{l}\text { No geral, você ficou satisfeito } \\
\text { com o sistema? } \\
\text { Pouco } 12345 \text { Bastante }\end{array}$ & $\begin{array}{l}\text { Alguns usuáriós (dois usuários) assinálaram a opção" " } 5 \text { ", significando qué } \\
\text { ficaram bastante satisfeitos coṃ o. sistema. Um, dos usuários assinalou a } \\
\text { opção "4", que corresponde a dizer que ficou satisfeito. Os oütros dois } \\
\text { usuários.assinalaram a opção " } 3 \text { ", que corresponde a dizer que ficaram mais } \\
\text { ou menos satisfeitos com o sistema. }\end{array}$ \\
\hline
\end{tabular}

A avaliação ou análise dos resultados é realizada da messma forma que na primeira e segunda etapà̉s/turnos de'avaliação (Seção 6.1 .2 e 6.2.2). O Quadro 6.6 apresenta os dados obtidos como resposta à análise completa realizada nesta fase. Para a representação destes dados foi feita uma média dos dados obtidos da análise das 5 sessões de teste de usuário com a ferramenta.

\section{QUADRO 6.6-Dados Resultantes da Terceira Etapa de Avaliação da Ferramenta de Crítica}

\section{Item consideratio Datus abtitlio}

Em média, qual o tempo total Os usuários levaram em média 1:12 (uma hora e doze minutos) para realizar de teste?

Em média, qual o número de tarefas completadas e quais foram completadas?

Em média, quantas e quais Nenhuma tarefa foi realizada com falha.

tarefas foram realizadas, porém com falhas?

Em média, quais as tarefas que 0 (zero) tarefas.

os usuários não foram capazes de executar?

Em média, quanto tempo cada tarefa levou para completar (o tempo de realização das tarefas abstratas é calculado somandose o tempo das tarefas filhas)? o teste.

Todas as tarefas descritas no Capítulo 5, Seção 5.2.2.3 foram realizadas. Isto soma um total de 12 tarefas.

Preparar o Processo de Seleção dos Componentes Esquemáticos: 0:80 min

Definir os Componentes Esquemáticos: 3:9 min

Pedi e Visualiza Críticas: 3:9 min

Pedir Casos Semelhantes: 4:24 min

Reesthuturar a Introdução: 2:31 min

Visualizar Casos Semelhantes: 2:66 min

Em média, qual o número de erros cometidos (classificados por tipo de erro) e quais são os erros (classificados por tipo de erro)?
Não foram cometidos erros de pré-condição e nenhum outro tipo de erro durante a interação do usuário com a ferramenta, apesar de se ter encontrado alguns problemas com a interface. 
QUADRO 6.6 - Dados Resultantes da.Terceira Etapa de Avaliação da Ferramenta de Crítica

\begin{tabular}{|l|l|}
\hline $\begin{array}{l}\text { Em média, quantas vezes e } \\
\text { quando os usuários consultaram } \\
\text { a documentação e/ou o help? }\end{array}$ & $\begin{array}{l}\text { Em média, os usuários consultaram a documentação 2,8 vezes. A maioria } \\
\text { quase absoluta dos usuários consultou a documentação na fase relacionado à } \\
\text { visualização das criticas e a pedir para recuperar casos semelhantes. }\end{array}$ \\
\hline $\begin{array}{l}\text { Em média, quantas tarefas } \\
\text { nunca foram tentadas e quais } \\
\text { são elas? }\end{array}$ & Todas as tarefas foram tentadas por todos os usuários. \\
\hline $\begin{array}{l}\text { Em média, quantas vezes os os } \\
\text { usuários tiveram que recomeçar } \\
\text { desde o inicio? }\end{array}$ & $\begin{array}{l}\text { A maioria quase absoluta dos usuários teve que recomeçar a estruturação da } \\
\text { introdução. Em média o número de vezes que os usuários tiveram que } \\
\text { recomecar a introdução foi 1,8 vezes. }\end{array}$ \\
\hline $\begin{array}{l}\text { Em média, quantas vezes cada ar } \\
\text { tarefa foi realizada? }\end{array}$ & $\begin{array}{l}\text { Por se tratar de um sistema recursivo, o número de vezes que cada tarefa foi } \\
\text { realizada não é necessário ser avaliado. Por exemplo, o número de vezes que } \\
\text { se realiza a tarefa "Escolher Componentes Esquemáticos" é proporcional ao } \\
\text { número de componentes que se deseja colocar na introdução, uma vez que } \\
\text { para escolher cada elemento é preciso executá-la. }\end{array}$ \\
\hline $\begin{array}{l}\text { Em média, em que ordem as } \\
\text { tarefas foram executadas? }\end{array}$ & $\begin{array}{l}\text { Por ser a aplicação bastante flexível em relação a ordem de execução das } \\
\text { tarefas percebe-se que a execução das tarefas ocorreu aleatoriamente. }\end{array}$ \\
\hline $\begin{array}{l}\text { Em média, qual o grau de } \\
\text { satisfação dos usuários? }\end{array}$ & De um modo geral, os usuários ficaram satisfeitos com o sistema. \\
\hline
\end{tabular}

\subsubsection{Fase de Apresentaçăo dos Resultados}

$\mathrm{Na}$ fase anterior foi feita uma análise baseando-se principalmente nos logs dos usuários, no Modelo de Tarefas da aplicação e nos questionários respondidos pelos usuários. A partir da interpretação dos resultados obtidos dessa análise, tornou-se possivel propor soluções aos problemas encontrados na interface da aplicação.

A apresentação dos resultados obtidos desta etapa de avaliação é feita em um relatọ́rio estruturado em quatro colunas, conforme a Tabela 6.5. A primeira. coluna se refere aos problemas identificados através de sequiências de ações realizadas pelos, usuários e pelas respostas dadas aos queștionários. A segunḍa coluna diz respeito à identificação do problema, que é uma descrição de como o problema foi identificado. Na terceira coluna é feita uma descrição dos possíveis problemas cognitivos que podem ter gẹado o problema. E por último, na quarta coluna é apresentada a solução proposta, que é uma indicação para melhorar o projeto da interface do usuário. 


\section{TABELA 6.5 - Apresentação dos Resultados da Terceira Etapa de Avaliação}

\begin{tabular}{|c|c|c|c|}
\hline Problilema & itaç्ân. & fio (ougnitiva & is Propostat \\
\hline $\begin{array}{l}\text { Na fase de } \\
\text { escolha dos } \\
\text { componentes } \\
\text { esquemáticos os } \\
\text { usuários dizem } \\
\text { não ter uma } \\
\text { retroalimentação } \\
\text { sobre o } \\
\text { significado de } \\
\text { cada componente }\end{array}$ & $\begin{array}{l}\text { Este, problema foi identificado através das } \\
\text { respostas dos usuários ao questionário. Porém, } \\
\text { este problema não levou a nenhum erro ou } \\
\text { seqüência de açóes indesejável durante a } \\
\text { interação com a ferramenta. }\end{array}$ & $\begin{array}{l}\text { Uma vez que nenhum } \\
\text { erro foi cometida e } \\
\text { nenhuma sequêtncia de } \\
\text { ações indesejável } \\
\text { ocorreu, não há } \\
\text { nenhuma motivação } \\
\text { cognitiva explicita } \\
\text { para este problema. O } \\
\text { que ocorre é uma falta } \\
\text { de retroalimentação do } \\
\text { sistema. }\end{array}$ & 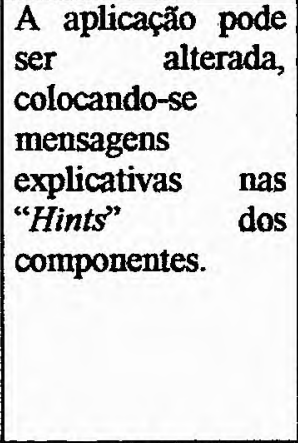 \\
\hline $\begin{array}{l}\text { Dificuldade de } \\
\text { identificar qual a } \\
\text { crítica que está } \\
\text { sendo lida. Isso } \\
\text { porque o item de } \\
\text { crítica não fica } \\
\begin{array}{l}\text { selecionado } \\
\text { enquanto }\end{array} \text { o } \\
\text { usuário le a } \\
\text { crítica. }\end{array}$ & $\begin{array}{l}\text { Este problema foi identificado através das } \\
\text { respostas dos usuários ao questionário. Porém, } \\
\text { este problema nåo levou a nenhum erro ou } \\
\text { sequêêcia de ações indesejável durante a } \\
\text { interação com a ferramenta. }\end{array}$ & $\begin{array}{l}\text { Esta dificuldade } \\
\text { aconteceu pelo fato de } \\
\text { o usuário ter percebido } \\
\text { de fórma errada a } \\
\text { açöes. Desta forma, é } \\
\text { necessário que o } \\
\text { sistema ofereça uma } \\
\text { retroalimentação } \\
\text { maior ao usuário nesta } \\
\text { fasse da interacaão. }\end{array}$ & 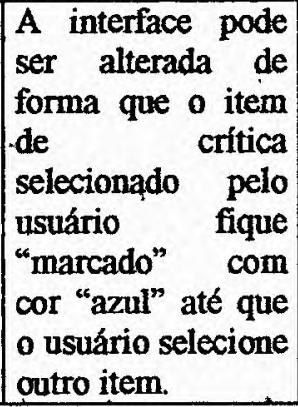 \\
\hline
\end{tabular}

\subsection{Análise Comparativa dos Resultados}

A partir de uma análise dos dados obtidos das três etapas de avaliaçấo réalizadas neste trabalho, pode-se dizer que as razões para se usar a a abordagem Iterativa proposta por Nièlsen (2000) se concretizaram no caso específico da avaliação da Ferramenta de Crítica: Iśso pode ser vistơ pelos seguintes itèns:

1. Em cáda turno, os problemas ideñtificàdos pelos dois últimos usuários quase sempré foram os mèsmos identificados pèlòs três primeiros. Porém, para Nielsen (2000), cinco é ó número ideal de usuários a fim de se evitar o riscó de ser enganado por um comportamento particular de uma só pessoa, que pode executár certás áções por acidentè ou de formá não representativa.

2. O número de problemas identificados na primeira etapa de avaliaçãa é maior qué ó número de problemas identificados na segunda etapa e os problemas identificados na segunda etapa somam-se um número maior do que aqueles identificados na terceira etapa de avaliação. Além disso, a importância dos problemas é mais marcante na primeira e segunda etapas (com mais intensidade na primeira), caracterizando uma dificuldade de interação do usuário com a ferramenta. 
3. Dentre os problemas identificados na segunda etapa encontrou-se um problema que foi introduzido na interface da aplicação como resultado das modificações feitas a fim de solucionar os problemas encontrados na avaliação realizada na primeira etapa. Isso confirma a afirmativa de Nielsen (2000) de que novos problemas podem ser inseridos como resultado de alguma alteração realizada.

Outros dados importantes a serem observados são:

- Na primeira etapa de avaliação, o tempo total de teste gasto pelos usuários foi maior que nas demais etapas, visto que os usuários tiveram um grau maior de dificuldade na interação. Dificuldade que foi identificada também através do maior número de vezes que o usuário consultou a documentação, do maior número de erros (classificados em erros de pré-condição e outros erros) que o usuário cometeu, pelo maior número de tarefas realizadas com falhas, pelo número de vezes que o usuário teve que recomeçar desde o início.

- O esforço para se aplicar o processo de avaliação foi compensado pelos resultados obtidos visto que não somente os problemas foram identificados, mas também resolvidos. Além disso, os passos iniciais do processo, mostrados no Capítulo 5 (Seções 5.2.1, 5.2.2, 5.2.3, 5.2.4), são realizados uma única vez durante todo o processo de avaliação. Enquanto que a especificação do a) Modelo de Tarefas, b) da Tabela de Tarefa-Log, e c) da Tabela de PréCondições pode ou não ser modificada de uma etapa para outra. Na segunda etapa da aplicação do processo à Ferramenta de Crítica, os itens a), b) e c) foram modificados, porém as modificações foram rápidas e simples. Na terceira etapa nenhuma modificação foi realizada em nenhum dos itens a), b) e c), pois as soluções propostas na Etapa 2 foram somente relacionadas à disposição de objetos na tela e não na forma de realização das tarefas.

Assim, pode-se dizer que a aplicação manual do processo pode ser realizada em um tempo relativamente curto, devido a não modificação do Modelo de Tarefas, da Tabela de Tarefa-Log e da Tabela de Pré-Condições da Etapa 2 para a Etapa 3. Espera-se que esse tempo seja muito menor com a utilização da ferramenta RemUSINE ou de outra similar feita nos nossos moldes.

Nesse capítulo abordou-se a avaliação de usabilidade da interface do protótipo da Ferramenta de Crítica, procurando mostrar as melhorias realizadas nesse sistema adquiridas da aplicação do processo de avaliação elaborado no Capítulo 5, e ressaltar os benefícios 
114 Aplicação de um Processa de Avaliação de Usabilidade em uma Ferramenta de Suporte à Escrita Técnica em Inglês

fornecidos por esse processo. O próximo capítulo mostra as contribuições e limitações encontradas nesse trabalho de mestrado e apresenta propostas para trabalhos futuros. 


\section{Capítulo 7}

\section{Conclusão}

Neste trabalho abordamos a aplicação de um processo de avaliação de usabilidade a uma ferramenta de suporte à escrita técnica em inglês. Esse processo foi elaborado baseando-se no método USINE (Lacerof \& Paternò, 1998) de avaliação de usabilidade e na abordagem de melhoria contínua proposta por Nielsen (2000).

As principais atividades desenvolvidas foram a elaboração do processo (a partir de um estudo comparativo entre vários métodos e técnicas de avaliação de usabilidade), vista no Capítulo 5, e a aplicação do processo elaborado para avaliar a Ferramenta de Crítica do ambiente AMADEUS, descrita no Capitulo 6.

\subsection{Contribuições}

Várias etapas foram realizadas para a concretização deste trabalho. Inicialmente, foi realizada uma ampla revisão da literatura sobre a importância dos fatores humanos em sistemas interativos, o conceito de usabilidade, as técnicas e métodos de avaliação de usabilidade.

A ferramenta alvo de avaliação foi então selecionada. A escolha da Ferramenta de Crítica se deu pelo fato dela ser um protótipo funcional (o que é um pré-requisito necessário à utilização do método de avaliação de usabilidade escolhido), desenvolvido em um mestrado 
do ICMC (Barreviera e Silva, 1999) estando seu código fonte facilmente disponível e à espera de melhorias para que seu uso seja difundido. Além de ser um sistema que dá suporte à uma tarefa com sobrecarga cognitiva (escrita), exigindo uma interface que não seja mais um peso para o usuário.

Baseado em uma análise de custo e benefício dos vários métodos de avaliação de usabilidade estudados escolheu-se o método USINE para ser utilizado nơ prócesso elaborado. Essa análise considera a importância dos problemas identificados, o custo e o tempo gasto para realizar a avaliação. O método USINE, por ser um método que utiliza suporte automático durante toda a avaliação requer menos tempo para a análise dos resultados e um custo menor, por não necessitar deslocar os usuários de seus locais de trabalho. Além disso, garante resultados maiș seguros, por empregar usuários reais nos testes do sistema.

A partir da escolha do método USINE, tornou-se evidente o uso de testes de usuários, que se enquadra no grupo de técnicas objetivas de avaliação. Então, baseando-se na abordagem de melhoria contínua de Nielsen, que aplica três etapas de testes de usuários com o sistema (a cada etapa são feitas propostas de solução para os problemas identificados), e no método USINE, elaborou-se um processo de avaliação de usabilidade. Este processo é uma das principais contribuições, visto que é um processo genérico que pode ser aplicado a qualquer tipo de sistema computacional interativo.

Outra importante contribuição foi a aplicação do processo elaborado. Primeiramente, realizou-se um estudo detalhado da Ferramenta de Crítica, em que foram analisadas suas principais características. Em seguida, fez-se um estudo do contexto de uso da aplicação, momento em que foi identificado quem são os seus usuários, o ambiente no qual ela está inserida e as tarefas que podem ser realizadas através da interação do usuário com a ferramenta. Posteriormente, estabeleceu-se os objetivos da avaliação e documentou-se alguns passos: a) a forma de condução dos testes; b) o critério de seleção dos usuários e o número de usuários teste necessários a cada etapa de avaliação; c) o material de suporte ao usuário e ao avaliador; d) o critério de realização das tarefas (com ou sem treinamento); e) as medidas a serem tomadas; f) a forma de preparação e análise dos resultados; e g) a forma de apresentação dos resultados. Por último, aplicou-se as três etapas de avaliação, implementando-se em cada etapa as melhorias propostas. 


\subsection{Limitações}

O método USINE utiliza três ferrametas: o edito de Árvore de Tarefas (ConcurTaskTrees), a ferramenta RemUSINE para a preparação e análise de resultados e uma ferramenta de captura de logs. No que diz respeito ao editor ConcurTaskTrees, seu funcionamento é bastante adequado e está disponivel.

A ferramenta RemUSINE, por ser ainda um protótipo, não está funcionando adequadamente e não foi possível usá-la. Com isso, as tarefas de fazer a Tabela de Tarefa-Log (que é a țabela de associação entre as tarefas básicas do Modelo de Tarefas e as ações dos usuários) e a análise dos resultados é tediosa e gasta muito tempo.

O fato de não ter conseguido encontrar uma ferramenta de captura de logs que registra os logs no formato compatível com o formato aceito pela ferramenta RemUSINE e que trabalhe com uma ferramenta desenvolvida para Windows foi também uma sobrecarga à realização da avaliação, visto que foi necessário reservar um tempo para a implementação da camada de software que registra os logs no formato desejado.

Esses fatos representam limitações em termos de tempo e custo, pois um dos maiores beneficios de se aplicar o método USINE para a avaliação de usabilidade de sistemas computacionais interativos está no fato de se utilizar ferramentas automáticas, o que aumenta a precisão dos resultados e diminui o tempo e o custo gastos com a avaliação.

Existem algumas limitações intrínsecas ao próprio método USINE que podem existir mesmo utilizando-se todas as ferramentas automáticas necessárias para a aplicação do método. Uma dessas limitações está relacionada ao tempo e esforço extra gasto para especificar o Modelo e Tarefas. Porém, é preciso fazer uma análise de custo e beneficio, pois este tempo extra pode ser benéfico tendo em vista que o exercício de se especificar o Modelo de Tarefas ajuda a entender melhor a aplicação. Outra limitação é o tempo extra gasto para fazer a Tabela de Tarefa-Log. Esse tempo pode ser considerado relativamente baixo, visto que a parte de preparação da ferramenta RemUSINE auxilia nesta tarefa. Além disso, esta tabela, assim como o Modelo de Tarefas, é feito uma única vez para se testar quantos usuários se queira avaliar em uma etapa de avaliação (se for realizado mais que uma etapa de avaliação o esforço e o tempo em adaptar o Modelo de Tarefas e a Tabela de Tarefa-Log é relativamente baixo, nem sempre sendo necessário modificá-los para todas as etapas). 


\subsection{Trabalhos Futuros}

Como observado na Subseção 7.2, não foi possível encontrar uma ferramenta de captura de logs que registrasse os logs no formato aceito pela ferramenta RemUSINE, sendo necessário se trabalhar no código da aplicação a ser avaliada. Essa não é a melhor alternativa, pois demanda tempo e esforço para se entender o código da aplicação e codificar a parte relativa à captura dos logs. Assim, um possível trabalho seria desenvolver uma ferramenta multiplataforma, que pudesse ser facilmente ajustada às necessidades não só da ferramenta RemUSINE, mas também de outras ferramentas semelhantes. Ex́iste um trabalho publicado nos anais do IHC'2000 que registra a interação humano-computador em ambiente Windows (Neto et al., 2000). Este pode ser um ponto de partida para se desenvolver uma nos mesmos moldes ou utilizar tal ferramenta.

Além disso, espera-se que se possa desenvolver uma ferramenta similar a RemUSINE (uma vez que já se conhece os algoritmos e conceitos envolvidos em tal ferramenta) ou obter a versão final dela com o autor. 


\section{Referências Bibliográficas}

(Abowd, 1992) Abowd, G.D.; Coutaz, J.; Nigay, L.; Cockton, G.; Harrison M.; Kazman R.; Unger, C.; ShneiderHufschmidt M.; Jarvinen, P. Structuring The Space of Interactive System Properties. IFIP Transactions A-Computer Science and Technolog, v.18, p.113129, 1992.

(Aluísio, 1995) Aluísio, S.M. Ferramentas para Auxiliar a Escrita de Artigos Científicos em Inglês como Língua Estrangeira. Master's Thesis, IFSC-USP. Tese de Doutorado, 1995.

(Aluísio \& Oliveira Jr., 1995a) Aluísio, S.M.; Oliveira Jr., O.N. A Case-Based Approach for Developing Writing Tools Aimed at Non-native English Users. Lecture Notes in Artificial Inteligence 1010, pages 121-132, 1995.

(Aluísio \& Oliveira Jr., 1995b) Aluísio, S.M.; Oliveira Jr., O.N. Developing Corpus-Based Writing Tools Aimed at Non-native Users of English. Proceedings of The Eighth Annual Conference on Writing and Computers., 1995.

(Barreviera e Silva et al., 1998) Barreviera e Silva, M.H.; Pellizoni, J.M.; Alúsio, S.M. Uma Abordagem Híbrida Baseada em Críticas e Casos para a Construção de Ferramentas Colaborativas de Ensino da Escrita de Artigos Científicos. In: Anais do IX SIMPÓSIO BRASILEIRO DE INFORMÁTICA NA EDUCAÇÃO, Fortaleza, CE, Novembro de 1998. (CD-ROM). 
(Barreviera e Silva et al., 1999) Barreviera e Silva, M.H. Um Sistema de Critica para um Ambiente de Escrita Técnica em Inglês. São Carlos, 1999. Dissertação (Mestrado) Instituto de Ciências Matemáticas e de Computação, Universidade de São Paulo.

(Bastien \& Scapin, 1993) Bastien, C; Scapin, D. Ergonomic Criteria for the Evaluation of Human-Computer Interfaces. INRIA, Repport Tecnique, n. 156, 1993.

(Bevan \& Macleod, 1994) Bevan, N.; Macleod, M. Usability Measurement in Context. Behavior and Information Techonology, v.13, p.132-145, 1994.

(Bevan, 1995).Bevan, N. Measuring Usability as Usability of Use. Software Quality Journal, n.4, p.115-130, 1995.

(Blandford, 1994) Blandford, A.E. Teaching Through Collaborative Problem Solving. Journal of Artificial Intelligence in Education, 5 (1), pages 51-84, 1994.

(Card et al., 1980) Card, S.K.; Moran, T.P.; Newell, A. The Keystroke-Level Model for User Performance Time With Interactive Systems. Communications of the $A C M, \mathrm{v} .23, \mathrm{n} .7$, p.396-410, 1980 .

(Burton et al., 1997) Burton, M.; Brna, P.; Treasure-Jones, T: Spliting the Collaborative Atom: How to Support Learning About Collaboration. Artificial Intelligence in Education, B. du Boulay and R. Mizoguchi (Eds.), IOS Press, pages 135-142, 1997.

(Card et al., 1983) Card, S.K.; Moran, T.P.; Newell, A. The Psyclyology of Human-Computer Interation. Hillsdate, N.J, Lawrence Erlbaum Assoc., 1983.

(Carroll \& Rosson, 1987) Carroll, J.M.; Rosson, M.B. The Paradox of the Active User. In: Carrol, J.M. Interfacing Thought: Cognitive Aspects of Human-Computer Interaction. Cambridge, Bradford Books?MTT Press, 1987. p.80-111.

(Carroll \& Rosson, 1990) Carroll, J.M.; Rosson, M.B. Human Computer Interaction Scenarios as a Design Representation. Proceeding of THE 23RD HAWAII INTERNATIONAL CONFERENCE ON SYSTEM SCIENCE (IEEE HICSS-23). Howaii, 1990, p.555-561:

(Clarke, 1991) Clarke, L. The use of Scenarios by User Interface Designers. In: Diaper, D; Hammond, N. People and Computers VI. Cambridge, Cambridge University Press, 1991. p.103-115. 
(Cuomo \& Bowen, 1992) Cuomo, D.L.; Bowner, C.D. Stages of User Activity Model as a Basis for User-System Interface Evaluations. In: HUMAN FACTORS SOCIETY 36TH ANNUAL MEETING. Atlanta, GA, 1992. Proceedings. p.1254-1258.

(Desurvire et al., 1992) Desurvise, H.W.; Kondiziela; J.M.; Atwood, M.E. What is Gained and Lost When Using Evaluation Methods Other Than Empirical Testing. In: Monk, A.; Diaper, D.; Harrison, M.D. People and Computers VII. Cambridge, Cambridge University Press, 1992. p.89-102.

(Diaper, 1989) Diaper, D. Task Analysis for Human - Computer Interaction. Chichester, Ellis Horwood, 1989.

(Dix, 1987) Dix, A.J.: Formal Methods and Interactive Systems: Principles and Practice. University of York - Department of Computer Science, 1987.

(Dumas \& Redish, 1994) Dumas, J.S.; Redish, J.C. A Pratical Guide to Usability Testing. Norwood, N.J, Ablex, 1994.

(Fischer, 1991) Fischer, G. Supporting Learning On Demand With Design Environments. Proceedings of the INTERNATIONAL CONFERENCE ON THE LEARNING SCIENCES. Charlottesville, 1991, p.165-172.

(Fisher et al., 1991) Fisher, G.; Lemke, A.C.; Mastaglio, T. Critics: An Emerging Approach to Knowlwdge-Based Human-Computer Interaction. International J. of Man-Machine Sdudies, 35, pages 695-721, 1991.

(Fisher et al., 1993) Fisher, G.; Nakakoji, K.; Ostwald; J.; Stahl, F.; Summer, T. Embedding Computer-Based Critics in the Contexts of Design. Conference on Human Factors in Computing Systems, Amsterdam, 24-29 April/1993, pages 157-164, 1993.

(Fisher, 1995) Fisher, G. Rethinking and Reinventing Artificial Intelligence from the Perspective of Human-Centered Computacional Artifacts. Lecture Notes in Artificial Intelligence 991, pages 1-11, 1995.

(Fontana et al., 1993) Fontana, N.; Caldeira, S.M.A.; De Oliveira, M.C.F.; Oliveira Jr., O.N. Computer Assisted Writing - Aplications to English as a Foreign Language. CALL, Volume 6(2), pages 145-161, 1993. 
(Hartson, 1998) Hartson, H.R. Human-Computer Interaction: Interdiciplinary roots and trends. The Journal of System and Software, v.43, p.103-1.18, 1998.

(ISO, 1988) ISO/IS 8807, Information Processing Systems - Open Systems Interconnection LOTOS- A formal Description Based on Temporal. Ordering of Observational Behavior. ISO Central Secretariat, 1988.

(ISO, 1991) ISO 9241, Ergonomic Requiriments for office work With Visual Display Terminals, 1991.

(Jefries et al., 1991) Jefries, R.; Miller, J.R.; Wharton, C.; Uyeda, K.M. User Interface Evaluation in the Real World: A Comparison of Four Techniques. In.. CONFERENCE ON HUMAN FAC̣TORS IN COMPUTING SYSTEMS (CHI'91). ACM Press, 1991. Proceedings. p.119-124.

(Karat et al., 1992) Karat, C. M; Campbell, R.; Fiegel, T. Comparison of Empirical Testing and Walkthrough Methods in User Interface Evaluation. In: CONFERENCE ON HUMAN FACTORS IN COMPUTING SYSTEMS (CHI'92). New York, 1992. Proceedings. p.397. 404.

(Kirakoswski \& Corbett, 1993) Kirakoswski, J.; Corbett, M. SUMI: The Software Usability Measurement Inventory. British Journal of Education Technology, v.24, n.3, p.210-214, 1993.

(Kirakoswski, 1995) Kirakoswski, J. The Software Usability Measurement Inventory: Background and Usage. In: Jordan, P.; Thomas, B.; Weerdmeester, B. Usability Evaluation in Industry. London, 1995.

(Lacerof \& Paternò, 1998) Lacerof, A;; Paternò, F. Automatic Support for Usability Evaluation. IEEE Transactions on Software Engineering, v.24, n.10, p.863-887, 1998.

(Landauer, 1996) Landauer, T.K. The Trouble With Computers: Usefulness, Usability and Productivity. The MIT Press, 1996.

(Lavery; et al., 1997) Lavery, D.; Cockton, G.; Atkinson, M.P. Comparison of Evaluation Methods Using Structured Usability Problems Reports. Behaviour \& Information Technology, v.16, p.246-266, 1997. 
(Lewis et al., 1990) Lewis, C.; Polson, P.; Wharton, C.; Rieman, J. Testing a Walkthrough Methodology for Theory-Based Design of walk-up-and-use Interfaces. Proceedings of the ACM CHI'90 Conference, Seattle, pp.235-242,1990.

(Macleod \& Rangge, 1993) Macleod, M; Rengger, R. The Development of DRUM: A Software Tool for Video-assisted Usability Evaluation. Proceeding of the Conference HCI'93. Loughborough, UK, 1993, p. 293-309.

(Macleod, 1994) Macleod, M. Usability in Context: Improving Quality of Use. Proceedings of the International Ergonomics Association 4th International Symposium on Human Factors in Organizational Design and Management. Amsterdam, Stockholm, 1994.

(Macleod, 1996) Macleod, M. Performance measurement and ecological validity. In. Jordan P.; Thomas, B.; Weerdmeester. Usability Evaluation in Industry. Taylor \& Frances, UK, 1996.

(Macleod et al., 1997) Macleod, M.; Bowden, R.; Bevan, N. The Music Performance Measurement Method. Behavior \& Information Technology, v. 10, 1997.

(Mantaras \& Plaza, 1995) Mantara,R. T.; Plaza, E. Case based Reasoning. The Newsletter of the European Network of Excellence in ML, p. 29-37, Special Issue, September, 1995.

(Morris \& Dilon, 1996) Morris, M.G.; Dillon, A.P. The Importance of Usability in the Establishment of Organizational Software Standards for End User Computing. Int. J. Human-Computer Studies, n.45, p.243-258, 1996.

(Neto et al., 2000) Neto, S.M; Matias, M; Santos, N. Uma Ferramenta de Apoio ao Registro da Interação Humano-Computador. In: $3^{\mathrm{RD}}$ WORKSHOP ON HUMAN FACTORS IN COMPUTING SYSTEMS (IHC'2000). Gramado, 2000. Proceedings. p.142-150.

(Nicholls, 1979) Nicholls, J.E. Programming the End User. In Shackel, B. Man-Computer Comunication. Maidenhaead, Infotech International, 1979.

(Nielsen, 1992) Nielsen, J. Finding Usability Problems Through Heuristic Evaluation. Proceedings of the ACM CHI'92 CONFERENCE. Monterey, CA, 1992, p.373-380.

(Nielsen, 1993) Nielsen, J. Usability Engineering. Academic Press, London, United Kingdom. 1993. 
(Nielsen, 1994a) Nielsen, J. Heuristic Evaluation. In: Nielsen,J.; Mack, R.L. Usability Inspection Methods. New York, John Wiley \& Sons, 1994.

(Nielsen, 1994b) Nieisen, J. Guerrilha HCI: Using Discount Usability Engineering to Penetrate the Intimidation Barrier. In: Bias, R.G.; Mayhew, D.J. Cost-Justifying Usability. Boston, Academic Press, 1994.

(Nielsen, 2000) Nielsen, J. Nielsen, J. Why you Only Need to Text With 5 Users. [Online] [20/06/2000] Disponível na Internet http://www.useit.com/alertbox/20000319.html.

(Norman, 1986) Norman, D.A. Cognitive Engineering. In: Norman, D.; Draper, S. User Centered System Design: New Perspectives on Human-Computer Interaction. Hillsdale, NJ, Erlbaum, 1986. p.31-61.

(Paternò et al., 1995) Paternó, F.; Sciacchitano, M.S.; Löwgren, J.A. User Interface Evaluation Mapping Physical User Actions to Task-Driven Formal Specifications. In: Palanque, P.; Bastide, R. Design, Specification, and Verification of Interactive. System. Tolouse, Springer-Verlag, 1995. p.35-53.

(Paternò et al., 1997a) Paternò, F.; Mancini, C.; Menicone, S. ConcurTaskTrees: . A Diagrammatic Notation for Specifying Task models. Proceeding of the INTERACT"97. Sydney, 1997, p.362-369.

(Paternò et al., 1997b) Paternò, F; Mancini, C.; Menicone, S. Engineering Task Models. IEEE Config. Eng. Complex Sistems, v.9, p.69-76, 1997.

(Paternò \& Menicone, 1998) Paternò, F; Menicone, S. TLIM: A Sistematic Method for the Design of Interactive Systems. In: Palanque, F.; Paternó, F. Formal Methods in HumanComputer Interaction. London, Springer-Verlag, 1998, p.241-259.

(Paternò, 1999) Paternò,. F. Model-Base Design and Evaluation of Interactive Applications. Springer-Verlag, London.

(Polson et al., 1992) Polson, P.; Lewis, C.; Rieman, J.; Wharton, C. Cognitive Walkthrough: A Method for Theory-Based Evaluation of User Interfaces. International Journal of Machine Studies, v.36, p.741-773, 1992. 
(Prates, 1998) Prates, R.O. A Engenharia Semiótica de Interfaces Multi-Usuário. Rio de Janeiro, 1998, 113p. Tese (Doutorado) - Departamento de Informática, Pontificia Universidade Católica do Rio de Janeiro.

(Pressman, 1995) Pressman, R.S. Engenharia de Software. 3ed., São Paulo, Makron Books, 1995.

Rankin (1993) Rankin, I. Natural Language generation in Critiquing. The Knowledge Engineering.Review, Vol.8, n.4, pages 329-347, 1993.

(Renié \& Chanier, 1995) Renié, D.; Chanier, T. Collaboration and Computer-Assisted Acquisition of a Second Language. CALL Journal, Vol 8, n. 1, pages 3-29, 1995.

(Rowley \& Rhoades, 1992) Rowley, D.E.; Rhoades, D.G. The Cognitive jogthrough: a FastPaced User Interface Evaluation Procedure. Proceedings of the ACM CHI'92 CONFERENCE. Monterey, CA, 1992, p.389-395.

(Scapin \& Bastien, 1997) Scapin, D.L.; Bastian, J.M. Ergonomic Criteria for Evaluating of Ergonomic Quality of Interactive Systems. Behaviour \& Information Technology, v.16, n.4, p.220-231, 1997.

(Scholtz, 1995) Scholtz, J. Usability: What's it all about? Software Quality Journal, n.4, p.95-100, 1995.

(Shackel \& Richardson, 1991) Shackel, B.; Richardson, S. Human Factors for Informatics Usability. Cambridge University Press, 1991.

(Shneiderman, 1987) Shneiderman, B. Designing the User Interface, Addison- Wesley, 1987.

(Shneiderman, 1998) Shneiderman, B. Designing the User Interfac: Strategies for Effective Human-Computer Interaction.3rd ed. Addison- Wesley, 1998.

(Silverman, 1992) Silverman, B.C. Survey of Expert Critiquing Systems: Pratical and Theoretical Frontiers. CACM, Vol.35, N.4, pages 107-127, 1992.

(Smith et al., 1997) Smith, P.A.; Newman, I.A; Parks, L.M. Virtual hierarquies and virtual Networks: some lessons from hipermidia usability research applied to the World Wide Web. Int. J. Human - Computer Studies, n.47, p.67-95, 1997. 
(Thomas \& Curson, 1996) Thomas, C; Curson, I. Performance Measurement Handbook. National Physical Laboratory, Teddington, UK, v3, 1996.

(Thomas \& Bevan, 1996) Thomas, C; Bevan, N. Usability Context Analysis Guide. National Physical Laboratoy, 'Teddington, UK, v4, 1996.

(Wharton et al., 1992) Wharton, C.; Bradford, J.; Jeffries, R.; Franzke, M. Applying Cognitive Walkthrough to More Complex User Interfaces: Experiences, Issues, and Recommendations. Proceedings of the ACM CHI'92 CONFERENCE. Monterey, CA, 1992, p.381-388.

(Wharton et al., 1994) Wharton, C.; Rieman, J.; Lewis, C.; Polson, P. Cognitive Walkthrough Methods: A Practitioner's Guide. In: Nielsen, J.; Mark, R.L. Usability Inspection Methods. New York. John Wiley \& Sons, 1994.

(Wilson et al., 1993) Wilson, S.; Johnson, P.; Kelly, C.; Cunningham; J.; Mafkopoulos, P. Beyond Hacking: A Model-Based Approach to User Interface Design. Proceeding of the HCI'93 CONFERENCE. Loughborough, UK, Cambridge, 1993.

(Wisner, 1987) Wisner, A. Por dentro do trabalho: ergonomia, método \& técnica. São Paulo, FTD, Oboré, 1987.

(Yourdon, 1989) Yourdon, E. Structured Walkthrough. (4th ed.), Englewood Cliffs, NJ, Yourdon Press, 1989. 
Este documento apresenta um exemplo do arquivo de logs capturado através da camada de software implementada (Seção 1) e parte da análise dos logs de um usuário (Seção 2).

\section{Exemplo de um Arquivo de Logs}

Abaixo é apresentado um exemplo de um arquivo de logs obtido de uma sessão de testes com o usuário. A primeira linha se refere ao tempo gasto entre uma ação e outra, dado em milisegundos. A segunda linha se refere à ação realizada, que aparece concatenada com o Widget, por exemplo "DragOvePalette_domain" para arrastar o componente "Domain" da Palette.

Delay(ms): 0

Evento : ClickTrab_schematics 0

Delay(ms): 9400

Evento : DblClickPalette_intro(0)

Delay(ms): 4370

Evento : DragOverPalette_intro() 
Delay(ms): 1040

Evento : DragDropT_Trab_F_Palette_intro0

Delay(ms): 3520

Evento : ClickTrab_intro_FirstO

$\operatorname{Delay}(\mathrm{ms}): 44280$

Evento : DragOverPalette_domain()

Delay(ms): 3680

Evento : DragDropT_Trab_F_Palette_domain0

Delay(ms): 4650

Evento : DragOverPalette_contents()

Delay(ms): 1100

Evento : DragDropT_Trab_F_Palette_contents 0

$\operatorname{Delay}(\mathrm{ms}): 61510$

Evento :ClickReplacePalette_what's been done0

Delay(ms): 7570

Evento :DragOverPalette_structure()

Delay(ms): 880

Evento :DragDropT_Trab_F_Palette_structure0

Delay(ms): 4810

Evento : DragOverTrab_what's been done 0

Delay(ms): 1070

Evento : DragDropT_Trab_F_Trab_what's been done0

Delay(ms): 3920

Evento : DblClickTrab_specifics 0

Delay(ms): 113150

Evento : ClickTrab_specifics 0

Delay(ms): 69120

Evento : ActivatePeerAnnotationo

Delay(ms): 1340

Evento : ClickCritica()

Delay(ms): 7030

Evento :ClickTrab_intro0

Delay(ms): 1010

Evento : DragOverPalette_contribution(s)0 
Delay(ms): 1210

Evento : DragDropT_Trab_F_Palette_contribution(s)0

Delay(ms): 2470

Evento : ClickReplacePalette_background()

Delay(ms): 1270

Evento :DblClickTrab_specifics()

Delay(ms): 11480

Evento : ActivatePeerAnnotation()

Delay(ms): 2570

Evento : ClickCritica()

$\operatorname{Delay}(\mathrm{ms}): 110$

Evento : ClickCriticaO

Delay(ms): 14220

Evento : ClickCritica0

Delay(ms): 2070

Evento : DragOverPalette_contribution(s)0

Delay(ms): 1120

Evento :DragDropT_Trab_F_Palette_contribution(s)0

Delay(ms): 2140

Evento : ClickReplacePalette_background 0

Delay(ms): 3300

Evento : ClickTrab_paper0

$\operatorname{Delay}(\mathrm{ms}): 61200$

Evento : TextWrite_examples()

$\operatorname{Delay}(\mathrm{ms}): 12740$

Evento : ClickLink()

Delay(ms): 4320

Evento : ClickLinkO

Delay(ms): 90420

Evento : CloseWorkBench0 


\section{Parte de uma Análise de Teste}

O texto abaixo ilustra a análise dos logs obtidos de uma sessão de teste de usuário com a Ferramenta de Crítica. A seguinte análise foi realizada utilizando-se o procedimento descrito no Capítulo 6, Seção 6.1.

$v$ - ClickTrab-schematics 0

Está associada com a tarefa "FocSchem", a qual não tem pré-condição. Então a tarefa "FocSchem" é realizada e mudamos seu valor na tabela de pré-condições para verdade. Assim a linha 6 da tabela de pré-condições passa a ser:

6 - IntroPall | FocSchem < true $>$

F - DblClickTrab_intro 0

A ação não existe na tabela de associação, portanto o usuário tentou executar uma ação (dar duplo click em "Intro" na área de trabalho, tentando preparar o ambiente para seleção dos componentes) que não é permitida pela aplicação.

Isso representa que o usuário teve dificuldade na fase inicial de execução da ferramenta, mais especificamente em saber que para compor a introdução deveria arrastar "Intro" para dentro de "schematics" na área de trabalho (conta-se como 1 erro).

$v$ - DragOverPalette_intro0

Está associada com a tarefa "ArrastIntro", a qual tem "FocSchem" como pré-condição. Uma vez que a tarefa "FocSchem" está marcada com o valor <true>, a tarefa "ArrastIntro" é realizada e mudamos seu valor na tabela de pré-condições para verdade. Assim a linha 9 da tabela de pré-condições passa a ser:

9 - SoltaIntro | ArrastIntro < true $>$

V - DragDropT_Trab_F_Palette_intro0

Está associada com a tarefa "SoltatIntro", a qual tem "ArrastIntro" como pré-condição. Uma vez que a tarefa "ArrastIntro" está marcada com o valor <true>, a tarefa "Soltatintro" é realizada e mudamos seu valor na tabela de pré-condições para verdade. Assim a linha 7 da tabela de pré-condições passa a ser:

7 - IntroduzirIntro| SoltaIntro $<$ true $>$ FocaSchematics $<$ true $>$ 
v - ClickTrab_Intro_First

Está associada com a tarefa "FocIntroFirst", a qual tem "Introduzir" como pré-condição. Uma vez que a tarefa "Introduzir " está marcada com o valor <true>, a tarefa " FocIntroFirst " é realizada e mudamos seu valor na tabela de pré-condições para verdade. Assim a linha 12 da tabela de pré-condições passa a ser:

12 - CompPallFirst $\mid$ FocIntroFirst $<$ true $>$

$V$ - DragOverPalette_domain()

Está associada com a tarefa "ArrastDom", a qual não tem pré-condição, então a tarefa "ArrastDom" é realizada e mudamos seu valor na tabela de pré-condições para verdade. Assim a linha 17 da tabela de pré-condições passa a ser:

17 - SoltaDom | ArrastDom < true $>$

$V$ - DragDropT_Trab_F_Palette_domain()

Está associada com a tarefa "SoltaDom", a qual tem "ArrastDom" como pré-condição. Uma vez que a tarefa “ ArrastDom” está marcada com o valor <true>, a tarefa “ SoltaDom” é realizada e mudamos seu valor na tabela de pré-condições para verdade. Assim a linha 15 da tabela de pré-condições passa a ser:

15 - Domain $\mid$ SoltaDom < true $>$

$V$ - DragOverPalette_contents ()

Está associada com a tarefa "ArrastCont", a qual não tem pré-condição, então a tarefa "ArrastCont" é realizada e mudamos seu valor na tabela de pré-condições para verdade. Assim a linha 32 da tabela de pré-condições passa a ser:

32 - SoltaContent $\mid$ ArrastCont $<$ true $>$

V - DragDropT_Trab_F_Palette_contents()

Está associada com a tarefa "SoltaContent", a qual tem "ArrastCont" como pré-condição. Uma vez que a tarefa “ArrastCont" está marcada com o valor <true>, a tarefa " SoltaContent" é realizada e mudamos seu valor na tabela de pré-condições para verdade. Assim as linhas 33 e 34 da tabela de pré-condições passa a ser:

33 - EsCont $\mid$ SoltaContent $<$ true $>$ e 34 Comp $\mid$ SoltaContent $<$ true $>$ 
v - ClickReplacePalette_What's been done 0

Está associada com a tarefa "FoiFeito", a qual tem "Comp" como pré-condição. Uma vez que a tarefa "Comp" está marcada com o valor <true>, a tarefa "FoiFeito" é realizada e mudamos seu valor na tabela de pré-condições para verdade. Assim a linha 33 da tabela de précondiçðes passa a ser:

33-EsCont $\mid$ FoiFeito< true $>$

$\boldsymbol{v}$-DragOverPalette_structure 0

Está associada com a tarefa "ArrastEstruc", a qual não tem pré-condição, então a tarefa "ArrastEstruc" é realizada e mudamos seu valor na tabela de pré-condições para verdade. Assim a linha da tabela de pré-condições passa a ser:

20 - SoltaEstruct | ArrastEstruc < true >

v - DragDropT_Trab_F_Palette_structure 0

Está. associada com a tarefa "SoltaEstruct", a qual tem "ArrastEstruc" como pré-condição. Uma vez que a tarefa "ArrastEstruc" está setada com o valor <true >, a tarefa "SoltaEstruct" é realizada e mudamos seu valor na tabela de pré-condições para verdade. Assim a linha $18 \mathrm{da}$ tabela de pré-condições passa a ser:

18 -structure | SoltaEstruct $<$ true $>$

$v$ - DragOverTrab_what's been done 0

Está associada com a tarefa "TFFeito", a qual não tem pré-condição, então a tarefa "TFFeito" é realizada e mudamos seu valor na tabela de pré-condições para verdade. Assim a linha $67 \mathrm{da}$ tabela de pré-condições passa a ser:

58 - SFFeito | TFFeito < true >

v - DragDropT_Trab_F_Trab_what's been done0

Está associada com a tarefa "SFFeito", a qual tem "TFFFeito" como pré-condição. Uma vez que a tarefa "TFFeito" está setada com o valor <true〉, a tạrefa "SFFeito" é realizada e mudamos seu valor na tabela de pré-condições para verdade. Assim a linha 65 da tabela de pré-condições passa a ser:

65 - TrocaFFeito | SFFeito<true $>$ 


\section{F-DblClickTrab_specifics()}

A ação não existe na tabela de associação, portanto o usuário tentou executar uma ação (dar duplo click em "specifics" na área de trabalho na tentativa de pedir críticas.

Isso representa que o usuário teve dificuldade em pedir críticas (conta-se como 1 erro).

\section{$v$ - ClickTrab_specifics ()}

Está associada com a tarefa "FocSpecif". Uma vez que a tarefa "FocSpecif" não tem précondição ela é realizada e mudamos seu valor na tabela de pré-condições para verdade. Assim a linha 98 da tabela de pré-condições passa a ser:

98 - Criticas $\mid$ FocSpecif < true $>$

\section{$v$ - ActivatePeerAnnotation()}

Está associada com a tarefa "ClickIconeCritic", a qual tem " Criticas" como pré-condição. Uma vez que a tarefa "Criticas" está marcada com o valor <true>, a tarefa “ ClickIconeCritic" é realizada e mudamos seu valor na tabela de pré-condições para verdade. Assim a linha 100 da tabela de pré-condições passa a ser:

100- ClicVerCritica | ClickIconeCritic < true >

\section{v - ClickCritica()}

Está associada com a tarefa " ClicVerCritic", a qual tem "ClickIconeCritic " como précondição. Uma vez que a tarefa "ClickIconeCritic" está marcada com o valor <true>, a tarefa "ClicVerCritic" é realizada e mudamos seu valor na tabela de pré-condições para verdade. Assim a linha 96 da tabela de pré-condições passa a ser:

96 - PedirCriticas | ClicVerCritic <true $>$

\section{$v$ - ClicTrab_intro ()}

Está associada com a tarefa "FocIntroTrab". Uma vez que a tarefa "FocIntroTrab " não tem pré-condição ela é realizada e mudamos seu valor na tabela de pré-condições para verdade. Assim a linha 104 da tabela de pré-condições passa a ser:

104 - CompPall | FocIntroTrab < true $>$ 
v - DragOverPalette_contribution(s) 0

Está associada com a tarèfa “ ArrastContrib “, a qual não tem pré-condição, então a tárefa “ ArrastContrib " é realizada e muđamos seu valor na tabela de pré-condições para verdade. Assim a linha 24 da tabela de pré-condições passa a ser:

24 -SoltaContrib | ArrastContrib < true $>$

v - DragDropT_Trab_F_Palette_contribution(s)0.

Está associada com a tarefa "SoltaContrib", a qual tem "ArrastContrib" como pré-çndição. Uma vez que a tarefa "ArrastContrib " está marcada com o valor $<$ true $>$, a tarefa " SoltaContrib" é realizada e mudamos seu valor na tabela de pré-condições para verdade. Assim as linhas 25 e 26 da tabela de pré-condições passa a ser:

25 - EsContrib $\mid$ SoltaContrib $<$ true $>$

26 - ApresComp |SoltaContrib < <rue $>$

v - ClickReplacePalette_background 0

Está associada com a tarefa "Background", a qual tem "ApresComp" como pré-condição. Uma vez que a tarefa "ApresComp" está marcada com o valor <true>, a tarefa "Background" é realizada e mudamos seu valor na tabela de pré-condições para verdade. Ássim a linha $25 \mathrm{da}$ tabela de pré-condições passa a ser:

25- EsContrib | Backgrouind < true >

F -DblClickTrab_specifics $0^{\circ}$

A ação não existe na tabela de associação, portanto o usúátio tentou executar uma ação (dar duplo click em "specifics" na área de trabalho) errada.

F -ActivatePeerAnnotation0

Está associada com a tarefa "ClickIconeCritic", a qual tem "Criticas" como pré-condição. Uma vez que.a tarefa "Criticas". está marcada com o valor <false>, a tarefa "ClickIconeCritic" não é realizada e tem-se um erro de pré-condição.

\section{F-ClickCritica)}

Está associada com a tarefa "ClicVerCritic", a qual tem "ClickIconeCritic " como précondição. Uma vez que a tarefa "ClickIconeCritic" está setada com o valor $<$ false $\rangle$, a tarefa " 
ClicVerCritic" nao é realizada e tem-se um erro de pré-condição. Esta ação é realizada três vezes, o que conta como três erros.

- O usuário insere novamente o componente "background", pois por ter executado as ações anteriores ele leu as críticas antigas, que informavam a falta do componente mencionado.

\section{$v$ - ClicTrab_paper ()}

Está associada com a tarefa "Hum". Uma vez que a tarefa "Hum" não tem pré-condição ela é realizada e mudamos seu valor na tabela de pré-condições para verdade. Assim as linhas 107, 108, 109 e 112 da tabela de pré-condições passa a ser:

107 - Opcao $\mid$ Hum < true $>$

108 - OpcaoRecup $\mid$ Hum < true $>$

109 - Example $\mid$ Hum $<$ true $>$

112 - Cancel $4 \mid$ Hum $<$ true $>$

$v$ - TextWrite_example ()

Está associada com a tarefa "Example", a qual tem "Hum" como pré-condição. Uma vez que a tarefa "Hum" está marcada com o valor <true $>$, a tarefa "Example“ é realizada e mudamos seu valor na tabela de pré-condições para verdade. Assim a linha 110 da tabela de précondições passa a ser:

110- Links $\mid$ Example $<$ true $>$

\section{v - ClickLink ()}

Está associada com a tarefa "Result", a qual tem "Links" como pré-condição. Uma vez que a tarefa "Links" está marcada com o valor <true>, a tarefa "Result" é realizada e mudamos seu valor na tabela de pré-condições para verdade. Assim a linha 108 da tabela de pré-condições passa a ser:

108- OpcaoRecup | Result < true $>$

- O usuário realiza esta ação outra vez, que é um procedimento natural.

\section{$v$ - CloseWorkbench ()}

Está associada com a tarefa "Sair". Uma vez que a tarefa "Sair " não tem pré-condição ela é realizada . 
O Modelo de Tarefas, a Tabela de Tarefa-Log e a Tabela de Pré-Condições obtidos na segunda e terceira etapas/turnos de avaliação são os mesmos. Esses dados são mostrados abaixo.

\section{Modelo de Tarefas}

Apenas algumas partes do Modelo de Tarefas da Ferramenta de Critica foram alteradas na segunda etapa/turno de avaliação. Na terceira etapa/turno nenhuma alteração foi feita no modelo especificado na segunda etapa. Assim, optou-se por apresentar nesse apêndice apenas as partes alteradas na segunda etapa de avaliação. O Modelo de Tarefas completo da Ferramenta de Crítica é apresentado na Figura B.1. As Figuras B.2, B.3 e B.4 representam a especificação das sub-árvores que sofreram alteração: PrepararSelecaoCompEsquem, SelecionarComponentes e ExcluirComponentes. As demais sub-árvores da Figura B.1 correspondem às sub-árvores Trocas e VisualizarCríticas (Figuras 6.4 e 6.6, respectivamente) do modelo de tarefa foram apresentadas no Capitulo 6. 


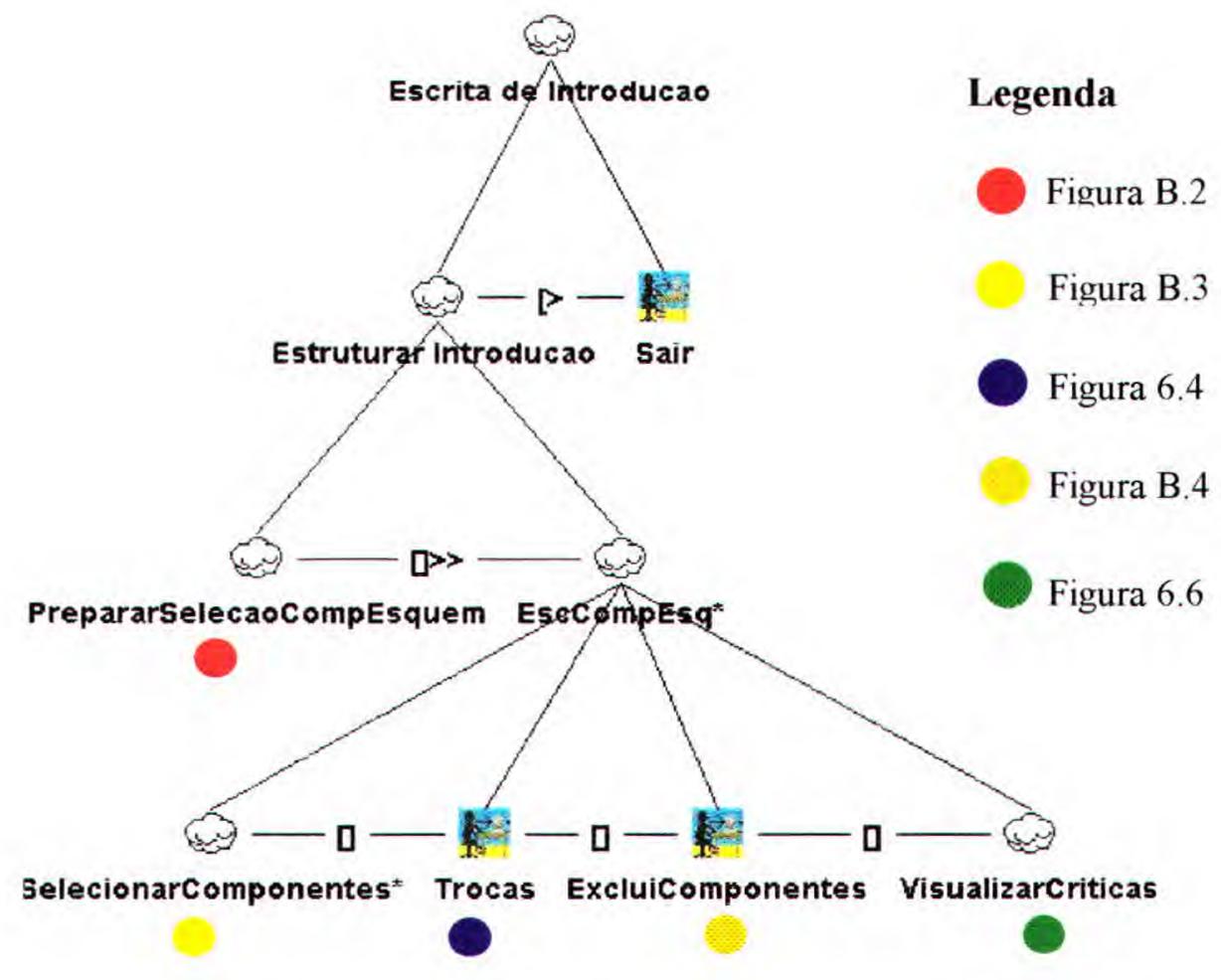

FIGURA B.1 - Modelo de Tarefas da Interface da Ferramenta de Crítica da Segunda e Terceira Etapa/Turno de Avaliação

A fase de preparação do ambiente de seleção dos componentes esquemáticos foi simplificada, inserindo "Intro" direto em "schematics". Desta forma, ao iniciar a interação com a ferramenta o usuário terá apenas que focalizar em "schematics" e em seguida em "Intro", visualizando os componentes a serem escolhidos para compor a Introdução. A parte do Modelo de Tarefas relacionada a essa alteração é mostrada pela Figura B.2.

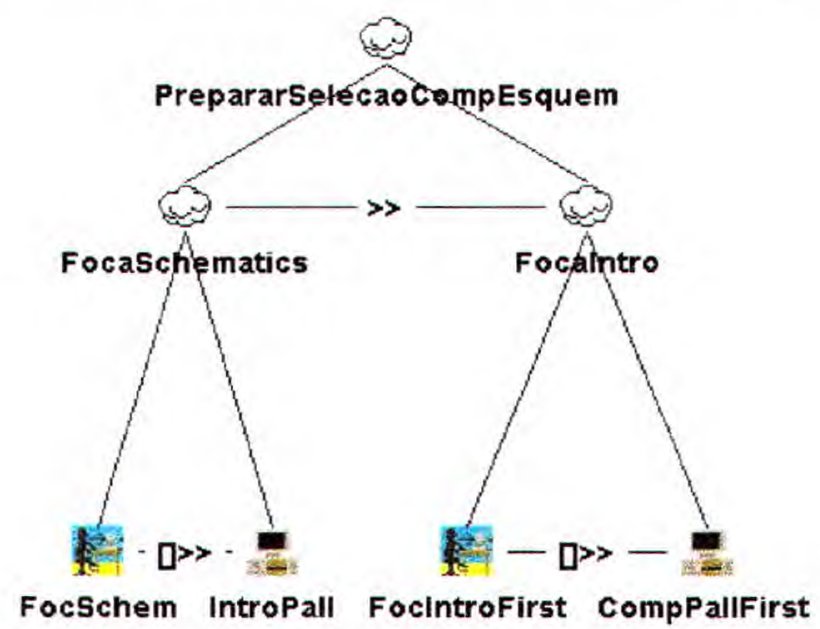

FIGURA B. 2 - Sub-árvore PrepararSelecaoCompEsquem da Segunda e Terceira Etapa/Turno de Avaliação 
Uma vez que os usuários tiveram dificuldade em inserir os componentes esquemáticos em Intro usando somente a opção de arraste, a aplicação foi alterada de forma a permitir que os componentes esquemáticos fossem escolhidos na Pallete e inseridos em Intro através de um duplo click no componente ou arrastando-o da Pallete para dentro de Intro. A parte do Modelo de Tarefas relacionada a essa alteração é mostrada pela Figura B.3.

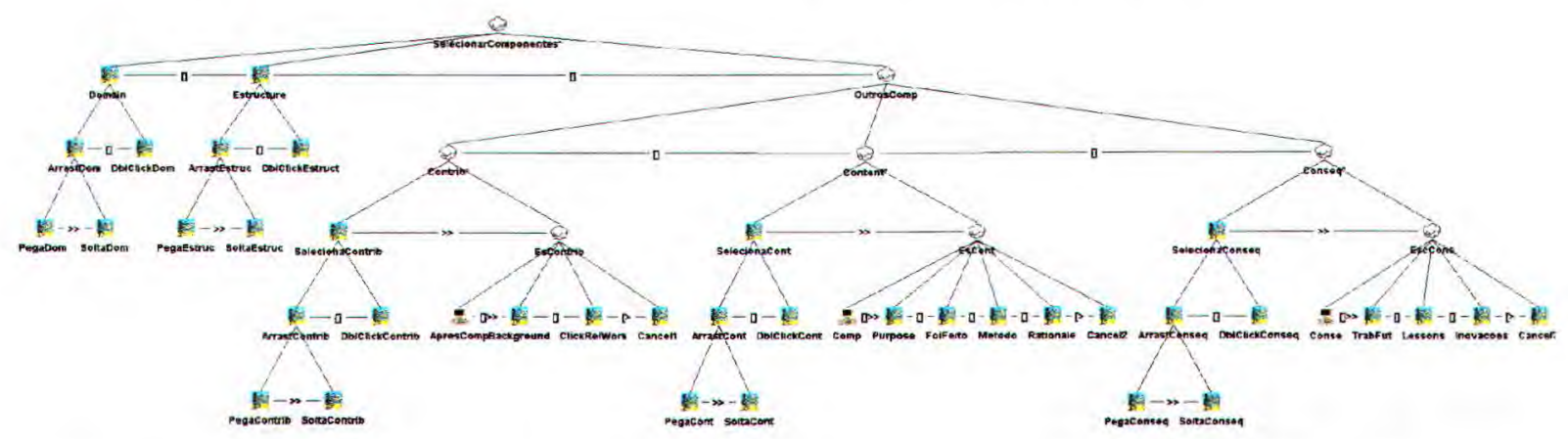

FIGURA B.3 - Sub-árvore SelecionarComponentes da Segunda e Terceira Etapa/Turno de Avaliação

Os usuários tiveram problemas relacionados a excluir componentes, pois a única possibilidade para realizar tal tarefa era através da tecla "Delete" do teclado. A fim de permitir uma flexibilidade maior neste sentido, a aplicação foi alterada de forma a permitir a exclusão de componentes esquemáticos através de um item "Excluir" exibido no menu popup de cada componente. A parte do Modelo de Tarefas relacionada a essa alteração é mostrada pela Figura B.4.

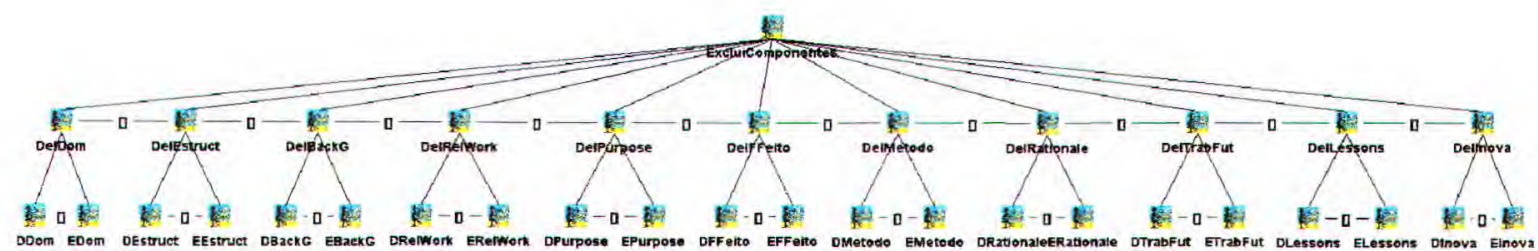

FIGURA B.4 - Sub-árvore ExcluirComponentes da Segunda e Terceira Etapa/ Turno de Avaliação 


\section{Tabela de Tarefa-Log}

Em virtude das mudanças realizadas na aplicação na primeira etapa de avaliação, a Tabela de Tarefa-Log foi alterada de forma a incorporar as mudanças da interface. As modificações estão relacionadas à preparação do ambiente de seleção dos componentes esquemáticos, à forma de escolher os componentes esquemáticos (arraste ou duplo click) e a forma de excluir componentes (usando a tecla "Delete" ou através do item "Excluir" apresentado no menu popup). A Tabela de Tarefa-Log da segunda e terceira etapa/turno de avaliação é apresentada na Tabela B.1.

TABELA B.1 - Tabela de Tarefa-Log da Segunda e Terceira Etapa/Turno de Avaliação

\begin{tabular}{|c|c|}
\hline Exentio cacão do usuarios & Tarefa Basici de Interacios \\
\hline ClickTrab schematics 0 & FocSchem \\
\hline ClickTrab intro First 0 & FocIntroFirst \\
\hline DragOverPalette domain 0 & PegaDom \\
\hline DragDropT_Trab_F Palette domain 0 & SoltaDom \\
\hline DblClickPalette domain() & DblClickDom \\
\hline DragOverPalette structure () & PegaEstruc \\
\hline DragDropT Trab F Palette structure () & SoltaEstruc \\
\hline DblClickPalette_structure 0 & DblClickEstruct \\
\hline DragOverPalette contribution(s) 0 & PegaContrib \\
\hline DragDropT Trab F Palette contribution(s) 0 & SoltaContrib \\
\hline DblClickPalette contribution(s) 0 & DblClickContrib \\
\hline ClickReplacePalette background () & Background \\
\hline ClickReplacePalette related work(s) 0 & ClickRelWork \\
\hline ClickCancelReplacePalette contribution(s) 0 & Cancell \\
\hline DragOverPalette contents 0 & PegaCont \\
\hline DragDropT Trab F Palette contents $O$ & SoltaCont \\
\hline DblClickPalette contents 0 & DblClickCont \\
\hline ClickReplacePalette purpose 0 & Purpose \\
\hline ClickReplacePalette what's been done 0 & Foifeito \\
\hline ClickReplacePalette methodology applied O & Metodo \\
\hline ClickReplacePalette rationale ( & Rationale \\
\hline ClickCancelReplacePalette contents () & Cancel2 \\
\hline DragOverPalette consequence(s) 0 & PegaConseq \\
\hline DragDropT Trab F Palette consequence(s) 0 & SoltaConseq \\
\hline DblClickPalette consequence(s)O & DblClickConseg \\
\hline ClickReplacePalette future work(s) 0 & TrabFut \\
\hline ClickReplacePalette lesson(s) learned 0 & Lessons \\
\hline ClickReplacePalette innovation(s) 0 & Inovacoes \\
\hline ClickCancelReplacePalette consequence(s) 0 & Cancel3 \\
\hline DragOverTrab domain 0 & TDom \\
\hline DragDropT Trab F Trab domain 0 & SDom \\
\hline DragOverTrab structure () & TEstruct \\
\hline DragDropT_Trab_F Trab_structure () & SEstruct \\
\hline DragOverTrab background 0 & TBackG \\
\hline DragDropT_Trab_F_Trab_background 0 & SBackG \\
\hline
\end{tabular}


TABELA B.1 - Tabela de Tarefa-Log da Segunda e Terceira Etapa/Turno de Avaliação

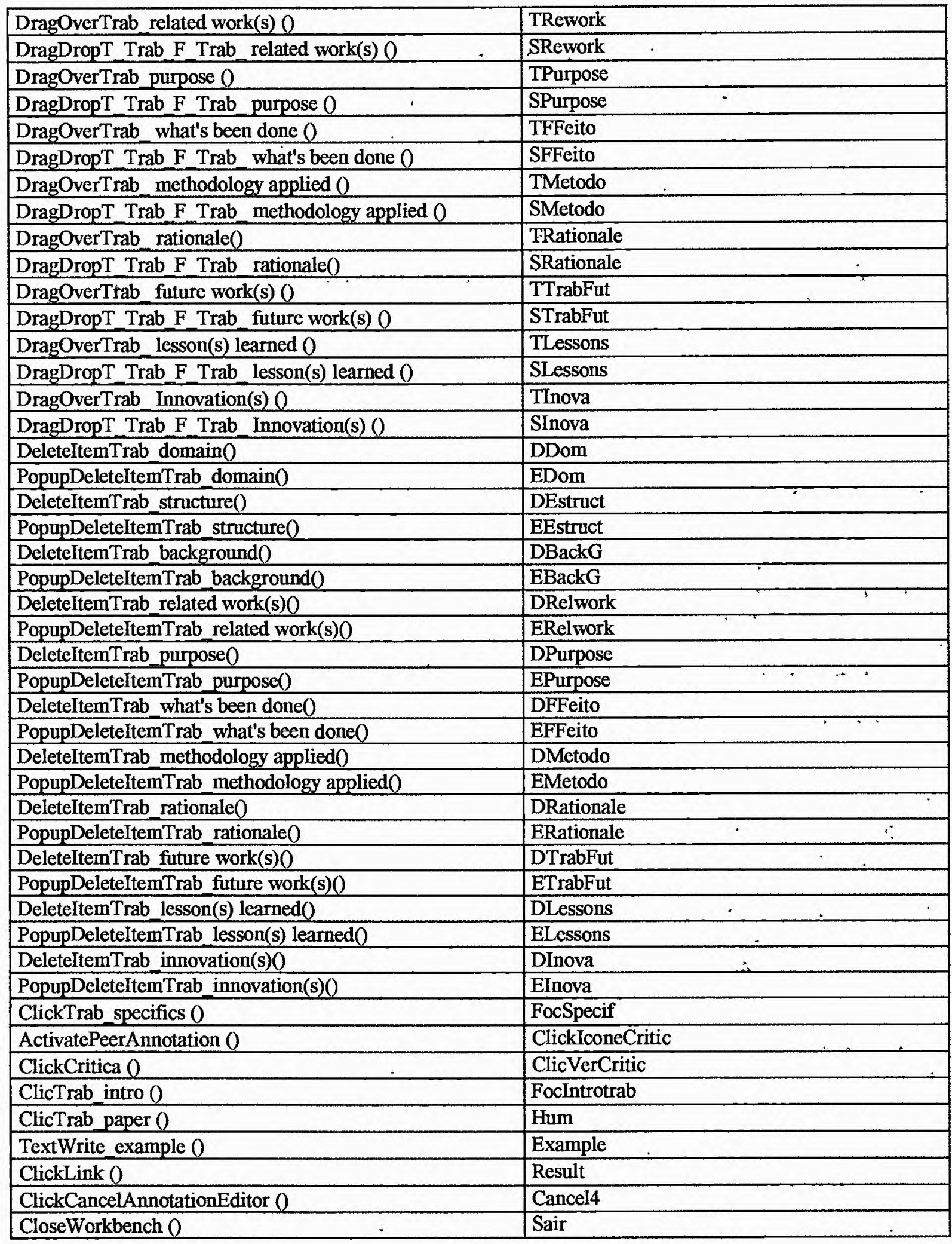




\section{Tabela de Pré-Condições}

Tabela de Pré-Condições extraída do Modelo de Tarefas da Ferramenta de Crítica modificada (as modificações são baseadas nos resultados obtidos na primeira etapa de testes). A Tabela de Pré-Condições da segunda e terceira etapa/turno de avaliação é apresentada na-Tabela B.2.

TABELA B. 2 - Tabela de Pré-Condições da Segunda e Terceira Etapaa/Turno de Avaliação

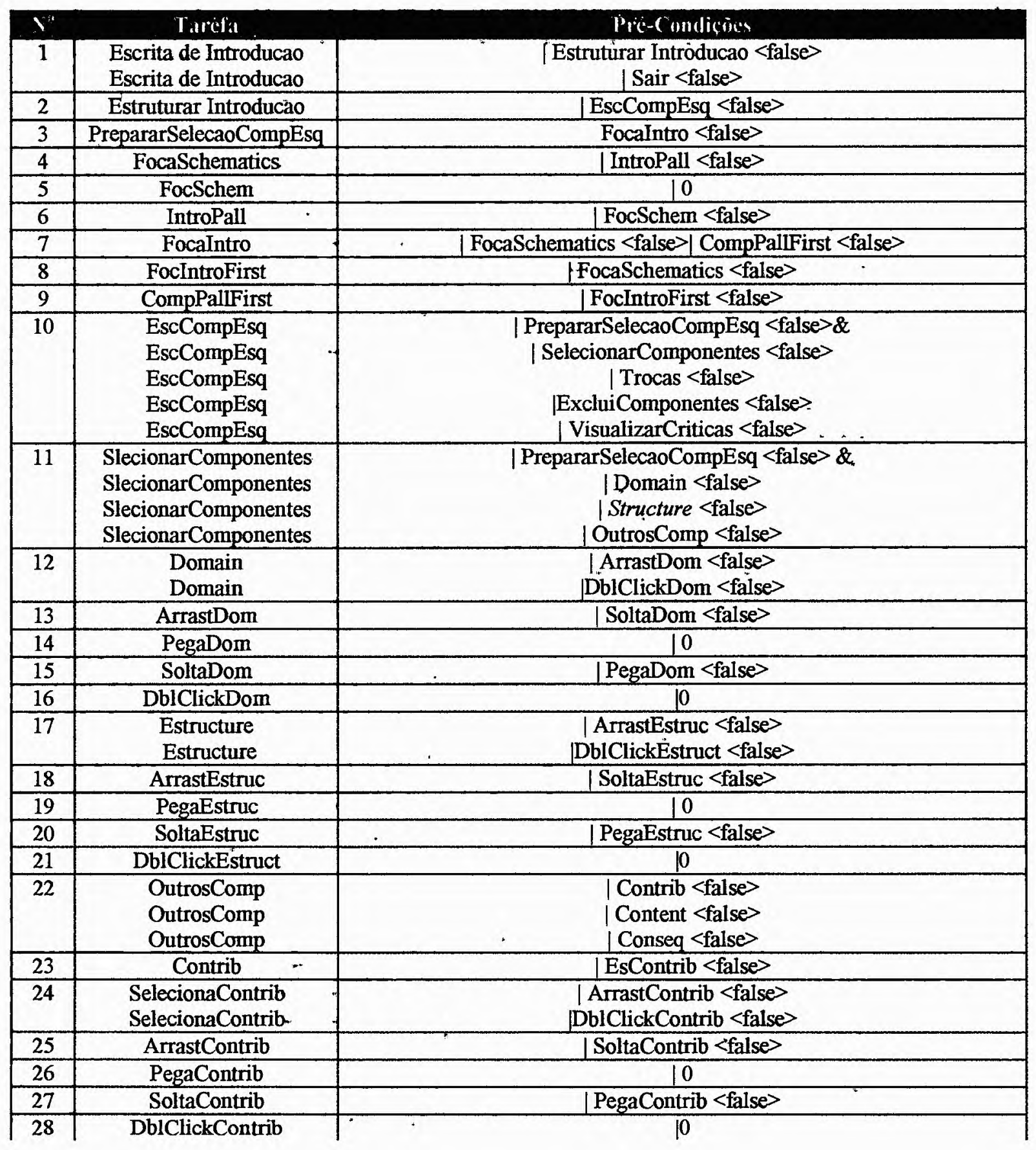


TABELA B. 2 - Tabela de Pré-Condições da Segunda e Terceira Etapa/Turno de Avaliação

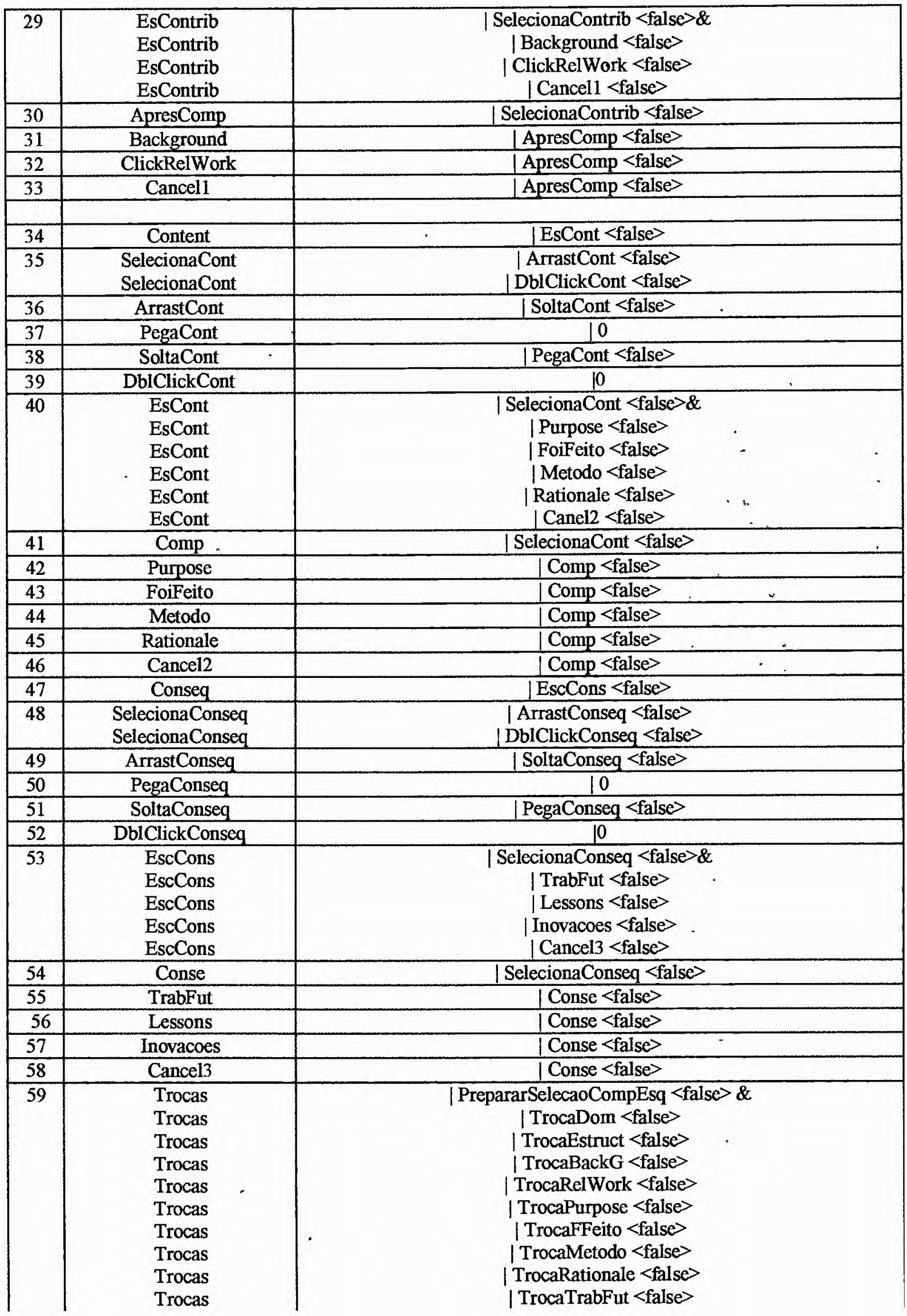


TABELA B.2 - Tabela de Pré-Condições'da Segunda e Terceira Etapa/Turno de AAvaliação

\begin{tabular}{|c|c|c|}
\hline & $\begin{array}{l}\text { Trocas } \\
\text { Trocas }\end{array}$ & $\begin{array}{l}\text { TrocaLessons <false } \\
\text { | TrocaInovacoes }<\text { false }\end{array}$ \\
\hline 60 & TrocaDom & SDom $<$ false $>$ \\
\hline 61 & TDom & $0-$ \\
\hline 62 & SDom & | TDom <false $>$ \\
\hline 63 & TrocaEstruct & Sestruct $<$ false $>$ \\
\hline 64 & TEstruct & 10 \\
\hline 65 & SEstruct & TEstruct $<$ false $>$ \\
\hline 66 & TrocaBackG & SBackG < false $>$ \\
\hline 67 & TBackG & 10 \\
\hline 68 & SBackG & | TBackG < false $>$ \\
\hline 69 & TrocaRelWork & SReWork < false > \\
\hline 70 & TReWork & 10 \\
\hline 71 & SReWork & TReWork < false $>$ \\
\hline 72 & TrocaPurpose & SPurpose $<$ false $>$ \\
\hline 73 & TPurpose & 10 \\
\hline 74 & SPurpose & |TPurpose $<$ false $>$ \\
\hline 75 & TrocaFFeito & 1 SFFeito < false $>$ \\
\hline 76 & TFFeito & 10 \\
\hline 77 & SFFeito & | TFFeito <false > \\
\hline 78 & TrocaMetodo & SMetodo $<$ false $>$ \\
\hline 79 & TMetodo & 10 \\
\hline 80 & SMetodo & TMetodo <false > \\
\hline 81 & TrocaRationale & | SRationale < false $>$ \\
\hline 82 & TRationale & 10 \\
\hline 83 & SRationale & TRationale < false $>$ \\
\hline 84 & TrocaTrabFut & | STrabFut <false $>$ \\
\hline 85 & TTrabFut & 10 \\
\hline 86 & STrabFut & | TTrabFut $<$ false $>$ \\
\hline 87 & TrocaLessons & SLessons $<$ false $>$ \\
\hline 88 & TLessons & 10 \\
\hline 89 & SLessons & TLessons $<$ false $>$ \\
\hline 90 & TrocaInovações & | SInova $<$ false $>$ \\
\hline 91 & TInova & 10 \\
\hline 92 & SInova & | TInova $<$ false $>$ \\
\hline 93 & $\begin{array}{c}\text { ExcluirComponentes } \\
\text {.. }\end{array}$ & $\begin{array}{c}\text { | PrepararSelecaoCompEsq }<\text { false }>\& \\
\text { | DelDom }<\text { false } \\
\text { | DelEtruct }<\text { false }> \\
\text { | DelBackG }<\text { false }> \\
\text { | DelRelWork }<\text { false }> \\
\text { | DelPurpose }<\text { false }> \\
\text { | DelFFeito }<\text { false }> \\
\text { | DelMetodo }<\text { false }> \\
\text { | DelRationale }<\text { false }> \\
\text { | DelTrabFut }<\text { false }> \\
\mid \text { DelLessons }<\text { false }> \\
\mid \text { DelInova }<\text { false }> \\
\end{array}$ \\
\hline 94 & $\begin{array}{l}\text { DelDom } \\
\text { DelDom }\end{array}$ & $\begin{array}{l}\mid \text { DDom <false }> \\
\text { EDom <false }>\end{array}$ \\
\hline 95 & DDom & 10 \\
\hline 96 & EDom & 10 \\
\hline 97 & $\begin{array}{l}\text { DelEstruct } \\
\text { DelEstruct }\end{array}$ & $\begin{array}{l}\mid \text { DEtruct }<\text { false }> \\
\mid \text { EEtruct }<\text { false }>\end{array}$ \\
\hline 98 & DEtruct & 10 \\
\hline
\end{tabular}


TABELA B. 2 - Tabela de Pré-Condições da Segunda e Terceira Etapa/Turno de Avaliação

\begin{tabular}{|c|c|c|}
\hline 99 & EEtruct & 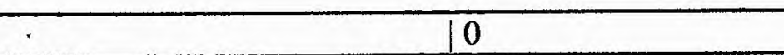 \\
\hline 100 & $\begin{array}{l}\text { DelBackG } \\
\text { DelBackG }\end{array}$ & $\begin{array}{l}\mid \text { DBackG < false }> \\
\mid \text { EBackG }<\text { false }>\end{array}$ \\
\hline 101 & DBackG & 10 \\
\hline 102 & EBackG & 10 \\
\hline 103 & $\begin{array}{l}\text { DelRelWork } \\
\text { DelRelWork }\end{array}$ & $\begin{array}{l}\text { DRelWork < false > } \\
\text { | ERelWork <false }>\end{array}$ \\
\hline 104 & DRelWork & 10 \\
\hline 105 & ERelWork & 10 \\
\hline 106 & $\begin{array}{l}\text { DelPurpose } \\
\text { DelPurpose }\end{array}$ & $\begin{array}{l}\mid \text { DPurpose <false> } \\
\text { EPurpose }<\text { false }>\end{array}$ \\
\hline 107 & DPurpose & 10 \\
\hline 108 & EPurpose & 0 \\
\hline 109 & $\begin{array}{l}\text { DelFFeito } \\
\text { DelFFeito }\end{array}$ & $\begin{array}{l}\mid \text { DFFeito<false }> \\
\mid \text { EFFeito < false }>\end{array}$ \\
\hline 110 & DFFeito & 10 \\
\hline 111 & EFFeito & 10 \\
\hline 112 & $\begin{array}{l}\text { DelMetodo } \\
\text { DelMetodo }\end{array}$ & $\begin{array}{l}\mid \text { DMetodo < false }> \\
\text { EMetodo < false }>\end{array}$ \\
\hline 113 & DMetodo & 10 \\
\hline 114 & EMetodo & 10 \\
\hline 115 & $\begin{array}{l}\text { DelRationale } \\
\text { DelRationale }\end{array}$ & $\begin{array}{l}\text { |DRationale < false }> \\
\text { |ERationale < false }>\end{array}$ \\
\hline 116 & DRational & 10 \\
\hline 117 & ERationale & 10 \\
\hline 118 & $\begin{array}{l}\text { DelTrabFut } \\
\text { DelTrabFut }\end{array}$ & $\begin{array}{l}\mid \text { DTrabFut <false }> \\
\text { |ETrabFut }<\text { false }>\end{array}$ \\
\hline 119 & DTrabFut & 10 \\
\hline 120 & ETrabFut & 10 \\
\hline 121 & $\begin{array}{l}\text { DelLessons } \\
\text { DelLessons }\end{array}$ & $\begin{array}{l}\mid \text { DLessons }<\text { false }> \\
\mid \text { ELessons }<\text { false }>\end{array}$ \\
\hline 122 & DLessons & 0 \\
\hline 123 & ELessons & 10 \\
\hline 124 & $\begin{array}{l}\text { DelInova } \\
\text { Dellnova }\end{array}$ & $\begin{array}{l}\text { |DInova < false> } \\
\mid \text { EInova < false > }\end{array}$ \\
\hline 125 & DInova & 10 \\
\hline 126 & EInova & 10 \\
\hline 127 & $\begin{array}{l}\text { VisualizarCriticas } \\
\text { VisualizarCriticas } \\
\text { VisualizarCriticas }\end{array}$ & $\begin{array}{c}\mid \text { PrepararSelecaoCompEsquem }<\text { false }>(\&) \\
\mid \text { PedirCriticas }<\text { false }> \\
\mid \text { FazerOpcao }<\text { false }> \\
\end{array}$ \\
\hline 128 & PedirCriticas & ClicVerCritic $<$ false $>$ \\
\hline 129 & FocSpecif & 10 \\
\hline 130 & Criticas & $\mid$ FocSpecif $<$ false $>$ \\
\hline 131 & ClickIconeCritic & | Criticas < false $>$ \\
\hline 132 & ClicVerCritic & ClickIconeCritic $<$ false $>$ \\
\hline 133 & $\begin{array}{l}\text { FazerOpcao } \\
\text { FazerOpcao }\end{array}$ & $\begin{array}{l}\text { | RetornProcEscolha <false }> \\
\mid \text { EncontreCasoEscolhe }<\text { false }>\end{array}$ \\
\hline 134 & RetornProcEscolha & $\mid$ CompPall $<$ false $>$ \\
\hline 135 & FocIntroTrab & 0 \\
\hline 136 & CompPall & FocIntrotrab < false $>$, \\
\hline 137 & EncontreCasoEscolhe & 1 Opcao <false $>$ \\
\hline 138 & Hum & 10 \\
\hline
\end{tabular}


TABELA B.2 - Tabela de Pré-Condições da Segunda e Terceira Etapa/Turno de Avaliação

\begin{tabular}{|c|c|c|}
\hline 139 & $\begin{array}{l}\text { Opcao } \\
\text { Opcao } \\
\text { Opcao } \\
\end{array}$ & $\begin{array}{c}\mid \text { Hum <false }>\& \\
\mid \text { OpcaoRecup }<\text { false }> \\
\mid \text { Cancel4 < false }> \\
\end{array}$ \\
\hline 140 & $\begin{array}{l}\text { OpcaoRecup } \\
\text { OpcaoRecup }\end{array}$ & $\begin{array}{l}\mid \text { Hum }<\text { false }>\text { \& } \\
\mid \text { Result }<\text { false }>\end{array}$ \\
\hline 141 & Example & | Hum < false $>$ \\
\hline 142 & Links & Example <false $>$ \\
\hline 143 & Result & Links < false > \\
\hline 144 & Cancel4 & | Hum $<$ false $>$ \\
\hline 145 & Sair & 0 \\
\hline
\end{tabular}




\section{Apêndice C}

Aos usuários foi dada uma documentação para auxiliá-los na interação com a Ferramenta de Crítica (Seção 1). Essa documentação foi organizada seguindo a sequiência lógica da descrição das tarefas mostrada no Capítulo 5. A partir das modificações realizadas na primeira etapa de avaliação foram feitas algumas alterações na documentação de auxilio inicial. A parte da documentação inicial que sofreu alteração é mostrada na Seção 2. A Seção 3 apresenta algumas telas da interface após as alterações feitas na primeira e segunda etapas/turnos de avaliação.

\section{Documentação de Auxílio ao Usuário}

Esta documentação contém um conjunto de instruções que direciona o usuário na realização das tarefas, podendo ser utilizada para consulta no momento do teste.

\section{Como Preparar o Processo de Seleção dos Componentes Esquemáticos?}

Para preparar o ambiente para a seleção dos componentes esquemáticos, o usuário deve: 
1. Focalizar o componente "schematics" e então irá visualizar o componente "Intro" dentro de Schematics. Veja o item Como focalizar um objeto?.

2. Introduzir Intro, que esta na Pallete, na área de trabalho como componente de schematics.

\section{Como Focalizar um Objeto?}

1. Vale ressaltar que a ação de focalizar consiste em clicar com o ponteiro do mouse sobre o botão "change focus" e em seguida;

2. Clicar sobre o componente a ser focalizado.

\section{Como Escolher os Componentes Esquemáticos?}

1. Deve-se focalizar "Intro", que desencadeará a visualização dos componentes da estrutura de componentes esquemáticos na pallete, Figura C.1. Como focalizar um objeto?.

2. O usuário deverá escolher os componentes desejados, que aparecem na Pallete para compor a introdução e inseri-los como componentes de Intro. Ver o item Como inserir componentes esquemáticos?

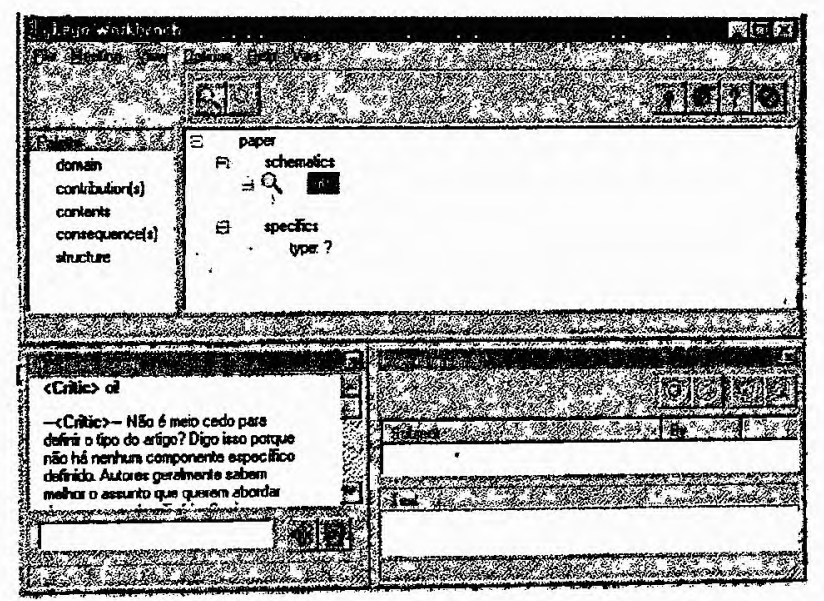

FIGURC 1 - Mudança de Foco para "Intro" e Visualização de Componentes Esquemáticos na

\section{Pallete}

\section{Como Inserir Componentes Esquemáticos?}

O processo de inserção de componentes se restringe a:

1. Arrastar o componente selecionado na pallete para a área à direita, onde a introdução está sendo estruturada, Figura C.2. 


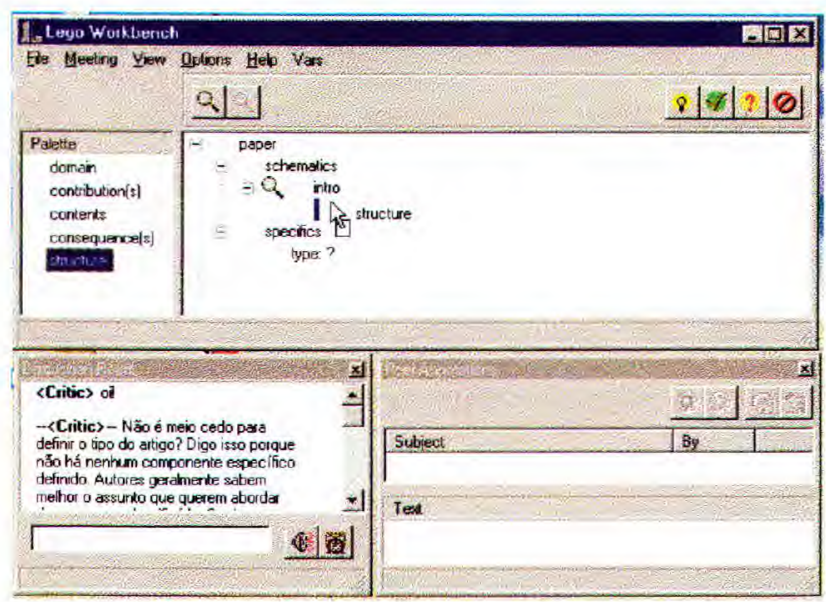

FIGURA C.2 - Seleção do Componente Esquemático "structure"

2. Alguns componentes da pallete disponibilizam uma nova lista de componentes.Para selecionar componentes dessa nova lista basta clicar sobre o componente escolhido, conforme ilustrado na Figura C.3.

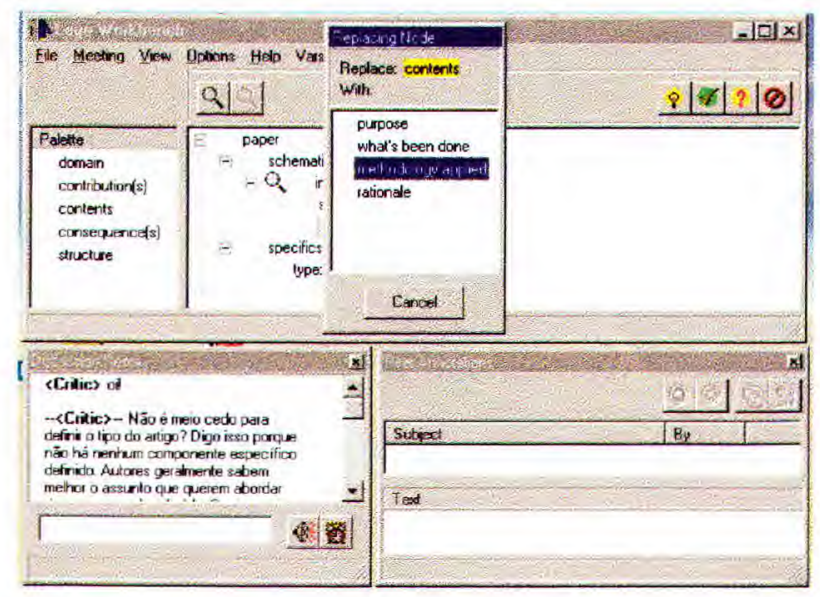

FIGURA C.3 - Escolha do Componente "Contents", Visualização de Lista de Componentes Esquemáticos e Seleção do Componente "Methodology Applied

\section{Como Visualizar as Críticas?}

1. Após a escolha dos componentes que irão formar a estrutura da introdução do artigo, o usuário deve focalizar em "specifics" (neste ponto o usuário deve ficar atento, pois ele irá visualizar na pallete os componentes específicos). Ver item Como focalizar um objeto?

2. Devido à mudança de foco, o usuário recebe as críticas do protótipo quanto aos componentes esquemáticos e deverá clicar no ícone de crítica que aparece ao lado de um dos componentes. 
3. O usuário deverá clicar no Item de crítica exibido na Peer annotation. Assim ele visualizará as críticas propriamente ditas, como ilustra a Figura C.4.

4. As críticas exibidas pelo protótipo elogiam o aparecimento de componentes importantes ou alertam o usuário sobre a necessidade de componentes que não aparecem na estrutura e são essenciais para caracterizar determinadas partes que devem existir em uma introdução, como por exemplo, a falta de componentes como o domínio do assunto a ser abordado e o propósito do artigo.

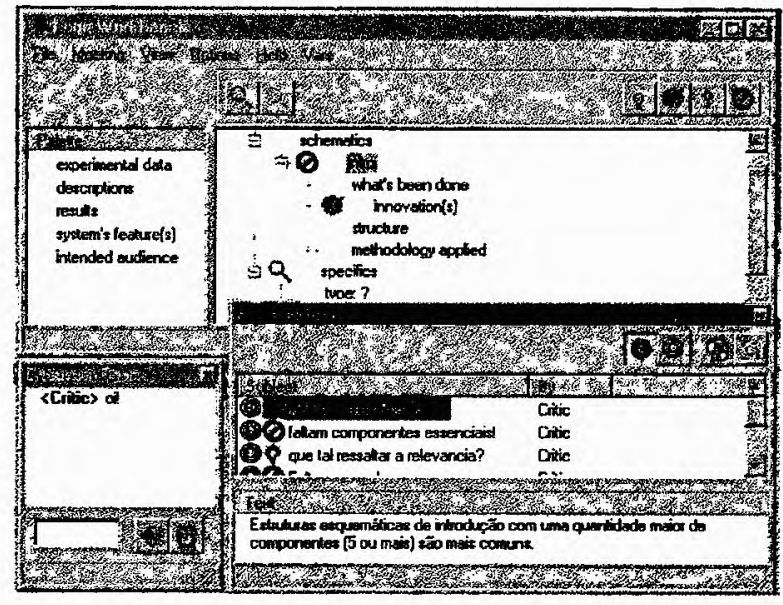

FIGURA C.4 - Mudança de Foco e Visualização de Críticas

\section{Como Excluir um Componente?}

Baseado nas críticas, o usuário pode melhorar a estrutura da introdução do artigo excluindo um dos componentes. Isso é feito como se segue:

1. Seleciona o componente desejado (com um click no mouse) e.

2. Pressiona a tecla delete.

\section{Como Alterar a Ordem dos Componentes?}

Baseado nas críticas, o usuário pode melhorar a estrutura da introdução do artigo alterando a ordem de componentes. Isso é feito como se segue:

1. Seleciona o componente desejado (com um click no mouse).

2. Arrasta-o para o local desejado.

\section{Como Alterar a Estrutura da Introdução Composta?}

Baseado nas críticas, o usuário pode melhorar a estrutura da introdução do artigo fazendo alterações na estrutura da introdução proposta. Isso é feito como se segue:

1. Focaliza em Intro. Ver item: Como focalizar um objeto?. 
2. Insere um novo componente (Ver item: Como inserir componentes esquemáticos?) ou; exclui um componente (Ver item: Como excluir um componente?) ou; altera a ordem dos componentes (Ver item: Como alterar a ordem dos componentes?).

\section{Como Encontrar e Recuperar os Casos Semelhantes ao Caso Proposto?}

Digamos que o usuário queira visualizar os casos mais semelhantes; então

1. Ele deve clicar sobre o botão "Hum..." ? I e em seguida;

2. Ele deve clicar sobre o componente "paper" de Lego Workbench;

3. Na janela Annotation Editor que surgirá, no espaço para o "subject", o usuário deve digitar "example" e clicar sobre o botão $\mathrm{OK}$, conforme ilustra a Figura C.5.

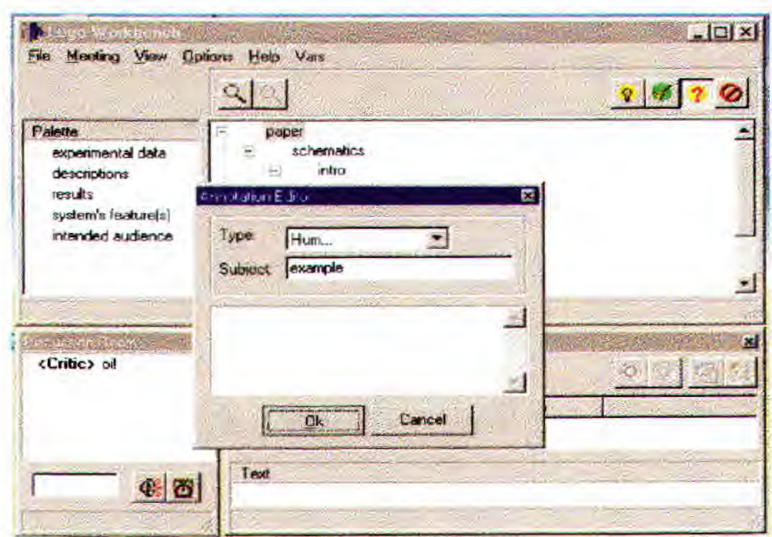

FIGURA C.5 - Pedido ao Protótipo para que Recupere Casos Semelhantes ao Esquematizado

\section{Como Visualizar Exemplos de Introduções de Artigos?}

A crítica ilustrada na Figura C.6 disponibiliza estatísticas e "links" para a visualização dos casos anotados quanto aos componentes esquemáticos, Figura C.7.

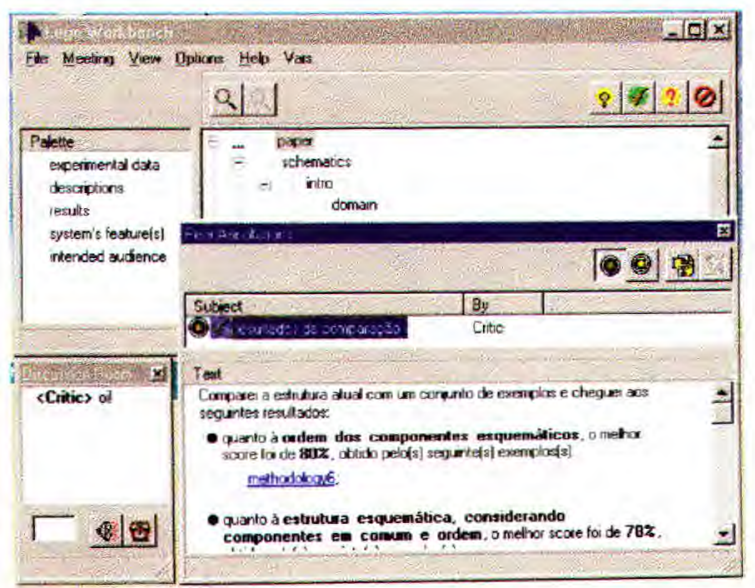

FIGURA C.6 - Crítica que Indica os Casos da Base mais Semelhantes ao Caso Proposto 


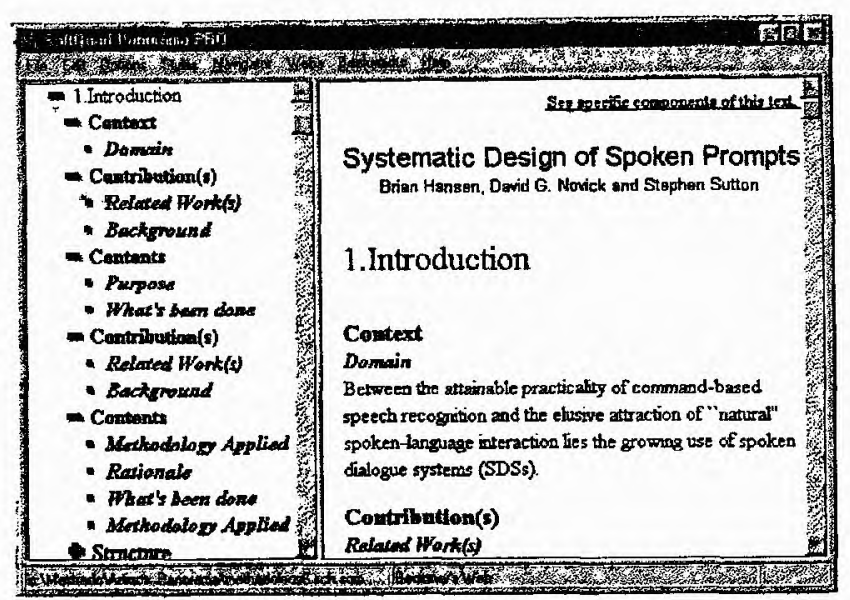

FIGURA C.7 - Visualização do Caso Recuperado Anotado com os Componentes

Esquemáticos

Nesse momento de interação o usuário visualiza exemplos de introduções de artigos, seguindo os seguintes passos:

1. Verifica o caso que mais se assemelha ao caso proposto;

2. Clica no link relativo ao caso escolhido

\section{Como Ativar a Área de Visualização das Críticas?}

1. Deve-se ir ao menu view;

2. Escolher a opção Peer Annotations.

\section{Como Ativar a Área de Discussão?}

1. Deve-se ir ao menu view;

2. Escolher a opção Discussion Roon.

\section{Como Retirar o Foco de um Objeto?}

1. Para retirar o foco de um componente basta clicar sobre o botão "clear focus"

2. Focalizar outro componente qualquer. Ver item "Como focalizar um objeto?"

\section{Como Definir Type?}

Situação: Se durante a utilização do protótipo da Ferramenta de Crítica, o colaborador iniciar definindo o tipo de artigo cuja introdução quer esquematizar, ou seja, ele focalizar em "Type: ?" e em seguida define-o como Theory, por imaginar ser esta a classificação ideal para o tipo de artigo que pretende estruturar como mostrado pela Figura C.8. 


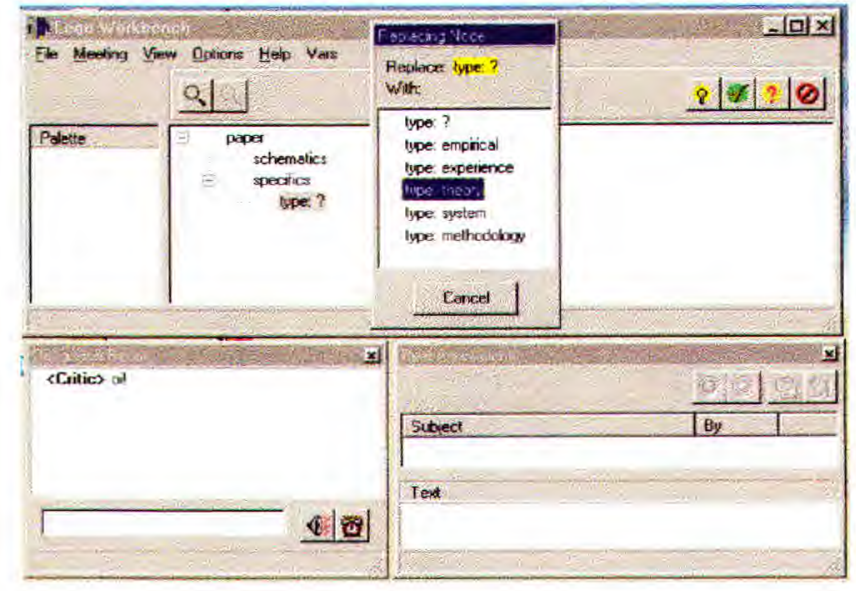

FIGURA C.8 - Definição Precoce de um Tipo de Artigo

Resposta à essa situação: Como resposta a esse procedimento pouco recomendado, o colaborador recebe uma crítica intrusiva, apresentada no Discussion Room conforme Figura C.9, alertando-o sobre essa ação. A melhor atitude a ser tomada neste momento é retornar o tipo de artigo, por exemplo focalizando em "Type: ?".

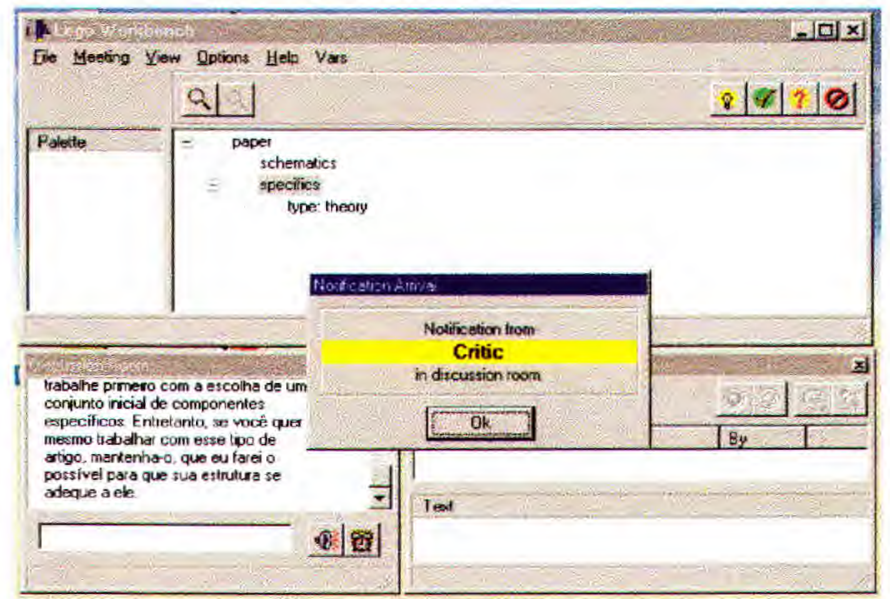

FIGURA C.9 - Crítica Intrusiva em Resposta a uma Decisão Precoce

Dica: Esse tipo de procedimento não é recomendado, pois geralmente, um usuário sabe melhor o assunto que deseja abordar e quais as características que devem ser enfocadas, do que precisamente qual o tipo de artigo a ser elaborado. O procedimento mais apropriado para um usuário novato na escrita técnica é definir os componentes esquemáticos e, com base nessas informações, o próprio protótipo irá indicar qual o tipo mais provável de artigo para a estrutura elaborada. 


\section{Como Encerrar a Sessão?}

1. O usuário deve selecionar o menu Meeting (de Lego Workbench) e;

2. O usuário deve selecionar a opção Quit (para encerrar o projeto);

3. O módulo Lego Workbench deve ser fechado através do menu File, opção Exit;

Os outros dois módulos - Lego Meeting Server e Lego Prolog Agent-devem ser finalizados pela utilização do botão fechar de cada uma das janelas.

\section{Modificações Realizadas na Documentação de Auxílio}

Após as modificações realizadas na interface na primeira e segunda etapas/turnos de avaliação, alguns itens da documentação de auxilio foram alterados. A descrição dos itens alterados é mostrada abaixo.

\section{Como Preparar o Processo de Seleção dos Componéntes Esquemáticos?}

Para preparar o ambiente para a seleção dos componentes esquemáticos, o usuário deve simplesmente focalizar o componente "schematics". Após focalizar "schematics" o componente "Intro" torna-se visível dentro de "schematics". Veja o item Como focalizar um objeto?.

\section{Como Inserir Componentes Esquemáticos?}

Para inserir um componente o usuário deve:

- Dar um duplo click no componente ou;

- Arrastar o componente selecionado na pallete para a área de trabalho à direita, onde a introdução está sendo estruturada.

Observação:

Alguns componentes da pallete disponibilizam uma nova lista. de componentes.Para selecionar componentes dessa nova lista basta clicar sobre o componente escolhido, conforme ilustrado na Figura C.3 acima.

\section{Como Excluir um Componente?}

Baseado nas criticas, o usuário pode melhorar a estrutura da introdução do artigo excluindo um dos componentes. Isso é feito como se segue: 
3. Seleciona o componente desejado (com um click no mouse) e.

4. Pressiona a tecla "Delete" ou;

5. Clica com o botão direito do mouse e seleciona a opção "Excluir Componente" do menu popup.

\section{Telas da Interface Alterada}

Nessa seção são apresentadas algumas telas da interface resultantes das alterações feitas na primeira e segunda etapas/turnos de avaliação da Ferramenta de Crítica.

A Figura C.10 representa as modificações na parte inicial da ferramenta, em que o componente "Intro" aparece dentro de "schematics" assim que a janela Lego Workbench é ativada. Além disso, a janela "Peer Annotation", que antes era ativada depois de pedir críticas, passa a ser exibida junto da janela Lego Workbench.

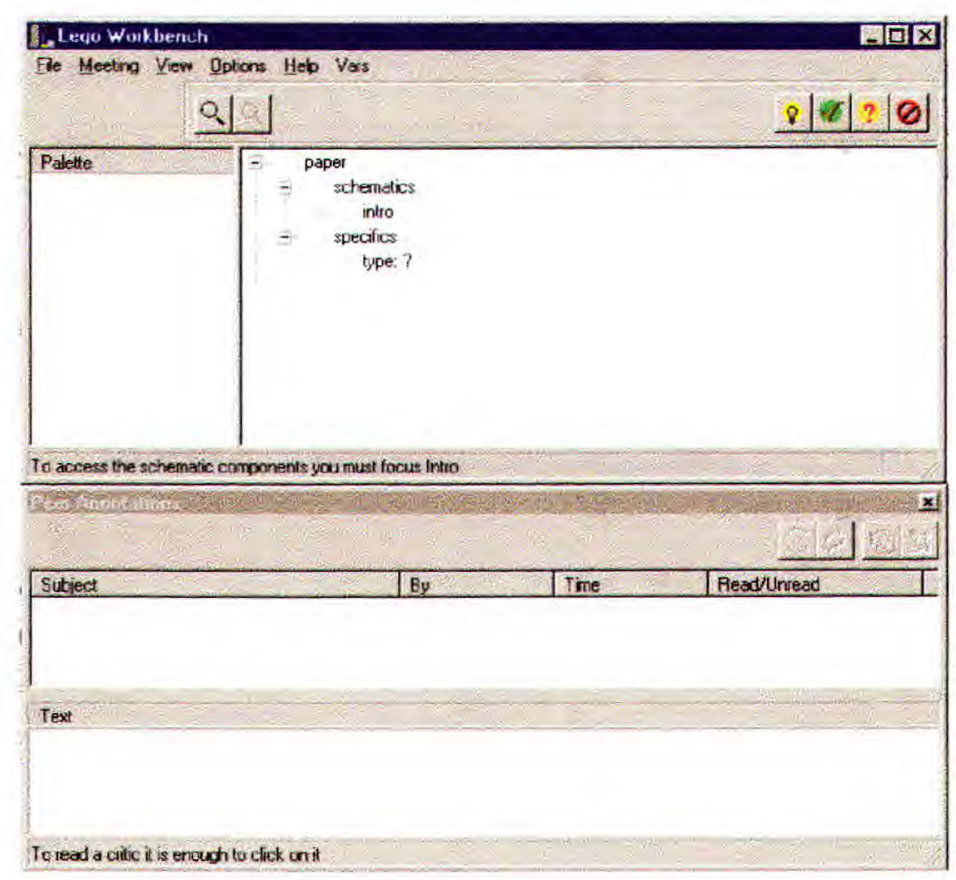

FIGURA C. 10 - Tela Inicial da Ferramenta de Crítica

A interface inicial apresentava ícones pouco intuitivos de críticas lidas e não lidas, o que levou os usuários a se confundirem entre as mensagens antigas e as novas. A Figura C.11 representa as modificações relacionadas com a forma de exibição das crítica, em que é exibido um ícone "New" e um campo "Hora" junto das críticas na janela Peer Annotation. Além disso, o texto das críticas passou a ser exibido em Inglês, e não mais em Português. 


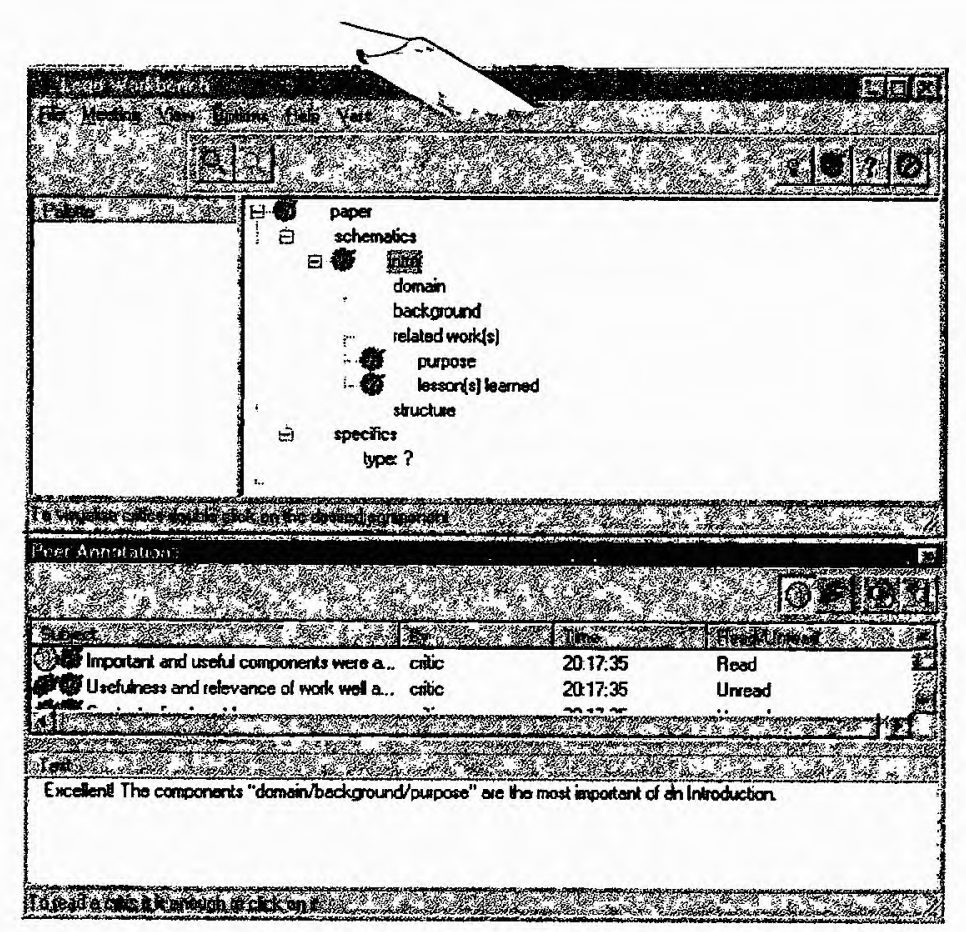

FIGURA C.11 - Tela de Visualização de Críticas

A Figura C.12 ilustra uma das telas da interface da Ferramenta de Crítica que exibe mensagem na "Barra de Status" para dar retroalimentação aos usuários durante a interação com a aplicação. As mensagens exibidas direcionam o usuário na forma de realização das tarefas, por exemplo, como inserir um componente esquemático na área de trabalho.

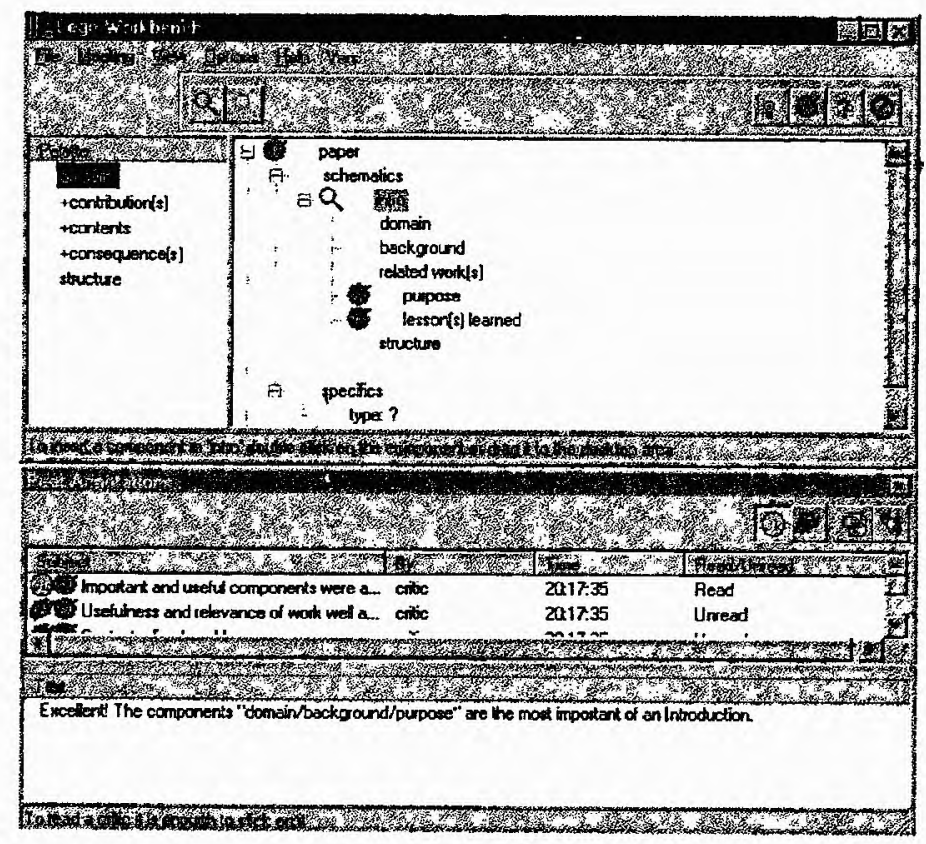

FIGURA C. 12 - Tela de Inserção de Componentes Esquemáticos 